REPORT TITLE: Treatment of Produced Waters Using a Surfactant Modified Zeolite/Vapor Phase Bioreactor System

REPORT TYPE: Final Technical Report

REPORT PERIOD: 1 October 2002 - 01 January 2006

PRINCIPAL AUTHORS: Lynn E. Katz, Kerry A. Kinney, Robert S. Bowman, Enid .J. Sullivan, Soondong Kwon, Elaine B. Darby, Li-Jung Chen and Craig R. Altare

REPORT ISSUE DATE: June 2006

DOE AWARD NUMBER: DE-FC26-02NT15461

This project, jointly funded by the U.S. Department of Energy, National Energy Technology Laboratory (No. DE-FC26-02-NT15461), included participation by The University of Texas at Austin, Los Alamos National Lab and New Mexico Tech. 


\section{Treatment of Produced Waters Using a Surfactant Modified Zeolite/Vapor Phase Bioreactor System}

Final Technical Report

1 October $2002-1$ January 2006

DOE AWARD NUMBER: DE-FC26-02NT15461

DISCLAIMER: This report was prepared as an account of work sponsored by an agency of the United States Government. Neither the United States Government nor any agency thereof, nor any of their employees, makes any warranty, express or implied, or assumes any legal liability or responsibility for the accuracy, completeness, or usefulness of any information, apparatus, product, or process disclosed, or represents that its use would not infringe privately owned rights. Reference herein to any specific commercial product, process, or service by trade name, trademark, manufacturer, or otherwise does not necessarily constitute or imply its endorsement, recommendation, or favoring by the United States Government or any agency thereof. The views and opinions of authors expressed herein do not necessarily state or reflect those of the United States Government or any agency thereof.

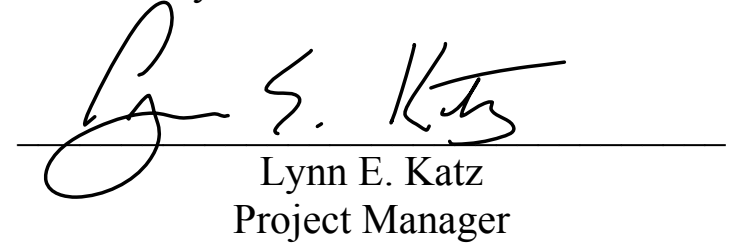




\section{EXECUTIVE SUMMARY}

Co-produced water from the oil and gas industry accounts for a significant waste stream in the United States. Produced waters typically contain a high total dissolved solids content, dissolved organic constituents such as benzene and toluene, an oil and grease component as well as chemicals added during the oil-production process. It has been estimated that a total of 14 billion barrels of produced water were generated in 2002 from onshore operations (Veil, 2004). Although much of this produced water is disposed via reinjection, environmental and cost considerations can make surface discharge of this water a more practical means of disposal. In addition, reinjection is not always a feasible option because of geographic, economic, or regulatory considerations. In these situations, it may be desirable, and often necessary from a regulatory viewpoint, to treat produced water before discharge. It may also be feasible to treat waters that slightly exceed regulatory limits for re-use in arid or drought-prone areas, rather than losing them to reinjection.

A previous project conducted under DOE Contract DE-AC26-99BC15221 demonstrated that surfactant modified zeolite (SMZ) represents a potential treatment technology for produced water containing BTEX. Laboratory and field experiments suggest that: (1) sorption of benzene, toluene, ethylbenzene and xylenes (BTEX) to SMZ follows linear isotherms in which sorption increases with increasing solute hydrophobicity; (2) the presence of high salt concentrations substantially increases the capacity of the SMZ for BTEX; (3) competitive sorption among the BTEX compounds is negligible; and, (4) complete recovery of the SMZ sorption capacity for BTEX can be achieved by air sparging the SMZ.

This report summarizes research for a follow on project to optimize the regeneration process for multiple sorption/regeneration cycles, and to develop and incorporate a vapor phase bioreactor (VPB) system for treatment of the off-gas generated during air sparging. To this end, we conducted batch and column laboratory SMZ and VPB experiments with synthetic and actual produced waters. Based on the results of the laboratory testing, a pilot scale study was designed and conducted to evaluate the combined SMZ/VPB process. An economic and regulatory feasibility analysis was also completed as part of the current study to assess the viability of the process for various water re-use options.

\section{Batch Equilibrium Sorption Studies}

Single-solute and multi-solute sorption tests showed that the partitioning of BTEX was unaffected by $\mathrm{pH}$ and increased in the presence of a background synthetic water containing phenols and napthalenes. The results were consistent with regular solution theory which predicts that differences in the solubility parameter between HDTMA and the semi-volatile compounds present in the produced water could lead to co-sorption effects. Oxyanion sorption was consistent with previous studies suggesting that the 
presence of competing ions would substantially reduce oxyanion sorption. Comparison of chromate and selenate sorption showed that chromate preferentially sorbed to SMZ; however, for both solutes the presence of produced water brine components substantially reduced the extent of sorption. Sorption of the divalent cation barium was dominated by cation exchange with the interior of the zeolite. As a result, the presence of the surfactant had only a minor impact on barium sorption as the HDTMA can not penetrate the interior sufaces of the zeolite. Overall, while SMZ has potential for oxyanion and cation sorption, the capacity of SMZ for these solutes will be highly dependent on the produced water composition.

\section{Regeneration Studies}

Surfactant-modified zeolite (SMZ) is an effective sorptive medium for removing dissolved organics from produced water. It offers a low-cost, easily regenerable option for producers who want or need to treat their produced water. Long-term laboratory-scale column tests (50 sorption and regeneration cycles; $5000 \mathrm{PV}$ total water treated) show that SMZ retains its ability to remove BTEX compounds over many cycles. Observation of $K d$ over the 50 cycles reveals a weakly decreasing trend. Even if the $K_{d}$ in a field column dropped too low, additional HDTMA could be pumped through the column to restore surfactant loading on the SMZ. Hydraulic conductivity of the SMZ decreased by approximately $30 \%$ during the tests. This decrease cannot be explained by biofouling or the accumulation of surface coatings on the SMZ particles. The decreasing conductivity was most likely caused by particle breakdown in the column. Particle attrition may be the limiting factor on the lifetime of SMZ beds. Further work needs to be done in order to quantify the amount of HDTMA washed off during the long-term tests. Although quantification of HDTMA wash-off was not completed for this study, indirect evidence suggests that surfactant loading did not drop below equivalent monolayer coverage.

Regeneration-curve predictions can be made simply by knowing the volume of air pumped through the column. Kinetic effects due to various airflow rates do not have a large impact on the removal rate of BTEX during air sparging. Thus, when interfacing the $\mathrm{SMZ}$ regeneration process with a VPB or other off-gas treatment system, the end user can tailor the delivery of BTEX to the VPB by changing the airflow rate.

\section{Vapor Phase Bioreactor Studies}

Results of the laboratory scale VPB studies indicate that biofilters packed with a synthetic polyurethane foam or a compost-based material can readily achieve BTEX removal efficiencies of greater than $95 \%$ under steady feed conditions. However, more frequent nutrient addition was required to maintain performance in the polyurethane foam bioreactor than in the compost bioreactor. Given the remote location of many produced water sites, this result suggests that the compost system is better suited to field conditions. Even in the compost system which was initially spiked with a concentrated nutrient solution, the nitrogen supply present in the packing material became depleted with time. However, addition of a concentrated nutrient solution quickly restored the biodegradation capacity of the biofilter. 
Another concern associated with long term operation of biofilters is bed compaction and pressure drop buildup. Pressure drops of less than 1.5 inches of water were observed for 250 days of operation in the compost biofilter under steady feed conditions. However, a gradual increase in pressure drop was observed. Mixing the packing with fresh packing media effectively reduced the pressure drop and restored performance. Packing the biofilter bed with larger size compost materials and mixing a greater volume of bulking agents in with the compost could also be used to minimize bed compaction.

When the VPB is coupled to a SMZ system, the influent gas stream varies greatly as a function of time. Not only do the BTEX concentrations vary over a given SMZ regeneration cycle, but the air sparging regeneration process is periodic in nature. As a result, the VPB experiences shutdown periods some of which are planned as part of the $\mathrm{SMZ}$ cycling process and some of which are unexpected due to maintenance or scheduling problems. A series of shutdown tests were conducted under controlled conditions in the laboratory to investigate the response of the biofilter to short shutdown periods on the order of one to three days. After a one-day shutdown period, the BTEX removal efficiencies observed in the biofilter immediately after resumption of the waste gas feed were generally 5 to $15 \%$ less than those observed under steady feed conditions. The drops in BTEX removal efficiencies following a three day shutdown period were more significant. However, the biofilter recovered quickly - usually within 6 to 10 hours. Since the VPB shutdowns are likely to be cyclic in nature, the response of the system to short, repeated shutdown and restart events was also examined. The results indicate that the system adapted to repeated one-day shutdown periods and the BTEX removals following restart improved over time. However, for the 2.8 day shutdown periods, the same short term drop in removal efficiency was observed. Nevertheless, the biofilters recovered relatively quickly indicating that they can handle the short shutdown periods which would be expected in the field.

\section{SMZ/VPB Pilot Scale Studies}

The results of the laboratory experiments were used to design a field test of the process which was conducted at a produced water disposal facility near Farmington, New Mexico in July and August of 2005. The system was designed to treat up to 30 gallons of produced water per hour on a continuous basis by running two SMZ columns in series. The system performed well over repeated feed and regeneration cycles demonstrating the viability of the process for long term operation. Of the BTEX components present in the produced water, benzene had the lowest adsorption affinity for the SMZ and thus controlled the sorption cycle length. Regeneration of the SMZ using air sparging was found to be sufficient in the field to maintain the SMZ adsorption capacity and to allow continuous operation of the system. The BTEX concentrations in the regeneration off gas stream were initially very high in a given regeneration cycle. However, a granular activated carbon buffering column placed upstream of the VPB reduced the peak BTEX concentrations to acceptable levels for the VPB. In this way, the VPB was able to maintain stable performance over the entire SMZ regeneration period despite the intermittent nature of the feed. Indeed, TPH removals in excess of 90 percent were obtainable by the VPB during pilot operation. 


\section{Engineering and Economic Assessment}

Produced water is a viable water resource for several uses in the arid western states, including surface discharge, power production, agriculture as well as oil and gas exploration and production.. Each end use will define the water quality and regulatory limits on total dissolved solids and volatile organic compounds. Produced water from coal bed methane wells has received considerable attention by industries in search of reused water. However, water from coal bed methane wells in New Mexico must first be treated to reach levels acceptable for disposal. The SMZ/VPB system provides an economically viable option for the removal and destruction of the BTEX compounds in produced water. Addition of a reverse osmosis unit following the SMZ/VPB process to reduce the total dissolved solids content could allow for re-use of the treated water in the oil and gas, agriculture and power industries.

\section{Future Research}

There are two areas of potential future research that would be necessary for optimizing the process and for meeting water quality requirements for a number of potential re-use options. These include the removal of organic acids and a long term assessment of the performance of the process. The SMZ adsorption system is not effective for removal of organic acids from produced water. The average concentrations of acetate, malonate and propionate were $330 \mathrm{mg} / \mathrm{L}, 135 \mathrm{mg} / \mathrm{L}$ and $30 \mathrm{mg} / \mathrm{L}$, respectively, the influent produced water at the New Mexico field site. Other anions including formate, butyrate, valerate, succinate and glutarate were not detected. Although not hazardous, these organic acids constitute a significant portion of the total organic carbon in produced water. As a result, a downstream method for removal of these constituents may be required depending on the re-use option desired for the produced water.

Final evaluation of the SMZ/VPB system should include a long term field evaluation of the process. As shown in the laboratory regeneration experiments, there is evidence that the surfactant would need to be replaced; however, the frequency of replacement has not been determined. In addition, more reseach is needed to address the potential for headloss buildup during operation. A long term study would provide the necessary data to address these issues and to evaluate their economic impact on the process. 


\section{Table of Contents}

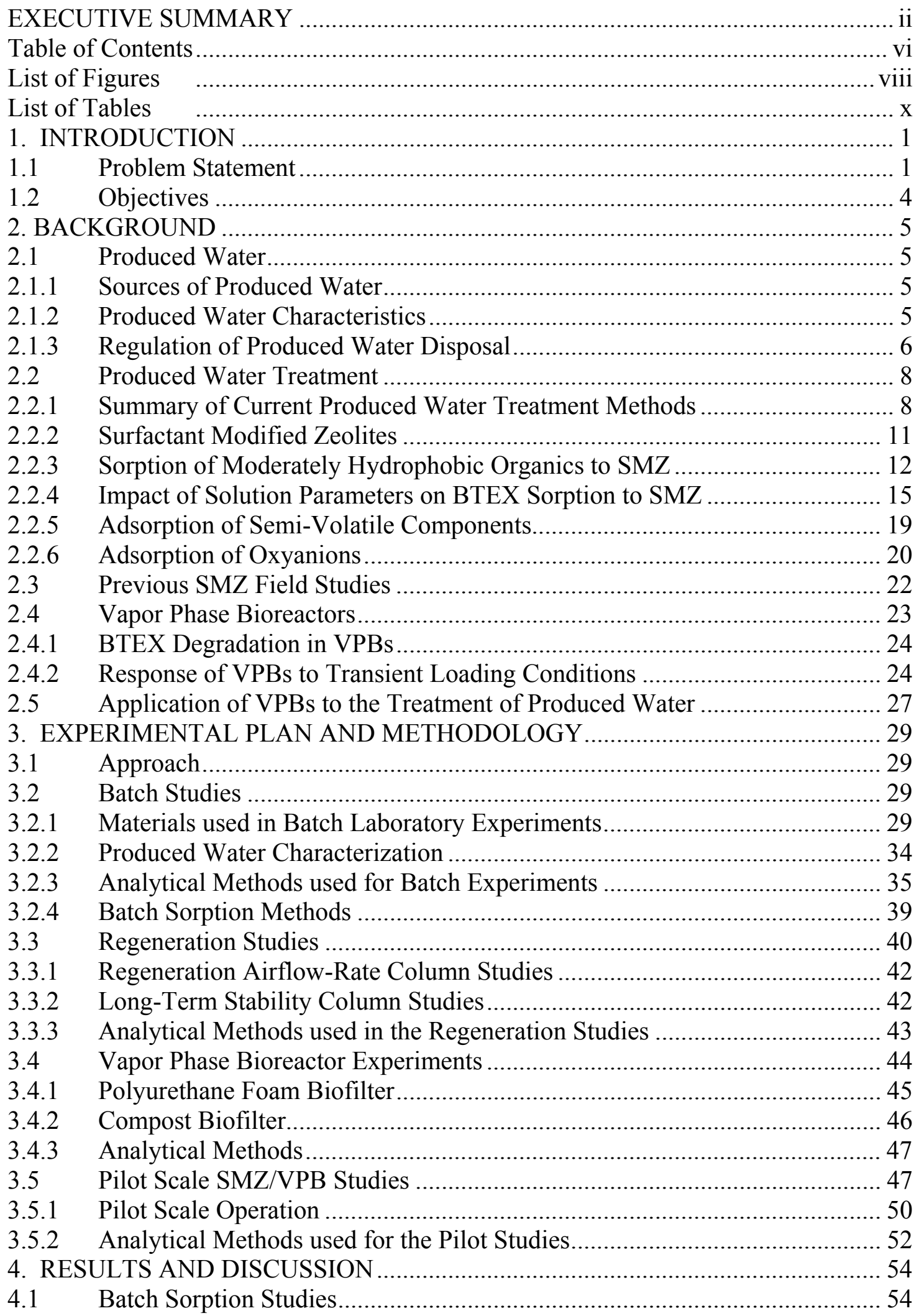


4.1.1 Effect of $\mathrm{pH}$ on BTEX and Phenol Sorption to SMZ ................................. 54

4.1.2 Effect of Co-solutes on BTEX Sorption ..................................................... 56

4.1.3 Sorption of Inorganic Constituents in Produced Water ................................. 58

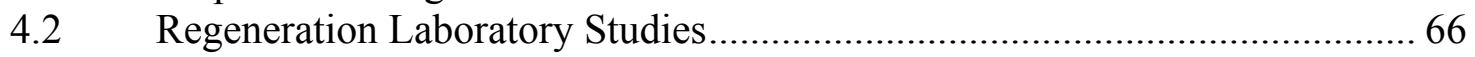

4.2.1 Regeneration-Rate-Test (RRT) Experimental Results................................. 66

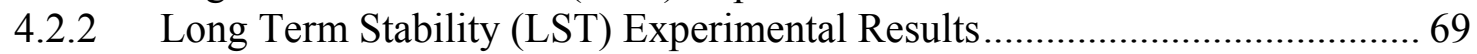

4.3 Performance of VPB Under Steady Feed Conditions (Laboratory Scale)...... 78

4.3.1 Polyurethane Foam Biofilter...................................................................... 78

4.3.2 Compost Biofilter................................................................................. 80

4.4 Performance of VPB under Variable Loading Conditions (Laboratory-Scale)..

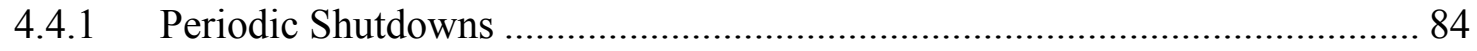

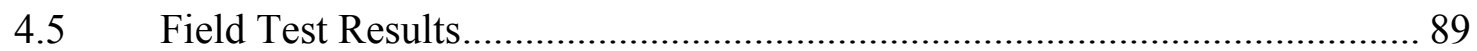

4.5.1 Adsorption on SMZ .......................................................................... 90

4.5.2 SMZ Regeneration \& Off-Gas Treatment in the VPB.................................95

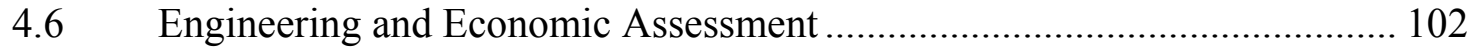

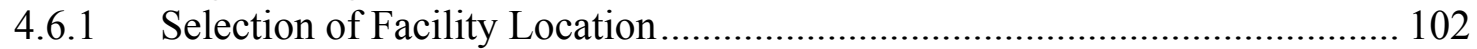

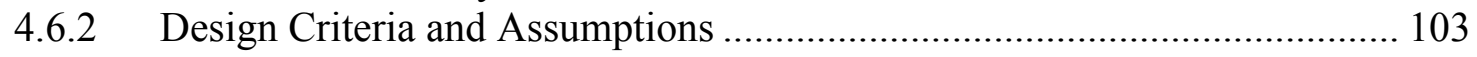

4.6.3 SMZ/VPB Cost Estimation Correlations ................................................... 107

4.6.4 Reverse Osmosis Option......................................................................... 110

4.6.5 Total Cost Estimates for SMZ/VPB with Reverse Osmosis......................... 111

4.6.6 Cost Survey of Disposal Costs for Produced Water ..................................... 112

4.6.7 Cost of Treatment Compared to Cost of Current Water Supply Options ..... 114

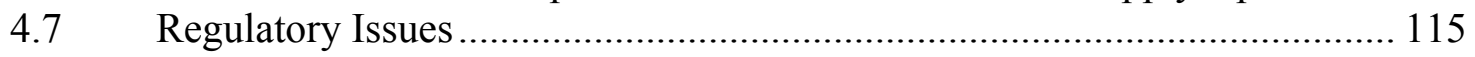

4.7.1 Beneficial Re-use versus Disposal.................................................... 115

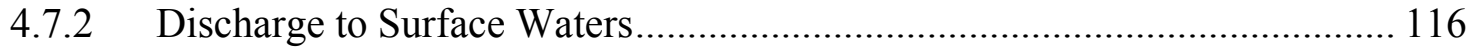

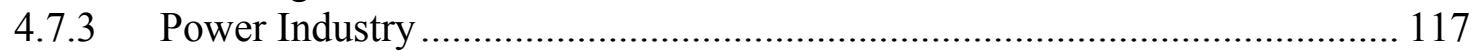

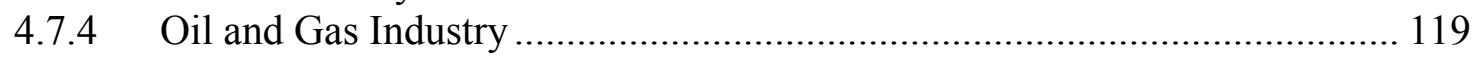

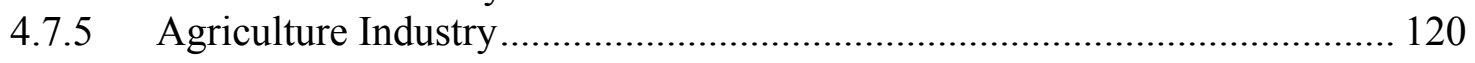

Appendix: Economic Analysis Spreadsheets...................................................... 133 


\section{List of Figures}

Figure 2.1 Relationships between $\mathrm{K}_{\mathrm{d}}$ and $\mathrm{K}_{\mathrm{ow}}$ developed by various authors. 13

Figure 2.2 Relationships between (a) $\log \mathrm{K}_{\mathrm{om}}$ and $\log \mathrm{K}_{\mathrm{ow}}$, (b) $\log \mathrm{K}_{\mathrm{om}}$ and $\log \mathrm{S}_{\mathrm{w}}$, and

(c) $\log \mathrm{K}_{\mathrm{om}} \mathrm{V}$ and $\log \mathrm{S}_{\mathrm{w}}$. Literature values are from Schwarzenbach et al. (2003).. 14

Figure 2.3 Effects of salinity on $\log \mathrm{K}_{\mathrm{d}}$ for (a) benzene and toluene and for (b)

ethylbenzene and xylenes. Dashed lines and solid lines indicate predicted $\log \mathrm{K}_{\mathrm{d}}$ from equation 2.4 and 2.5 .

Figure 2.4 Van't Hoff isochors for the sorption onto SMZ of BTEX. ........................... 18

Figure 2.5 - Chromate sorption capacity as a function of HDTMA surface coverage. ... 21

Figure 2.6 - Benzene and toluene breakthrough on virgin and regenerated SMZ in field columns (Ranck et al. 2005).

Figure 2.7. Schematic diagram of the SMZ /VPB system for treating produced water. . 28

Figure 3.1: Typical benzene standard curve ............................................................ 37

Figure 3.2. Schematic diagram of vapor phase biofilter.......................................... 45

Figure 3.3 Produced water storage tanks and SMZ columns used in the pilot test ......... 48

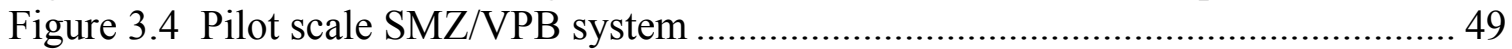

Figure 3.5. Schematic diagram of the pilot scale coupled SMZ/VPB system ................. 51

Figure 3.6 Building constructed for pilot scale studies and on-site BTEX analysis......... 53

Figure 4.1 Benzene isotherm data collected in the presence of the synthetic produced

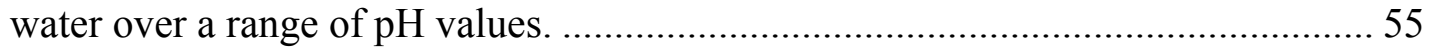

Figure 4.2 Chromium sorption edge for SMZ in a synthetic salt solution (Initial chromate

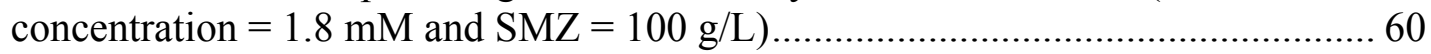

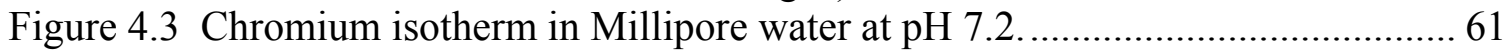

Figure 4.4 Comparison of chromium isotherms in ultrapure water and saline water at $\mathrm{pH}$

7.2.

Figure 4.5 Selenium isotherm and Langmuir isotherm fit in synthetic saline solution at $\mathrm{pH} 7.2$.

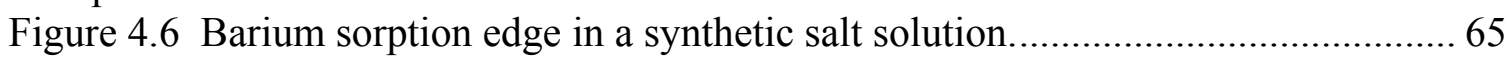

Figure 4.7 Comparison of barium sorption onto natural and modified zeolite in salt water

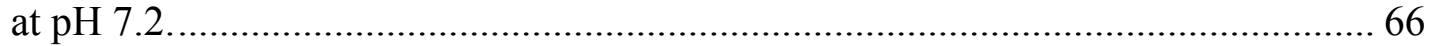

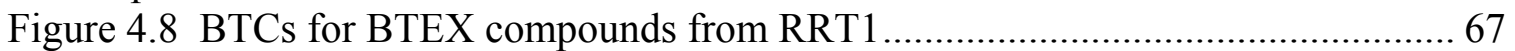

Figure 4.9 Reproducibility of BTCs for toluene and $p$ - and $m$-xylene on virgin SMZ ... 67

Figure $4.10 p$ - and $m$-xylene regeneration curves as a function of (a) time and (b) pore volumes of air. Columns RRT1, RRT2, RRT3, and RRT4 used airflow rates of 1.3

$\mathrm{PV} / \mathrm{min}, 2.7 \mathrm{PV} / \mathrm{min}, 5 \mathrm{PV} / \mathrm{min}$, and $10 \mathrm{PV} / \mathrm{min}$, respectively............................ 68

Figure 4.11 BTCs of tritiated water in column LST2 for (a) virgin SMZ and (b) after the $25^{\text {th }}$ regeneration cycle and (c) after the 50th regeneration cycle (Solid lines

represent fitted values using an equilibrium advection-dispersion equation)...........70

Figure 4.12. BTCs for every fifth sorption cycle on column LST1 for (a) benzene and (b)

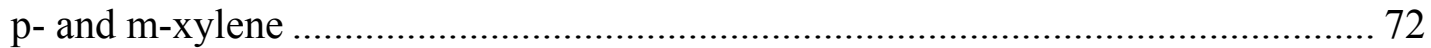

Figure 4.13 Observed and fitted BTCs of $p$ - and $m$-xylene for the first sorption cycle on column LST1. The solid line shows the fit using an equilibrium advection-dispersion equation while the dashed line shows the fit using a two-site chemical nonequilibrium advection-dispersion equation. 73 
Figure 4.14 Distribution coefficients and lines fit to the Kd values for columns LST1 and LST2 for (a) benzene and (b) $p$ - and $m$-xylene................................................ 75

Figure 4.15 Vapor-phase concentrations of toluene and p- and m-xylene over 50 regeneration cycles on column LST1 ............................................................ 76

Figure 4.16 Normalized VOC removal profiles along the foam biofilter column on (A)

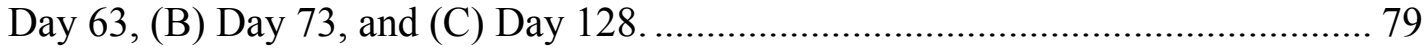

Figure 4.17 Total biomass accumulation as determined by COD measurements along the foam biofilter column on Day 88 of operation. 80

Figure 4.18 Normalized VOC removal profiles along the compost biofilter column on (A) Day 9 and (B) Day 19

Figure 4.19 Effect of nutrient addition on BTEX removal efficiency in the compost biofilter. A concentrated nutrient solution was added on Day 85 of operation. ...... 82

Figure 4.20 Response of the compost biofilter to reducing the gas-phase EBCT from 60 to 30 seconds. The total inlet BTEX concentration was maintained at $130 \mathrm{ppm}_{\mathrm{v}} \ldots 83$

Figure 4.21 Pressure drop across the compost biofilter column .................................... 84

Figure 4.22 BTEX removal efficiency after a 24-hour shutdown period in the polyurethane foam biofilter. (A): $1^{\text {st }}$ shutdown, (B): $3^{\text {rd }}$ shutdown. ...................... 85

Figure 4.23 BTEX removal efficiency after a 2.8-day shutdown period in the polyurethane foam biofilter. (A): $1^{\text {st }}$ shutdown, (B): $3^{\text {rd }}$ shutdown.

Figure 4.24 BTEX removal efficiency after a 24-hour shutdown period in the compost biofilter. (A): $1^{\text {st }}$ shutdown, (B): $3^{\text {rd }}$ shutdown.

Figure 4.25 BTEX removal efficiency after a 2.8-day shutdown period in the compost biofilter: $(\mathrm{A}): 1^{\text {st }}$ shutdown, $(\mathrm{B}): 3^{\text {rd }}$ shutdown.

Figure 4.26 Breakthrough curves of selected organic compounds in produced ............. 91 water through virgin SMZ at a flow rate of $27 \mathrm{gph}$.

Figure 4.27 Comparison of benzene and toluene breakthrough curves on virgin SMZ in two field tests conducted separately in New Mexico, 2005 and in Wyoming, 2002.92

Figure 4.28 Comparison of benzene breakthrough curves on virgin and regenerated SMZ.

Figure 4.29 Cumulative mass of benzene on SMZ over different flow rates used in the New Mexico field test.

Figure 4.30 BTEX breakthrough on regenerated SMZ over two sorption/ regeneration cycles at 5 gph flow rate during the New Mexico field test. ................................ 95

Figure 4.31 BTEX concentration profile of gas phase effluent during regeneration of SMZ column: (a) Regeneration in the field, and (b) regeneration in the lab........... 96

Figure 4.32 Benzene and toluene concentrations in the gas stream entering and exiting the GAC buffering column during SMZ regeneration. (a) 1 second EBCT in the buffering column, and (b) 5 second EBCT in the buffering column.

Figure 4.33 Removal of VOCs in the VPB during the field test at two different operating conditions. (a) Biomass accustomed to low concentration (12 $\left.\mathrm{ppm}_{\mathrm{v}}\right)$ of benzene, and (b) biomass accustomed to high concentration $\left(90 \mathrm{ppm}_{\mathrm{v}}\right)$ of benzene.

Figure 4.34 Mass fraction of adsorbed BTEX removed from the SMZ as a function of air sparging regeneration time.

Figure 4.35 Performance of the GAC buffering column and VPB during the regeneration of the saturated SMZ field column. 101

Figure 4.36 Diesel prices for 1993 - 2006 113 


\section{List of Tables}

Table 2.1 Ranges of contaminants detected in produced water...................................... 7

Table 2.2 Membrane filtration technologies ................................................................ 9

Table 2.3 Overall sorption enthalpies $\left(\Delta \mathrm{H}_{\mathrm{s}}\right)$, entropies $\left(\Delta \mathrm{S}_{\mathrm{s}}\right)$, calculated dissolution

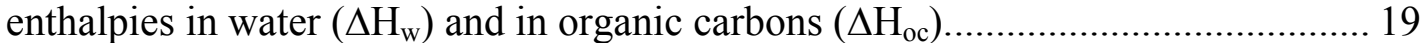

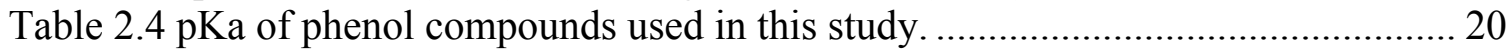

Table 3.1 Analysis of produced water from Wamsutter, Wyoming ............................... 31

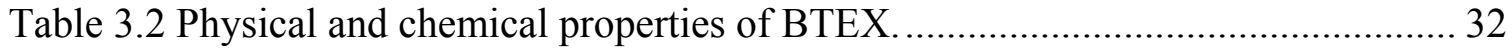

Table 3.3 Approximate semi-volatile concentrations in a sample of produced water...... 32

Table 3.4 Chemical formulas, molecular weights, pKas, water solubilites, Henry's constants, and $\log \mathrm{K}_{\mathrm{ow}} \mathrm{S}$ of semi-volatiles used in this study. ............................... 33

Table 3.5 Major ion concentrations in the Wyoming produced water. ........................... 35

Table 3.6 Composition of synthetic water used in batch sorption experiments ............... 39

Table 3.7 Composition of produced waters used in regeneration tests........................... 41

Table 4.1 Comparison of $\mathrm{K}_{\mathrm{D}}$ values at various $\mathrm{pHs}$ in the presence of semi-volatiles in

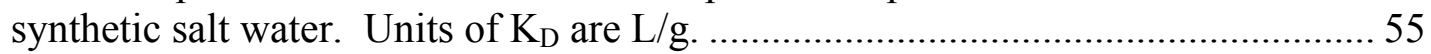

Table 4.2 Average single point $\mathrm{K}_{\mathrm{D}}$ values for various equilibrium $\mathrm{pH}$ values............... 56

Table 4.3 Distribution coefficients of BTEX in produced water and synthetic produced water.

Table 4.4 Solubility parameters of BTEX and other representative organic compounds 58

Table 4.5 Fitted D and R values for tritium tracer tests conducted on columns LST1 and LST2 for the virgin column, after the 25th regeneration cycle, and after the 50th

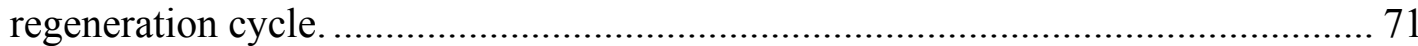

Table 4.6 Impact of regeneration on BTEX distribution coefficients on SMZ ............... 76

Table 4.7 Composition of produced water at the salt water disposal facility located in

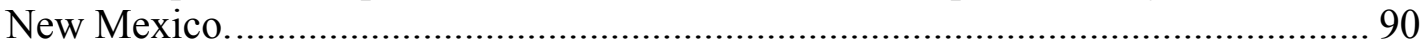

Table 4.8 SMZ column design parameters for 6 gpm design flow............................. 105

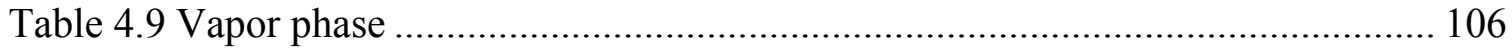

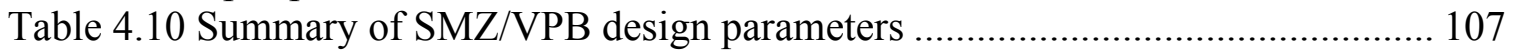

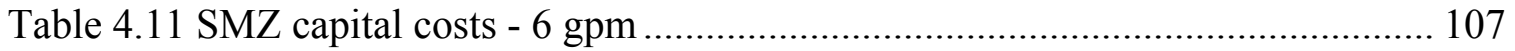

Table 4.12 Capital costs for a $20 \mathrm{gpm}$ SMZ system ............................................... 108

Table 4.13 Capital costs for a $40 \mathrm{gpm}$ SMZsystem .................................................. 108

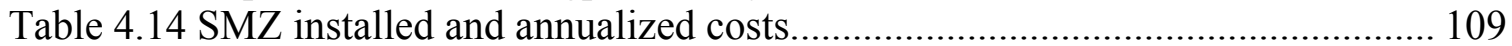

Table 4.15 Installed and annualized costs for vapor phase biofilter systems ................ 109

Table 4.16 Operating costs for a 6 gpm design flowrate .......................................... 110

Table 4.17 Cost estimate for SMZ/VPB with reverse osmosis ................................... 112

Table 4.18 Injection operation and maintenance costs ............................................. 113

Table 4.19 Estimates of total costs for salt water disposal in 2006 .............................. 114

Table 4.20 Water quality of produced water and targets for SJGS .............................. 118

Table 4.21 Water quality goals for SJGS (Zammit, Oct. 2004) ..................................... 118

Table 4.22 Water quality limits for the oil and gas industry ...................................... 120

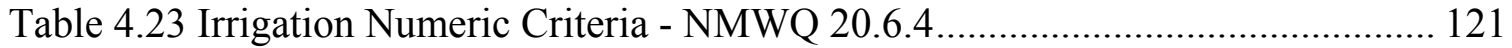

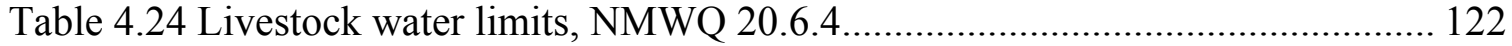

Table 4.25 Recommended TDS and SAR limits ..................................................... 123 


\section{INTRODUCTION}

\subsection{Problem Statement}

Co-produced water from the oil and gas industry accounts for a significant waste stream in the United States. It is estimated that a total of 14 billion barrels of produced water was generated in 2002 from onshore operations (Veil, et al, 2004). This is by some estimates the largest single waste stream in the country, aside from nonhazardous industrial wastes (Allen and Rosselot, 1994). Although as much as 95\% of this produced water is disposed via reinjection, the remaining amounts that are discharged on the surface are significant. Environmental and cost considerations make surface discharge of this water a more practical means of disposal in many instances. In addition, reinjection is not always a feasible option because of geographic, economic, or regulatory considerations. In these situations, it may be desirable, and often necessary from a regulatory viewpoint, to treat produced water before discharge. It may also be feasible to treat waters that slightly exceed regulatory limits for re-use in arid or drought-prone areas, rather than losing them to re-injection.

Characteristics of produced water include high total dissolved solids content (TDS), dissolved organic constituents such as benzene and toluene, an oil and grease component (which may be a dissolved product, an emulsion, or a separate phase) and chemicals added during the oil-production process. Current solutions to oil and grease restrictions and dissolved toxics (mostly from dissolved organic constituents) include ultrafiltration, advanced oil-water separation, hydrocyclones, chemical clarification, and gas flotation. Although many of these treatment options are successful at reducing the organic content of produced waters, they cannot always meet the levels of the current or proposed regulations. A need therefore exists to develop a cost-efficient treatment technology for the organic content in produced water. Such a technology is estimated to potentially maintain several thousand bbl of domestic production in a single impacted county. This can be multiplied by a factor of 10 to 20 for other counties that may be potentially impacted within the state of Texas alone. Therefore, the impact of regulation and the need for inexpensive treatment processes is considerable.

Surfactant-modified zeolite (SMZ) is an innovative filtration/sorption medium that can meet these needs. This adsorbent can be cost-effectively produced using naturally occurring zeolites and commercially available surfactant. Zeolites are hydrated aluminum tectosilicates characterized by cage like structures having high internal and external surface areas, and high-cation exchange capacities. The low cost of natural zeolites ( $\$ 45$ to $\$ 60 /$ ton) makes their use attractive in water-treatment applications. In contrast to clays, however, natural zeolites can occur as millimeter- or-greater-sized particles and are free of shrink-swell behavior. As a result, zeolites exhibit superior hydraulic characteristics and are suitable for use in filtration systems. 
Treatment of natural zeolites using cationic surfactants dramatically alters their surface chemistry. The large organic cations exchange readily with the native counterions on the external surface of the zeolite. This exchange produces a high-organic-carbon-content external surface while preserving a significant portion of the internal-surface cationexchange capacity. The surfactant used to coat the external surface of zeolites in our previous work was hexadecyltrimethylammonium bromide (HDTMA). In addition to increasing the organic content of the sorbent, the HDTMA cation also produces the unique property of oxyanion sorption under high loading levels. Thus, the adsorbent produced can remove cationic, anionic and organic constituents of produced water. In our previous research project, batch and laboratory column adsorption studies suggested that: 1) sorption of benzene, toluene, ethylbenzene and xylenes (BTEX) to SMZ follows linear isotherms in which sorption increases with increasing solute hydrophobicity; 2) the presence of high salt concentrations can substantially increase the capacity of the SMZ for BTEX; 3) competitive sorption among the BTEX compounds is negligible; and, 4) in tests conducted to date, a reduction in sorption capacity of benzene (the design-controlling solute) was not evident in the samples containing produced water. Our studies also indicate that due to benzene's relatively low sorption potential, the column design and regeneration requirements are controlled by benzene breakthrough from the SMZ columns.

A key feature required for successful application of SMZ to the treatment of produced water is regeneration of the SMZ. Although SMZ is not as efficient as activated carbon in removing highly soluble organics such as benzene, studies completed under DOE Contract DE-AC26-99BC15221 indicate that SMZ can be readily regenerated for BTEX compounds simply by sparging ambient air through the SMZ column (Ranck et al. 2005; Katz et al. 2003). This process generates a moist air stream contaminated with relatively low concentrations of volatile organic compounds (VOCs) including BTEX. Because these VOCs are biodegradable and present in dilute concentrations, a vapor phase bioreactor can be used to destroy the pollutants generated in the SMZ regeneration step. In vapor phase bioreactors (VPBs), microorganisms growing on a fixed packing media are used to biodegrade organic pollutants found in the waste gas stream being treated. Products of the biodegradation include carbon dioxide, water and new biomass. This technology has several advantages for this application including high destruction efficiencies for many VOCs including BTEX compounds, low operating costs and minimal generation of undesirable byproducts (van Groenestijn and Hesselink, 1993; Deshusses and Webster, 2000). For instance, removal efficiencies of greater than $90 \%$ can be achieved at BTEX loads below $96 \mathrm{~g} / \mathrm{m}^{3}$ packing $\mathrm{hr}$, (Lu, et al. 2000). VPBs were originally developed to treat waste gas streams containing relatively low concentrations of VOCs and this is considered the ideal application for the VPB technology (Leson and Winer, 1991; Leson and Smith, 1997; van Groenestijn and Hesselink, 1993).

Several VPB configurations are possible for the SMZ application including a biofilter configuration with a stationary liquid film containing nutrients and biomass. Biofilters 
are often packed with a natural media such as peat or compost which is biologically active and can provide nutrients to the microorganisms growing on the packing material. Synthetic packing materials such as silicon oxide pellets have also been used successfully in biofilters (Song and Kinney, 2000; Woertz, et. al, 2001) and often allow greater control over key operating parameters such as nutrient supply and biomass distribution. Biotrickling filters are an alternative VPB configuration in which a liquid nutrient phase is continuously recirculated throughout a synthetic packing material. Both VPB configurations have been used successfully to treat waste gas streams containing BTEX and other volatile hydrocarbons and hybrid systems which contain both biofilter and biotrickling filter design elements are also under development for treating complex VOC mixtures.

Although VPBs are an attractive treatment for the SMZ regeneration step, several issues will need to be investigated to ascertain the effectiveness of the SMZ/VPB combination. For instance, the presence of multiple VOCs in the inlet gas stream can lead to competitive inhibition between the VOC substrates (Deeb and Alvarez-Cohen, 1999; Deshusses et al. 1995). In addition to BTEX compounds, the air stream generated from the SMZ regeneration step will include other volatile hydrocarbons. Vapor phase bioreactors have the ability to treat complex hydrocarbon streams such as those generated from the remediation of gasoline-impacted sites (Jutras, et al. 1997) but interactions between the VOC components of the waste gas stream must be determined for a particular application. For instance, it has been observed in a biofilter packed with synthetic media that the presence of toluene can inhibit the degradation of xylene; however, once the toluene has been degraded in the front end of the bioreactor, the remaining aromatic constituents can be successfully degraded. Such VOC degradation interactions may be mediated by the nitrogen availability in the biofilm. In the presence of excess nitrogen, for instance, toluene, xylene and ethylbenzene can be degraded simultaneously but under nitrogen limitation, xylene degradation is reduced (Song et al. 2003). The effect of nitrogen on VPB performance has been studied by several researchers and is an important operating parameter for the system (Kinney et al. 1999; Moe and Irvine, 2001).

Another issue to consider for the SMZ/VPB combined treatment system is that VPBs prefer a continuous feed stream and thus the operation of the SMZ/VPB system will need to be optimized to match SMZ regeneration and VPB feed cycles. For instance, a VPB supplied with a very small but continuous VOC feed achieved much higher removal efficiencies following restart of the bioreactor than did a system that was simply shut off and not provided any VOCs during the shutdown period (Park and Kinney, 2001). Finally, it is important to note that although many of the organic constituents found in produced water are biodegradable, the high salinity of produced water inhibits direct biological treatment of the produced water. Furthermore, direct air stripping of the produced water phase will not remove the less volatile organic contaminants. Thus, treatment of the water via SMZ followed by treatment of the regeneration gas via a VPB 
should allow the removal of organic and inorganic constituents and ultimate destruction of the VOCs without the problems associated with high salinity and the presence of heavier organic species.

\section{$1.2 \quad$ Objectives}

The overall goal of this project was to develop a robust SMZ/VPB treatment system to efficiently remove the organic constituents from produced water in a cost-effective manner. Although both SMZ and VPB technologies have been developed separately, a series of laboratory and field scale experiments were required to optimize the SMZ/VPB combination specifically for produced water.

Thus, the four objectives of the project were as follows:

Objective 1: Characterize and optimize the SMZ regeneration process to enable longterm operation of the SMZ process for a wide range of produced water applications;

Objective 2: Develop a VPB that is optimized for treating the waste gas streams generated by SMZ regeneration;

Objective 3: Optimize the coupled SMZ/VPB treatment technology both at the laboratory and field scale; and

Objective 4: In conjunction with industry and DOE, conduct a detailed cost and feasibility evaluation to compare the SMZ/VPB treatment technology to existing techniques for treating produced water from a variety of processes across the country. 


\section{BACKGROUND}

The overall goal of this research project was to extend our previous research examining the potential for removal of BTEX from produced water using surfactant modified zeolite (SMZ) to address issues associated with multiple cycling of the SMZ and treatment of the off-gas during regeneration using a vapor phase bioreactor (VPB). This section provides background pertaining to the characteristics of produced water, a discussion of regulations relevant to produced water treatment, a description of SMZ and previous studies examining sorption onto SMZ and a description of VPB systems relevant to its application to this project.

\subsection{Produced Water}

\subsubsection{Sources of Produced Water}

The three production processes that compose the oil and natural gas (O\&NG) industry are oil, coalbed methane, and conventional non-associated gas. Produced water is generated during O\&NG production, refining, and transportation processes. These processes use and generate large amounts of water through both onshore and offshore operations (Fillo et al, 1992). Produced water is the largest waste stream in the entire oil exploration and production process (Janks \& Cadena, 1992). During the later stages of production, water can account for as much as $98 \%$ of the total extracted liquid (Stephenson, 1992). Most of the produced water stems from oil production, where ten barrels of water typically result from one barrel of oil. Every 1000 cubic feet of coalbed methane and conventional nonassociated gas results in 0.31 and 0.023 barrels of produced water, respectively. The American Petroleum Institute reported that 18 billion barrels of produced water were generated by onshore operations in 1995 (API, 2000). More recent updates have adjusted this estimate to 14 billion barrels for 2002 although actual values are likely higher (Veil, et al, 2004).

Water that is naturally present in O\&NG reservoirs, commonly referred to as formation water, is found both in liquid and vapor phases. This water is often recovered at the wellhead, but can also result from further processing. Water is sometimes pumped into a reservoir to maintain well pressure or to force oil into production wells. Smaller volumes of produced water arise from oil storage facilities and process and drainage water (Jacobs et al. 1992). Pipeline drips and oil/water separators can be located at gathering stations, processing/conditioning plants, and underground storage facilities (Fillo et al. 1992).

\subsubsection{Produced Water Characteristics}

Produced water can be generally characterized as saline water with small amounts of organic and inorganic species. The composition of the water varies depending on geological setting and production methods, but usually includes dissolved mineral salts and metals, soluble and insoluble hydrocarbons, hydrogen sulfides, and radionuclides. In general, offshore oil production generates effluent that is higher in total dissolved solids 
(TDS) but lower in BTEX concentrations than onshore gas production. Onshore oil production usually results in water with BTEX and TDS concentrations between those of offshore oil and onshore gas production (Lawrence et al. 1995; Smith et al. 1996; Fillo et al. 1992).

Many hydrocarbons are found in produced water. Oil and grease, volatile, and semivolatile compounds are present at different levels, depending on the source. Oil and grease are usually the result of isolated droplets that escape the oil/water separation process. The most common volatile compounds are BTEX. Their presence is a direct result of the hydrocarbons present in oil and natural gas liquids. Water from gas production operations is generally higher in BTEX concentrations than that from oil production and gas storage. Other volatile organics such as chlorinated solvents are less frequently present; however, polynuclear aromatic hydrocarbons, phenols, and carboxylic acids are typically identified (Fillo et al. 1992). $\mathrm{C}_{10}-\mathrm{C}_{30}$ straight-chain alkanes are the most prevalent semi-volatile organics, with their concentrations frequency generally decreasing as molecular weight increases. Arsenic, barium, chromium, copper, lead, lithium, silicon, strontium, zinc, and many more metals are also frequently identified in produced water samples. Naturally occurring radioactive matter (NORM) can also be present depending on the source. The radioactivity is primarily associated with radium isotopes, ${ }^{226} \mathrm{Ra}$ and ${ }^{228} \mathrm{Ra}$ (Fillo et al. 1992; Stephenson, 1992). A general range of contaminant concentrations are listed in Table 2.1. This data was provided in Tibbets et al. (1992).

\subsubsection{Regulation of Produced Water Disposal}

Produced water is normally disposed of through three options: deep-well injection, surface discharge, and recycle/reuse. Regulation of water that is injected into saline aquifers is conducted through the Underground Injection Control program of the Safe Drinking Water Act (SDWA). This water is exempt from Subtitle C of the Resource Conservation and Recovery Act (RCRA) and can be injected into non-drinking water aquifers through Class II wells (RCRA: Section 3001 (b) (2) (A)). Despite the exemption from Subtitle C, Subtitle D of RCRA continues to apply, and handling and disposal of produced water must still be conducted in compliance with these regulations. In addition, states can also have restrictions on deep-well injection and applicable state regulations must be followed.

Discharge to onshore, coastal, and offshore waters is primarily governed through the Clean Water Act and issuance of National Pollutant Discharge Elimination System (NPDES) permits (Fillo et al. 1992). Only those onshore producers who generate a maximum of 10 barrels of oil or associated gas per day, or those who generate effluent of sufficiently high quality for beneficial reuse can be granted NPDES permits for onshore surface discharge (Lawrence et al. 1995). In addition to limiting the volume of effluent wasted, these permits also state maximum allowable oil and grease concentrations, metal concentrations, toxicity, and a variety of other parameters. Although most coastal and 
offshore waters are classified as federal territories, some waters off the states of Florida and Texas remain within state boundaries. In these states, as well as several others, the state environmental agencies are responsible for issuing NPDES permits and overseeing compliance with other federal and state regulations.

Table 2.1 Ranges of contaminants detected in produced water.

\begin{tabular}{|c|c|c|c|}
\hline Test & Parameter & units & Literature \\
\hline $\begin{array}{l}\text { Petroleum } \\
\text { Hydrocarbons }\end{array}$ & Total & $\mathrm{mg} / \mathrm{L}$ & $2-565$ \\
\hline Organic Carbon & Total & $\mathrm{mg} / \mathrm{L}$ & $0-1500$ \\
\hline \multirow{2}{*}{ Anions } & Chloride & $\mathrm{mg} / \mathrm{L}$ & $80-200000$ \\
\hline & Sulfate & $\mathrm{mg} / \mathrm{L}$ & $2-1650$ \\
\hline \multirow{4}{*}{ Cations } & Calcium & $\mathrm{mg} / \mathrm{L}$ & $13-25800$ \\
\hline & Magnesium & $\mathrm{mg} / \mathrm{L}$ & $8-6000$ \\
\hline & Potassium & $\mathrm{mg} / \mathrm{L}$ & $24-4300$ \\
\hline & Sodium & $\mathrm{mg} / \mathrm{L}$ & $132-97000$ \\
\hline Alkalinity $\left(\mathrm{CaCO}_{3}\right)$ & Total & $\mathrm{mg} / \mathrm{L}$ & $77-3990$ \\
\hline \multirow{8}{*}{ Metals } & Mercury & $\mu \mathrm{g} / \mathrm{L}$ & $1-2$ \\
\hline & Arsenic & $\mu \mathrm{g} / \mathrm{L}$ & $5-300$ \\
\hline & Barium & $\mu \mathrm{g} / \mathrm{L}$ & $1300-650000$ \\
\hline & Cadmium & $\mu \mathrm{g} / \mathrm{L}$ & $5-200$ \\
\hline & Chromium & $\mu \mathrm{g} / \mathrm{L}$ & $20-1100$ \\
\hline & Lead & $\mu \mathrm{g} / \mathrm{L}$ & $2-8800$ \\
\hline & Selenium & $\mu \mathrm{g} / \mathrm{L}$ & $<0.001$ \\
\hline & Silver & $\mu \mathrm{g} / \mathrm{L}$ & $1-150$ \\
\hline Semivolatiles & Phenols & $\mu \mathrm{g} / \mathrm{L}$ & $9-23000^{1}$ \\
\hline \multirow{5}{*}{ BTEX } & Benzene & $\mu \mathrm{g} / \mathrm{L}$ & $77-44000$ \\
\hline & Tolulene & $\mu \mathrm{g} / \mathrm{L}$ & $90-5800$ \\
\hline & Ethylbenzene & $\mu \mathrm{g} / \mathrm{L}$ & $29-110$ \\
\hline & m\&p-Xylene & $\mu \mathrm{g} / \mathrm{L}$ & $47-400$ \\
\hline & o-Xylene & $\mu \mathrm{g} / \mathrm{L}$ & $70-460$ \\
\hline
\end{tabular}

${ }^{1}$ Reported value of phenol is the sum of all measured phenols

State regulations are also the primary method of control over recycling and reuse of produced water. Many western states experience arid conditions which limit the amount of water available for irrigation, livestock watering, and wetting of unpaved dirt roads. 
Some waters generated through oil and gas production are of sufficient quality for these uses and are therefore utilized. Application of produced water for these purposes is usually governed by state agencies on a case-by-case basis (Fillo et al. 1992). Treatment of the produced water that does not currently meet standards for beneficial reuse would allow this wastewater to become a commodity for both producers and residents of waterscarce areas. Lawrence et al. (1995) state that future regulations for produced water would require additional treatment for the removal of organic compounds and minerals. Thus, removal of BTEX would be an important step in the treatment of produced water.

\subsection{Produced Water Treatment}

\subsubsection{Summary of Current Produced Water Treatment Methods}

Most current treatment methods for produced water focus on the separation of aqueous and organic phases. Most producers rely on oil/water separation tanks, hydrocyclones, or gas floatation devises to achieve phase separation. Each of these processes has the potential to recover oil from a waste stream. Due to the economic incentives associated with oil recovery, these methods have been continually refined by the industry (Santos and Wiesner, 1997). Unfortunately, most of these processes only separate large insoluble organics from water, and do not remove dissolved hydrocarbons, metals, or salts (Bilstad and Espedal, 1996). In the future, regulations may become stricter regarding the disposal of produced water. Therefore the need to investigate further treatment options to remove these constituents remains (Santos and Wiesner, 1997). In addition, there is a desire to evaluate the potential for reuse of produced water, especially in arid areas. Reuse would require significant improvements in water quality using a treatment system that includes both pretreatment and polishing processes. Several treatment technologies involving filtration, adsorption, membrane processes, and oxidation have been evaluated for produced water treatment. However, none of these options is particularly cost-effective, and the need for alternative treatment approaches is evident. In a previous, DOE Project, CE-AC26-99BC15221, we reviewed the alternative processes and examined the potential of a surfactant modified zeolite adsorption process for removal of BTEX from produced water.

Produced water can initially have a large oil fraction that can easily be separated using a variety of methods. The oil that is removed is often recovered for use. Phase separation is often conducted using an oil-water separation process. The typical American Petroleum Institute (API) oil-water separation tank consists of a channel or channels where water flows horizontally with sufficient time to allow oil droplets to rise to the surface. Floating oil is skimmed from the surface, while water is allowed to flow through the reactor at a constant rate. Additional treatment procedures can be used in conjunction with the tank to improve the removal efficiency of hazardous constitiuents. These include chemical flocculants and gas floatation methods. For example, Thoma et al. (1999) experimented with the separation of organics from produced water by bubbling 
air; however, even after 360 minutes at a gas flow rate of $60 \mathrm{~mL} / \mathrm{min}$, only $40 \%$ of the dissolved ethylbenzene and toluene was removed. Raising the gas flow rate to 200 $\mathrm{mL} / \mathrm{min}$ increased the removal of the aromatic hydrocarbons to $70 \%$. Benzene was reported to be a test compound, but no experimental results were given.

Membranes have been shown to be of great promise in water treatment. Membrane technologies are classified by average pore size, as shown in Table 2.2. Newer membranes are manufactured in a spiral wound configurations.

Table 2.2 Membrane filtration technologies

\begin{tabular}{|l|l|}
\hline Technology & Pore size range \\
\hline Microfiltration & $0.1-10$ microns \\
\hline Ultrafiltration & $500-100,000$ Daltons \\
\hline Nanofiltration & $100-500$ Daltons \\
\hline Reverse Osmosis & Up to 100 Daltons \\
\hline
\end{tabular}

Although membrane treatment technologies have the capability to produce extremely pure water, they have many drawbacks. High pressure gradients are required to force water through the narrow membrane pores. Membranes themselves are also prone to 'fouling', or significant deterioration in functionality. The three primary reasons for fouling are particles in the feed stream, buildup of sparingly soluble materials, and microbial growth on the membrane (Nicolaisen, 2002). To reduce the potential for fouling, membrane processes often require pretreatment to remove large fractions of these components. Adsorption processes represent one potential pretreatment option.

A number of potential adsorbents have been studied for removing contaminants from produced water. Activated carbon (AC) has been used on an industrial scale since the 1920 's to remove chemicals that caused odors and bad taste in drinking water (Sontheimer et al. 1988). AC was later found to remove non-polar organic pollutants from water and has been used for this purpose in many remediation sites and water treatment plants. AC is produced from the pyrolysis of raw carbon sources like peat, coconut shells, wood, and bituminous coal. This material is then chemically activated and sieved into different sizes. The activation process produces a highly porous material with surface areas typically ranging from 500 to $1400 \mathrm{~m}^{2} / \mathrm{g}$. The surface of activated carbon is primarily hydrophobic, and therefore, an excellent sorbent for organic compounds. Sorption onto AC is typically described using a non-linear isotherm model, and the overall process is controlled by surface and/or pore diffusion mechanisms (Sontheimer et al. 1988).

Depending on the particle size, AC is classified as powdered (particles less than $0.05 \mathrm{~mm}$ in diameter), or granular (typically 0.3 to $3 \mathrm{~mm}$ in diameter). Powdered activated carbon (PAC) is usually added to a rapid mix and flocculation tanks. After a contact time of 10 
to 15 minutes, the PAC is usually removed through filtration or flocculation. PAC is usually not used as a filter media itself because of its small particle size. For AC filtration purposes, the larger particle size granular activated carbon (GAC) is commonly packed into columns. It is the most commonly used sorbent used in remediation projects because of its excellent sorption properties. However, some drawbacks occur when it is used for the removal of dissolved organic chemicals. Competitive sorption often limits the applicability of AC when used to treat a mixture of organic chemicals, as only a fixed number of adsorption sites are available on the surface. If one compound has a greater affinity for the $\mathrm{AC}$, then it can take up most of the available sorption sites, while other less competitive compounds remain in solution. Another drawback to the use of AC is its inability to effectively remove metal and polar species in waters with multiple types of pollutants. Produced waters typically have trace amounts of heavy metals and hydrophilic pollutants in addition to organic compounds. The hydrophobicity of the AC prevents the sorption of these polar compounds. The regeneration of $\mathrm{AC}$ requires large amounts of energy, and therefore is cost prohibitive for the treatment of produced waters. Even with these drawbacks, AC is still the most commonly used sorbent for the removal of organic constituents from wastewaters, and has been proven to remove these compounds from produced waters (Gallup et al. 1996).

Another carbonaceous sorbent, Ambersorb, is made from the partial pyrolysis of macroporous polymer beads. The pyrolysis process causes the materials to lose their ionic functional groups and retain non-polar surfaces (Weber and van Vliet, 1981). The resulting compounds exhibit hydrophobic properties that allow non-polar organic compounds to be effectively removed from water. Gallup et al. (1996) used column studies to compare Ambersorb ${ }^{\circledR} 572$ (Rohm and Haas Company; Spring House, PA) to Hydrodarco GAC (American Norit Co., Inc.; Atlanta, GA) and the organically-modified clays EC-100 and EC-199 (Biomin Inc.; Huntington Woods, MI) for treatment of BTEX in oil-field produced waters. The authors stated that the Ambersorb ${ }^{\circledR}$ outperformed both GAC and both modified clays. After treatment of 1200 bed volumes, Ambersorb $® 572$ was reported to remove $93 \%$ of benzene and toluene while Hydrodarco GAC provided only $23 \%$ removal. Additionally, the authors stated that the modified clays used in the study removed between $21-23 \%$ of benzene and toluene in the produced water. Although neither the commercial sorbents nor the GAC removed the emulsified oil, modified clays reduced the emulsified oil from $25 \mathrm{mg} / \mathrm{L}$ to $12 \mathrm{mg} / \mathrm{L}$. Isotherms and isotherm parameters were not included in the study, although sorption densities could be estimated with additional information obtained from the California MTBE Research Partnership (1999).

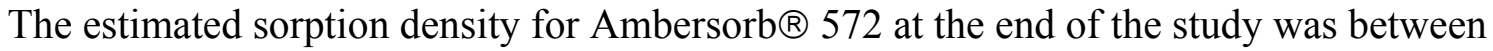
$125-376 \mathrm{mg} / \mathrm{g}$ for an influent concentration of 25-130 mg/L BTEX. Regenerated Ambersorb $® 572$ exhibited a 1 to $40 \%$ reduction in sorptive capacity. This potential for loss of adsorption capacity was one of the motivations for examining surfactant modified zeolite in this research. 


\subsubsection{Surfactant Modified Zeolites}

Natural zeolites are hydrated aluminosilicate minerals with cage-like structures. They have very high internal and external surfaces areas and high internal and external cation exchange capacities (CEC). The zeolite used in this research was obtained from the St. Cloud mine in Winston, New Mexico. The BET external surface area and CEC were $15.7 \mathrm{~m}^{2} / \mathrm{g}$ and $230 \mathrm{meq} / \mathrm{kg}$, and the organic carbon content was less than $0.5 \%$.

Surfactants are surface active agents that exhibit both hydrophobic and hydrophilic properties. The surfactanct used in this research was hexadecyltrimethylammonium (HDTMA), a tetrasubstituted ammonium cation with a permanently charged pentavalent nitrogen and a long, straight alkyl chain $\left(\mathrm{C}_{16}\right)$ (Haggerty and Bowman, 1994). This surfactant is commonly used in products such as hair conditioner, mouthwash, and fabric softener so it is assumed that the chemical is not hazardous (Li et al. 1998). The long hydrocarbon chain imparts a strong degree of hydrophobicity to the surfactant tail while the positively charged ammonium head remains hydrophilic. Counterions such as bromide or chloride serve to neutralize the cationic effect of the head group and provide anion exchange capacity.

Saturation of natural zeolite with a surfactant such as HDTMA yields a surfactantmodified zeolite. As mentioned above, the cationic surfactant head exchanges with the naturally occurring cations on the surface of the zeolite. Due to the large size of HDTMA monomers, only external pore spaces are subject to this cation exchange. The surfactant is unable to enter the small internal pores and therefore, leaves the internal surface chemistry of the zeolite unchanged (Barrer et al. 1967; Li and Bowman, 1997).

Sorption of HDTMA has been described by a Langmuir isotherm for which the external exchange capacity has been reported to be between $90-210 \mathrm{meq} / \mathrm{kg}$ depending on the anionic counterion, and it was postulated that sorption occurs within HDTMA bilayers that develop on the external surface. Studies conducted by Sullivan et al. (1997) showed that the buildup of HDTMA bilayers began prior to completion of monolayer coverage. Chen et al. (1992) suggested that once the critical micelle concentration (CMC) is surpassed, previously formed micelles sorb onto negatively charged surfaces to create an admicelle or bilayer. Organic sorption occurs within the hydrophobic region inside the bilayer. These results were supported by Li and Bowman (1998) who determined that organic contaminants are sorbed at low HDTMA concentrations.

Through anion exchange with the counterions bonded to the HDTMA head groups, anionic contaminants can be removed from aqueous solutions. Several studies have shown that oxyanions such as arsenate, chromate, and selenate are very effectively removed from water by SMZ but not by untreated zeolite (Li and Bowman, 1997; Bowman et al. 1997; Haggerty and Bowman, 1994). It has also been shown that better sorption of oxyanions occurs when the counterions are weakly bonded (Li and Bowman, 1997). This intuitive trend was shown to increase in strength for hydrogen sulfate, 
chloride, and bromide, in that order. Although the sorption isotherms for these oxyanions all resembled Langmuir isotherms, the authors in each study were quick to point out that the sorption of the anions does not meet the assumed criteria for the Langmuir isotherm. Thus, the sorption can be described by the Langmuir parameters $\mathrm{K}_{\mathrm{L}}$ and $\mathrm{q}_{\max }$, but these parameters do not have true chemical significance.

The natural ability of zeolite to remove metallic cations from solution is somewhat altered by surfactant modification. The sorption of metals such as lead that originally sorbed to the internal pores of zeolite has been shown to remain unchanged (Haggerty and Bowman, 1994; Bowman et al. 1997). Thus, the presence of HDTMA seems to have little effect on the sorption of metals onto internal pore sites within zeolite. However, those cations that were removed by cation exchange with the external surface of the natural zeolite cannot be removed from solution by treated zeolite (Bowman et al. 1997). This inability to remove cations such as strontium is due to the strong sorption of the surfactant to the surface and to the repulsion between the metallic cations and the surfactant head groups.

\subsubsection{Sorption of Moderately Hydrophobic Organics to SMZ}

In addition to removing oxyanions and selectively removing metallic cations from solution, surfactant-modified zeolite has been found to sorb several types of organic contaminants. The mechanism for non-polar organic sorption onto SMZ has been described as partitioning into the hydrophobic pseudophase formed by the tail groups of the HDTMA bilayer (Li and Bowman, 1998). Hydrophobic compounds have extremely large activity coefficients in water. A great deal of energy is required to break the hydrogen bonds linking water molecules to create cavities suitable for hydrophobic compounds (Schwarzenbach et al. 1993). Additional energy is required to reconfigure water molecules into ice-like formations around non-polar organics. However, in most soil systems containing soil organic matter, much less energy is required for non-polar organics to dissolve into a hydrophobic phase. Thus, thermodynamics drive this partitioning process and cause organic compounds such as BTEX to exit the aqueous phase. The magnitude of the thermodynamic driving force is based on the water solubility of the various organic compounds. At equilibrium, non-polar organic compounds distribute themselves between the hydrocarbon and water phases according to their distribution coefficients, $K_{d}$. These distribution coefficients can be normalized to fractional organic matter content which generates organic matter partitioning coefficients, $\mathrm{K}_{\mathrm{om}}$ (Li and Bowman, 1998).

$$
K_{d}=K_{o m} f_{o m}
$$

A relationship developed by Olsen and Davis (1990) relates $\mathrm{K}_{\mathrm{om}}$ to $\mathrm{K}_{\mathrm{oc}}$, the organic carbon partitioning coefficient.

$$
K_{o c}=1.724 K_{o m}
$$


Thus, by measuring the distribution coefficient and the fractional organic matter content of the sorbent, the organic carbon partitioning coefficient can be determined.

Furthermore, a number of studies have shown that the value of $\mathrm{K}_{\mathrm{om}}$ can be correlated to physicochemical parameters such as solubility and octanol water partitioning coefficient.

In previous research, we showed that it was possible to apply this approach to characterizing the sorption of BTEX to surfactant modified zeolite (Gupta, 2001). Figure 2.1 shows the results of Gupta's correlations between $K_{D}$ and $K_{o w}$ and those from other authors.

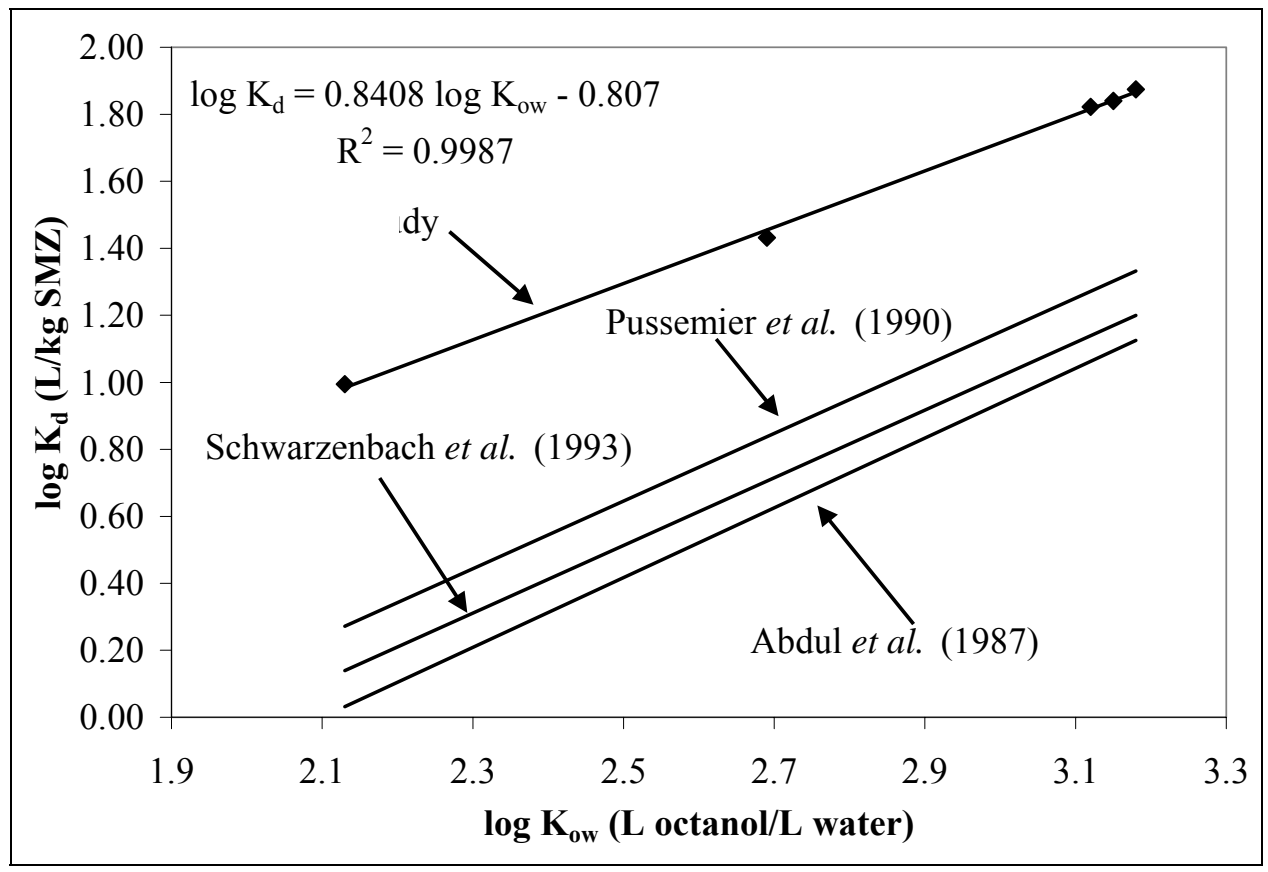

Figure 2.1 Relationships between $K_{d}$ and $K_{0 w}$ developed by various authors.

Figure 2.2 shows the relationships between the logarithm of the distribution coefficients $\left(\log \mathrm{K}_{\mathrm{om}}\right)$ for BTEX normalized by organic matter of SMZ and other physico-chemical properties of BTEX. Logarithms of octanol-water partition coefficients $\left(\log \mathrm{K}_{\mathrm{OW}}\right)$ and logarithms of aqueous solubility $\left(\log \mathrm{S}_{\mathrm{w}}\right)$ in moles per liter were obtained from

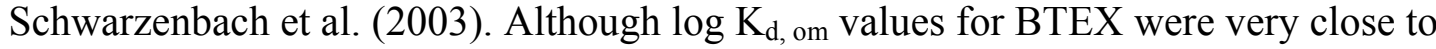
their $\log \mathrm{K}_{\mathrm{OW}}$ values, the slope of the regression was only 0.8 (Figure $2.2 \mathrm{a}$ ), implying that sorption onto the SMZ surface is less selective than partitioning into 1-octanol for BTEX. As reported in literature for partition coefficients between water and natural organic matters, $\log \mathrm{K}_{\mathrm{d} \text {, om }}$ correlates very well with $\log \mathrm{S}_{\mathrm{w}}$ with a slope of -0.748 (Figure $2.2 \mathrm{~b}$ ). 

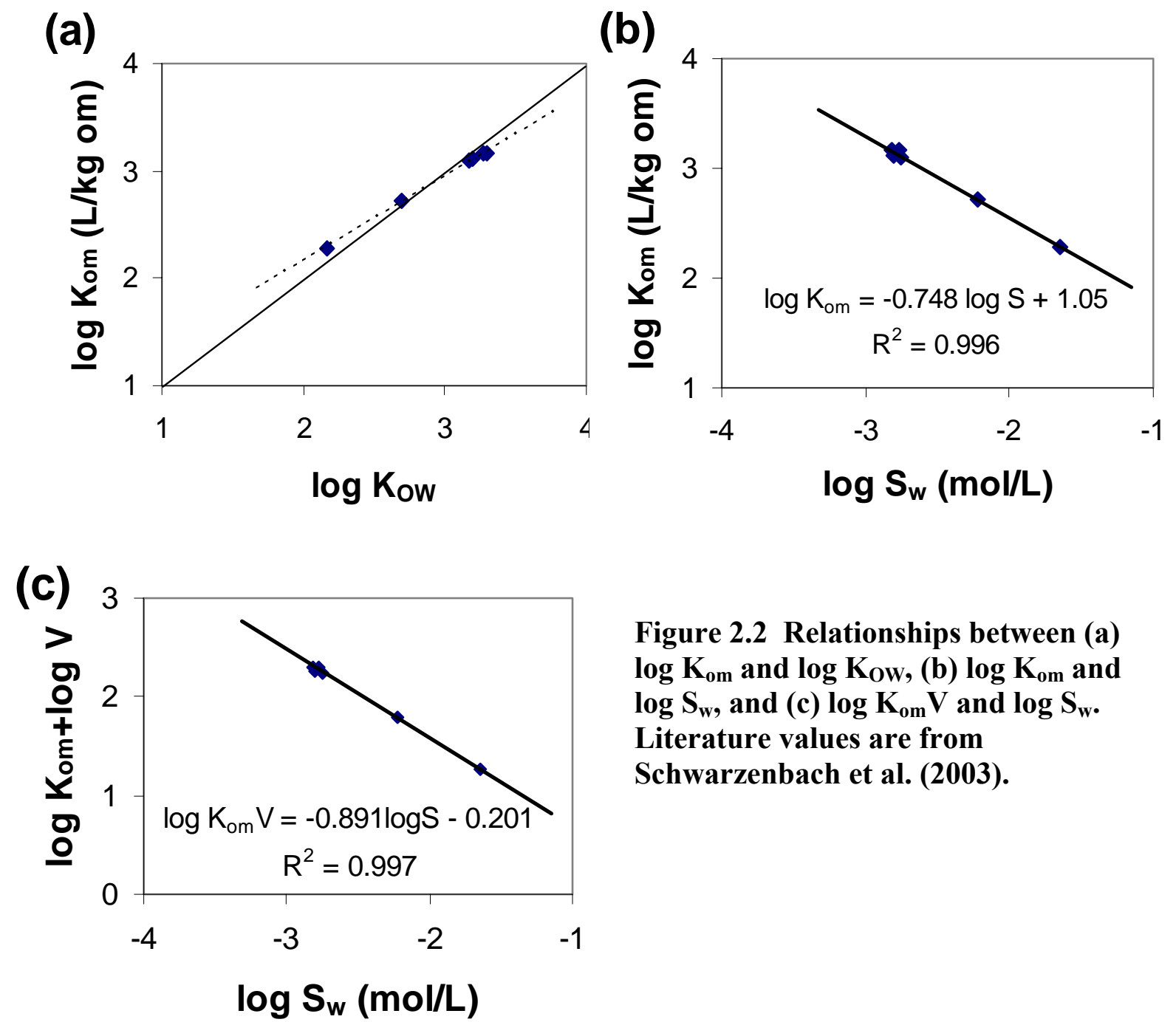

Figure 2.2 Relationships between (a) $\log K_{\text {om }}$ and $\log K_{O W}$, (b) $\log K_{o m}$ and $\log S_{w}$, and (c) $\log K_{0 m} V$ and $\log S_{w}$. Literature values are from Schwarzenbach et al. (2003).

Partition coefficients between water and organic phases can be expressed by the aqueous solubility and the molar volume of a solute, if the solute obeys Henry's law for concentrations up to its saturation in the aqueous solvent (Sangster, 1989). Furthermore, it is reasonable to assume that water and HDTMA do not dissolve each other. Then, the distribution coefficient normalized by organic matters is given as

$$
\log K_{d, o m}=-\log S_{w}-\log \bar{V}-\log \gamma_{\text {om }}
$$

where $\bar{V}$ is the solute molar volume and $\gamma_{o m}$ is the activity coefficient in organic phase on a volume-fraction basis. Because the larger BTEX compound has the lower water solubility, it is expected that the apparent slope in Figure $2.2 \mathrm{~b}$ becomes greater than -1 . In order to correct the effects of the solute molar volume, one can add $\log \bar{V}$ to both sides of 
equation (2.3) and perform a regression analysis for $\log K_{d, o m} \bar{V}$ versus $\log S_{w}$. Using the molar volumes of BTEX calculated by LeBas method (Mackay et al. 1992), the empirical slope of the plot is -0.89 (Figure $2.2 \mathrm{c}$ ), indicating that the disparity between the theoretical and the apparent slope of the regression could be due to the activity coefficient of BTEX in HDTMA layer. $\gamma_{\text {om }}$ may increase with increasing molar volume, although $\gamma_{\text {om }}$ is generally regarded the same for all organic solutes in a simple organic solvent such as 1-octanol. Bilayer-like structure of HDTMA molecules on zeolite surface may cause higher $\gamma_{\text {om }}$ for larger BTEX.

\subsubsection{Impact of Solution Parameters on BTEX Sorption to SMZ}

In our previous research, we quantified the impacts of salinity and temperature on BTEX sorption to SMZ (Katz et al, 2003). Figure 2.3 shows the changes in the distribution coefficient $\left(\mathrm{K}_{\mathrm{d}}\right)$ with respect to the changes in ionic strength of the solution. For all BTEX compounds investigated, $\mathrm{K}_{\mathrm{d}}$ exponentially increases with increasing ionic strength except for negligible changes between 0 and $0.50 \mathrm{M}$, the typical ionic strength of seawater. This is unusual since the previous studies have shown that partition coefficients of hydrophobic organic chemicals between water and organic carbons is typically $1.3 \sim 1.5$ fold higher in seawater than in fresh water due to the salting out effect (Hegemann et al. 1995; Rubio et al. 1996). Activity of benzene in the solution at $\mathrm{I}=0.5 \mathrm{M}$ comprised of $\mathrm{NaCl}$ should be 1.24 times that in pure water (McDevit and Long). Therefore, a negligible increase in the distribution coefficient at $\mathrm{I}=0.5 \mathrm{M}$ should be justified by a corresponding increase in the activity coefficient of BTEX in the HDTMA phase. The amount of HDTMA molecules used in this study exceeds the amount required to cover a single monolayer on the negatively charged zeolite surface, indicating that HDTMA molecules form an interfingered bilayer ( $\mathrm{Li}$ and Bowman, 1998). Ammonium head groups at the outer shell of SMZ particles are positively charged. The alignment of ammonium head groups at the surface could be further stabilized in a higher ionic strength solution. This may result in tighter packing of interfingered bilayers and cause small increases in the activity coefficient of a solute due to steric effects. However, the activity coefficient in HDTMA layer will be invariant with increasing salt concentration, once there are sufficient anions in the aqueous solution to further stabilize the interfingered bilayers. The distribution coefficient may depend more on the change in aqueous activity of a solute. 
(a)

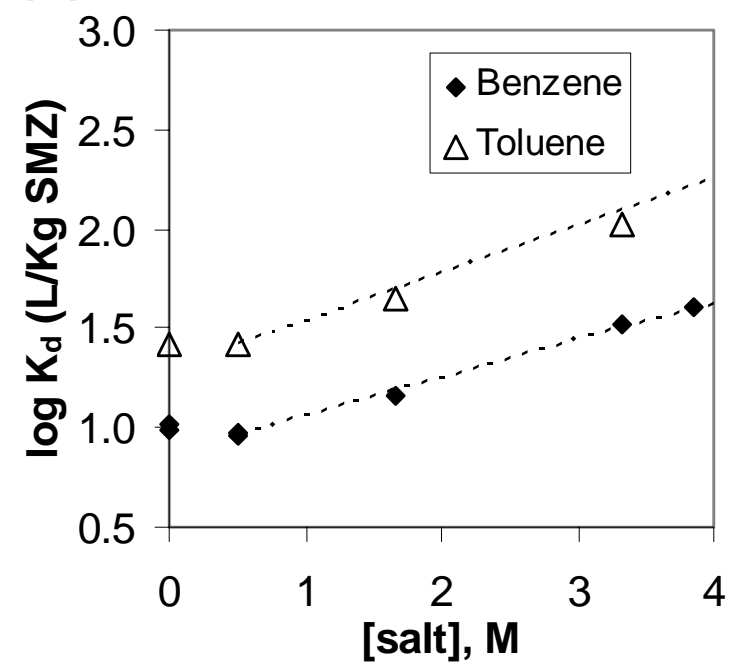

(b)

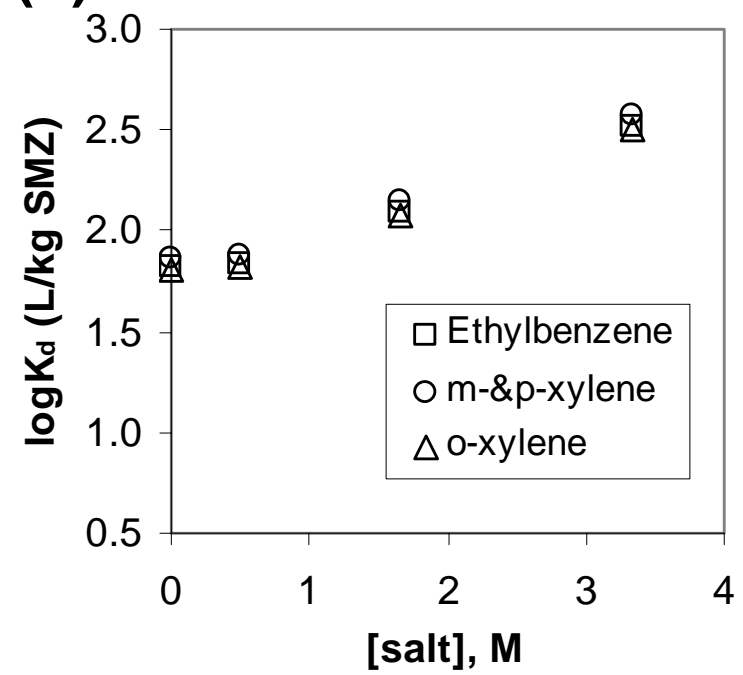

Figure 2.3 Effects of salinity on $\log K_{d}$ for (a) benzene and toluene and for (b) ethylbenzene and xylenes. Dashed lines and solid lines indicate predicted $\log K_{d}$ from equation 2.4 and 2.5 .

According to Setschenow equation, aqueous solubility of a solute in saline solution is related to that in pure water by:

$$
S_{w, \text { salt }}=S_{w} 10^{-K^{s}[\text { salt }]_{\text {tot }}}
$$

where $S_{w, s a l t}$ and $S_{w}$ are molar solubility in aqueous saline solution and in pure water, respectively, $K^{s}$ is the salting constant in $\mathrm{L} \mathrm{mole}^{-1}$, and [salt $]_{\text {tot }}$ is total salt concentration 
in mole/L. Therefore, the distribution coefficient will exponentially increase with increasing salt solution assuming that the activity coefficient of a solute at the saturation is not different from that in dilute solution. Thus, salt effects on the distribution coefficient can be described by:

$$
\log K_{d, \text { salt }}=\log K_{d}+K^{s}[\text { salt }]_{\text {tot }}
$$

Predicted values of the distribution coefficient were calculated for benzene and toluene because salting constants are available only for benzene and toluene in $\mathrm{NaCl}, 0.20$ and 0.24, respectively (McDevit and Long, 1952; Peng and Wan, 1998). As suggested previously, the distribution coefficient in pure water may not be a good reference value. The dashed lines in Figure 2.3a show distribution coefficient calculated from equation 2.4 using $\log \mathrm{K}_{\mathrm{d}, \mathrm{I}=0.5 \mathrm{M}}$ as a reference value. The experimental results fit very well to equation 2.4 , implying that Setschenow equation is useful to predict sorption of BTEX onto SMZ at various ionic strength of produced water. Prediction for the sorption of ethylbenzene and xylenes could not be made due to lack of salting constants. Experimental results fit best at the salting constants of 0.25 for ethylbenzene and xylenes.

Measurement of the distribution coefficient at six different temperatures from $5^{\circ} \mathrm{C}$ to $36^{\circ} \mathrm{C}$ revealed that the distribution coefficient increases with increasing temperature. Figure 2.4 shows the relationship between $\ln \mathrm{K}_{\mathrm{d}}$ and 1/T using the van't Hoff equation:

$$
\ln K_{d}=-\frac{\Delta H}{R} \frac{1}{T}+\frac{\Delta S}{R}
$$

where $\Delta \mathrm{H}$ is enthalpy change $(\mathrm{J} /$ mole $), \Delta \mathrm{S}$ is entropy change $(\mathrm{J} /$ mole-K), $\mathrm{R}$ is gas constant $(8.314 \mathrm{~J} / \mathrm{mole}-\mathrm{K})$, and $\mathrm{T}$ is absolute temperature $(\mathrm{K})$. Sorption enthalpies and entropies were calculated from the slope and the intercept of linear regression. These values are presented in Table 2.3 with the correlation coefficients $\left(\mathrm{R}^{2}\right)$. Sorption of BTEX onto SMZ is more likely to be driven by entropy change. The sorption process is endothermic (i.e. thermally not favored) but an increase in entropy compensates for the heat required to drive the process. Sorption of organic pollutants in water onto natural sediment or organic matters is generally regarded to be exothermic or enthalpy driven (Chiou et al. 1983; Lüers and tenHulscher, 1996). However, Dewulf et al. showed that the sediment/water partition coefficient for BTEX increases with increasing temperature although the results were not statistically significant (Dewulf et al. 1999). Sorption enthalpies in their study ranged between $3.5 \mathrm{~kJ} / \mathrm{mole}$ for benzene and $12.8 \mathrm{~kJ} / \mathrm{mole}$ for pxylene. They are very close to the values obtained in this study. Dissolution enthalpies in water $\left(\Delta \mathrm{H}_{\mathrm{w}}\right)$ calculated from aqueous activities of a solute at different temperatures by Dewulf et al. are also presented in Table 2.3. Because all $\Delta \mathrm{H}_{\mathrm{w}}$ for BTEX are positive, dissolution enthalpies onto $\operatorname{SMZ}\left(\Delta \mathrm{H}_{\mathrm{om}}\right)$ are higher than the overall sorption enthalpies (Table 2.3). 


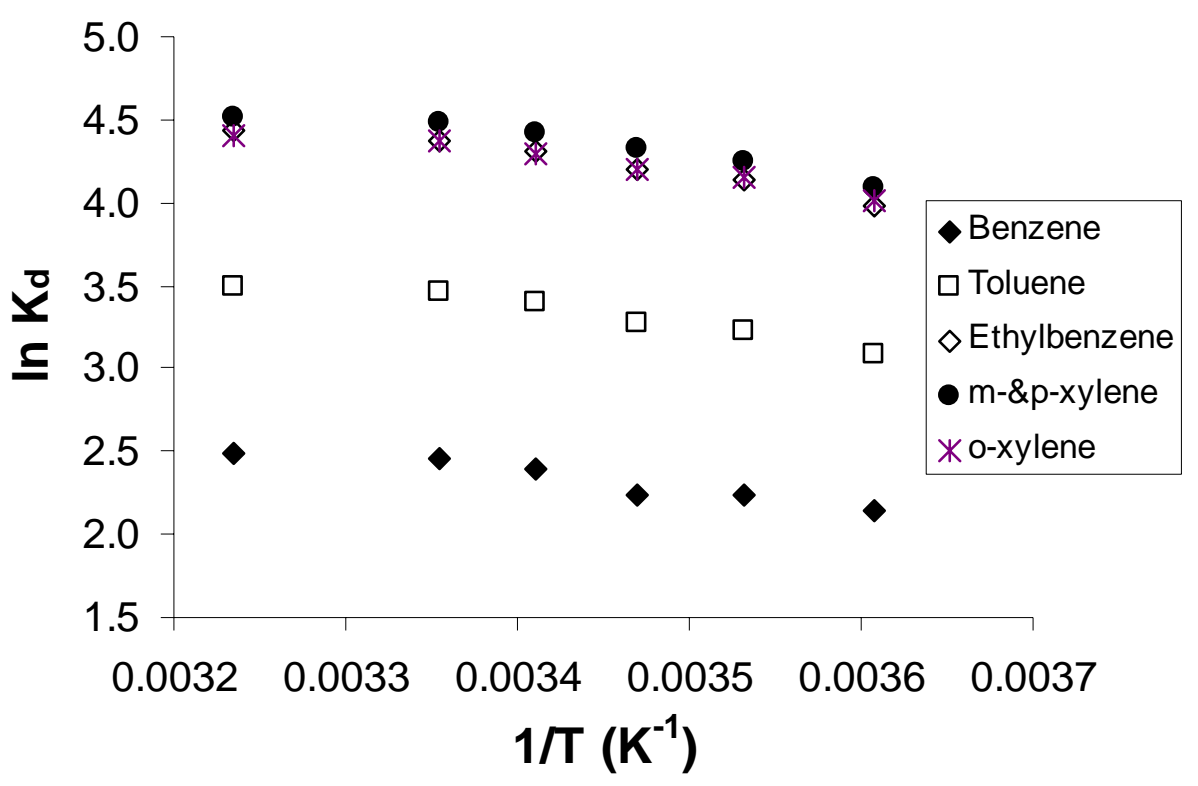

Figure 2.4 Van't Hoff isochors for the sorption onto SMZ of BTEX.

A solute transfer process from water to SMZ can be explained by two processes, loss of a solute in water and dissolution of the solute in SMZ. As can be seen from Table 2.3, loss of a solute from water is favored in terms of enthalpy change. Entropy change is also thought to be positive because water molecules near BTEX solutes are more organized and distribution of water molecules becomes more random after they lose the solute. Dissolution into the hydrophobic tails of HDTMA could be further divided into two processes - cavity creation and formation of new van der Waals interactions. Creating a cavity requires heat energy to take apart two adjacent hydrophobic tails. After the creation of a cavity, the hydrophobic layers are less structured and consequently increase entropy. Formation of new van der Waals interactions is accompanied by an enthalpy gain. It is also thought to be accompanied by entropy loss because introducing a solute in organic phase restricts conformational change of a solute and the expansion of the organic phase surface causes more surface hydration (i.e. more structured water molecules). Changes in enthalpy and entropy in the first step depends on the characteristics (or orderness) of the organic phase, while the second step depends more on the hydrophobicity of a solute than the characteristics of the organic phase. No apparent relation between $\Delta \mathrm{H}_{\mathrm{oc}}$ and solute molar volume or hydrophobicity was evident in Table 2.3 suggesting that these two processes balanced each other. 
Table 2.3 Overall sorption enthalpies $\left(\Delta \mathbf{H}_{\mathrm{s}}\right)$, entropies $\left(\Delta \mathrm{S}_{\mathrm{s}}\right)$, calculated dissolution enthalpies in water $\left(\Delta H_{w}\right)$ and in organic carbons $\left(\Delta H_{0 c}\right)$ with correlation coefficient.

\begin{tabular}{|c|c|c|c|c|c|}
\hline \multirow[b]{2}{*}{ Compound } & \multicolumn{3}{|c|}{ Experimental results } & \multirow{2}{*}{$\begin{array}{c}\Delta \mathrm{H}_{\mathrm{w}}{ }^{\mathrm{b}} \\
(\mathrm{kJ} / \text { mole })\end{array}$} & \multirow{2}{*}{$\begin{array}{c}\Delta \mathrm{H}_{\mathrm{oc}}^{\mathrm{c}} \\
(\mathrm{kJ} / \mathrm{mole})\end{array}$} \\
\hline & $\Delta \mathrm{H}_{\mathrm{s}}(\mathrm{kJ} / \mathrm{mole})$ & $\mathrm{T} \Delta \mathrm{S}_{\mathrm{s}}(\mathrm{kJ} / \mathrm{mole})^{\mathrm{a}}$ & $\mathrm{R}^{2}$ & & \\
\hline benzene & $8.29( \pm 1.31)$ & $14.0( \pm 1.3)$ & 0.909 & 6.32 & 14.61 \\
\hline toluene & $9.48( \pm 1.37)$ & $17.6( \pm 1.4)$ & 0.923 & 1.75 & 11.23 \\
\hline ethylbenzene & $10.17( \pm 1.28)$ & $20.6( \pm 1.3)$ & 0.940 & 0.35 & 10.52 \\
\hline o-xylene & $8.90( \pm 1.27)$ & $20.2( \pm 1.5)$ & 0.925 & 1.39 & 10.29 \\
\hline m-\&p-xylene & $9.53( \pm 1.45)$ & $19.3( \pm 1.3)$ & 0.915 & 4.22 & 13.75 \\
\hline
\end{tabular}

Li and Bowman (1998) found that the sorption coefficient of PCE increases with increasing organic carbon content below monolayer coverage, but it does not increase with increasing HDTMA content above monolayer coverage. This would be due to the fact that more energy is required to create a cavity of sorption at higher density of HDTMA on zeolite. Sorption behavior onto SMZ in this study is compatible with what has been observed in partitioning between water and highly organized organic phases, such as surfactant micelles or lipid bilayers. Free energy of solute transfer is dominated by the entropy change for micelle-water system using chloroebenzenes and sodium dodecyl sulfate as a model surfactant (Woodrow and Dorsey, 1997). Although sorption enthalpies were slightly negative, these were much less than $\mathrm{T} \Delta \mathrm{S}$ at $293 \mathrm{~K}$ and the overall process is entropy-driven. Sorption enthalpy onto more structurally organized organic phase, dipalmitoylphosphatidylcholine liposomes (C16, saturated) of chlorobenzenes and various endocrine disrupting chemicals are positive below the main transition temperature of the liposomes and the process was dominated by entropic term (van Wezel et al. 1996, Kwon et al. 2006). Therefore, sorption of BTEX onto SMZ is thermodynamically closer to partitioning into surfactant micelles or a lipid bilayer rather than partitioning into naturally occurring organic carbons. This is consistent with the proposed structure of HDTMA on zeolite surfaces (Li and Bowman, 1998).

\subsubsection{Adsorption of Semi-Volatile Components}

Produced water contains a number of semi-volatile contaminants including polynuclear aromatic hydrocarbons, phenols, and carboxylic acids (Fillo et al. 1992). Semi-volatile compounds can either be permanently non-polar or can contain functional groups that exhibit a constant or variable charge. Therefore sorption of these compounds can be related to the sorption of either non-polar organic compounds or charged metals species depending on the structure of the chemical. Naphthalene and methyl-naphthalenes are structurally similar to benzene and toluene, and would be expected to exhibit similar sorption characteristics (i.e. linear partitioning coefficients). Phenol and methyl-phenols are also similar to benzene and toluene, but they contain a hydroxyl group. Depending on the solution $\mathrm{pH}$, these hydroxyl groups can either have a net charge of zero or a negative charge after the loss of their proton. The $\mathrm{pH}$ where the ratio of charged and 
uncharged species of the same compounds is equal to one occurs at the compound's pKa. pKas for the four phenol compounds used in this study are listed in Table 2.4.

Table 2.4 pKa of phenol compounds used in this study.

\begin{tabular}{|c|c|}
\hline compound & pKa \\
\hline phenol & 9.99 \\
\hline 2-methylphenol & 10.3 \\
\hline 4-methylphenol & 10.26 \\
\hline 2,4-dimethylphenol & 10.6 \\
\hline
\end{tabular}

Li et al. (2000) showed that in addition to non-polar organics, phenol and aniline sorption onto $\mathrm{SMZ}$ can be described with linear isotherms at a variety of $\mathrm{pHs}$. At neutral $\mathrm{pH}$, sorption of phenol was the same onto the surfactant monolayer and the bilayer. This indicates that when the neutral form of an ionizable compound dominates, coverage beyond the monolayer is unimportant. The importance of the bilayer was apparent as phenol sorption increased with increases in $\mathrm{pH}$ up to 9.8. This reflects the additional anion exchange mechanism present with bilayer coverage. An additional increase in $\mathrm{pH}$ to 11.2 , however, showed an approximate $25 \%$ decrease in sorption. This decrease was attributed to the increased concentration of competing anions in the buffer solution necessary to raise the $\mathrm{pH}$. High amounts of carbonate, in fact, are useful at desorbing anions from the SMZ surface. Thus, further research examining sorption of these compounds in produced water is warranted.

\subsubsection{Adsorption of Oxyanions}

The versatility of SMZ for use as a sorbent is further shown with its capability of sorbing anions and cations. Haggerty and Bowman (1994) discovered that SMZ was capable of adsorbing oxyanions, attributing the mechanism of sorption to surface complexation and surface precipitation. Li et al. (1998) found that the presence of other anions can inhibit chromate sorption. Multivalent ions, such as sulfate $\left(\mathrm{SO}_{4}{ }^{2-}\right)$, carbonate $\left(\mathrm{CO}_{3}{ }^{2-}\right)$, and phosphate $\left(\mathrm{PO}_{4}{ }^{3-}\right)$ with a tetragonal shape similar to chromate were found to compete better for sorption sites than monovalent ions like nitrate $\left(\mathrm{NO}_{3}{ }^{-}\right.$, planar structure) and chloride $\left(\mathrm{Cl}^{-}\right.$, spherical structure) .

Li et al. (1998) reported that chromate sorption onto SMZ could be modeled with either a linear or Langmuir isotherms, depending on the concentration range. Chromate sorption was dependent on whether the surfactant concentration was greater than the critical micelle concentration (CMC). Below the $\mathrm{CMC}$, limited sorption was observed. As the surfactant concentration surpassed the $\mathrm{CMC}$, chromate sorption increased. A better description of chromate sorption can be provided by observing the surfactant surface coverage. If the total surfactant coverage is less than $100 \%$ of the external cation exchange capacity, limited chromate sorption was observed irregardless of the CMC. Above $100 \%$ surface coverage, chromate sorption increases with increasing surface 
coverage. The exponential relationship illustrated in Figure 2.5 describes this increase in sorption.

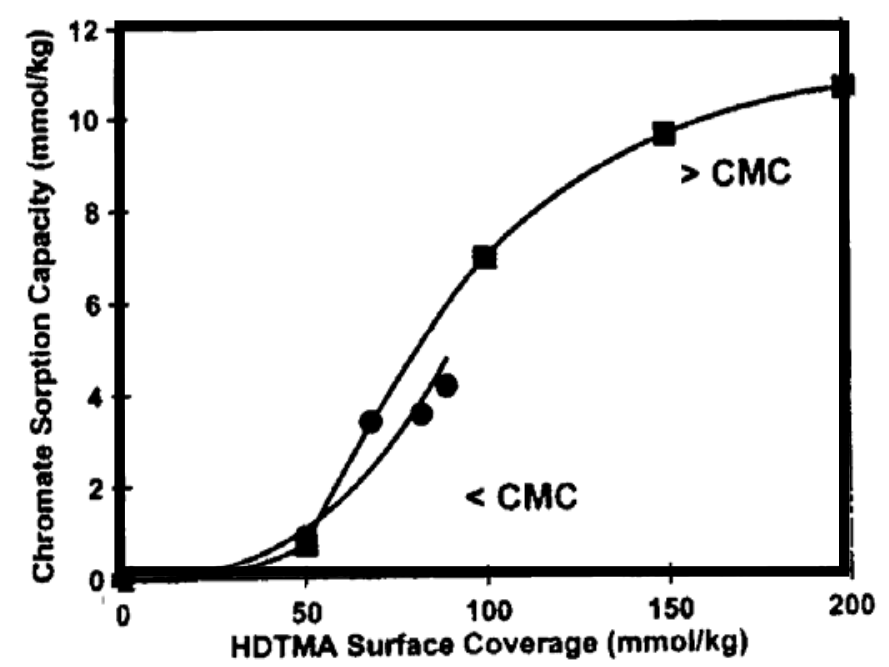

Figure 2.5 Chromate sorption capacity as a function of HDTMA surface coverage. (Li et al. 1998)

Li et al. (1998) also described nitrate sorption onto SMZ. Sorption onto SMZ in which the surfactant surface coverage was $200 \%$ followed a Langmuir isotherm. A nitrate sorption maximum capacity of $110 \mathrm{mmol} / \mathrm{kg}$ indicated that complete coverage of the surfactant bilayer was achieved.

To determine if SMZ has preferential sorption of one anion over another, equal concentrations of nitrate and chromate were equilibrated with the sorbent. It was assumed that the divalent chromate would have preference because of the higher charge density, but the results showed otherwise. Nitrate was shown to have a greater preference for SMZ whether it was alone in solution or mixed with chromate. These results indicated that nitrate is sterically more suitable for sorption, because two adjacent empty sites are required for a divalent ion, while nitrate can fit in any free site. In addition, the surfactant bilayer is not a rigid structure. The (HDTMA) $)_{2}-\mathrm{CrO}_{4}$ ion pair may be less stable than the monovalent (HDTMA)- $\mathrm{NO}_{3}$ ion pair.

Li et al. (1998) also reported that sulfate concentrations greater than $10 \mathrm{mM}$ were inhibitory to chromate sorption. Lower sulfate concentrations did not seem to have an effect on sorption. Three synthetic waters of different ionic strengths were also tested for chromate sorption. As the ionic strength increased from $5 \mathrm{mM}$ to $15 \mathrm{mM}$, chromate linear partitioning coefficients decreased by a factor of four. 


\subsection{Previous SMZ Field Studies}

The removal of BTEX from produced water using SMZ was demonstrated in an earlier project as shown in Figure 2.6 for benzene and toluene (Katz et al, 2003, Ranck et al, 2005). The results confirmed the feasibility of using SMZ to remove BTEX from produced water. In this field study, regeneraton was accomplished through air-sparging the saturated SMZ column. The data collected in the field study suggested that adsorption actually improved after regeneration. Ranck et al (2005) studied the regeneration of laboratory scale columns using produced water from Wyoming. After 10 regeneration cycles, benzene and toluene removal efficiencies actually improved. This was attributed to the retention of organic compounds with volatilities lower than those of BTEX which created an additional sorption medium (Jaynes and Vance 1996). Batch sorption studies with virgin SMZ (no previous BTEX exposure) and exposed SMZ (5 \& 10 saturation and regeneration cycles), however, indicated that linear partitioning coefficients had no statistical difference (t-test with 95\% confidence level).

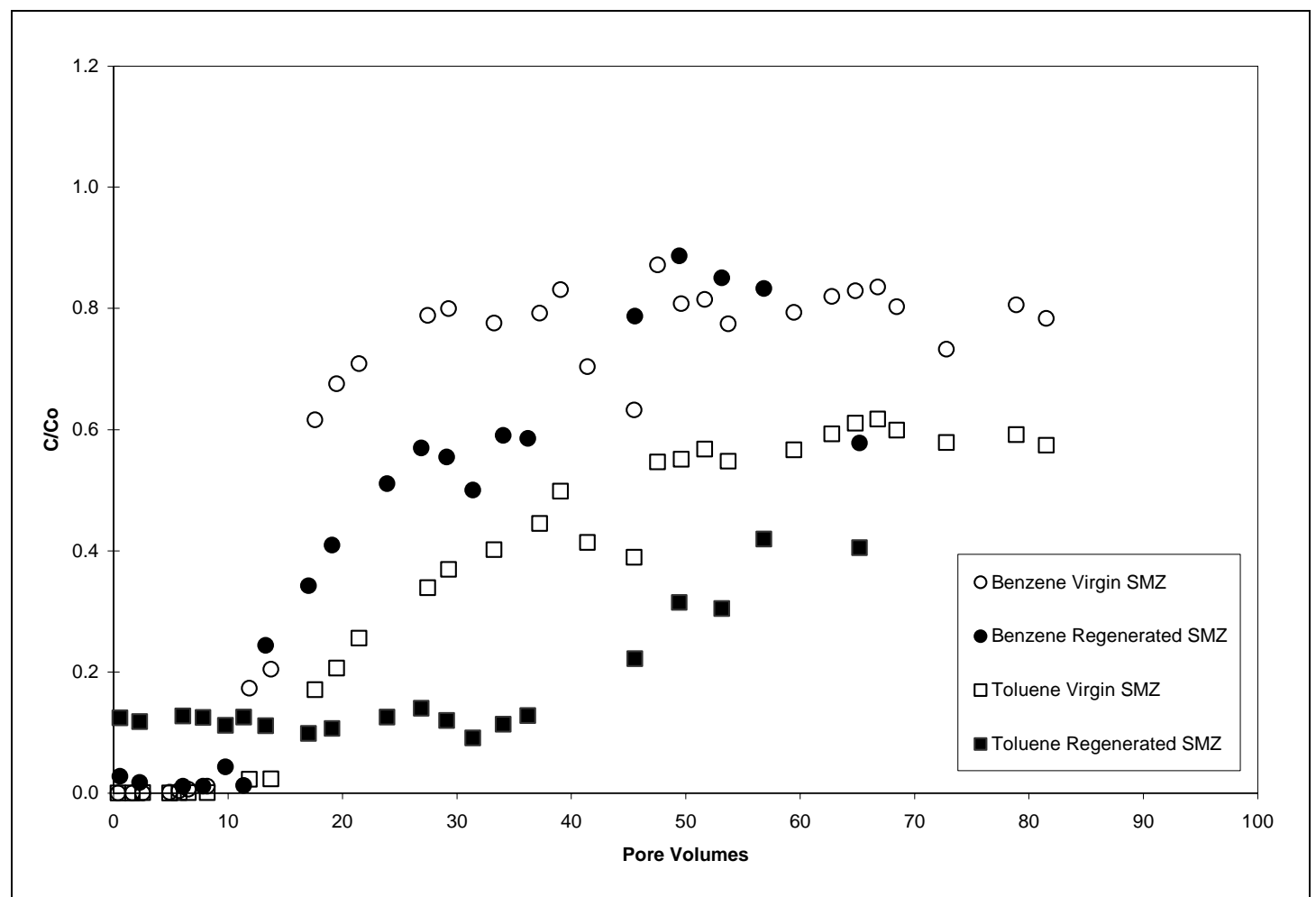

Figure 2.6 Benzene and toluene breakthrough on virgin and regenerated SMZ in field columns (Ranck et al. 2005). 


\subsection{Vapor Phase Bioreactors}

Vapor-phase biofiltration is an air pollution control method for volatile organic compounds (VOCs) and inorganic compounds such as $\mathrm{H}_{2} \mathrm{~S}$. Numerous studies have demonstrated that VPBs can successfully treat a wide range of VOCs and odors. However, the application of VPBs to a broader range of sources has been limited because biological treatment systems can be sensitive to the unstable operating conditions typically encountered in the field. Biofiltration technology was initially applied to remove odorous compounds, such as $\mathrm{H}_{2} \mathrm{~S}$ from wastewater treatment plants. Since the 1980's, biofiltration has also been used to eliminate VOCs from a wide range of processes (Leson and Winer 1991). In the biofiltration process, VOCs from the waste gas diffuse into an aqueous biofilm where they are converted to compounds such as $\mathrm{H}_{2} \mathrm{O}$ and $\mathrm{CO}_{2}$ by biological oxidation. Biofiltration technologies can be divided into three basic types: biofilters, bioscubbers, and biotrickling filters. Biofilters are the simplest type of biological air pollution control. The contaminated gas stream passes through a packed bed on which biomass is attached. Biodegradable contaminants are absorbed into the biofilm and biologically oxidized. Bioscrubbers combine physicochemical removal with biological degradation by combining an absorption column in series with a bioreactor. The contaminated gas is first passed through an absorption tower packed with inert media where the pollutants are transferred from the gas to liquid phase. The liquid with the dissolved pollutants is subsequently treated in a separate bioreactor. The circulating liquid makes it easier to control reaction conditions in the bioscrubber as compared to a biofilter. However, bioscrubbers are effective only for highly water soluble compounds. Biotrickling filters are similar to biofilters in that the microorganisms growing on the packing media degrade the contaminants from the air stream. However, a liquid stream is sprayed over the bed continuously; by changing the composition of the liquid stream, operating conditions such as $\mathrm{pH}$ and nutrient levels in the bed can be readily adjusted. Although these systems can achieve high removal efficiencies, they are prone to excess biomass accumulation (Alonso et al. 1997).

A wide range of pollutants can be treated by biofiltration including volatile organics and reduced sulfur and nitrogen compounds (Delhomenie and Heitz 2005; Gunsch 2004; Swanson and Loehr 1997). The biodegradation of pollutants in biofilters consists of two steps: (1) mass transfer of pollutants from the gas phase to a liquid biofilm containing microorganisms, and (2) biological degradation of the pollutant by the microorganisms within the biofilm. Less volatile, readily degradable, and non toxic chemicals are more easily removed in these systems. A wide range of microorganisms are responsible for pollutant degradation in biofiltration systems. Bacteria are most common in biofilters; however, fungal bioreactors can also be effective particularly under adverse operating conditions such transient loading conditions, low moisture content and low pH (Cox and Deshusses 1999; Pakula and Freeman 1996; Woertz et al. 2001). 


\subsubsection{BTEX Degradation in VPBs}

Relatively extensive studies of BTEX biodegradation have been conducted over the last 10 years and high elimination capacities of these compounds have been obtained in biofilters over a wide range of loading rates (Lu et al. 2000; Mallakin and Ward 1996; Morgan et al. 1993; Sorial et al. 1997; Thomas et al. 1990; Wright et al. 1997). Removal capacities of BTEX, however, vary considerably depending on the biofilter packing material utilized, operating conditions, microbial species present, concentration of each substrate, and inhibition by other compounds.

Jorio et al. (1998) observed that the presence of a para, meta, and ortho - xylene mixture inhibited the biodegradation of toluene, but toluene negligibly inhibited the biodegradation of a xylene mixture in a peat biofilter. $m$-xylene was degraded fastest, followed by $p$-xylene, and $o$-xylene among the xylene isomers. du Plessis et al. (2001) reported that toluene inhibited the degradation of benzene, ethylbenzene, and $m, o-$ xylene in a biofilter which was acclimated to toluene, while $p$-xylene degradation was enhanced by the toluene. Also, toluene degradation was inhibited by the presence of benzene, ethylbenzene, and $m, o$-xylene. In a compost biofilter, $p$-xylene inhibited the degradation of benzene and toluene, but the degradation of xylenes was not inhibited by the presence of benzene, toluene, and ethyl benzene (Quinlan et al. 1999). Results of these studies indicate substrate interactions in microbial systems such as VPBs vary with the microbial species present and substrate mixture as well as the operating conditions of the microbial system. Therefore, one must be cautious when interpreting the reported results based on a specific set of conditions (Swanson and Loehr 1997).

\subsubsection{Response of VPBs to Transient Loading Conditions}

Numerous lab-scale studies of VOC destruction by VPBs have demonstrated that VPBs are an attractive method for gas phase pollutant treatment. However, unlike many laboratory studies where stable conditions are maintained, field conditions are often quite variable and VPBs are subjected to transient pollutant loads (Dirk-Faitakis and Allen 2003). A decrease in VPB performance is commonly observed in the field due to these variable operating conditions which are unfavorable for biomass metabolism.

One common problem in the field is frequent shutdowns of the biofiltration system. Loss of biomass activity during carbon deprived conditions can lead to poor performance of VPBs. For instance, Martin and Loehr (1996) observed that biomass activity dropped by almost $70 \%$ after 3 days of starvation, and it took 8 hours to recover full toluene removal capacity. Cox and Deshusses (2002) demonstrated that a biotrickling filter required to 24 hours to reestablish full performance after 2-8 days shutdown. Moe and Qi (2004) observed the response of a fungal biofilter treating a gas phase solvent mixture during intermittent loading and showed that it required a longer time interval to recover its removal efficiency following long term (e.g., 9 day) VOC loading shutdown than it did for shorter periods of no loading. Wani et al. (1998) investigated the effect of starvation period on a biofilter treating $\mathrm{H}_{2} \mathrm{~S}$. In their research, 25-30 hours was necessary to fully 
recover after 7 days of starvation, and 122 hours was necessary after 3 months of starvation.

In addition to frequent system shutdowns, variations in the VOC concentration in the waste gas stream is anther challenge for VPBs. Sudden changes in the VOC concentration in the influent gas can cause poor performance of a biofiltration treatment system (Deshusses 1997; Jorio et al. 2000; Wright 2005). Most field tests report a wide range of VOC removal efficiencies in biofilters subjected to variable VOC loadings, even though the average removal was relatively high (Chang et al. 2001; Choi et al. 2004; Ergas et al. 1995; Leson and Smith 1997; Wright et al. 1997).

Although numerous studies have examined the effects of transient loading on biofilter performance, little research has been done to mitigate these effects. In wastewater treatment facilities, load equalizing basins are widely used as a pre-treatment process to minimize the effects of transient loading. Such equalization basins are not applicable to gas phase treatment systems but other approaches have been examined to minimize the negative effects of transient loading on biofilter performance.

Minimizing the decrease in biomass activity that occurs during periods of non loading is one possible solution. Park and Kinney (2001) demonstrated that a VPB supplied with a small but continuous VOC feed achieved much higher removal efficiencies following restart of the bioreactor than did a system that was simply shut off and not provided any VOCs during the shutdown period. Aeration during non loading periods is also helpful to maintain biomass activity (Wani et al. 1998).

Mixing an adsorbent material into the biofilter packing media can also be used to buffer variable VOC loadings. GAC is a well known adsorbent that has been mixed with compost to provide buffering capacity against shock loads due to its high adsorption capacity (Medina et al. 1995); however coal particle, chaff, and diatomaceous earth, etc are also used (Chang et al. 2001; Tang and Hwang 1997). Abumaizar et al. (1998) investigated the effect that the quantity of GAC had on the performance of compost biofilters treating gas phase BTEX. For GAC quantities between 0 and $7 \%$ by volume, it was determined that increasing the GAC fraction in the compost packed bed, increased the removal efficiency achievable in compost biofilters subjected to BTEX concentrations varying from less than $50 \mathrm{ppm}_{\mathrm{v}}$ to $450 \mathrm{ppm}_{\mathrm{v}}$. However, these GAC mixed biofilters showed poor performance in response to sudden increases in BTEX concentration in the inlet gas stream. Weber and Hartmans (1995) also investigated the buffering efficiency of GAC when it was mixed with compost in a biofilter subjected to step feeds of high concentrations $\left(900 \mathrm{mg} / \mathrm{m}^{3}\right)$ of toluene. In this study, the authors found the the GAC mixture provided negligible buffering capacity when the biofilter was subjected to high concentration fluctuations. Although the presence of GAC in the packing material appears to mitigate moderate fluctuations in inlet VOC concentration, the presence of water in a packed bed can greatly diminish the buffering capacity of 
activated carbon, since the contaminant must first diffuse through a water layer to reach the carbon surface (Weber and Hartmans 1995). It appears that mixing adsorbent with packing media in a biofilter may be helpful to mitigate moderate fluctuations in the gas stream. However, the proper quantity of adsorbent required for a given application is difficult to predict. Also, adjusting the load equalizing capacity is extremely difficult once the biofilter system has been installed. Thus, if the variations in inlet pollutant concentration vary to a greater extent than anticipated in the design, biofilter performance will suffer.

Al-Rayes et al. (2001) investigated the load dampening provided by a modified humidification system placed upstream of a biofilter. The water recirculating through the pre-humidification system absorbed the contaminants from the feed gas during periods of high concentration and desorbed them back to the gas stream when the inlet gas phase contaminant concentration declined. This system effectively buffered transient loading for hydrophilic compounds, but not for hydrophobic compounds. When an organic cosolvent was used in conjunction with water, hydrophobic compounds such as toluene were also effectively buffered.

Another method to address transient loadings is to place a separate load-buffering column containing a buffering agent such as GAC in front of the biofilter bed. The GAC bed can accumulate VOCs during high concentration periods, and desorb contaminants during low concentration periods, resulting in a more stable loading of VOCs to the VPB. Weber and Hartmans (1995) observed the performance of a GAC buffering column during a series of toluene step feeding tests. When $1000 \mathrm{mg} / \mathrm{m}^{3}$ of toluene was introduced in a step feed manner ( $8 \mathrm{hrs}$ on/16hrs off), the GAC buffering column attenuated the toluene concentration to a stable concentration of approximately 300 $\mathrm{mg} / \mathrm{m}^{3}$. However, 16 hours per day was not enough time to completely desorb the adsorbed toluene, thus the buffering capacity of GAC buffering column would be expected to be greatly reduced over time if it was subjected to continuous step feed cycles.

Moe and Li (2005) also evaluated the effectiveness of a separate GAC buffering column placed upstream of a biofilter subjected to step feeds of toluene and acetone. The response of the system to single-component contaminants and as well as to contaminant mixtures was evaluated. As in the Weber and Hartmans (1995) study, contaminated air was supplied 8 hours per day and uncontaminated air was supplied 16 hours per day. When the toluene and acetone were supplied as single-component contaminants at concentrations ranging from $217 \mathrm{ppm}_{\mathrm{v}}$ to $868 \mathrm{ppm}_{\mathrm{v}}$, peak contaminant concentrations exiting the GAC column (6.1 sec EBCT) were less than half of the influent concentration. However, when toluene and acetone were supplied as a mixture $\left(550 \mathrm{ppm}_{\mathrm{V}}\right.$ each), the buffering of the acetone was significantly reduced as a result of competitive sorption effects. As the more strongly adsorbed toluene accumulated in the carbon bed, it displaced the more weakly adsorbed acetone. The authors also investigated the 
relationship between toluene concentrations (from $210 \mathrm{ppm}_{\mathrm{V}}$ to $1000 \mathrm{ppm}_{\mathrm{V}}$ ) and $\mathrm{EBCTs}$ (from $1.5 \mathrm{sec}$ to $10 \mathrm{sec}$ ) on the performance of a GAC buffering column (Li and Moe 2005). They observed that the degree of load attenuation becomes more pronounced at lower contaminant concentrations and higher GAC EBCTs. As in the previous studies, however, the study evaluated the response of the biofilter to step feeds (8hr on/16hrs off), in which a constant VOC loading was provided during each feed period. In the field, actual contaminant concentrations can often change dynamically during the loading period and additional studies are required to assess the effectiveness of the system under such conditions.

Another factor that should be considered is the humidity of the gas streams being treated. Numerous studies have shown that high relative humidity in the inlet gas stream significantly decreases the adsorption capacity of solid adsorbents such as GAC, activated carbon cloth, and soil (Cal et al. 1996; Chen and Wu 1998; Crittenden et al. 1988; Ruiz et al. 1998; Storey et al. 1995; Thibaud et al. 1993). Crittenden et al. (1988) observed that RH (relative humidity) values greater that $45 \%$ in a gas stream significantly decreased the adsorption of TCE on GAC. Cal et al. (1996) found that water vapor in a gas stream had little effect on benzene $\left(500 \mathrm{ppm}_{\mathrm{v}}\right)$ adsorption onto the activated carbon cloth until the RH exceeded $65 \%$ at which point a rapid decrease in adsorption capacity was observed. Thus, examining the effect of high relative humidity is important for developing proper design criteria for adsorbent buffering systems, particularly for VPB applications where high humidity conditions are expected.

\subsection{Application of VPBs to the Treatment of Produced Water}

Vapor phase biofilters are typically used to treat biodegradable gas phase contaminants present in waste gas streams. However, VOCs present in a liquid phase can also be treated by VPBs, if the liquid phase contaminants are transferred to the gas phase. Treatment of produced water in a SMZ/VPB system is one such method to treat liquid phase VOCs by coupling an SMZ adsorbent system with a VPB.

Produced water is characterized by high total dissolved solids content and contains dissolved organic constituents, an oil and grease component, and chemicals added during the oil-production process. Dissolved benzene, toluene, ethylbenzene, and xylenes (BTEX) are the most abundant hydrocarbons present, with BTEX concentrations ranging from 68 to $600,000 \mu \mathrm{g} / \mathrm{L}$ in produced waters (Neff 1996). The high salinity of produced water, typically ranging from $1,000 \mathrm{mg} / \mathrm{L}$ to $400,000 \mathrm{mg} / \mathrm{L}$, inhibits biological activity thus making biological treatment of organic pollutants in produced water much more difficult. Nevertheless, some researchers have tried to apply biological treatment directly to produced water (Freire et al. 2001; Gilbert et al. 2005; Raterman et al. 1993; Woolard and Irvine 1995). Most of this research has been limited to the removal of specific organic compounds using microorganisms isolated to tolerate high salinity. 
An alternative approach is to use an integrated SMZ/VPB system to treat produced water. In this process, produced water passes through adsorbent beds of SMZ, which has high selectivity for produced water organics. The BTEX and other organics sorb to the SMZ and the treated water can subsequently be treated by RO to remove the brine. Spent SMZ is regenerated via air stripping and the organic-laden air is directed to a vapor phase biofilter (VPB) where the stripped organics are degraded to nontoxic products (Figure 2.7). In this process, biological degradation of the BTEX constituents occurs in the VPB without the limitations associated with trying to biologically degrade organics in high salinity water.

One key issue for successful application of this combined SMZ/VPB system is to determine how to optimize the SMZ regeneration process for successful degradation of the BTEX constituents in a downstream VPB. The regenerated gas stream from used SMZ is expected to have relatively high concentrations of BTEX in the early stages of regeneration (on the order of thousands of $\mathrm{ppm}_{\mathrm{v}}$ or greater), but drop off exponentially as the air sparging process continues. As noted in numerous studies, biofilters have difficulty treating sudden changes in the VOC concentration in the influent gas streams (Deshusses 1997; Jorio et al. 2000; Wright 2005). For a successful operation of a VPB coupled to a SMZ system, therefore, a load equalizing system before the biofilter is likely needed.

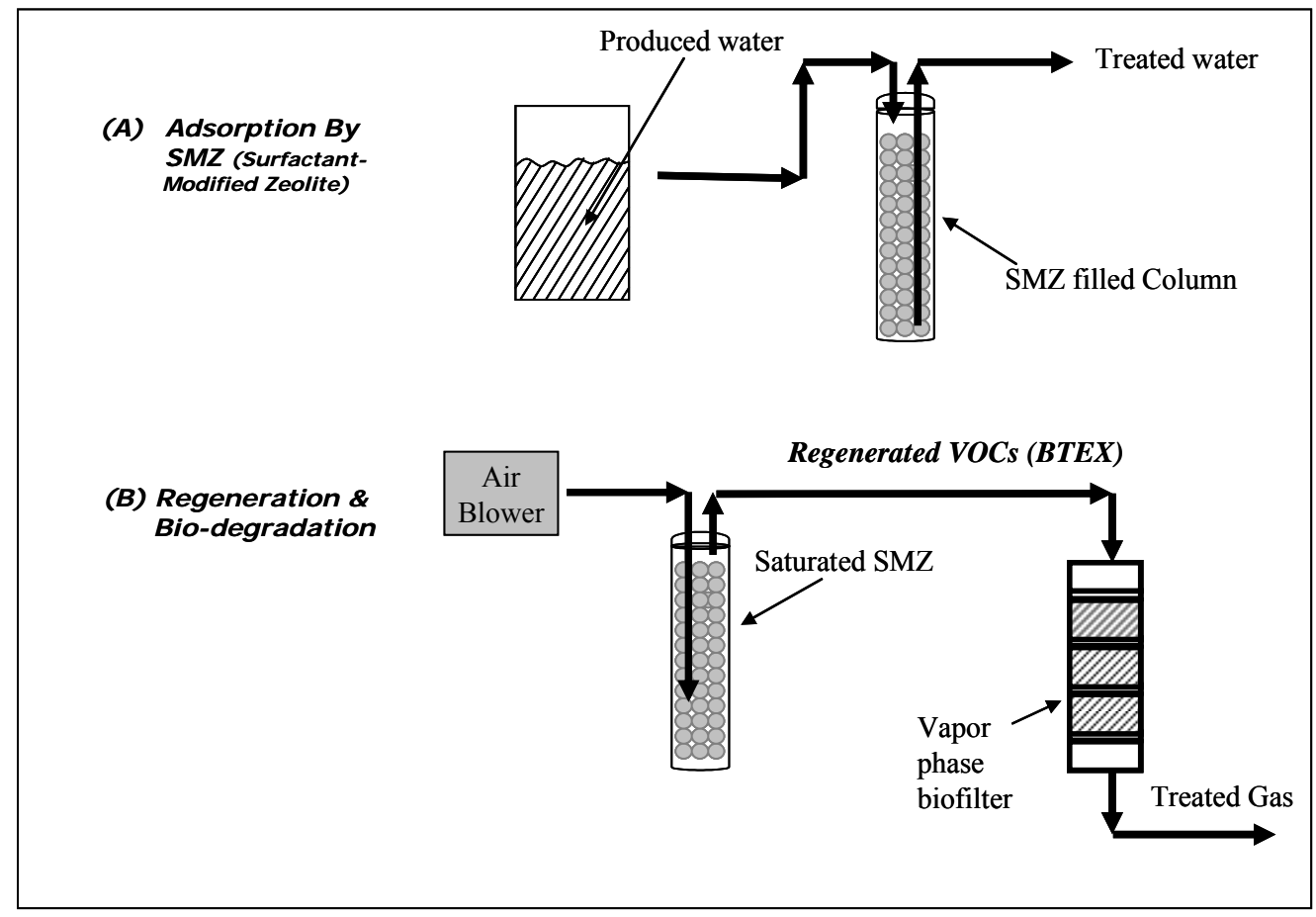

Figure 2.7 Schematic diagram of the SMZ /VPB system for treating produced water. 


\section{EXPERIMENTAL PLAN AND METHODOLOGY}

\subsection{Approach}

The research approach involved laboratory and field experimentation as indicated by the following tasks:

Task 1: Evaluate the sorption capacity of SMZ for BTEX, other moderately hydrophobic contaminants, and inorganic constituents in produced water;

Task 2: Assess the long term stability of SMZ and the potential for loss of sorption capacity after multiple regeneration cycles

Task 3: Evaluate the potential of the vapor phase bioreactor for BTEX removal from off-gas produced during SMZ regeneration

Task 4: Demonstrate the feasibility of the combined SMZ/VPB system at pilot scale.

Batch reactor experiments were conducted to provide a better understanding of the sorption of produced water constituents to SMZ. Laboratory column studies with SMZ were designed to address the issue of regeneration and stability of the SMZ system. These experiments examined multiple cycles of sorption/regeneration using air sparging as the regeneration option. Vapor phase bioreactors were designed and operated in the laboratory to assess the poentitial for BTEX biodegradation of the off-gas from air sparging, and to evaluate the capacity of the VPB to respond to transient loading of BTEX. A pilot study of the combined SMZ/VPB process was conducted at a produced water processing facility near Farmington, New Mexico. The pilot test evaluated SMZ adsorption, SMZ regeneration, VPB buffering, and VPB performance. The design of the pilot study was based on the results from the previous three experimental tasks.

\subsection{Batch Studies}

Batch sorption experiments were performed to characterize sorption of BTEX to SMZ in the presence of synthetic produced water and to characterize the adsorption of representative polar and non-polar aromatic hydrocarbons, a representative divalent cation, and two oxyanions known to be present in produced water.

\subsubsection{Materials used in Batch Laboratory Experiments}

Surfactant Modified Zeolite (SMZ) was prepared by adsorbing a surfactant to the surface of zeolite; thus altering the zeolite's adsorptive capabilities. The zeolite used in this study was purchased from the St. Cloud Mine in Winston, New Mexico. An X-ray diffraction analysis conduced by Sulivan et al. (1997) found the material to be comprised of $74 \%$ clinoptilolite, $10 \%$ feldspar, $10 \%$ quartz and cristobalite, $5 \%$ smectite clay and $1 \%$ illite. Calcium and potassium were determined prior to this research to be the major exchangeable cations present on the raw material. The external and internal cation 
exchange capacities were $90-110 \mathrm{meq} / \mathrm{kg}$ and $800 \mathrm{meq} / \mathrm{kg}$ (Li and Bowman, 1997). The BET external surface area of the zeolite was $15.7 \mathrm{~m}^{2} / \mathrm{g}$ (Sulivan et al. 1997).

Hexadecyltrimethylammonium (HDTMA) was selected as the surfactant because its long hydrocarbon tail and cationic head exhibit ideal characteristics for the formation of adsorbed bilayers. The cationic head can adsorb to the zeolite surface, while the hydrocarbon tail is capable of forming hydrophobic bilayers capable of sorbing organic molecules. The chemical formula of HDTMA is $\mathrm{N}\left(\mathrm{CH}_{3}\right)_{3} \mathrm{C}_{16} \mathrm{H}_{33}$. The critical micelle concentration of HDTMA is $0.9 \mathrm{mmol} / \mathrm{L}$. HDTMA-Cl $(25 \% \mathrm{w}$ in water) surfactant was obtained from Aldrich (Milwaukee, WI).

Surfactant modification of the zeolite creates an organic coating on the external surface of the zeolite. This layer provides a hydrophobic organic phase favorable for sorption of non-polar organic molecules. The preparation of SMZ involves mixing an HDTMA solution and zeolite for several hours, followed by a series of washings with ultrapure water. Ultrapure water was prepared by a filtration system water using a Milli-Q system (Millipore Corp., Bedford, MA). Detailed procedures describing the SMZ preparation procedure are described in Tan (2002). The expected HDTMA sorption capacity was 200 $\mathrm{mmol} / \mathrm{kg}(\mathrm{Li}, 1999)$.

The batch tests focused on the sorption of the primary organic and metal components found in produced water from a collection facility in Wyoming (Table 3.1). Of interest were BTEX, phenols, naphthalenes, barium, chromate, and selenate. Benzene and orthoxylene were obtained from J. T. Baker (Phillipsburg, NJ). Toluene was obtained from EM Science (Gibbstown, NJ), ethylbenzene from Mallinckrodt Chemical Inc. (Paris, KY), meta-xylene from Aldrich (Milwaukee, WI), and para-xylene from Fisher Scientific (Fairlawn, NJ). All chemicals were of $99 \%$ purity or greater. Their chemical formulas, molecular weight, and water solubilities $\left(25^{\circ} \mathrm{C}, 1 \mathrm{~atm}\right)$ are reported in Table 3.2 (Dean, 1999).

A number of semi-volatile compounds were selected for study in this research based on the results of the analyses shown in Table 3.1. Representative concentrations of these compounds used in the majority of the batch studies are shown in Table 3.3 and the properties of these constituesnts are shown in Table 3.4. Phenol, 2-methylphenol, 4methylphenol, 2,4-dimethylphenol, naphthalene, and 2-methylnaphthalene were purchased in solid form from Aldrich (Milwaukee, WI). The molecular weight, pKa, and solubility of each species are shown in Table 3.4 (Lide, 1995). 
Final Technical Report

DE-FC26-02NT15461

Table 3.1 Analysis of produced water from Wamsutter, Wyoming

\begin{tabular}{|lccc|}
\hline Parameter & $\mathrm{units}$ & Summer 2002 & Summer 2003 \\
\hline Total Petroleum Hydrocarbons (TPH) & $\mathrm{mg} / \mathrm{L}$ & 135.8 & 43.5 \\
C6-C12 TPH & $\mathrm{mg} / \mathrm{L}$ & 128.5 & 43.5 \\
C12-C28 TPH & $\mathrm{mg} / \mathrm{L}$ & 7.3 & $\mathrm{ND}$ \\
C28-C35 TPH & $\mathrm{mg} / \mathrm{L}$ & $\mathrm{ND}$ & $\mathrm{ND}$ \\
\hline Total Dissolved Solids & $\mathrm{mg} / \mathrm{L}$ & 11400 & 10230 \\
\hline Total Organic Carbon & $\mathrm{mg} / \mathrm{L}$ & 470 & 2983 \\
\hline Bromide & $\mathrm{mg} / \mathrm{L}$ & $\mathrm{ND}$ & 22 \\
Chloride & $\mathrm{mg} / \mathrm{L}$ & 4510 & 4400 \\
Flouride & $\mathrm{mg} / \mathrm{L}$ & 10 & 57 \\
Sulfate & $\mathrm{mg} / \mathrm{L}$ & 56.6 & 13 \\
\hline Calcium & $\mathrm{mg} / \mathrm{L}$ & 38.1 & 30 \\
Magnesium & $\mathrm{mg} / \mathrm{L}$ & 9.47 & 6.4 \\
Potassium & $\mathrm{mg} / \mathrm{L}$ & 1530 & 44 \\
Sodium & $\mathrm{mg} / \mathrm{L}$ & 4050 & 4100 \\
\hline Mercury & $\mu \mathrm{g} / \mathrm{L}$ & $\mathrm{ND}$ & --- \\
Arsenic & $\mu \mathrm{g} / \mathrm{L}$ & $\mathrm{ND}$ & --- \\
Barium & $\mu \mathrm{g} / \mathrm{L}$ & 9920 & --- \\
Cadmium & $\mu \mathrm{g} / \mathrm{L}$ & $\mathrm{ND}$ & --- \\
Chromium & $\mu \mathrm{g} / \mathrm{L}$ & $\mathrm{ND}$ & --- \\
Lead & $\mu \mathrm{g} / \mathrm{L}$ & $\mathrm{ND}$ & --- \\
Selenium & $\mu \mathrm{g} / \mathrm{L}$ & 25.2 & --- \\
Silver & $\mu \mathrm{g} / \mathrm{L}$ & $\mathrm{ND}$ & --- \\
\hline 2,4-Dimethylphenol & $\mu \mathrm{g} / \mathrm{L}$ & 816 & 802 \\
2-Methylnaphthalene & $\mu \mathrm{g} / \mathrm{L}$ & 160 & 717 \\
2-Methylphenol & $\mu \mathrm{g} / \mathrm{L}$ & 1350 & 1440 \\
4-Methylphenol & $\mu \mathrm{g} / \mathrm{L}$ & 1000 & 672 \\
Dibenzofuran & $\mu \mathrm{g} / \mathrm{L}$ & 4.4 & $\mathrm{ND}$ \\
Fluorene & $\mu \mathrm{g} / \mathrm{L}$ & 4.6 & $\mathrm{ND}$ \\
Naphthalene & $\mu \mathrm{g} / \mathrm{L}$ & 164 & 419.2 \\
Phenanthrene & $\mu \mathrm{g} / \mathrm{L}$ & 3.8 & $\mathrm{ND}$ \\
Phenol & $\mu \mathrm{g} / \mathrm{L}$ & 764 & 2383 \\
\hline Benzene & $\mu \mathrm{g} / \mathrm{L}$ & 21300 & 15800 \\
Tolulene & $\mu \mathrm{g} / \mathrm{L}$ & 33200 & 36700 \\
Ethylbenzene & $\mu \mathrm{g} / \mathrm{L}$ & 22800 & 1400 \\
m\&p-Xylene & $\mu \mathrm{g} / \mathrm{L}$ & 9800 & 6400 \\
$o-X y l e n e$ & $\mu \mathrm{g} / \mathrm{L}$ & 4900 & 3400 \\
\hline P & & & \\
\hline
\end{tabular}

${ }^{1}$ Phenol data given as sum of all phenols 
Table 3.2 Physical and chemical properties of BTEX.

\begin{tabular}{|c|c|c|c|c|c|c|}
\hline & Benzene & Toluene & $\begin{array}{c}\text { m- } \\
\text { Xylene }\end{array}$ & $\begin{array}{c}\text { p- } \\
\text { Xylene }\end{array}$ & $\begin{array}{c}\text { o- } \\
\text { Xylene }\end{array}$ & $\begin{array}{c}\text { Ethyl- } \\
\text { benzene }\end{array}$ \\
\hline $\begin{array}{l}\text { Chemical } \\
\text { formula }\end{array}$ & $\mathrm{C}_{6} \mathrm{H}_{6}$ & $\mathrm{C}_{7} \mathrm{H}_{8}$ & $\mathrm{C}_{8} \mathrm{H}_{10}$ & $\mathrm{C}_{8} \mathrm{H}_{10}$ & $\mathrm{C}_{8} \mathrm{H}_{10}$ & $\mathrm{C}_{8} \mathrm{H}_{10}$ \\
\hline $\begin{array}{c}\text { Molecular } \\
\text { Weight } \\
\text { (g/mole) }\end{array}$ & 78 & 92 & 106 & 106 & 106 & 106 \\
\hline $\begin{array}{c}\text { Water } \\
\text { Solubility } \\
\text { at } 25^{\circ} \mathrm{C} \\
(\log \mathrm{M})\end{array}$ & -1.66 & -2.14 & -2.72 & -2.72 & -2.79 & -3.03 \\
\hline $\begin{array}{l}\text { Henry's } \\
\text { Constant } \\
\text { (M/atm) }\end{array}$ & 0.18 & 0.15 & 0.16 & 0.16 & 0.29 & 0.17 \\
\hline $\begin{array}{c}\log \mathrm{K}_{\text {ow }} \text { at } \\
20^{\circ} \mathrm{C} \\
(\mathrm{L} \text { octanol/ } / \\
\text { L water) }\end{array}$ & 2.13 & 2.69 & 3.20 & 3.15 & 3.12 & 3.15 \\
\hline
\end{tabular}

Table 3.3 Approximate semi-volatile concentrations in a sample of produced water

\begin{tabular}{|c|c|}
\hline Compound & $\begin{array}{c}\text { concentration } \\
\mu \mathrm{g} / \mathrm{L}\end{array}$ \\
\hline Phenol & 2383 \\
\hline 2-Methylphenol & 1440 \\
\hline 4-Methylphenol & 672 \\
\hline 2,4-Dimethylphenol & 802 \\
\hline Naphthalene & 419.2 \\
\hline 2-Methylnaphthalene & 717 \\
\hline
\end{tabular}


Table 3.4 Chemical formulas, molecular weights, pKas, water solubilites, Henry's constants, and $\log K_{0 w}$ s of semi-volatiles used in this study.

\begin{tabular}{|c|c|c|c|c|c|c|}
\hline & phenol & $\begin{array}{l}\text { 2-methyl } \\
\text { phenol }\end{array}$ & $\begin{array}{c}\text { 4- } \\
\text { methyl } \\
\text { phenol }\end{array}$ & $\begin{array}{c}2,4- \\
\text { dimethyl } \\
\text { phenol }\end{array}$ & naphthalene & $\begin{array}{c}\text { 2-methyl } \\
\text { naphthalene }\end{array}$ \\
\hline $\begin{array}{l}\text { chemical } \\
\text { formula }\end{array}$ & $\mathrm{C}_{6} \mathrm{H}_{6} \mathrm{O}$ & $\mathrm{C}_{7} \mathrm{H}_{8} \mathrm{O}$ & $\mathrm{C}_{7} \mathrm{H}_{8} \mathrm{O}$ & $\mathrm{C}_{8} \mathrm{H}_{10} \mathrm{O}$ & $\mathrm{C}_{10} \mathrm{H}_{8}$ & $\mathrm{C}_{11} \mathrm{H}_{10}$ \\
\hline $\begin{array}{c}\text { molecular } \\
\text { weight }\end{array}$ & 94 & 108 & 108 & 122 & 128 & 142 \\
\hline pKa & 9.99 & 10.3 & 10.26 & 10.6 & NA & NA \\
\hline $\begin{array}{c}\text { Water } \\
\text { Solubility } \\
\text { at } 25^{\circ} \mathrm{C} \\
(\log \mathrm{M}) \\
\end{array}$ & -0.03 & -0.54 & -0.67 & -1.19 & -3.63 & -3.68 \\
\hline $\begin{array}{l}\text { Henry's } \\
\text { Constant } \\
\text { (M/atm) }\end{array}$ & 2000 & 830 & 1000 & 410 & 2.1 & 2 \\
\hline $\begin{array}{c}\log K_{\text {ow }} \text { at } \\
20^{\circ} \mathrm{C} \\
(\mathrm{L} \\
\text { octanol/ } \\
\mathrm{L} \text { water }) \\
\end{array}$ & 1.48 & 1.96 & 1.96 & 2.30 & 3.37 & 4.37 \\
\hline
\end{tabular}

The only metals identified at concentrations above detection limits in the produced water from Wyoming were barium and selenium. These metals were chosen for sorption analysis. Chromium was also selected for analysis because it is frequently reported to be found in produced water. A series of separate metal salt solutions were prepared using barium chloride and potassium chromate from MCB Reagents (Cincinnati, $\mathrm{OH}$ ) and sodium selenate-decahydrate from Aldrich (Milwaukee, WI). Metals standards (1000 ppm) for ICP analysis were prepared with standards purchased form Fisher Scientific (Fairlawn, NJ).

Background water was prepared to mimic the salinity associated with produced water from the Wyoming site. Total ion concentrations were used to select appropriate salts that cumulatively would provide the same ion concentrations as the actual produced water; thus mimicking the ionic strength. Six anhydrous salt compounds were used to prepare this solution. Sodium bicarbonate and sodium carbonate were obtained from Fisher Scientific (Fairlawn, NJ). Potassium bromide was obtained from J. T. Baker (Phillipsburg, NJ), calcium chloride from MCB Reagents (Cincinnati, OH), sodium chloride from Mallinckrodt Chemical Inc. (Paris, KY), and sodium sulfate from EM Science (Gibbstown, NJ). Sodium sulfate was also used as a drying agent in aqueous semi-volatile extractions. The preparation of this synthetic salt solution is described in detail later. 
Concentrated acids and bases were used in the preparation of background water for both the organic and metal experiments. Nitric acid (68-70\% environmental grade) and hydrochloric acid (33\% environmental grade) were purchased from J. T. Baker (Phillipsburg, NJ). Sulfuric acid (95-98\%) and sodium hydroxide (0.1 and $5 \mathrm{M}$ ) were purchased from EM Science (Gibbstown, NJ). Potassium phosphate (mono and dihydrate) was used to buffer organic experiments at $\mathrm{pHs}$ typical of produced water. Both were obtained from J. T. Baker (Phillipsburg, NJ). Methanol and dichloromethane were used as solvents and rinsing agents. These solvents were used to prepare stock solutions of organic compounds, internal standards, and surrogate compounds. Both were purchased in HPLC grade from EM Science (Gibbstown, NJ).

Six semi-volatile surrogate compounds were used to evaluate the effectiveness of semivolatile extractions from aqueous solution. All were purchased in dichloromethane from Supelco (Bellafonte, PA). The acidic surrogates 2-flurophenol, d6-phenol, and tribromophenol were used to quantify phenol extractions. The base/neutral compounds d10-nitrobenzene, 2-flurobyphenyl, and d12-terphenyl were used to quantify naphthalene extractions.

$\alpha, \alpha, \alpha-$ (TFT) purchased from Restek Corption was used as an internal standard during gas chromatography flame ionization detection analyses of BTEX compounds. A six component semi-volatile mix obtained from Supelco (Bellafonte, PA) was used as an internal standard for gas chromatography mass spectrometry analysis. The semi-volatile internal standard (SVIS) mix was solvated in methanol and included d4-dicholorbenzene, d8-naphthalene, d10-acenaphthalene, d10-phenanthrene, d12-chrysene, and d12-perylene.

The metal standards, barium chloride, potassium dichromate, and selenium dioxide, were purchased from Fisher Scientific (Fairlawn, NJ). Scandium carbonate, purchased from Fisher Scientific (Fairlawn, NJ), was used as an internal standard for all metal analysis.

\subsubsection{Produced Water Characterization}

The water obtained from Crystal Solutions, LLC located near Wamsutter, Wyoming was used during this study to generate the composition of the synthetic produced water used in this research. Crystal Solutions is located in the Red Desert near a large natural gas reservoir. Produced water is collected throughout the region and transported to Crystal Solutions in tanker trucks. The water is pumped thought a series of two oil/water separation tanks. Oil is separated from the top of the two tanks and further processed to recover oil. The denser water is sent to lined evaporation ponds to reduce volume. Water was collected in December 2002 in 55 gallon drums and preserved at $4^{\circ} \mathrm{C}$. This water was taken back to New Mexico where samples were then sent to the University of Texas at Austin in the summer 2003. Analyses were preformed both in New Mexico and Austin to characterize the water. 
Salt concentrations in the produced water were obtained by the New Mexico Bureau of Geology. Cations concentrations were determined by flame absorption spectroscopy. Anion concentrations were measured by ion chromatography. A summary of the ion concentrations determined from the analysis of the produced water and the composition of the synthetic produced water are listed in Table 3.5. The ionic strength of the Wyoming water and the synthetic water were $0.183 \mathrm{M}$ and $0.179 \mathrm{M}$, respectively.

Table 3.5 Major ion concentrations in the Wyoming produced water.

\begin{tabular}{|c|c|c|}
\hline ion & $\begin{array}{c}\text { Concentation } \\
\text { from } \\
\text { analysis of } \\
\text { Wyoming } \\
\text { water sample } \\
\text { (mg/L) }\end{array}$ & $\begin{array}{c}\text { Concentration } \\
\text { used in } \\
\text { synthetic } \\
\text { water } \\
\text { (mg/L) }\end{array}$ \\
\hline $\mathrm{HCO}_{3}^{-}$ & 3120 & 3129 \\
\hline $\mathrm{Cl}^{-}$ & 4400 & 4373 \\
\hline $\mathrm{Na}^{+}$ & 4100 & 4051 \\
\hline $\mathrm{Br}^{-}$ & 22 & 90 \\
\hline $\mathrm{F}^{-}$ & 57 & 0 \\
\hline $\mathrm{SO}_{4}{ }^{2-}$ & 13 & 13 \\
\hline $\mathrm{K}^{+}$ & 44 & 44 \\
\hline $\mathrm{Mg}^{2+}$ & 6 & 0 \\
\hline $\mathrm{Ca}^{2+}$ & 30 & 30 \\
\hline
\end{tabular}

Produced water samples from the Wyoming facility were sent to DHL Analytical in Round Rock, TX on two occasions. Total petroleum hydrocarbon and semi-volatile GC/MS analyses were performed using standard EPA methods. The average total petroleum hydrocarbons measured in Summer 2003 was $43.5 \mathrm{mg} / \mathrm{L}$, and were all $\mathrm{C}_{6}-\mathrm{C}_{12}$ hydrocarbons. The average semi-volatile compound concentrations were listed previously in Table 3.1. These data were used to select the semi-volatile compounds and their concentrations for the batch sorption experiments.

\subsubsection{Analytical Methods used for Batch Experiments}

BTEX concentrations in the aqueous phase were measured using a gas chromatograph (GC) with a flame-ionization detector. A headspace autosampler was used to analyze the vapor phase of each sample. A standard curve was made for each compound in each water matrix. A series of highly concentrated BTEX stock solutions in methanol were used in the preparation of standard curve and batch samples. An initial BTEX solution was made by adding required amount of each chemical to make a $10 \mathrm{~g} / \mathrm{L}$ stock. Serial 
dilutions of $1,0.2,0.03,0.003 \mathrm{~g} / \mathrm{L}$ were made using glass volumetric pipettes and flasks. The bulk solutions were transferred to $2 \mathrm{~mL}$ vials using Pasteur pipettes and were immediately crimped shut with PTFE septa, labeled, and stored in a $-18^{\circ} \mathrm{C}$ freezer. Although some BTEX may have been lost during the transfer procedure, this was assumed to a negligible amount because the solutions were prepared in methanol.

Standard curves were prepared for each matrix in $22 \mathrm{~mL}$ headspace vials (Agilent Technologies; HP5182-0837) by using a $5 \mathrm{~mL}$ volumetric pipette to fill each vial with 5 $\mathrm{mL}$ of water. To avoid co-solvency effects, the amount of methanol in aqueous solutions was kept below $1 \%$ by volume (Pinal et al. 1990). Vials were then sealed using aluminum crimp caps fitted with PTFE/black butyl rubber septa (Agilent Technologies, HP9301-0976). After each vial was prepared, $\alpha, \alpha, \alpha$-Trifluorotoluene (TFT) was added as an internal standard because it eluted from the GC between the benzene and toluene peaks. Each $5 \mathrm{~mL}$ vial was injected with $250 \mu \mathrm{L}$ of a $2500 \mathrm{mg} / \mathrm{L}$ stock solution in methanol to yield an internal standard concentration of $1250 \mu \mathrm{g} / \mathrm{L}$. According to Gupta (2001), the flame-ionization detector was saturated after $1500 \mu \mathrm{g} / / \mathrm{L}$ of each compound. Therefore the highest standard of each BTEX compound was $1500 \mu \mathrm{g} / \mathrm{L}$. Eleven standards ranging from 9 to $1500 \mu \mathrm{g} / \mathrm{L}$ were prepared in triplicate for every compound in each matrix. Vials were then loaded onto a Tekmar 7000 Headspace Autosampler (HAS) for analysis. Samples were first heated to $80^{\circ} \mathrm{C}$ and allowed to equilibrate for 15 minutes. This was followed by 10 minutes of mixing, 1 minute of pressurization, 0.25 minutes for pressure equilibration, 1 minute of sample loop filling, and 0.25 minutes for loop equilibration. The sample loop contained $1 \mathrm{~mL}$ of sample and was kept at $170^{\circ} \mathrm{C}$ to prevent condensation. Finally, the sample was sent to the $\mathrm{GC}$ through a transfer line also maintained at $170^{\circ} \mathrm{C}$. Helium, flowing at $1 \mathrm{~mL} / \mathrm{min}$ was used as a carrier gas.

A Hewlett-Packard 5890 gas chromatograph fitted with a 30 m Restek capillary column (RTX-624; ID 0.53; DF 3.0) was used to analyze BTEX. The temperature ramping program was adapted from Tan (2002). It consisted of an initial oven temperature of $40^{\circ} \mathrm{C}$ for 1 minute followed by an increase of $20^{\circ} \mathrm{C} / \mathrm{min}$ to $85^{\circ} \mathrm{C}$. The oven temperature was then increased at a rate of $0.5^{\circ} \mathrm{C} / \mathrm{min}$ and held at $90^{\circ} \mathrm{C}$ for 1 minute. The injector temperature was maintained at $250^{\circ} \mathrm{C}$ and the flame-ionization detector (FID) at $275^{\circ} \mathrm{C}$. Helium, flowing at $36 \mathrm{~mL} / \mathrm{min}$ was used as an inert carrier gas. Hydrogen gas and ambient air with moisture and hydrocarbon traps were used to fuel the FID.

Results were analyzed with EZChrom Chromatography Data System v6.5 (Scientific Software, Inc., San Ramon, CA; (510) 244-6622). The ratio of the amount of BTEX detected to the amount of TFT detected was used to generate the standard curves. It was assumed that this ratio would be constant among vials of the same concentration.

All BTEX standard curves were linear with a $y$-intercept of zero $(y=m x)$. A typical benzene curve is shown in Figure 3.1. 


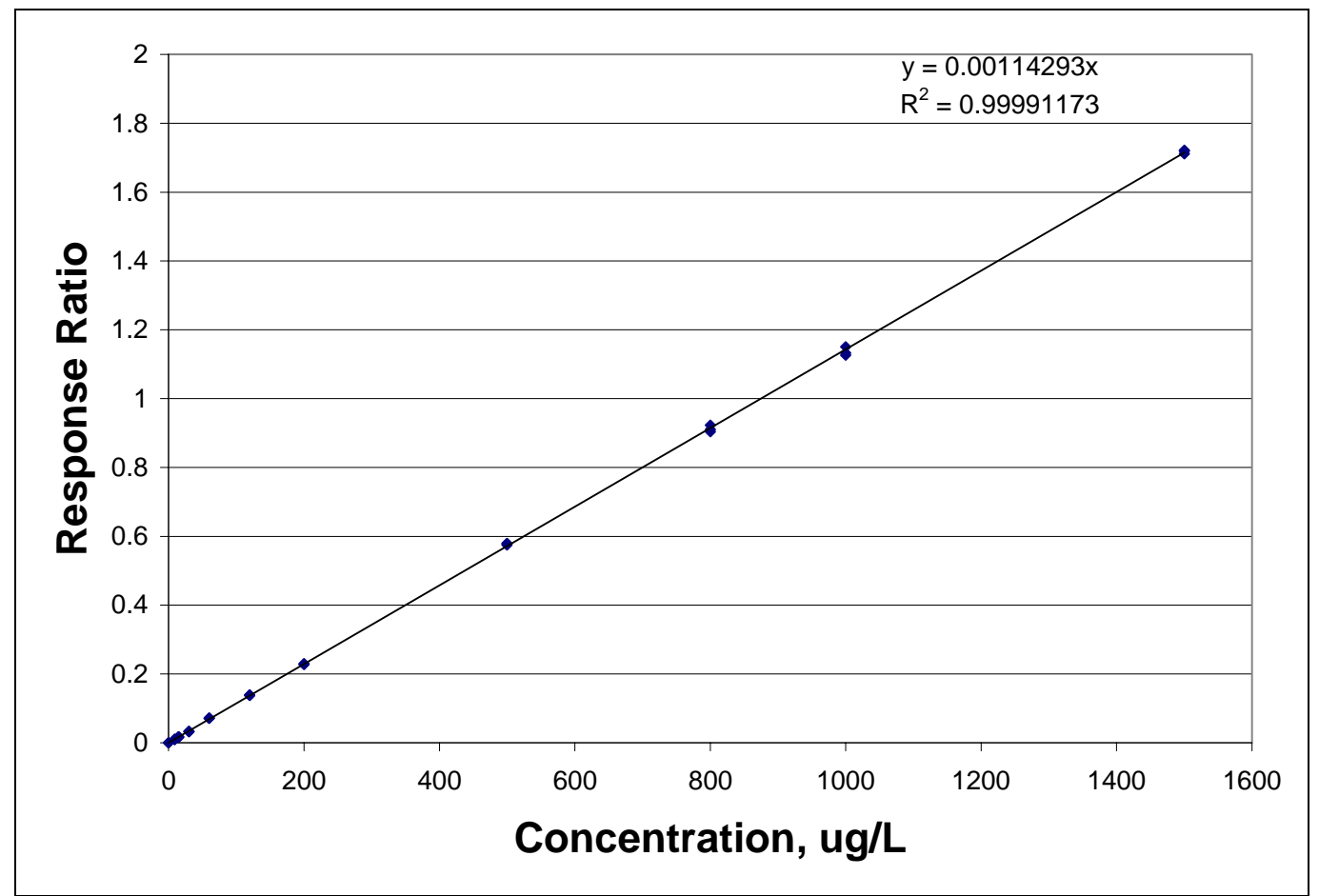

Figure 3.1 Typical benzene standard curve

Mass spectrometry was used to measure semi-volatile compounds using EPA methods 8720C (Semi-Volatile Organic Compounds by Gas Chromatography/Mass Spectrometry (GC/MS)). A Hewlett Packard HP5890 gas chromatograph with an OI Analytical 4430 photo ionization detector was used to quantify the semi-volatile concentrations in conjunction with a liquid-liquid extraction procedure adapted from EPA method 3510-C (Separatory Funnel Liquid/Liquid Extraction). Stock solutions of the six semi-volatile chemicals were made in both methanol and dichloromethane. A rough $10 \mathrm{~g} / \mathrm{L}$ solution was made by adding approximately $1 \mathrm{~g}$ of each chemical to $100 \mathrm{~mL}$ solvent. Serial dilutions were prepared so that sample concentrations could be prepared over several orders of magnitude. An additional solution was prepared of each chemical in methanol at concentrations typical of produced water. The acid and base/neutral surrogate compounds were combined and diluted to make 5 and $50 \mathrm{mg} / \mathrm{L}$ stock solutions in dichloromethane. An additional $20 \mathrm{mg} / \mathrm{L}$ solution of all six surrogates was made in methanol to help evaluate semi-volatile extraction efficiency. The SVIS solution was diluted tenfold to $200 \mathrm{mg} / \mathrm{L}$ in dichloromethane.

Standard curves were made using $1 \mathrm{~mL}$ dichloromethane samples containing all of the semi-volatile compounds at concentrations ranging from 100 to $10,000 \mu \mathrm{g} / \mathrm{L}$. The GCMS quantification was controlled by EnviroQuant Chemstation software (G1701BA version B.01.00). The initial oven temperature was held at $45^{\circ} \mathrm{C}$ for four minutes, and then increased at $15^{\circ} \mathrm{C} / \mathrm{min}$ until it reached $175^{\circ} \mathrm{C}$. The temperature was then increased at 
a rate of $20^{\circ} \mathrm{C} / \mathrm{min}$ until the oven reached $250^{\circ} \mathrm{C}$ and then $30^{\circ} \mathrm{C} / \mathrm{min}$ until the oven reached $310^{\circ} \mathrm{C}$. The temperature was then held constant for approximately 8.5 minutes until the run was completed. Helium was used as the carrier gas at $8.8 \mathrm{~mL} / \mathrm{min}$. Due to variability in the GC-MS measurements, each sample was analyzed three times and averaged.

The EPA extraction method (EPA method 3510-C) was altered for sample analysis due to the small sample volume used in the experiments. The method required $1 \mathrm{~L}$ of sample, but due to material limitations only $35 \mathrm{~mL}$ of water was used. A comparable water/dichloromethane ratio was maintained. $35 \mathrm{~mL}$ of sample was transferred to a 40 $\mathrm{mL}$ VOA vial. $110 \mu \mathrm{L}$ of surrogate solution was added to each sample. The $\mathrm{pH}$ was then lowered below 2 by adding $1 \mathrm{~mL}$ of $20 \%$ sulfuric acid. After adding $2 \mathrm{~mL}$ of dichloromethane to each VOA vial, they were shaken vigorously by hand for two minutes. The denser dichloromethane was then removed with a glass Pasteur pipette and transferred to a $6 \mathrm{~mL}$ vial. The $6 \mathrm{~mL}$ vials were sealed with a PTFE lined screw cap. This process was repeated twice; once with $2 \mathrm{~mL}$ dichloromethane and once with $1 \mathrm{~mL}$ dichloromethane. Although some dichloromethane was lost due to volatilization and emulsion with water, most was recovered. Any losses were accounted for by marking each vial at the $5 \mathrm{~mL}$ line prior to extraction. The differences between the amount extracted and the line were filled in with pure dichloromethane. Any water that solvated into the dichloromethane was removed by adding approximately $0.5 \mathrm{~g}$ of sodium sulfate to each $6 \mathrm{~mL}$ vial. One $\mathrm{mL}$ of each sample was then transferred to $2 \mathrm{~mL}$ vials. Before sealing with a PTFE lined cap, $5 \mu \mathrm{L}$ of internal standard (SVIS) was added to yield a 1 $\mathrm{mg} / \mathrm{L}$ concentration.

After achieving low phenol recovery rates, the water/dichloromethane extraction ratio was decreased from 7:1 to $3: 1$ to increase recovery efficiency. $30 \mathrm{~mL}$ of sample was extracted with five, five and then four $\mathrm{mL}$ dichloromethane. Although this was a higher ratio than the EPA method used, better results were obtained.

Inductively Coupled Plasma (ICP) Emisson Spectroscopy was used to quantify metal concentrations. All samples were analyzed with a SPECTROCIROS ${ }^{\mathrm{CCR}}$ ICP spectrometer according to EPA Method 200.7. One molar stock solutions were initially made with barium chloride, potassium chromate, and sodium selenate. Each solution was made with chemicals that had been dried in a $110^{\circ} \mathrm{C}$ oven overnight. Each one molar solution was then used to make dilutions of 100,10 , and $1 \mathrm{mM}$ solutions.

Standard curves solutions were made from the metal standards. Each standard was prepared in a $2 \%$ nitric acid background. A $1 \mathrm{mg} / \mathrm{L}$ scandium solution prepared with a $2 \%$ nitric acid background served an internal standard. Samples were run using Argon as a carrier gas. The autosampler was programmed to flush the system with $2 \%$ nitric acid for 80 seconds between each run. Each sample was measured five times; averages were used to generate standard curves. 


\subsubsection{Batch Sorption Methods}

Batch sorption experiments using semi-volatile species were conducted in the presence of BTEX using methods similar to those employed in our prior project (DE-AC2699BC15221). After 24 hours of tumbling SMZ with $5 \mathrm{~mL}$ water, a constant amount of the synthetic stock solution of phenols and naphthalenes was added to each $22 \mathrm{~mL}$ glass vial prior to BTEX addition. The composition of the synthetic water is shown in Table 3.6. After BTEX was added, the vials were sealed and then tumbled for 24 hours. The samples were then extracted with dichloromethane for analysis. The effects of semivolatile concentrations on BTEX adsorption was investigated by doubling the initial semi-volatile concentrations in a subset of samples. The produced water from Wyoming had a $\mathrm{pH}$ of 7.2. Organic experiments performed at that $\mathrm{pH}$ had to be buffered to keep the $\mathrm{pH}$ constant. $1 \mathrm{M}$ solutions of monohydrate and dihydrate potassium phosphate were used to keep the $\mathrm{pH}$ stable at 7.2. Experiments were also conducted several $\mathrm{pH}$ units above the pKas of the phenol species. This was done to investigate how these chemicals bind to the SMZ. Instead of buffering the experiment, the $\mathrm{pH}$ was initially raised to 12.4 using $5 \mathrm{M}$ sodium hydroxide. Buffering was not necessary, because the $\mathrm{pH}$ was well above the phenolic pKas.

\section{Table 3.6 Composition of synthetic water used in batch sorption experiments}

\begin{tabular}{|c|c|c|c|}
\hline \multirow[t]{6}{*}{ Semivolatiles } & 2,4-Dimethylphenol & 1000 & $\mu \mathrm{g} / \mathrm{L}$ \\
\hline & 2-Methylnaphthalene & 500 & $\mu \mathrm{g} / \mathrm{L}$ \\
\hline & 2-Methylphenol & 1500 & $\mu \mathrm{g} / \mathrm{L}$ \\
\hline & 4-Methylphenol & 1000 & $\mu \mathrm{g} / \mathrm{L}$ \\
\hline & Naphthalene & 250 & $\mu \mathrm{g} / \mathrm{L}$ \\
\hline & Phenol & 1500 & $\mu \mathrm{g} / \mathrm{L}$ \\
\hline \multirow[t]{5}{*}{ BTEX } & Benzene & 20000 & $\mu \mathrm{g} / \mathrm{L}$ \\
\hline & Tolulene & 35000 & $\mu \mathrm{g} / \mathrm{L}$ \\
\hline & Ethylbenzene & 25000 & $\mu \mathrm{g} / \mathrm{L}$ \\
\hline & m\&p-Xylene & 10000 & $\mu \mathrm{g} / \mathrm{L}$ \\
\hline & o-Xylene & 5000 & $\mu \mathrm{g} / \mathrm{L}$ \\
\hline \multirow[t]{9}{*}{ Ions } & $\mathrm{HCO}_{3}^{-}$ & 3120.2 & $\mathrm{mg} / \mathrm{L}$ \\
\hline & $\mathrm{Cl}^{-}$ & 4400.1 & $\mathrm{mg} / \mathrm{L}$ \\
\hline & $\mathrm{Na}^{+}$ & 4049.2 & $\mathrm{mg} / \mathrm{L}$ \\
\hline & $\mathrm{CO}_{3}{ }^{2-}$ & 60 & $\mathrm{mg} / \mathrm{L}$ \\
\hline & $\mathrm{Br}^{-}$ & 90.3 & $\mathrm{mg} / \mathrm{L}$ \\
\hline & $\mathrm{SO}_{4}{ }^{2-}$ & 13.4 & $\mathrm{mg} / \mathrm{L}$ \\
\hline & $\mathrm{K}^{+}$ & 44.2 & $\mathrm{mg} / \mathrm{L}$ \\
\hline & $\mathrm{Mg}^{2+}$ & 0 & $\mathrm{mg} / \mathrm{L}$ \\
\hline & $\mathrm{Ca}^{2+}$ & 30 & $\mathrm{mg} / \mathrm{L}$ \\
\hline
\end{tabular}


To control $\mathrm{pH}$ during metal and oxyanion experiments, all water used in the experiments was void of carbon dioxide. Thus, all experiments were conducted inside a nitrogen purged glove box. To the prepare carbon dioxide water, a large glass carboy was filled with ultrapure water and autoclaved. The carboy was then bubbled with ultra high purity nitrogen gas from below and above until cooled. Batch experiments with the inorganic constituents were conducted in $40 \mathrm{~mL}$ PTFE-lined centrifuged tubes. First $3 \mathrm{~g}$ of SMZ (or virgin zeolite) was added to the tube. An appropriate volume of stock solution was added with the required amount of carbon dioxide free water to fill the tube to $30 \mathrm{~mL}$. The $\mathrm{pH}$ was then adjusted with varying concentrations of sodium hydroxide, hydrochloric acid, and nitric acid. Acid/base concentrations were chosen to minimize volumetric additions that would dilute the metal concentrations. Vials were then tumbled at $11 \mathrm{rpm}$ at ambient temperature. The $\mathrm{pH}$ of each vial was checked every two hours and altered if necessary before returning to the tumbler. After 24 hours, all tubes were centrifuged at $11,000 \mathrm{rpm}$ for 10 minutes. $15 \mathrm{~mL}$ of each sample was transferred to a $15 \mathrm{~mL}$ centrifuge tube. The $\mathrm{pH}$ was lowered with $70 \%$ environmental grade nitric acid. This made each sample equivalent to the $2 \%$ nitric acid standard solution background.

To obtain a $\mathrm{pH}$ adsorption edge, initial metal ion or oxyanion concentrations were set at $1.8 \mu \mathrm{M}$. An attempt was made to keep each vial's $\mathrm{pH}$ one unit apart from the next in the range of $\mathrm{pH} 4$ to 10. Although samples were not exactly one unit apart, their respective $\mathrm{pHs}$ were kept constant. Isotherms were generated using the same methods described for the $\mathrm{pH}$ edges and by starting with a set of samples with initial concentrations ranging over several orders of magnitude. The $\mathrm{pH}$ was maintained within 0.05 unit of 7.20 by using the acids and bases mentioned previously.

\subsection{Regeneration Studies}

Regeneration studies were conducted to investigate the impact of airflow rate during regeneration and the long term stability of the SMZ. Regeneration rate tests (RRT) were designed to determine the relationship between BTEX removal during regeneration and flow rate of air through the column using laboratory-scale column tests. Experiments conducted to addresss long term stability (LST) were conducted because previous research suggested that a buildup of head loss occurred after multiple regeneration cycles (Ranck et al. 2005). The produced water for the RRT experiments was obtained from the Crystal Solutions, LLC, produced-water treatment facility in Wamsutter, Wyoming in December 2002. The water for the LST experiments was obtained from a produced-water reinjection facility located near Farmington, NM, in the San Juan basin. This facility was also the site of the pilot-scale SMZ and VPB field tests conducted in August 2005. Water was trucked in to the site and stored in tanks. The water was then put through a separation tank, sand filters, and $1-\mu \mathrm{m}$ filters before being reinjected. The water for the laboratory experiments was collected in July 2005 downstream of the sand filters and sealed in 208L metal drums. Composition of the water from the treatment facility collected for the laboratory experiments is shown in Table 3.7. Produced water used in the LST 
laboratory experiments described below was spiked with toluene so that concentrations were similar to that of the influent produced water from the August 2005 pilot tests (toluene $=3.3 \mathrm{mg} / \mathrm{L}$ ).

Table 3.7 Composition of produced waters used in regeneration tests

\begin{tabular}{|c|c|c|c|}
\hline & $\begin{array}{l}\text { Wyoming (used for } \\
\text { RRT experiments) } \\
\end{array}$ & $\begin{array}{l}\text { San Juan Basin, NM } \\
\text { (used for LST } \\
\text { experiments; collected } \\
\text { July 2005, analyzed } \\
\text { May 2006) } \\
\end{array}$ & $\begin{array}{l}\text { San Juan Basin, NM } \\
\text { (collected May } \\
\underline{\underline{2005)^{3}}}\end{array}$ \\
\hline Constituent & \multicolumn{3}{|c|}{ Concentration $(\mathrm{mg} / \mathrm{L})$} \\
\hline Benzene & 15.8 & 1.37 & 2.23 \\
\hline Toluene & 36.7 & $\mathrm{ND}^{4}$ & 7.07 \\
\hline Ethylbenzene & 1.4 & 0.21 & 0.38 \\
\hline p- \& m-xylene & 6.4 & \multirow{2}{*}{2.58 (total xylenes) } & 3.89 \\
\hline o-xylene & 3.4 & & 1.08 \\
\hline $\mathrm{Cl}^{-}$ & 4400 & 7000 & 5360 \\
\hline $\mathrm{HCO}_{3}^{-}$ & 3120 & 2150 & 672 \\
\hline $\mathrm{F}^{-}$ & 57 & $<10$ & \\
\hline $\mathrm{Br}^{-}$ & 22 & 19 & 12 \\
\hline $\mathrm{SO}^{-}$ & 13 & $<100$ & 408 \\
\hline $\mathrm{Na}^{+}$ & 4100 & 4870 & 3700 \\
\hline $\mathrm{K}^{+}$ & 44 & 150 & 74.7 \\
\hline $\mathrm{Ca}^{2+}$ & 30 & 20 & 77.8 \\
\hline $\mathrm{Mg}^{2+}$ & 6.4 & 46 & 25.4 \\
\hline Total Dissolved Solids & 11792 & 13180 & 10076 \\
\hline $\begin{array}{l}\text { Total Organic Carbon } \\
\text { 1Ranck et al, } 2005 \\
\text { 2 BTEX analysis performe } \\
\text { performed by New Mexicc } \\
3 \text { Analyzed at the Universi } \\
\text { } 4 \mathrm{ND}=\text { not detected above } \\
5 \mathrm{NA}=\text { not analyzed }\end{array}$ & $\begin{array}{l}\qquad 1000 \\
\text { d by General Engineerir } \\
\text { Bureau of Geology } \\
\text { ty of Texas at Austin } \\
\text { reporting limit }\end{array}$ & $\begin{array}{l}\text { NA }^{5} \\
\text { ng Laboratories, Charleston }\end{array}$ & , SC. Inorganic analysis \\
\hline
\end{tabular}

The RRT experiments used zeolite crushed to $0.18-0.15 \mathrm{~mm}$ grains $(80-100$ mesh. This zeolite was then treated with 0.10 M HDTMA-Cl (Aldrich, Milwaukee, WI) as described by Ranck et al (2005). HDTMA loading was $157 \mathrm{mmol} / \mathrm{kg}$ of zeolite.. SMZ used for the LST experiments was crushed to a grain size of 1.4-0.4 mm (14-40 mesh) and bulk produced by the St. Cloud mine (Bowman et al, 2001). HDTMA loading on this zeolite was $180 \mathrm{mmol} / \mathrm{kg}$ zeolite. Discrepancies in HDTMA loading rates likely resulted from differences in the zeolite content of the material mined at different times. 


\subsubsection{Regeneration Airflow-Rate Column Studies}

Columns for the RRT experiments were prepared by packing 80-110 mesh SMZ into four glass columns (ID $=0.4 \mathrm{~cm}, \mathrm{~L}=10 \mathrm{~cm}$ ) (Ace Glass, Vineland, NJ) capped with polytetrafluoroethylene (PTFE) end fittings. Four-way valves (Cole-Parmer, Vernon Hills, Ill.) were attached to the end fittings with Luer connections and served as sampling ports for influent and effluent waters. A separate column was packed for each RRT experiment. Each column was saturated from the bottom with a synthetic brine that matched the inorganic composition of the Wyoming produced water. The brine was injected using a Waters model 501 HPLC pump.

A 10-L Tedlar ${ }^{\circledR}$ gas sampling bag (Alltech Associates, Inc., Deerfield, Ill.) filled with Wyoming produced water was attached to the pump with PTFE tubing. A $0.45-$ / $m$ nylon syringe-tip filter (Supelco, Bellefonte, Pa.) was plumbed in between the pump and column to remove particulates. Produced water was pumped through each column individually until effluent BTEX concentrations equaled influent concentrations ( 400 PV). Influent and effluent water samples were collected approximately every $10 \mathrm{PV}$ for the first $100 \mathrm{PV}$ and every $50 \mathrm{PV}$ for the duration of the experiment. Three-milliliter water samples were withdrawn using a $10-\mathrm{mL}$ gastight syringe, injected into 10-mL glass headspace vials, and capped with PTFE-faced butyl septa (Supelco) for subsequent analysis.

The BTEX-saturated SMZ was then regenerated by air sparging. A compressed air tank was attached to the effluent end of the column and a $65-\mathrm{mm}$ single-float flow controller (Cole-Parmer) was placed between the tank and column to regulate airflow. The flow rate was measured downstream of the column with a soap-film flow meter. The four RRT columns were regenerated at 4.0, 7.5, 15 and $30 \mathrm{~mL} / \mathrm{min}(1.3,2.7,5.0$, and $10 \mathrm{PV} / \mathrm{min})$, respectively. The effluent gas was sampled by withdrawing $0.2-\mathrm{mL}$ samples with a 1.0$\mathrm{mL}$ gastight syringe. These samples were analyzed immediately using gas chromatography. Regeneration was continued for at least 3000 PV to ensure effluent gas BTEX concentrations were less than $2 \%$ of initial values. The RRT columns were not replicated.

\subsubsection{Long-Term Stability Column Studies}

Columns for the LST experiments were prepared by adding 14-40 mesh SMZ to two replicate glass columns with a length of $11 \mathrm{~cm}$ and radius of $2.5 \mathrm{~cm}$ (Omnifit, Boonton, NJ). These columns were outfitted with replaceable 100- $\mu \mathrm{m}$ PTFE frits and one fixed and one adjustable end fitting. The adjustable end fitting allowed any headspace that developed due to particle loss to be eliminated. The LST columns were saturated with $\mathrm{NaCl}$ brine with electrical conductivity similar to the New Mexico produced water $(21.5$ $\mathrm{mS} / \mathrm{cm})$. A constant-head tank was attached to the column inlet and the volumetric flow rate was measured at the effluent end in order to determine the hydraulic conductivity. This measurement was repeated after every fifth regeneration cycle. A 2-PV slug of tritiated water was then injected into each column at a specific discharge of $2.5 \mathrm{~cm} / \mathrm{min}$ in 
order to determine the hydraulic properties of the SMZ bed. This discharge was chosen to be similar to that of the New Mexico field experiments $(\sim 2.4 \mathrm{~cm} / \mathrm{min})$. Effluent samples were collected in 7-mL glass vials in 0.5 -min intervals using a Retriever II fraction collector (ISCO Inc., Lincoln, NE). One milliliter of each effluent sample was combined with $5 \mathrm{~mL}$ of scintillation cocktail solution (ICN Biomedicals, Inc., Irvine, CA) and analyzed with a LS6500 liquid scintillation counter (Beckman Coulter, Inc., Fullerton, CA). The tritium tracer tests were repeated after the $25_{\text {th }}$ and 50 th cycles to monitor changes in hydraulic properties.

Fifty sorption and regeneration cycles were performed on the LST columns, with water and off gas analyzed every fifth cycle. Each BTEX saturation step was carried out for 100 PV in order to better simulate operating conditions of the New Mexico field-scale experiments. The produced-water specific discharge during sorption cycles was 2.5 $\mathrm{cm} / \mathrm{min}$. The columns were regenerated using $160 \mathrm{~mL} / \mathrm{min}(5.5 \mathrm{PV} / \mathrm{min})$ of air. After the LST experiments were complete, the end fittings were removed, the used frits were replaced with new ones, and the columns were reassembled. The conductivity was measured once again to determine how much of the conductivity loss, if any, could be explained by clogging of the frits. The columns were then disassembled. Two 0.5-g SMZ samples were taken from the inlet end of each LST column, one for biological analysis and one for scanning electron microscope (SEM) analysis. The biological analysis consisted of DNA extractions using the methods described by Sambrook et al. (1989) and a protein analysis using SDS-PAGE gel (Laemmli, 1970). SEM images were obtained using an accelerating voltage of $15 \mathrm{kV}$ and a beam current of $20 \mathrm{nA}$. X-ray chemical distribution maps were collected at a resolution of 512 by 512 pixels with a 7 millisecond per pixel collection time. The remainder of the used SMZ from each column was removed and homogenized. An additional 0.5-g sample was taken from the homogenized SMZ from each column for a total chemical analysis. The chemical analysis was performed by digesting the samples with a four-acid method after Briggs (1996) and analyzing the digestion products by inductively coupled plasma-atomic emission spectroscopy. The remainder of the SMZ from each column was used for a hydrometer particle size analysis (ASTM, 1995) to determine changes in particle size and the amount of particle attrition.

\subsubsection{Analytical Methods used in the Regeneration Studies}

The influent and effluent produced-water sample vials were loaded into a HewlettPackard (HP) model 7694 headspace autosampler. The autosampler operating conditions were: oven temperature $70^{\circ} \mathrm{C}$, loop temperature $75^{\circ} \mathrm{C}$, transfer line temperature $75^{\circ} \mathrm{C}$, equilibrium time $1.0 \mathrm{~min}$, pressurization time $1.0 \mathrm{~min}$, loop fill time $1.0 \mathrm{~min}$, loop equilibration time $0.5 \mathrm{~min}$, and injection time $0.09 \mathrm{~min}$. The autosampler was attached to a HP model 5890A gas chromatograph (GC) with a 10-m long, 0.53-mm I.D. HP-5 capillary column and a flame ionization detector (FID). Operating conditions of the GC were: carrier gas (He) flow rate $35 \mathrm{~mL} / \mathrm{min}$, split gas $(\mathrm{He})$ flow rate $28 \mathrm{~mL} / \mathrm{min}$, oven temperature (isothermal) $55^{\circ} \mathrm{C}$, injector temperature $210^{\circ} \mathrm{C}$, and detector temperature 
$240^{\circ} \mathrm{C}$. The $\mathrm{GC}$ was calibrated for each run using five BTEX standards over a range from 0.5 to $40 \mathrm{mg} / \mathrm{L}$. $p$-xylene and $m$-xylene were not resolved by this method and as such were treated as a single compound. Gas-phase BTEX concentrations from the regeneration cycles of the RRT columns were measured by direct injection into the HP 5890A GC. Operating conditions of the GC were the same as for the sorption analysis with the exception of the split flow rate, which was increased to $63 \mathrm{~mL} / \mathrm{min}$. Calibration for these analyses was conducted by preparing BTEX standard solutions in 10-ml glass vials capped with PTFE-faced septa. BTEX concentrations in the headspace of the standards were calculated based on the Henry's Law constant for each compound. Gasphase BTEX concentrations for the LST regeneration experiments were measured using a Varian Inc. (Walnut Creek, CA) model 5890 GC equipped with an automated gassampling valve, FID, and a 15-m long, 0.25-mm I.D Varian Factor Four VF-1 ms column. The valve, which used a $0.25 \mathrm{~mL}$ sampling loop, automatically collected a sample every 20 minutes and injected it into the column. Off-gas from the LST columns was plumbed into the sampling valve with PTFE tubing. Operating conditions of this GC were: carrier gas (He) flow $25 \mathrm{~mL} / \mathrm{min}$, split ratio 50 , oven temperature (isothermal) $55^{\circ} \mathrm{C}$, column flow $2.0 \mathrm{~mL} / \mathrm{min}$, injector temperature $140^{\circ} \mathrm{C}$, and detector temperature $200^{\circ} \mathrm{C}$. Calibration was carried out by manual injection of BTEX standards in a manner similar to the manual-injection calibration for the HP $5890 \mathrm{GC}$.

\subsection{Vapor Phase Bioreactor Experiments}

Extensive biofiltration studies have examined the treatment of gas phase BTEX and verified that vapor phase bioreactors can be an efficient technique to remove these contaminants. The main concern in treating the effluent from the SMZ regeneration columns related to the transient operation of the system. Thus, the major objective of this phase of research was to assess the potential for VPBs to handle variable loading and to develop a strategy to optimize performance under variable loading conditions. Before beginning the transient loading tests, the system must be operated under stable, continuous feed conditions so that the impact of key operational parameters that affect performance can be evaluated over a long period. These parameters include nutrient levels, empty bed contact time (EBCT), $\mathrm{pH}$, and biomass distribution. The objective in this task was therefore to investigate the effect of key operating parameters on the performance of two biofilters, one packed with polyurethane foam (synthetic media) and one packed with a compost based material (natural media) under stable operating conditions. Based on these results, the biofilter that showed better reliability was selected for further testing in the laboratory and field. Polyurethane foam is an attractive packing material since it has a relatively high surface area, light weight and can be compressed to remove excess biomass (Moe and Irvine 2000). However, a frequent external nutrient supply is needed. Compost is the most widely used natural packing media. It has high surface area, high air permeability, and high water holding capacity. Also it contains nutrients and is cost efficient (Smet et al. 1996a). However, compost beds settle over 
time, creating short circuiting and consequently should be replaced every few years (Medina et al. 1995). Mixing an inert media such as perlite can be used to improve the permeability of bed and prevent bed compaction.

\subsubsection{Polyurethane Foam Biofilter}

The experimental bioreactor column (I.D. $16 \mathrm{~cm}$, stainless steel) consisted of three individual sections bolted together (Figure 3.2). Each section was packed with polyurethane foam cubes $(1.5 \mathrm{~cm})$ to a height of approximately $19 \mathrm{~cm}$, which resulted in $12 \mathrm{~L}$ of total packing volume. A plenum located between each packed section allowed the gas sampling and redistribution of the contaminant stream between sections.

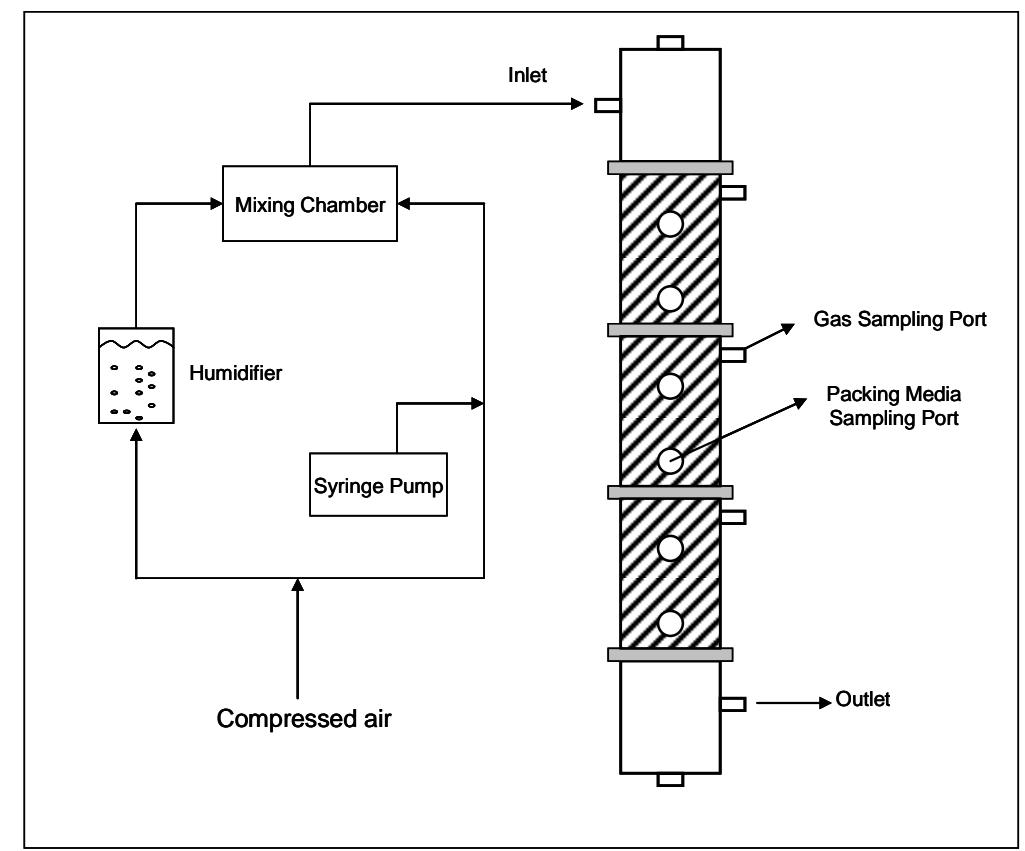

Figure 3.2. Schematic diagram of vapor phase biofilter

Microbial cultures capable of degrading BTEX mixtures were developed prior to the inoculation of the VPB. The original culture was obtained from an activated sludge samples from the South Austin Wastewater Treatment Plant. Ten $\mu 1$ of each BTEX constituent was added separately to $250 \mathrm{ml}$-glass bottles containing $100 \mathrm{ml}$ of nutrient medium and $1 \mathrm{ml}$ of original culture. After the forth cycle in which complete degradation of each BTEX constituent was observed, the cultures were mixed together. Previous research suggested that developing separate inoculation cultures may prevent undesirable substrate inhibitions from reducing the diversity of the microbial culture during inoculum development (Park, 2004). Inoculation of the biofilter was accomplished by recirculating a BTEX-degrading microbial culture through the bioreactor packing material for 12 hours. The inoculating solution was then drained from the column and the VOC feed to the biofilter was started. The design empty bed contact time for the gas phase was one minute and the total inlet BTEX concentration for the experiments was $130 \mathrm{ppm}_{\mathrm{v}}$ 
(Benzene 12, Toluene 24, Ethylbenzene 32, para \& meta-xylene 22, ortho-xylene 40 $\mathrm{ppm}_{\mathrm{v}}$ ). The ratio of each component in the BTEX mixture was selected to match the expected ratio in the waste gas produced during SMZ regeneration (Ranck et al. 2005).

The BTEX contaminants were injected into a small slip air stream using a syringe pump (Model 44, Harvard Apparatus, South Natick, MA). This contaminated air was mixed with humidified air in a mixing chamber prior to being introduced to the top of the biofilter (Figure 3.2). Twice a day, a modified hydrocarbon minimal medium was supplied as an external nutrient source to the biofilter for 30 minutes via a nutrient spray system. The modified hydrocarbon minimal medium (HCMM) consisted of $2.72 \mathrm{~g} / \mathrm{L}$ $\mathrm{KH}_{2} \mathrm{PO}_{4}, 1.42 \mathrm{~g} / \mathrm{L} \mathrm{Na}_{2} \mathrm{HPO}_{4}, 3.96 \mathrm{~g} / \mathrm{L}\left(\mathrm{NH}_{4}\right)_{2} \mathrm{SO}_{4}, 10.1 \mathrm{~g} / \mathrm{L} \mathrm{KNO}$, and $1 \mathrm{~mL} / \mathrm{L}$ of trace metal solution. The trace metal solution was composed of: $50 \mathrm{~g} / \mathrm{L} \mathrm{MgSO} 4 \cdot 7 \mathrm{H}_{2} \mathrm{O}, 14.7 \mathrm{~g} / \mathrm{L}$ $\mathrm{CaCl}_{2} \cdot 2 \mathrm{H}_{2} \mathrm{O}, 2.5 \mathrm{~g} / \mathrm{L} \mathrm{FeSO}_{4} \cdot 7 \mathrm{H}_{2} \mathrm{O}, 2.86 \mathrm{~g} / \mathrm{L} \mathrm{H}_{3} \mathrm{BO}_{3}, 1.54 \mathrm{~g} / \mathrm{L} \mathrm{MnSO}_{4} \cdot \mathrm{H}_{2} \mathrm{O}, 0.041 \mathrm{~g} / \mathrm{L}$ $\mathrm{CoCl}_{2} \cdot 6 \mathrm{H}_{2} \mathrm{O}, 0.027 \mathrm{~g} / \mathrm{L} \mathrm{CuCl} 2 \cdot 2 \mathrm{H}_{2} \mathrm{O}, 0.044 \mathrm{~g} / \mathrm{L} \mathrm{ZnSO} 4 \cdot 7 \mathrm{H}_{2} \mathrm{O}, 0.025 \mathrm{~g} / \mathrm{L} \mathrm{Na}_{2} \mathrm{MoO}_{4} \cdot 2 \mathrm{H}_{2} \mathrm{O}$, and $0.02 \mathrm{~g} / \mathrm{L} \mathrm{NiCl}_{2} \cdot 6 \mathrm{H}_{2} \mathrm{O}$. The HCMM in the biofilter was replaced every 3 days with fresh solution. In the early stages of biofilter operation, the nutrient spray system inhibited the attachment of biomass to the first section of the packing material. To remedy this problem, the foam packing material in the biofilter was removed, completely mixed and then returned to the biofilter column on Day 60. Fine steel mesh was also placed on top of the column-packing material at this time to reduce the impact of the nutrient spray on the packing and to prevent wash out of biomass from the column.

\subsubsection{Compost Biofilter}

The experimental reactor for the compost biofilter was similar to the polyurethane foam biofilter described previously, except that it was packed with a compost-based material. The compost filter media used to pack the columns consisted of the following materials (by volume): $60 \%$ compost, $36.5 \%$ perlite, and $3.5 \%$ crushed oyster shell. The compost, known as Dillo Dirt ${ }^{\mathrm{TM}}$, is produced from dewatered municipal sludge and bulking agents such as tree trimmings and yard waste. Prior to mixing the compost with the other ingredients, the compost was sieved to remove particles less than $2 \mathrm{~mm}$. Perlite was added to improve the air flow through the packing media and to reduce compaction of the packing media mixture. The oyster shell was added to the media to act as a $\mathrm{pH}$ buffer.

Before packing the media into the column, it was inoculated with a BTEX-degrading microbial consortium. The inoculum was developed from an activated sludge culture as described previously for the foam biofilter. To ensure the packing media would not be nitrogen limited during the start up period, the packing media was mixed with $1 \mathrm{~L}$ of a concentrated nutrient solution prior to being placed in the biofilter column. The concentrated nutrient solution consisted of a hydrocarbon minimal medium (HCMM) solution that was modified by increasing the concentration of $\mathrm{KNO}_{3}$ by a factor of ten to $101 \mathrm{~g} / \mathrm{L}$. The composition of the modified HCMM was the same as noted previously for the polyurethane foam biofilter with the exception of the $\mathrm{KNO}_{3}$ concentration. 


\subsubsection{Analytical Methods}

Gas samples were collected from the bioreactors with $0.5 \mathrm{~mL}$ gas tight syringes from sampling ports located in each column and immediately analyzed. A Hewlett-Packard 5890 gas chromatograph fitted with a $30 \mathrm{~m}$ Restek capillary column (RTX-624; ID 0.53; DF 3.0) was used to analyze BTEX. Para- and meta-xylenes were not distinguishable using GC-FID analysis. To determine the distribution of biomass along the column, packing materials containing attached biomass were collected periodically from each section in the column. Deionized water was added to samples which were homogenized in a vortexer and then sonicated to remove the biomass from the packing material. The COD of the biomass was determined via a colorimetric method described in Standard Methods (APHA et al. 1992). The liquid ammonium concentration was determined with an ammonium electrode probe (Orion 95-12, Orion Research Inc., MA). Nitrate measurements were performed in a similar manner using a nitrate combination electrode (Accumet, Fisher Scientific, NJ). Media moisture content was determined gravimetrically. During sampling, a media sample of approximately $0.5 \mathrm{~g}$ was obtained directly from the bioreactor, placed on the dish, and weighed. The dish and sample were then dried for 24 hours in a $105^{\circ} \mathrm{C}$ oven. After cooling the dry dish and sample to room temperature in a desiccator, the dry dish and sample were reweighed. The pressure drop across the column was measured periodically using a pressure gauge (Magnehelic ${ }^{\circledR}$, Dwyer Instrument Inc., IN). The gauges were directly connected to the inlet and outlet gas sampling ports, and the pressure difference was measured in inches of $\mathrm{H}_{2} \mathrm{O}$. The $\mathrm{pH}$ of leachate samples was measured using an Accument ${ }^{\mathrm{TM}} \mathrm{pH}$ meter (Fisher Scientific, Model $50)$.

To determine the nitrogen concentration along the compost column, samples of packing media were collected periodically from each section in the column. Deionized water was added to sample which was homogenized in a vortexer and then sonicated to remove the biomass from the packing material. The samples were equilibrated overnight to allow separation of the compost particles from liquid.

\subsection{Pilot Scale SMZ/VPB Studies}

The pilot system consisted of two SMZ columns in series treating produced water and one VPB treating the off-gas produced during the regeneration of the SMZ columns. The pilot scale SMZ columns were constructed of fiberglass, each 14" in diameter and 48" in height with a total packed capacity of $3.7 \mathrm{ft}^{3}$ (Culligan International Company) as shown in Figure 3.3. Each column was filled with approximately $170 \mathrm{lbs}$ of 14-40 mesh SMZ, leaving a 3" headspace below the inlet manifold. Sampling ports were installed in the one-inch pipelines entering and exiting each column. Several quick-disconnect valves were added to the system to allow a given SMZ column to be disconnected from the produced water flow when it was ready to be regenerated via air-sparging. 


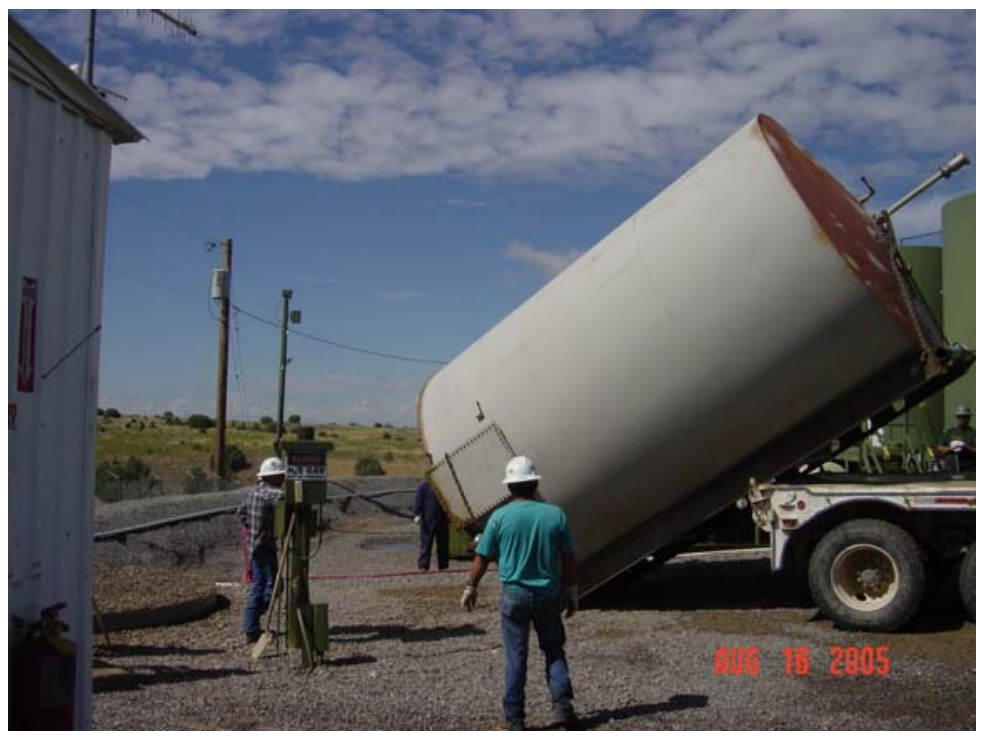

a) Placement of produced water tank outside of test building.
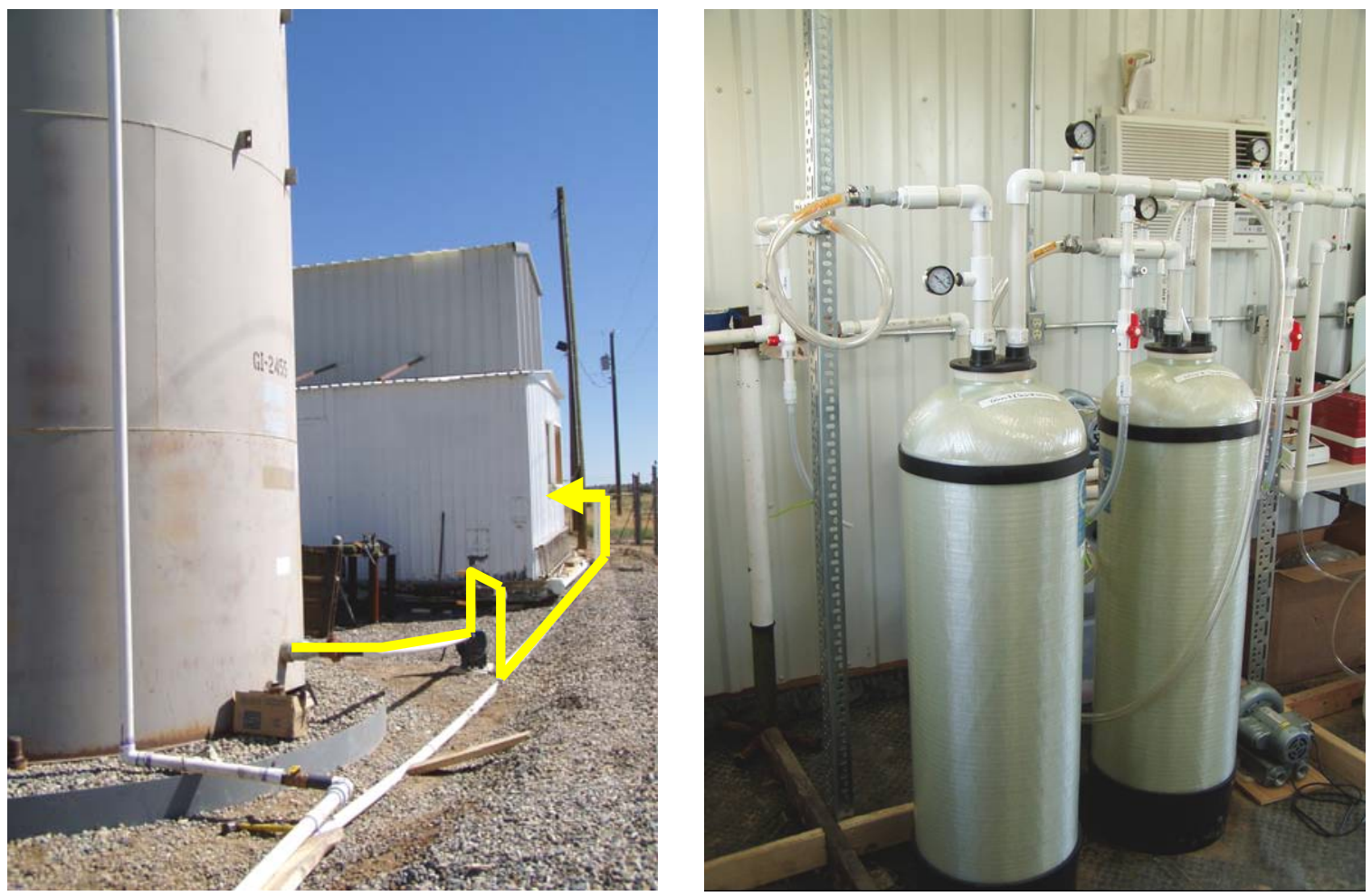

b) Produced water feed tank for SMZ columns c) Pilot Scale SMZ Columns

Figure 3.3 Produced water storage tanks and SMZ columns used in the pilot test 
In addition to the two SMZ columns, the system consisted of a compost-based vapor phase biofilter and a granular activated carbon (GAC) buffering column placed upstream of the VPB (Figure 3.4). The packing media was inoculated as described in the previous section of this report and the total packing volume of the VPB was $16 \mathrm{~L}$. During regeneration of a SMZ column, the regenerated gas stream containing BTEX was first passed through the GAC buffering column to attenuate the inlet VOC concentration. This buffered gas stream was humidified and then introduced to the top of the biofilter. The empty bed contact time (EBCT) in the VPB was 73 seconds while the GAC buffering column was operated at an EBCT ranging from 1 to 5 seconds.

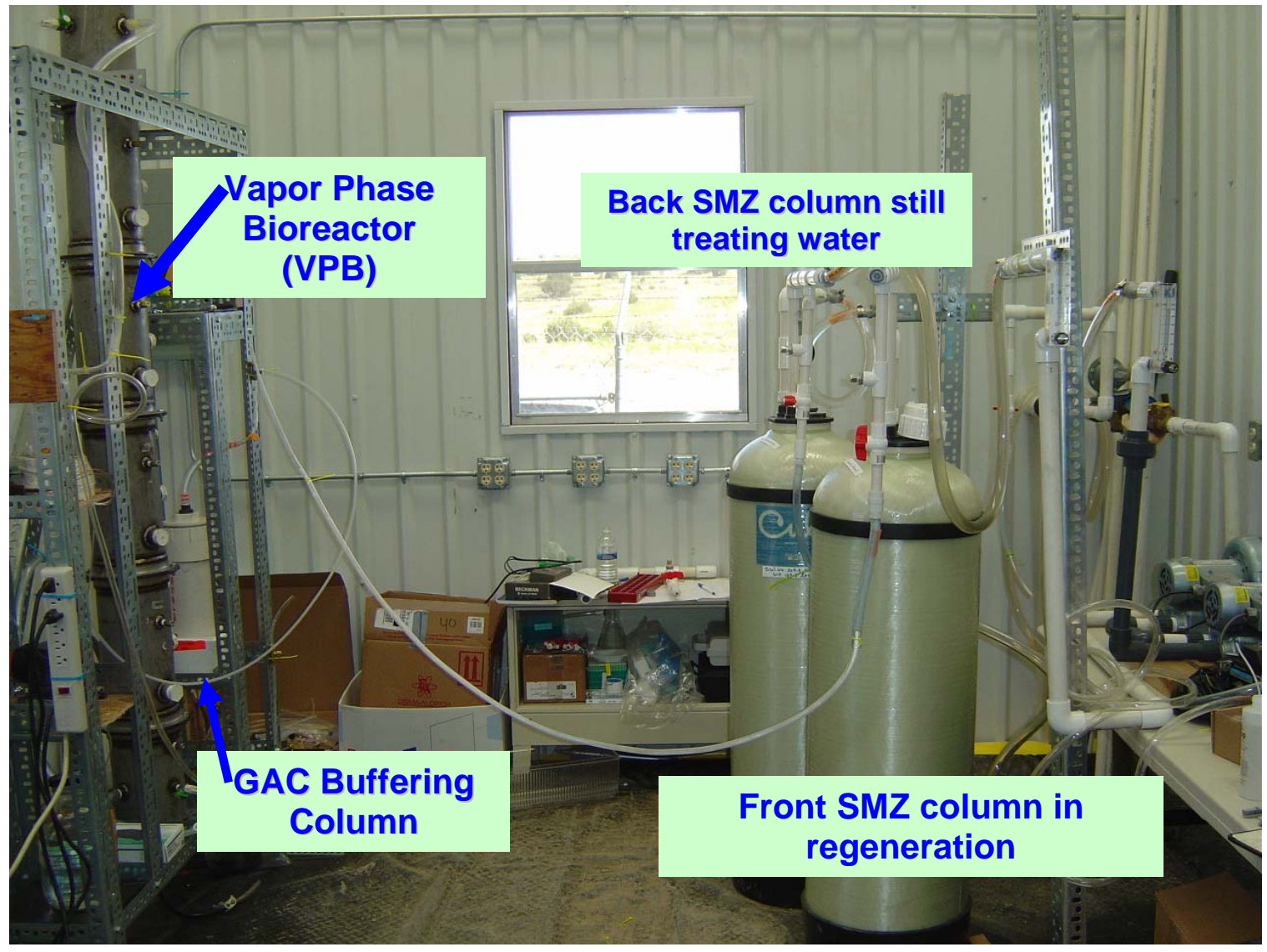

Figure 3.4 Pilot scale SMZ/VPB system 


\subsubsection{Pilot Scale Operation}

A schematic diagram of the operation of the SMZ system during the sorption phase of the process is shown in Figure 3.5a. An 8,800 gallon feed tank of produced water was filled daily with water (Figure 3.3a and $\mathrm{b}$ ) that had been filtered through the micron-filtration system at the field site. Flow from the storage tank was controlled by an electrical pump and was delivered through PVC pipelines to the pilot SMZ/VPB system. A total flowmeter and a real-time flowmeter were installed between the pump and the pilot system. The system was operated continuously at a specific flow rate until the upstream column reached the target breakthrough of the BTEX compounds. The target breakthrough varied during the field trial. During the initial experiments with virgin $\mathrm{SMZ}$, one SMZ column was operated until it was completely saturated with benzene and toluene and complete breakthrough occurred for these compounds. In subsequent runs, the SMZ columns were operated until the benzene concentration in the effluent was approximately $20 \%$ of the influent concentration. In each case, after breakthrough was reached, the upstream SMZ column was disconnected and regenerated while the downstream column remained online treating produced water. Once the upstream column was regenerated, it was placed back online downstream of the other SMZ column.

The process flow diagram for the regeneration phase of operation is in shown in Figure 3.5b. Before regenerating a saturated column, the water in the off-line column was removed using a peristaltic pump. Ambient air, provided by blowers (GAST REGENAIR Model R1102), was purged through the SMZ column countercurrent to the direction of produced water flow. Waste gas produced during regeneration flowed through the GAC passive buffering column and a humidifier before entering the VPB. The effluent air stream from the VPB was routed through an activated carbon drum to capture any residual VOCs that escaped the VPB during the field test. The air flow rate during regeneration was $13 \mathrm{~L} / \mathrm{min}$ resulting in a 73 second EBCT in the VPB. Although the flow rate was held constant, the period of regeneration for each SMZ column was varied to examine the effect of regeneration time on VOC removal from the SMZ columns.

To verify SMZ performance over multiple sorption/regeneration cycles and a range of produced water flow rates, three flow rates (27gph, 10gph, and 5gph) were tested to examine the sorption capacity of the SMZ system under field conditions. During the field test, influent and effluent water samples were collected from the sampling ports to capture the breakthrough of the contaminants through the upstream SMZ column prior to saturation. Analyses of water samples were performed at the field site as well as in the laboratory. The field site analyses included measuring BTEX concentrations present in the produced water as well as those in the contaminated air stream generated during the SMZ regeneration process. Laboratory analyses of the produced water included analyzing volatiles organic compounds (VOCs), semi-volatiles organic compounds (SVOCs) and organic acids concentrations. 


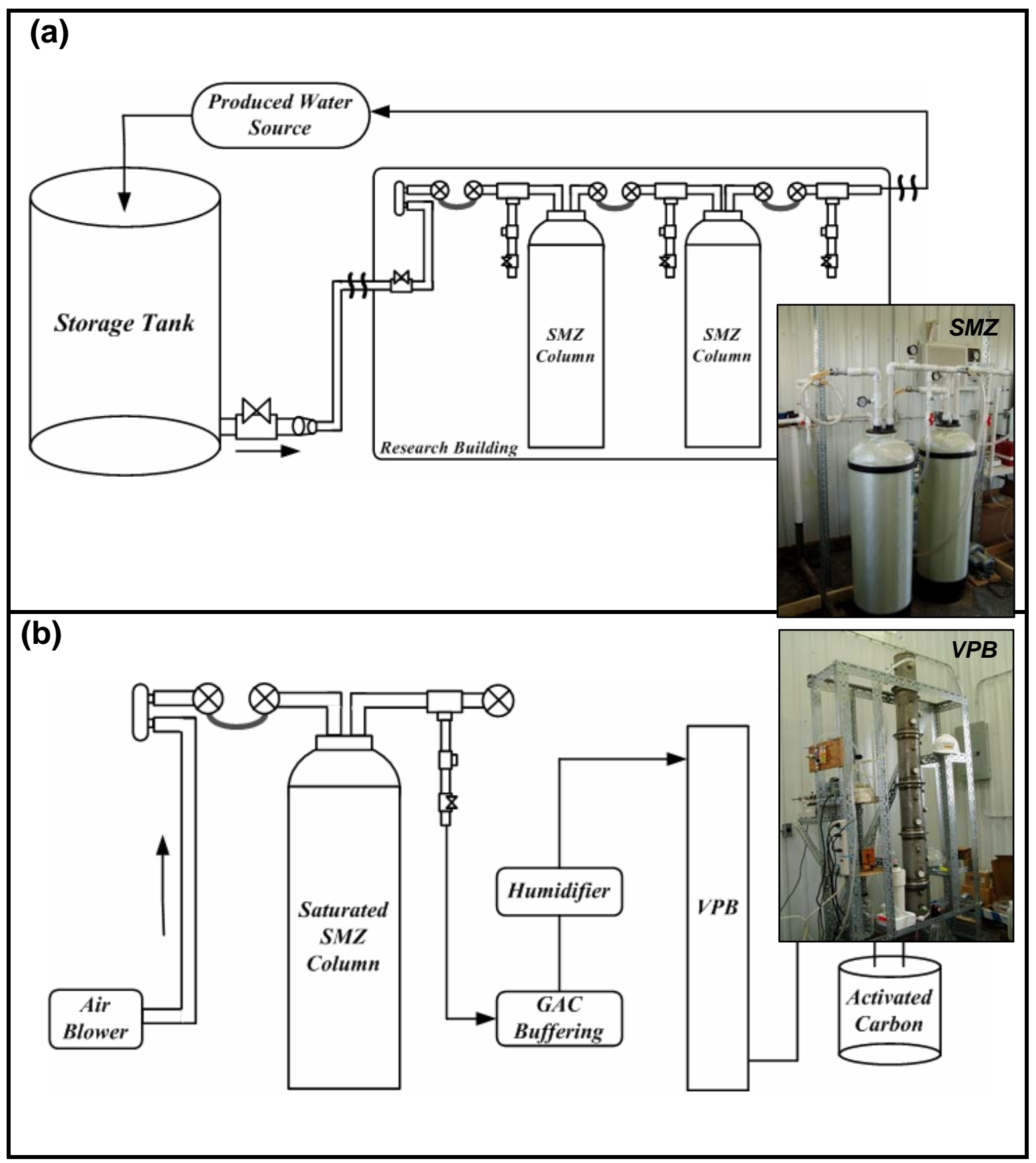

Figure 3.5 Schematic diagram of the pilot scale coupled SMZ/VPB system

(a) Treatment of produced water using the SMZ columns. (b) Treatment of off-gas from a saturated SMZ column during regeneration with air. 


\subsubsection{Analytical Methods used for the Pilot Studies}

BTEX concentrations of aqueous and gaseous samples were analyzed in the field using an on-site HP 5890 Series II Gas Chromatograph (GC) equipped with a 30 m Restek RTX-5 capillary column and a flame-ionization detector (FID) shown in Figure 3.6. A $2.5 \mathrm{~mL}$ aliquot of each water sample was placed in a $10 \mathrm{~mL}$ headspace vial fitted with a Telflon-faced butyl septum. The vials were placed in a heating block to equilibrate at $80^{\circ} \mathrm{C}$ for 15 minutes. Gas-tight syringes $(0.5 \mathrm{~mL})$ were used to extract gaseous samples from the headspace vials as well as gaseous samples from the inflow and outflow sampling ports of the VPB during regeneration. Gaseous samples were then injected into the GC/FID. Helium carrier gas was used at a flow rate of $1 \mathrm{~mL} / \mathrm{min}$. The FID was supplied with ultra high purity (UHP) $30 \mathrm{~mL} / \mathrm{min}$ nitrogen, $30 \mathrm{~mL} / \mathrm{min}$ UHP hydrogen, and $300 \mathrm{~mL} / \mathrm{min}$ air. The analyses were performed at an initial oven temperature of $40^{\circ} \mathrm{C}$ for 1 minute followed by $20^{\circ} \mathrm{C} / \mathrm{min}$ to $85^{\circ} \mathrm{C}$, and then increased at $0.5^{\circ} \mathrm{C} / \mathrm{min}$ to a final temperature of $90^{\circ} \mathrm{C}$ which was maintained for 1 minute. The temperatures of the injector and the detector were $250^{\circ} \mathrm{C}$ and $275^{\circ} \mathrm{C}$, respectively.

Aqueous concentrations of BTEX, phenols and naphthalenes, and C1-C5 carboxylic acids were also measured in the Environmental and Water Resources Engineering (EWRE) laboratory at the University of Texas at Austin. BTEX concentrations were measured using a Tekmar 7000 headspace sampler attached to a HP $5890 \mathrm{GC}$ with a $30 \mathrm{~m}$ Restek RTX-624 capillary column and a FID. The headspace sampler and the GC operating conditions were described previously by Ranck et al. (2005). Samples were selectively measured for semi-volatile concentrations (EPA Method 8270C) using a Thermo Gas Chromatograph/Mass Spectrometer (GC/MS) consisting of an Autosampler AS3000 attached to a Finnigan TraceGC Ultra with a 30m Restek RTX-5MS capillary column and a Finnigan Polaris Q Ion Trap MS. Prior to quantifying SVOCs in the GC/MS, aqueous semi-volatiles were extracted into dichloromethane (adapted from EPA Method 3510C). One microliter of extracted liquid was injected into the GC in splitless mode. The initial oven temperature was held at $40^{\circ} \mathrm{C}$ for 5 minutes, then increased at $7^{\circ} \mathrm{C} / \mathrm{min}$ to $250^{\circ} \mathrm{C}$, and ramped at $10^{\circ} \mathrm{C} / \mathrm{min}$ to a final temperature of $300^{\circ} \mathrm{C}$ which was held for 2 minutes. Helium was used as carrier gas at the flow rate of $1 \mathrm{~mL} / \mathrm{min}$. The injector temperature was $200^{\circ} \mathrm{C}$ while the MS transfer line temperature was $300^{\circ} \mathrm{C}$.

Organic acids concentrations were measured using a Dionex AS 40 Autosampler attached to a DX-600 Ion Chromatograph (IC). The IC was equipped with a Dionex CD25A conductivity detector, an ASRS ULTRA 4mm suppressor, an EG50 eluent generator and an IonPac AS11-HC analytical column. The oven temperature was maintained at $30^{\circ} \mathrm{C}$ for each run, the suppressor current was set at $300 \mathrm{~mA}$, and the flow rate of the eluent $(\mathrm{KOH})$ through the column was $1 \mathrm{~mL} / \mathrm{min}$. The eluent concentration was set as follows: $1 \mathrm{mM}$ for the first 4 minutes, $2 \mathrm{mM}$ from 4.2 to 13.2 minutes, $10 \mathrm{mM}$ from 13.5 to 28 minutes, $2 \mathrm{mM}$ from 28.5 to 30 minutes, $30 \mathrm{mM}$ from 30.5 to 40 minutes, and $0.5 \mathrm{mM}$ from 40.5 to 44 minutes. 


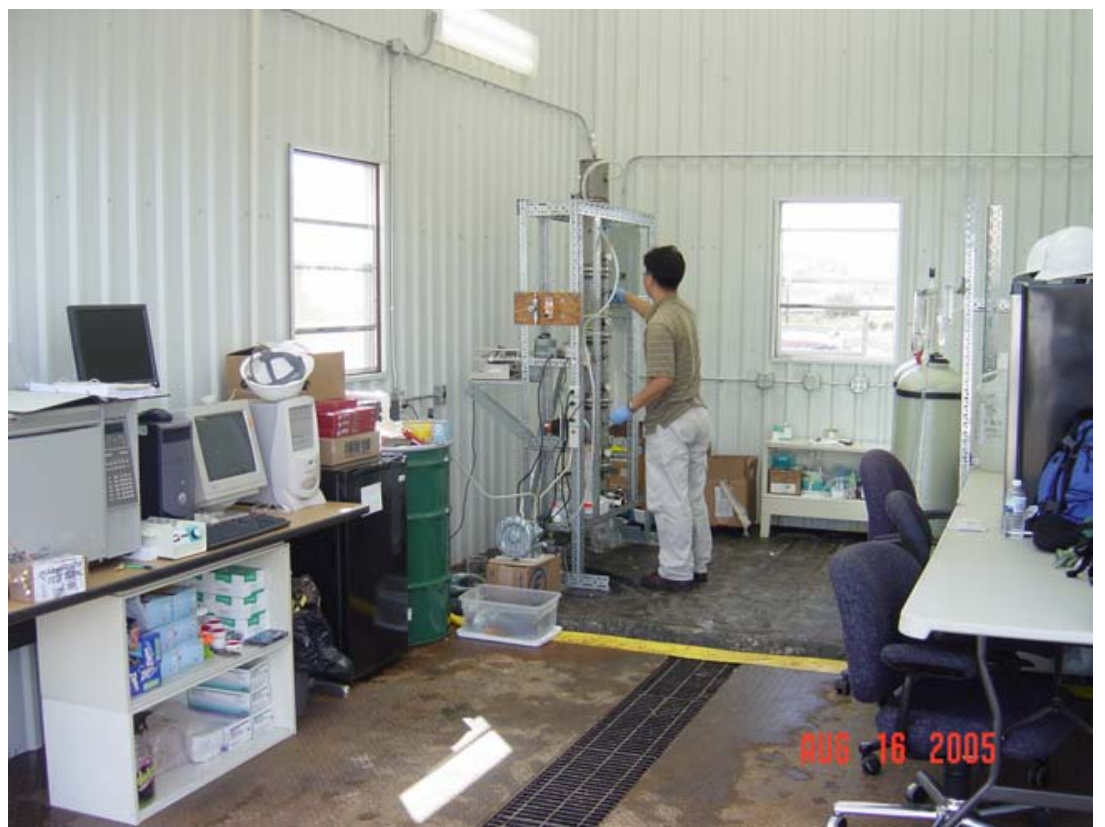

Figure 3.6 Building constructed for pilot scale studies and on-site BTEX analysis 


\section{RESULTS AND DISCUSSION}

\subsection{Batch Sorption Studies}

There were two primary objectives of the batch sorption studies. The first was to evaluate the sorption behavior of BTEX compounds on SMZ as a function of background water $\mathrm{pH}$ and composition to determine whether enhanced adsorption after regeneration in the field could be explained by the co-adsorption of other hydrophobic constituents. The second goal involved analysis of the sorption of a representative divalent cation, barium, and two oxyanions onto SMZ.

\subsubsection{Effect of pH on BTEX and Phenol Sorption to SMZ}

The results of experiments conducted to assess the impact of $\mathrm{pH}$ on BTEX adsorption capacity showed no major differences in sorption for benzene and toluene over the tested $\mathrm{pH}$ range. As shown in Figure 4.1, the slopes of the benzene isotherms were similar for the data collected at three $\mathrm{pH}$ values. In contrast, greater variation in the $K_{d}$ values was observed for ethylbenzene and the xylenes; $K_{d}$ values decreased slightly between $\mathrm{pH} 7.2$ and 10.2, and increased between $\mathrm{pH} 10.2$ and 12.2 as shown in Table 4.1. One potential explanation for the increase in sorption between $\mathrm{pH} 10.2$ and 12.2 for these more volatile compounds could be the increase in ionic strength $(0.2 \mathrm{M}$ at $\mathrm{pH} 7.2$ to $0.3 \mathrm{M}$ at $\mathrm{pH} 12.2)$ caused by addition of base. Indeed, our previous research demonstrated that the increase in sorption due to ionic strength could be predicted. The salinity effects could be predicted using

$$
\log K_{d, \text { salt }}=\log K_{d}+K^{s}[\text { salt }]_{\text {tot }}
$$

where $\mathrm{K}^{\mathrm{s}}$ for benzene and toluene are 0.20 and $0.25 \mathrm{~L} /$,mole and [salt] tot $_{\text {is }}$ total salt concentration in mole/L. However, as evident in this equation, the impact is relatively small over the ionic strength range of these data.

$\mathrm{pH}$ was expected to affect the sorption of phenolic compounds. By increasing the solution $\mathrm{pH}$ above the $\mathrm{pKas}$ of the phenol species, all of the phenol compounds become negatively charged. If phenol sorption is dependent on the charge of the molecule, then $\mathrm{K}_{\mathrm{D}}$ values would be expected to differ at $\mathrm{pHs}$ above and below a molecule's $\mathrm{pKa}$. Table 4.2 shows the average single point $\mathrm{K}_{\mathrm{D}}$ values measured in experiments conducted at $\mathrm{pH}$ 7.2, 10.2, and 12.2. As the $\mathrm{pH}$ increases from 7.2 to 10.2 (near the $\mathrm{pKas}$ of all four phenol compounds), sorption decreases by almost a factor of two. As the $\mathrm{pH}$ increases two units above the pKas of the phenol compounds, sorption continues to decrease. This indicates that as the phenol species become charged they are less likely to adsorb. 


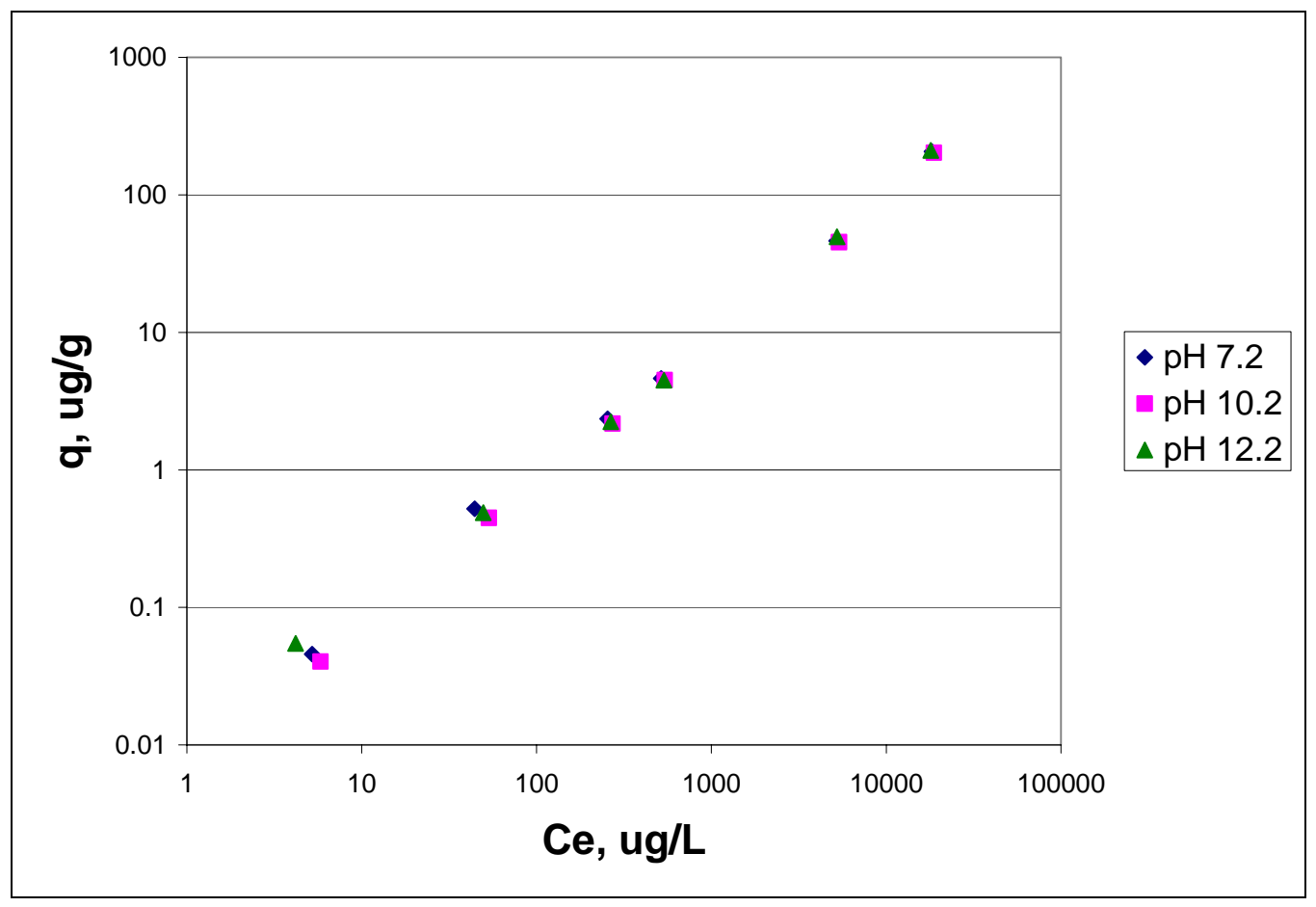

Figure 4.1 Benzene isotherm data collected in the presence of the synthetic produced water over a range of $\mathrm{pH}$ values.

Table 4.1 Comparison of $K_{D}$ values at various $p H s$ in the presence of semi-volatiles in synthetic salt water. Units of $K_{D}$ are $L / g$.

\begin{tabular}{|c|c|c|c|c|c|c|}
\hline compound & $\mathbf{p H ~ 7 . 2}$ & $\mathbf{R}^{2}$ & $\mathbf{p H ~ 1 0 . 2}$ & $\mathbf{R}^{2}$ & $\mathbf{p H ~ 1 2 . 2}$ & $\mathbf{R}^{2}$ \\
\hline benzene & 0.0112 & 0.9956 & 0.0108 & 0.9952 & 0.0116 & 0.9964 \\
\hline toluene & 0.0307 & 0.9942 & 0.0294 & 0.9932 & 0.0310 & 0.9940 \\
\hline ethyl-benzene & 0.0778 & 0.9916 & 0.0768 & 0.9891 & 0.0806 & 0.9913 \\
\hline m,p-xylene & 0.0846 & 0.9937 & 0.0834 & 0.9919 & 0.0862 & 0.9933 \\
\hline o-xylene & 0.0770 & 0.9916 & 0.0769 & 0.9888 & 0.0814 & 0.9896 \\
\hline compound & $\begin{array}{c}\text { 95\% confidence } \\
\text { limits on slope }\end{array}$ & \multicolumn{2}{|c|}{$\begin{array}{c}\mathbf{9 5 \%} \text { confidence } \\
\text { limits on slope }\end{array}$} & $\begin{array}{c}\mathbf{9 5 \%} \text { confidence } \\
\text { limits on slope }\end{array}$ \\
\hline benzene & $0.0107,0.0118$ & $0.0102,0.0113$ & $0.0111,0.0122$ \\
\hline toluene & $0.0289,0.0325$ & $0.0276,0.0313$ & $0.0291,0.0329$ \\
\hline ethyl-benzene & $0.0767,0.0790$ & $0.0756,0.0781$ & $0.0794,0.0818$ \\
\hline m,p-xylene & $0.0835,0.0857$ & $0.0821,0.0846$ & $0.0850,0.0873$ \\
\hline o-xylene & $0.0759,0.0781$ & $0.0757,0.0782$ & $0.0800,0.0827$ \\
\hline
\end{tabular}


Table 4.2 Average single point $K_{D}$ values for various equilibrium $p H$ values.

\begin{tabular}{|c|c|c|c|}
\hline Compound & $\begin{array}{c}\text { Kd at } \\
\mathbf{p H ~ 7 . 2} \\
(\mathrm{L} / \mathrm{kg})\end{array}$ & $\begin{array}{c}\text { Kd at } \\
\mathbf{p H ~ 1 0 . 2} \\
(\mathrm{L} / \mathrm{kg}\end{array}$ & $\begin{array}{c}\text { Kd at } \\
\mathbf{p H ~ 1 2 . 2} \\
(\mathbf{L} / \mathbf{k g}\end{array}$ \\
\hline Phenol & 0.0322 & 0.0167 & 0.0119 \\
\hline 2-methylphenol & 0.0734 & 0.0416 & 0.0217 \\
\hline 4-methylphenol & 0.0865 & 0.0474 & 0.017 \\
\hline 2,4-dimethylphenol & 0.2395 & 0.1305 & 0.0332 \\
\hline
\end{tabular}

Li et at. (2000), however, reported that phenol adsorption increased with solution $\mathrm{pH}$ onto $\mathrm{SMZ}$ over a $\mathrm{pH}$ range of 7 to 10 . The authors reported that this was evidence that phenol adsorbed as an ionic species. At high $\mathrm{pH}$, the phenol compounds lose their proton and become charged. Although the authors reported increased sorption at high $\mathrm{pH}$, sorption actually decreased at $\mathrm{pH}$ values above phenol's $\mathrm{pKa}$ of 10 . This was attributed to the increasing ionic strength of the water, although ionic strength employed in their research was one to two orders of magnitude smaller than the ionic strengths of the water used in this study. Although Gupta (2001) reported that ionic strengths in this range did not affect sorption of BTEX molecules, this evidence suggests that this may not be true for polar compounds.

\subsubsection{Effect of Co-solutes on BTEX Sorption}

BTEX sorption onto SMZ can be described using a linear isotherm model. Previous research has demonstrated that BTEX partitioning onto SMZ is a function of organic carbon content, salinity and temperature (Katz et al. 2003). Correlations were developed for predicting the impact of each of these parameters. However, previous laboratory and field testing provided evidence to support the hypothesis that $\mathrm{Kd}$ values for BTEX compounds increase in the presence of produced water constituents (Ranck et al, 2005; Tan, 2002). Indeed, laboratory sorption experiments conducted with produced water from the Wyoming field site yielded Kd values significantly higher than predicted by this equation or measured in the laboratory as shown in Table 4.3. Similar effects of cosorption of neutral organic contaminants by organoclay has been reported in literature (Jaynes and Vance, 1996; Sheng et al. 1996).

To further evaluate the impact of dissolved semi-volatile organic compounds present in produced water on BTEX sorption, BTEX isotherms were prepared using two synthetic produced water matrices. The first matrix consisted of the solution composition provided in Table 3.6, and the second matrix was similar to the first except that the concentration of each semi-volatile compound was doubled. This matrix was referred to as the concentrated synthetic water. The results suggest that distribution coefficients determined in synthetic water are comparable to those determined in produced water, and that increasing the semi-volatile concentration in the synthetic water led to a concomitant increase in the $\mathrm{Kd}$ values. 
Final Technical Report

DE-FC26-02NT15461

Table 4.3 Distribution coefficients of BTEX in produced water and synthetic produced water.

\begin{tabular}{|c|c|c|c|c|}
\hline \multirow[b]{2}{*}{ Compound } & \multicolumn{4}{|c|}{$\mathrm{K}_{\mathrm{d}}(\mathrm{L} / \mathrm{kg} \mathrm{SMZ})$} \\
\hline & $\begin{array}{l}\text { Produced } \\
\text { water }\end{array}$ & $\begin{array}{c}\text { Synthetic } \\
\text { produced } \\
\text { water }\end{array}$ & $\begin{array}{l}\text { Synthetic } \\
\qquad(\times 2) \\
\text { produced } \\
\text { water }\end{array}$ & $\begin{array}{l}\text { Millipore } \\
\text { water }\end{array}$ \\
\hline Benzene & $12.8( \pm 0.4)$ & $12.0( \pm 0.3)$ & $12.9( \pm 0.4)$ & $\begin{array}{l}10.5( \pm 0.1)^{\mathrm{a}} \\
9.70 \\
( \pm 0.01)\end{array}$ \\
\hline Toluene & $32.4( \pm 0.7)$ & $32.7( \pm 1.0)$ & $33.8( \pm 0.9)$ & $26.7( \pm 0.1)$ \\
\hline Ethylbenzene & $78.0( \pm 1.4)$ & $82.7( \pm 2.7)$ & $85.7( \pm 2.5)$ & $65.9( \pm 0.2)$ \\
\hline m-\&p-xylene & $91.2( \pm 1.6)$ & $90.6( \pm 2.7)$ & $93.3( \pm 2.4)$ & $73.5( \pm 0.2)$ \\
\hline o-xylene & $76.1( \pm 1.3)$ & $80.9( \pm 2.6)$ & $84.6( \pm 2.5)$ & $64.2( \pm 0.2)$ \\
\hline
\end{tabular}

Values in parenthesis denote standard errors.

Jaynes and Vance (1996) reported that more BTEX constituents sorb on the organo-clays than the pure compounds do when total loading exceeds $10 \mathrm{~g} / \mathrm{kg}$ because sorbed BTEX effectively increases the organic matter content of organo-clay at this high mass loading. In their study, the non-linear sorption isotherm was reduced to a linear isotherm by taking into account increased organic mass associated with other sorbed constituents. Typical field concentrations for total BTEX ranged from 60 to $100 \mathrm{mg} / \mathrm{L}$. Significant BTEX sorption under the field conditions onto SMZ may increase the total organic mass in SMZ by about 3\%; however, this mechanism alone cannot sufficiently explain the observed increase in the partition coefficient in the field experiment as well as the greater sorption capacity of the regenerated SMZ column observed in our research.

A second explanation for the observed phenomenon is provided by regular solution theory. According to regular solution theory, solvency of a solute in a solution is determined by the solubility parameter (Barton, 1991). Sheng et al. (1996) showed that addition of organic constituents to an HDTMA phase can lead to enhanced sorption when the change in solubility parameter due to addition of the organic constituents into HDTMA phase is positive. For example in the linear isotherm range, the sorption coefficient for trichloroethylene onto an HDTMA phase increased approximately $20 \%$ when the amount of carbon tetrachloride in the HDTMA phase was $3.8 \%$ and by $100 \%$ when the amount of nitrobenzene in the HDTMA phase was 5.7\%. As shown in Table 4.4, a greater increase in the linear sorption coefficient is expected for nitrobenzene as a co-solvent because differences in the solubility parameter between nitrobenzene and HDTMA is greater than between carbon tetrachloride and HDTMA. However, it should be noted that the solubility parameter for HDTMA was estimated based on the value of hexadecane. 
Table 4.4 Solubility parameters of BTEX and other representative organic compounds

\begin{tabular}{lc}
\hline Organic compounds & Solubility parameters $\left(\mathrm{MPa}^{1 / 2}\right)^{\mathrm{a}}$ \\
\hline Benzene & 18.7 \\
Toluene & 18.2 \\
Ethylbenzene & 18.0 \\
m-,p-Xylene & 18.0 \\
o-Xylene & 18.4 \\
2,4-Dimethylphenol & 22.5 \\
2-Methylphenol & 22.7 \\
4-Methylphenol & 23.9 \\
Phenol & 24.6 \\
Carbon tetrachloride & 17.6 \\
Nitrobenzene & 22.5 \\
HDTMA & 16.3 \\
a. from Barton (1991). & \\
b. Solubility parameter of HDTMA was substituted by that of hexadecane.
\end{tabular}

Comparison of the solubility parameters of BTEX compounds indicates that they are significantly higher than that of HDTMA, indicating that enhanced sorption may be possible by altering solvency in the HDTMA phase. In addition to BTEX, phenols are also a major contaminant found at high concentration in typical produced waters. They have greater solubility parameters than any of the BTEX compounds due to their polar characteristics. Furthermore, phenols have higher sorption coefficients than predicted based on their hydrophobicity because of sorption of anionic species to the ammonium head group of HDTMA (Li et al. 2000). Sorbed phenolates are not easily detached by conventional regeneration methods and potentially play a role in the enhanced sorption capacity of regenerated SMZ via the two potential mechanisms described above.

\subsubsection{Sorption of Inorganic Constituents in Produced Water}

Chromium and selenium were both found in the synthetic water from Wyoming. The most common species found in natural waters for each of these elements are the oxyanions chromate and selenate. These oxyanions were used to study the impact of background water composition on anion sorption to SMZ. Analyses of chromate and selenate in solutions prior to and following the sorption experiments were measured using ICP. ICP measures total metal concentrations. Therefore, all reported data is in terms of total chromium and total selenium, and no attempt was made to determine whether changes in oxidation state occurred during the course of the experiments. However, changes in oxidation state were not expected based on the redox conditions in the samples. 
Chromium sorption onto $\mathrm{SMZ}$ was determined as a function of $\mathrm{pH}$ for constant total chromium concentrations added ( $\mathrm{pH}$ adsorption edges) and as a function of aqueous chromium concentration at constant $\mathrm{pH}$ (isotherms). Initial chromium sorption results were very confusing. First, it was apparent that chromium adsorbs to SMZ in ultrapure water, but not in the synthetic salt solution. This was thought to be the result of competing ions in the salt solution. Further experimentation indicated that while chromium would adsorb in the salt solution at high $\mathrm{pH}$, it would not at low $\mathrm{pH}$. This is counterintuitive for the sorption of an anionic species. In these experiments, nitric acid was used to lower the $\mathrm{pH}$. Further research indicated that nitrate was a strong competitor with chromium for adsorption sites on SMZ (Li et al. 1998). In ultrapure water, very little acid is required to alter the $\mathrm{pH}$, so there was not enough nitrate to hinder chromium sorption. The synthetic salt water required addition of significant amounts of concentrated acid to adjust the $\mathrm{pH}$. Therefore, at low $\mathrm{pH}$ there was a significant increase in the nitrate concentration and the nitrate was able to successfully compete with chromium for sorption sites on the SMZ in the synthetic salt water. When hydrochloric acid was used to lower $\mathrm{pH}$, no competitive effects were observed, even though the increase in ionic strength resulting from the addition of either acid was similar.

A chromium sorption edge was prepared in the synthetic salt solution using hydrochloric acid and sodium hydroxide to adjust $\mathrm{pH}$. Thirty $\mathrm{mL}$ of $1.8 \mathrm{mM} \mathrm{K}_{2} \mathrm{CrO}_{4}$ was added to three grams of SMZ and the $\mathrm{pH}$ was adjusted to a series of vials to produce a $\mathrm{pH}$ range from 4 to 11. The results shown in Figure 4.2 are typical of anion sorption to variable charged surfaces that are $\mathrm{pH}$ dependent. Chromate sorption is assumed to occurs on the surfactant bilayer, where the ammonium head has a positive charged head counterbalanced with a negative chloride ion. Li (2004) studied chromate uptake by $\mathrm{SMZ}$ over a range of pHs. Chromate sorption was described by Langmuir isotherms over a $\mathrm{pH}$ range of 3 to 11 . The sorption capacity remained constant throughout this range, but the sorption intensity decreased from 42.2 to $4 \mathrm{~L} / \mathrm{mmol}$ for $\mathrm{pH} 3$ to 11 . The decrease in sorption intensity was attributed to competition from other ions in solution. As $\mathrm{pH}$ increased, although chromate sorption decreased, chloride desorption increased. No increase in aqueous HDTMA was measured; therefore, other anions in solution must have had a higher affinity for the surfactant bilayer. The only other anion in solution was hydroxide. The decrease in sorption seen in Figure 4.2 begins at $\mathrm{pH} 6$. This is close to $\mathrm{pKa}_{1}$ of carbonic acid $\left(\mathrm{pKa}_{1}=6.3\right)$. High $\mathrm{pH}$ carbonate/hydroxide solutions have been shown to remove as much as $90 \%$ of sorbed chromate ( $\mathrm{Li} \&$ Bowman, 2001). Therefore, the lower chromate sorption at high $\mathrm{pH}$ observed in this experiment must have resulted from competition from hydroxide and/or carbonate ions. 


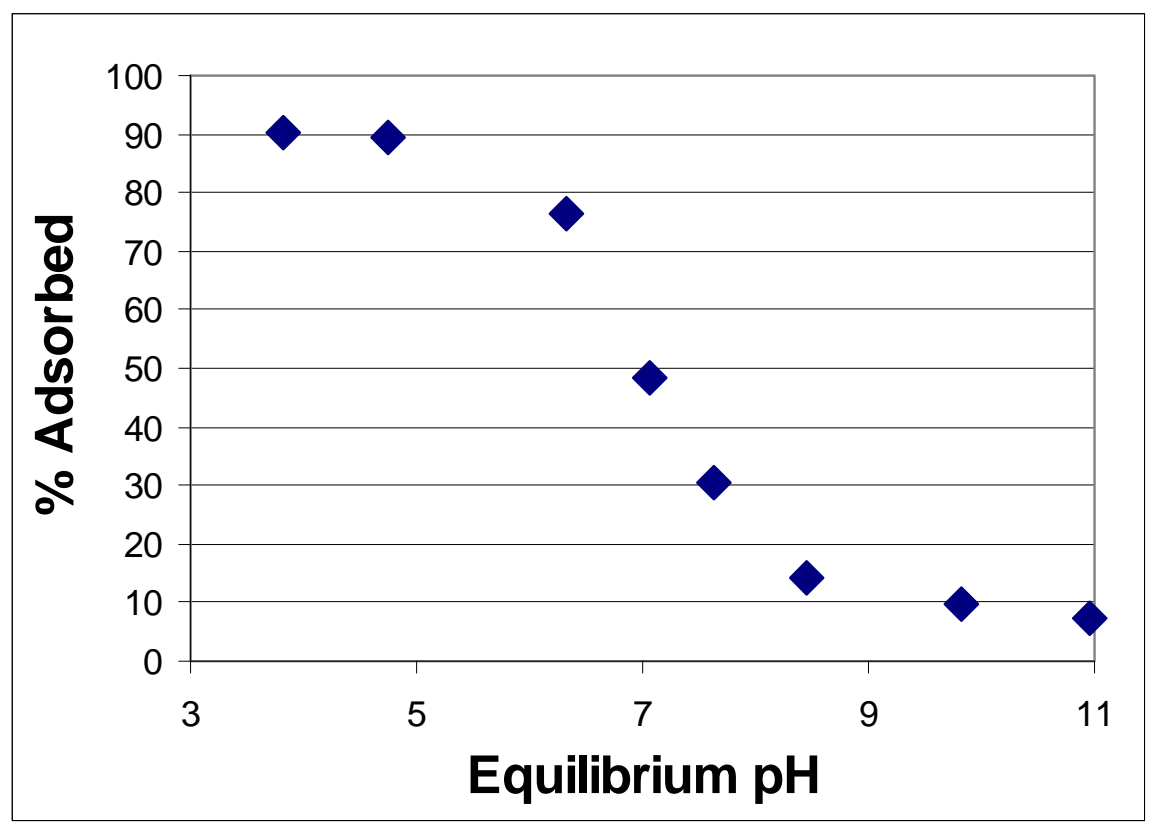

Figure 4.2 Chromium sorption edge for SMZ in a synthetic salt solution (Initial chromate concentration $=1.8 \mathrm{mM}$ and $\mathrm{SMZ}=100 \mathrm{~g} / \mathrm{L}$ )

A chromate isotherm was prepared in ultrapure water using hydrochloric acid and sodium hydroxide to maintain the $\mathrm{pH}$ at 7.2. This objective of this experiment was to determine how chromate sorption would be affected by background electrolytes in the next experiment. The results are presented in Figure 4.3. Also shown in the figure is a Langmuir isotherm that was fit to the data using nonlinear regression. The approximation is described with Equation 4.1, where $C_{e}$ is expressed in terms of $\mathrm{mmol} / \mathrm{L}$ :

$$
q_{L}=\frac{q_{\max } b C_{e}}{1+b C_{e}}
$$

where $\mathrm{q}_{\max }=0.0245 \mathrm{mmol} / \mathrm{g}$ and $\mathrm{b}=5.593 \mathrm{~L} / \mathrm{mmol}$ when $\mathrm{C}_{\mathrm{e}}$ is in $\mathrm{mmol} / \mathrm{L}$ units for chromate sorption. At low concentrations, the Langmuir isotherm appears to be linear with a $K_{D}$ value of approximately $0.05 \mathrm{~L} / \mathrm{g}$.

These results are consistent with Li et al. (1998). At 200\% surface coverage of zeolite with HDTMA, the authors report that chromium sorption followed a Langmuir isotherm, although no constants were given. However, maximum sorption in their isotherm appeared to occur at approximately $10 \mathrm{mmol} / \mathrm{kg}$, which is less than half of the 24.5 $\mathrm{mmol} / \mathrm{kg}$ predicted by Equation 4.1 for this experiment. No description of the water matrix was given. Assuming that Millipore water was used in Li et al.'s study, the results in this experiment indicate that much more chromium can sorb than was reported in their study. 


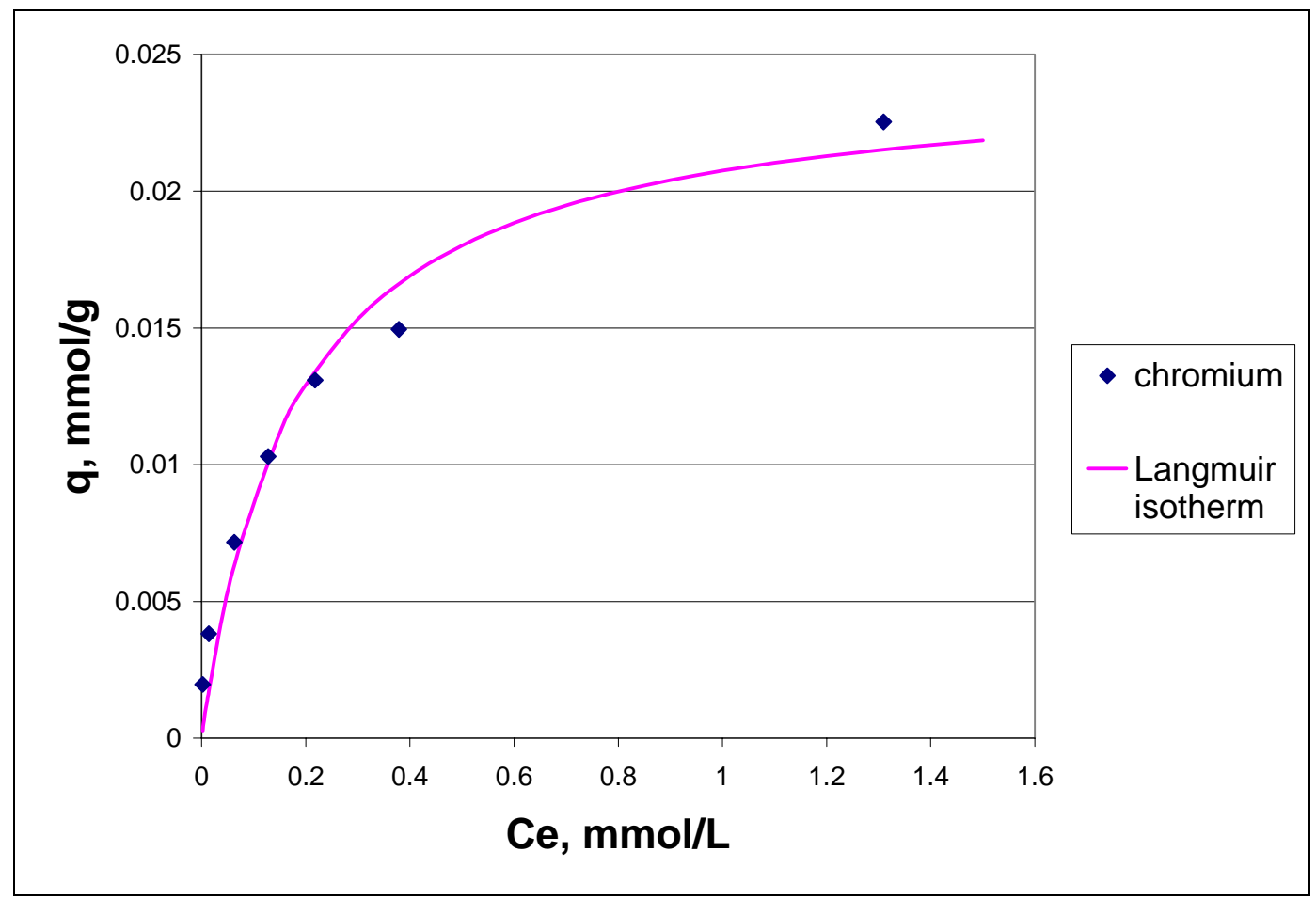

Figure 4.3 Chromium isotherm in Millipore water at $\mathrm{pH}$ 7.2.

A similar chromium isotherm was prepared in the synthetic salt water using hydrochloric acid and sodium hydroxide to maintain the $\mathrm{pH}$ at 7.2. The results are shown in Figure 4.4 The data could be fit to a linear isotherm with an $R^{2}$ value of 0.967 and a $K_{D}$ value of $0.011 \mathrm{~L} / \mathrm{g}$. This value is more than an order of magnitude lower than the distribution coefficient determined from the low concentration region in Figuer 4.3. This suggests that there is competition for exchange sites from ions in the salt solution.

Li et al. (1998) reported on competitive sorption between chromium and other anions. As sulfate concentrations increased from 0.1 to $10 \mathrm{mM}$, the Langmuir isotherm describing chromate sorption began to appear much more linear. The chromate sorption intensities, b, were $2.4,1.3$, and $0.4 \mathrm{~L} / \mathrm{mmol}$ for sulfate concentrations of $0.1,1$, and $10 \mathrm{mM}$, respectively. This data can be related to the results from this research. In this study, a background salt concentration of zero (ultrapure water) corresponded to a chromate sorption intensity of approximately $5.6 \mathrm{~L} / \mathrm{mmol}$; this is more than twice that of the sorption intensity of Li et al.'s $0.1 \mathrm{mM}$ sulfate experiment. Furthermore, the bicarbonate concentration in the saline water of this study was approximately $50 \mathrm{mM}$. This is higher than the $10 \mathrm{mM}$ sulfate solution used in Li et al.'s experiment, but bicarbonate is a monovalent ion, and would not be expected to compete as strongly as sulfate. Indeed, 


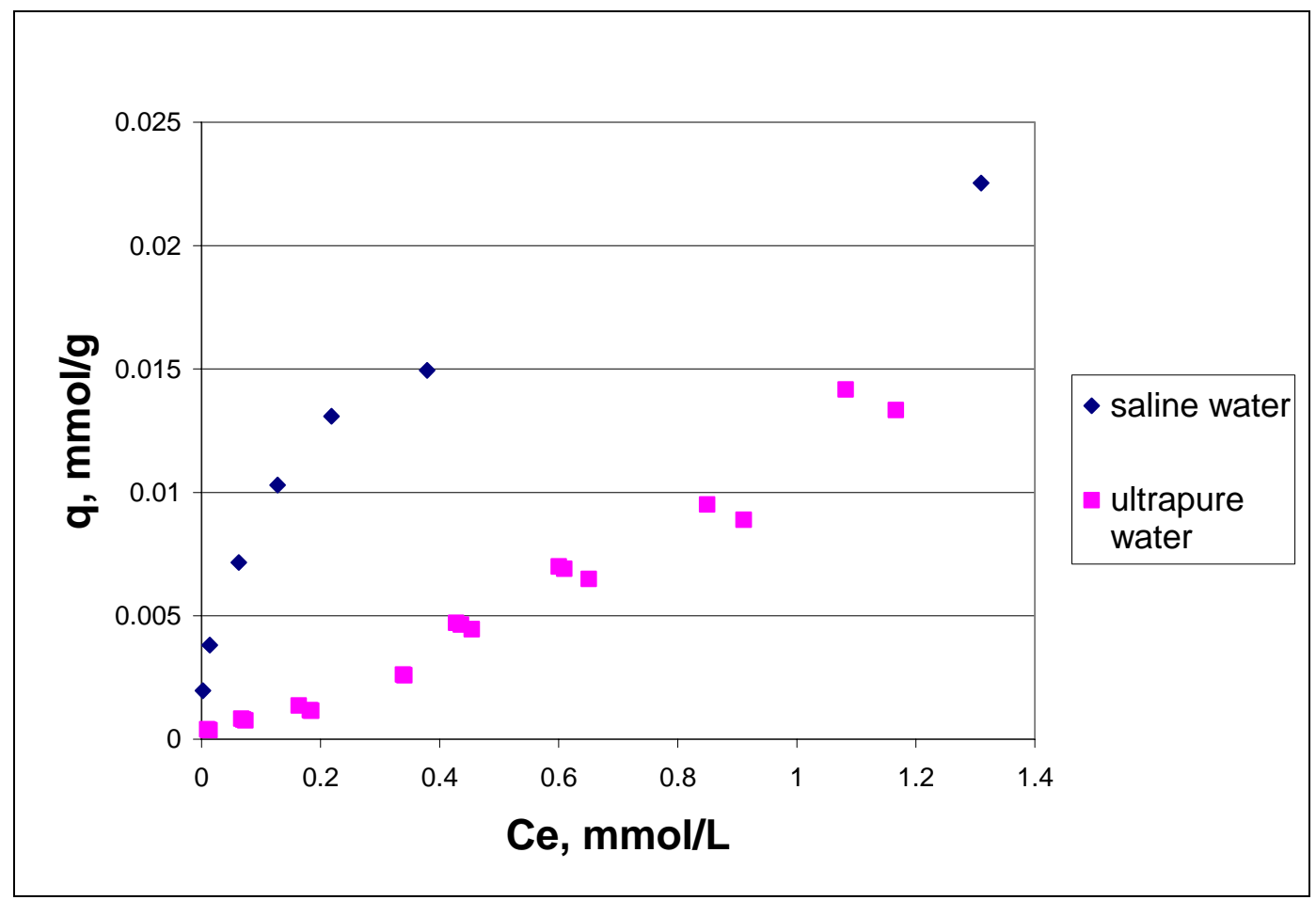

Figure 4.4 Comparison of chromium isotherms in ultrapure water and saline water at pH 7.2.

when carbonate is used to regenerate chromium saturated SMZ, its effectiveness is less effective at near neutral pHs (where bicarbonate is the dominant species) (Li \& Bowman, 2001). Li et al.'s chromate Langmuir isotherm in $10 \mathrm{mM}$ sulfate can be approximated at low concentrations as a linear isotherm with a $\mathrm{K}_{\mathrm{D}}$ value of $0.006 \mathrm{~L} / \mathrm{g}$. This is smaller, but comparable to the $\mathrm{K}_{\mathrm{D}}$ of $0.011 \mathrm{~L} / \mathrm{g}$ observed in this study. More data on the comparative effects of sulfate and carbonate would be needed to fully address the differences in the two data sets.

A selenium isotherm was also prepared in Millipore water at $\mathrm{pH}$ 7, and a Langmuir isotherm fitted to the data using non-linear regression is shown in Figure 4.5. The resulting Langmuir isotherm parameters were $\mathrm{q}_{\max }=0.0193 \mathrm{mmol} / \mathrm{g}$ and $\mathrm{b}=3.203 \mathrm{~L} / \mathrm{mmol}$ when $\mathrm{C}_{\mathrm{e}}$ is in $\mathrm{mmol} / \mathrm{L}$ units. 


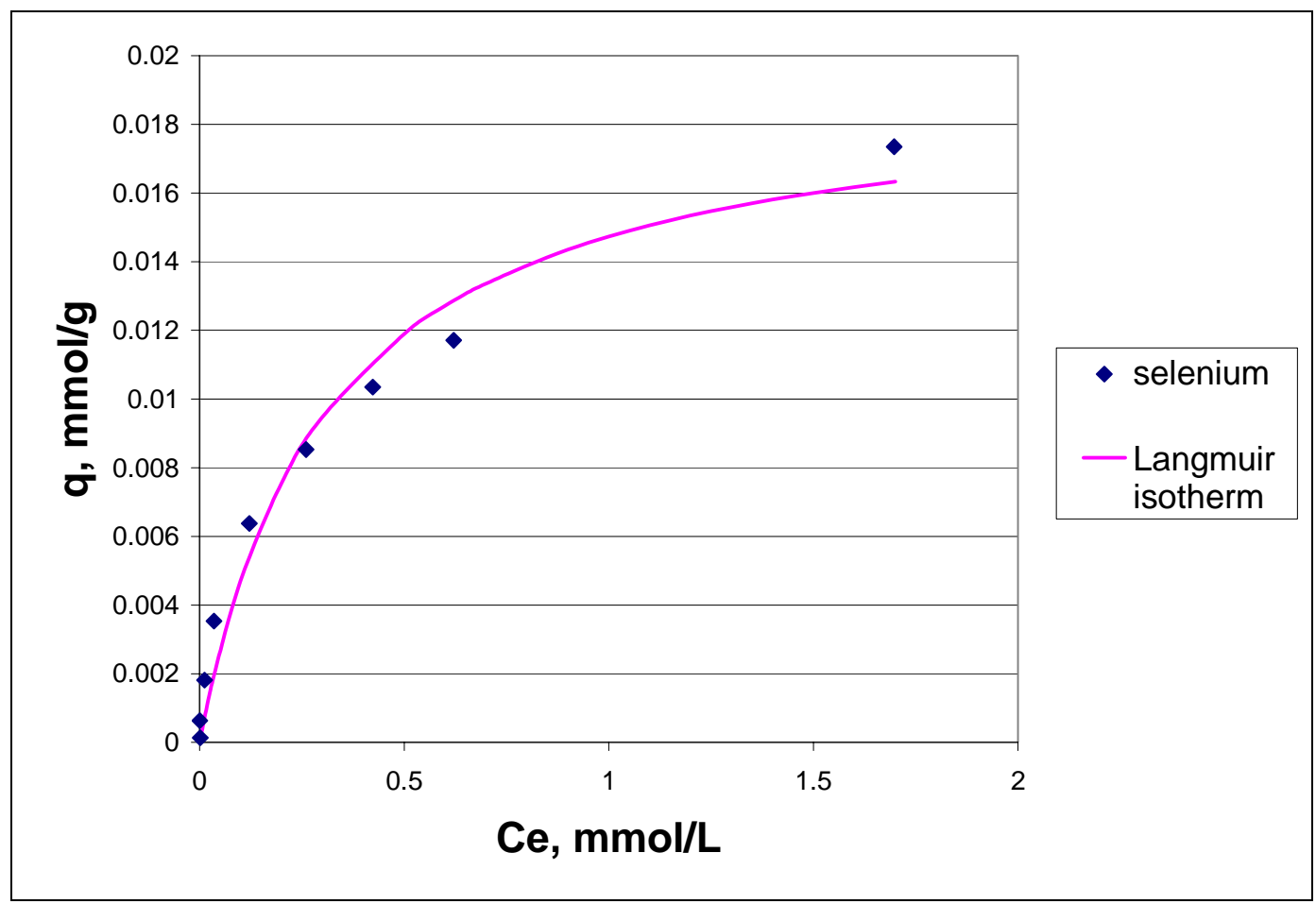

Figure 4.5 Selenium isotherm and Langmuir isotherm fit in synthetic saline solution at pH 7.2.

A comparison of the sorptive characteristics of chromium and selenium suggests that chromate sorbs preferentially to SMZ. Chromate, with $\mathrm{pKa}_{1}=0.74$ and $\mathrm{pKa}_{2}=6.49$, is primarily a divalent ion at $\mathrm{pH}$ 7.2. Selenate on the other hand is a monovalent ion at $\mathrm{pH}$ $7\left(\mathrm{pKa}_{1}=1.7\right)$. This would indicate that the more charged species have greater affinities for the surfactant bilayer. This is confirmed by Langmuir isotherms describing chromate and selenate sorption onto HDTMA-modified zeolite published by Haggerty \& Bowman (1994). They report sorption capacities for chromate and selenate to be 0.00360 and $0.00225 \mathrm{mmol} / \mathrm{g}$, respectively onto a surfactant bilayer. The difference in magnitude between these reported values and those obtained in this research could possibly be attributed to the background salinities of the respective solutions. This is in contrast to the findings of Li et al. (1998). They indicated that, although unexpected, the monovalent nitrate had a greater affinity for the surfactant bilayer. This was observed in this research for the chromium sorption edge data.

The greater affinity of chromate for SMZ was also apparent when a salt matrix was used. No selenium sorption was observed when the synthetic salt solution was used as a matrix. While similar reductions in sorption capacity were observed for for chromium, the effect on selenate was more pronounced. Although nitric acid was used to lower the $\mathrm{pH}$ in some samples, and some sulfate was present in the salt solution, the dominant competing anion was probably bicarbonate. This assumption is based upon the fact that there is 
approximately 500 times as much bicarbonate in the salt solution as sulfate, and any nitrate added was minimal in comparison to bicarbonate.

Barium was used in this study to model metal cation sorption because it was present in the produced water from Wyoming. No published data for barium sorption was found in the literature; however, previous research by Gupta demonstrated that approximately $91 \%$ percent of barium was removed from a produced water treated with SMZ.

A barium sorption edge was prepared in the synthetic salt solution. Thirty $\mathrm{mL}$ of $1.8 \mathrm{mM}$ $\mathrm{BaCl}_{2}$ was added to three grams of SMZ. Eight samples with $\mathrm{pHs}$ ranging from 3.5 to 10 were obtained by adding concentrated nitric acid and sodium hydroxide. Results are shown in Figure 4.6 Barium removal from produced water was hypothesized to occur as an ion exchange process, as the charge balancing calcium, potassium, and sodium ions leave the zeolite surface and enter solution. This represents the approximate $65 \%$ removal at low $\mathrm{pH}$ values. The increased removal efficiency at high $\mathrm{pH}$ must be the result of variable charge. Doula et al. (2002) investigated the removal of aqueous copper with zeolite. They attributed the increased removal of copper at high $\mathrm{pH}$ to adsorption to surface oxygen sites ( $\equiv \mathrm{Si}-\mathrm{OH}$ and $\equiv \mathrm{Al}-\mathrm{OH})$ and bridging oxygen sites $(\equiv \mathrm{Si}-\mathrm{OH}-\mathrm{Al} \equiv)$. As solution $\mathrm{pH}$ increases, $\mathrm{H}^{+}$ions desorb from these oxygen atoms, creating negatively charged adsorption sites. Um and Papelis (2003) confirmed these results with lead sorption onto zeolite. These authors also reported on the ionic strength dependency of cation sorption. At ionic strengths less than $0.1 \mathrm{M}$, adsorption was essentially complete $(100 \%)$ from $\mathrm{pH} 2$ to $\mathrm{pH} 9$. When the ionic strength was increased to $1 \mathrm{M}$, their sorption edge had the same inflection point as shown in Figure 4.6. They concluded that at low ionic strengths, there were enough cation exchange sites to completely remove all lead ions. At high ionic strengths, there are enough competing ions in solution that ion exchange to fixed charge sites can only account for partial lead removal. At $\mathrm{pH}$ values greater than 7, the additional sorption is attributed to adsorption to hydroxyl surface sites and surface precipitation. 


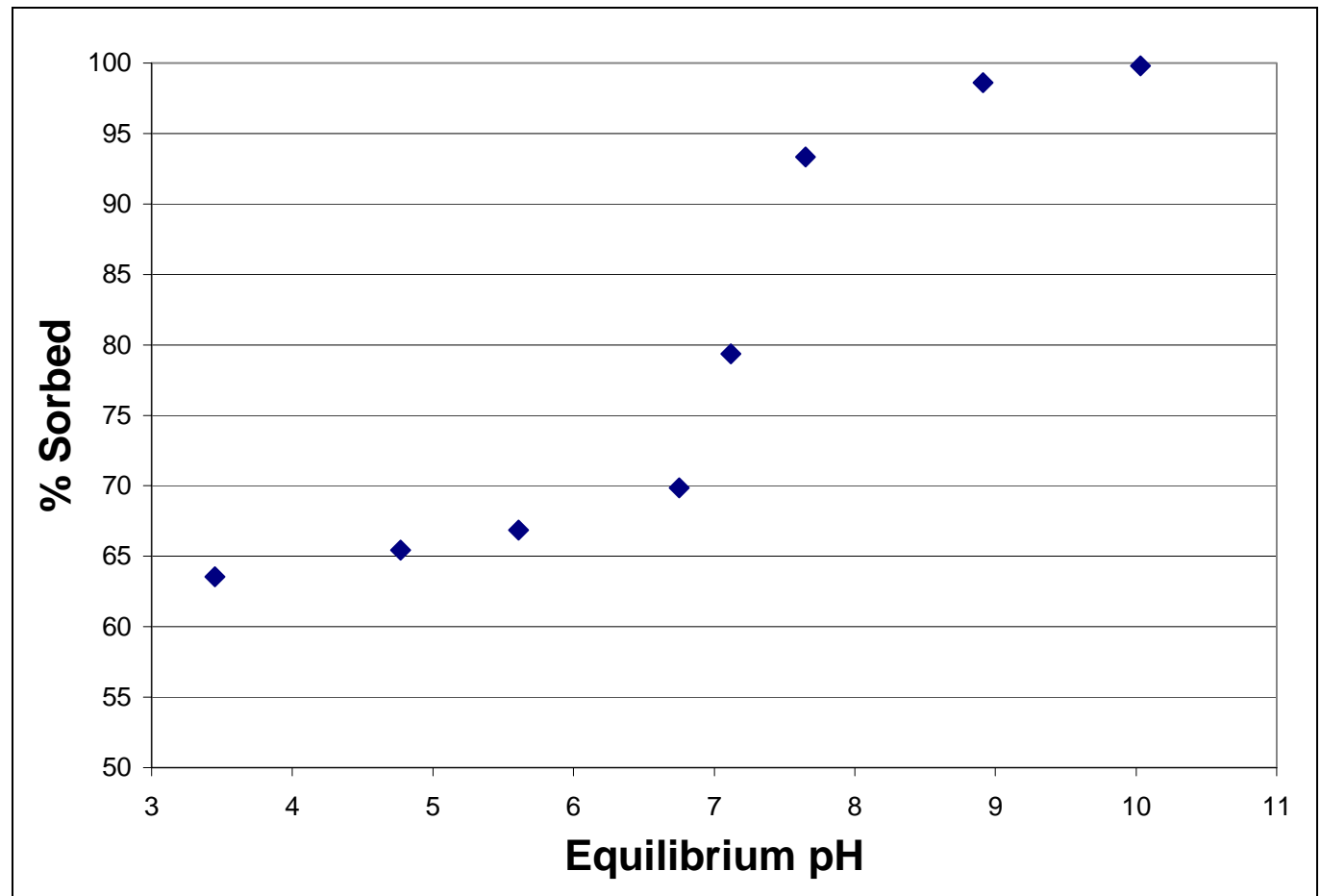

Figure 4.6 Barium sorption edge in a synthetic salt solution.

Barium isotherms were prepared by adding a range of initial barium concentrations to 30 $\mathrm{mL}$ vials containing a synthetic salt solution and either natural zeolite or surfactant modified zeolite. $\mathrm{pH}$ was held constant at 7.2 with nitric acid and sodium hydroxide. Figure 4.7 compares the results for the treated and untreated zeolite and Langmuir isotherm parameters were obtained from the data. The Langmuir parameters for the natural zeolite were $\mathrm{q}_{\max }=0.0225 \mathrm{mmol} / \mathrm{g}$ and $\mathrm{b}=2.909 \mathrm{~L} / \mathrm{mmol}$, and for the SMZ were $\mathrm{q}_{\max }=0.0214 \mathrm{mmol} / \mathrm{g}$ and $\mathrm{b}=2.277 \mathrm{~L} / \mathrm{mmol}$.

These results suggest that the modified zeolite had a slightly lower sorption capacity, although the differences do not appear to be significant. This indicates that the majority of barium sorption occured onto the internal exchange sites. Other metals, such as lanthanum and strontium have exhibited decreased sorption to modified zeolite, while sorption of other metals such as cesium and lead have proven to be unaffected by surfactant modification (Li et al. 2002). 


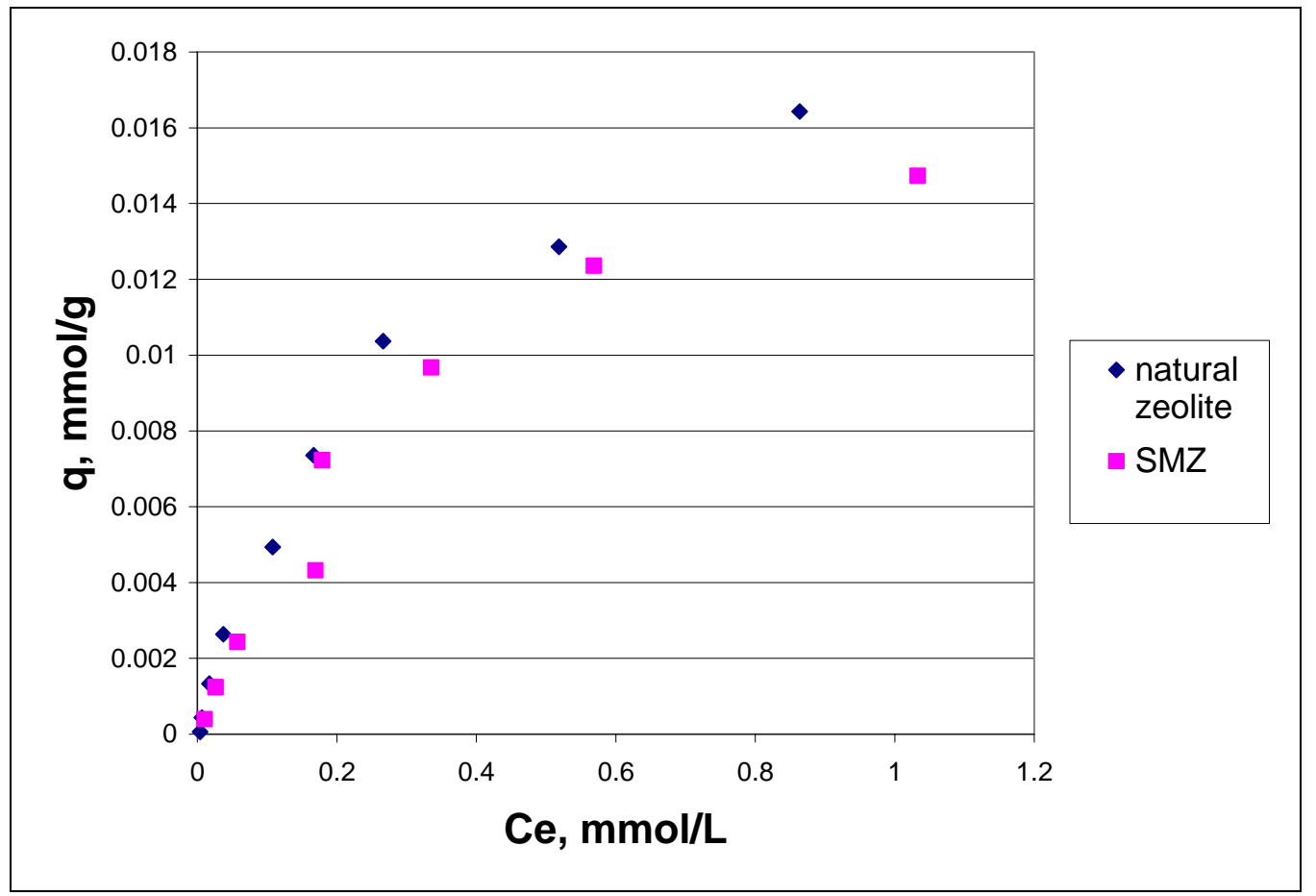

Figure 4.7 Comparison of barium sorption onto natural and modified zeolite in salt water at pH 7.2.

\subsection{Regeneration Laboratory Studies}

\subsubsection{Regeneration-Rate-Test (RRT) Experimental Results}

All four columns in the RRT experiments were fully and reproducibly saturated with BTEX. Figure 4.8 shows BTEX breakthrough on column RRT1. As expected, benzene, the least hydrophobic BTEX compound with the highest aqueous solubility and the lowest octanol-water partition coefficient, breaks through first. The other compounds elute in order of increasing hydrophobicity with ethylbenzene and the xylenes eluting at nearly the same time, as their similar Kow values would predict. Figure 4.9 shows the reproducibility of sorption for toluene and $p$ - and $m$-xylene.

The four RRT columns were then regenerated at airflow rates of $1.3 \mathrm{PV} / \mathrm{min}, 2.7 \mathrm{PV} / \mathrm{min}$, 5.0 PV/min, and 10 PV/min, respectively. Off-gas $p$ - and $m$-xylene concentrations, presented in Figure 4.10a as a function of time, show that, nearly all of the pand $m$-xylene was removed before $500 \mathrm{~min}$ at an airflow rate of $10 \mathrm{PV} / \mathrm{min}$. However, for an airflow rate of $1.3 \mathrm{PV} / \mathrm{min}$, similar removal required at least $1500 \mathrm{~min}$. When these data are viewed as a function of PV of air (Figure 4.10b), rather than time, we see that for earlytime regeneration, xylene concentration for the two highest flow rates $(10 \mathrm{PV} / \mathrm{min}$ and $5 \mathrm{PV} / \mathrm{min})$ is lower than the concentration for the two lowest flow rates $(1.3 \mathrm{PV} / \mathrm{min}$ and 


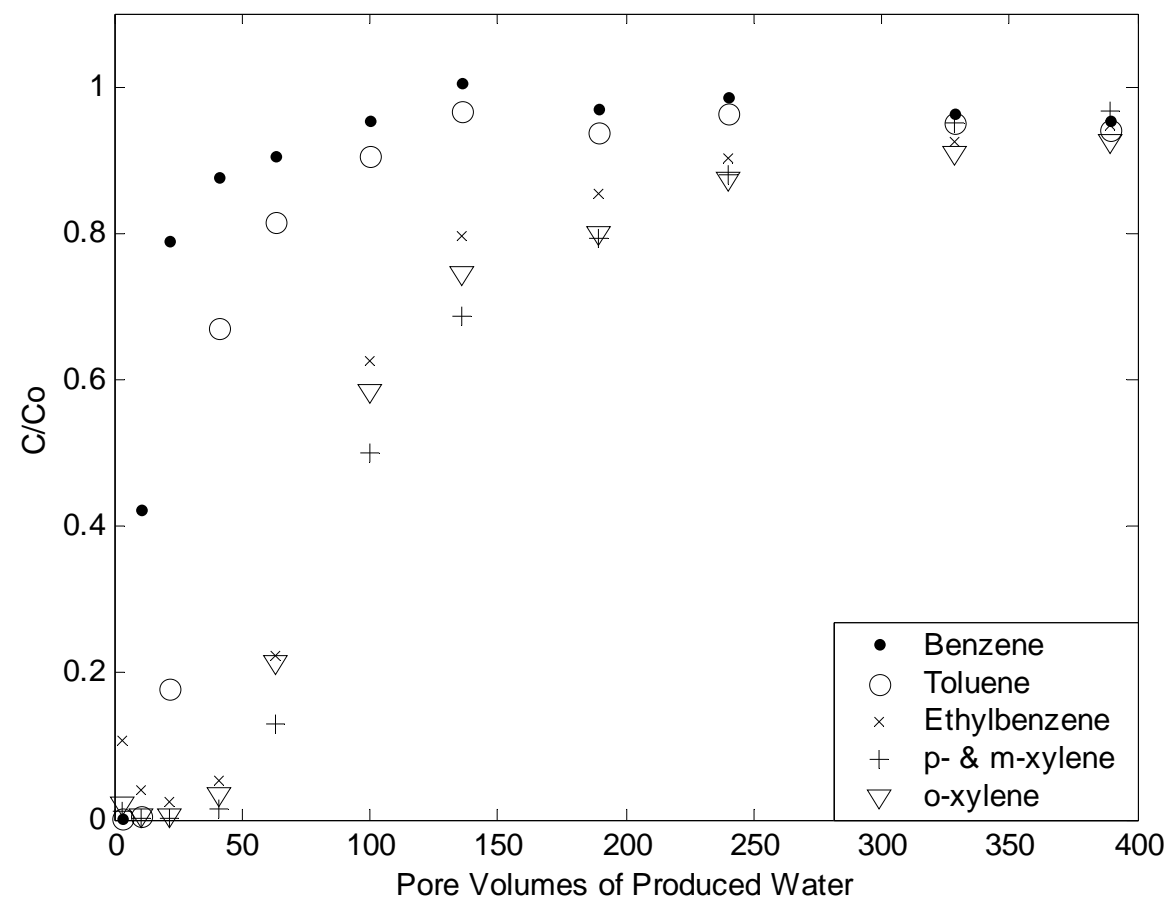

Figure 4.8 BTCs for BTEX compounds from RRT1

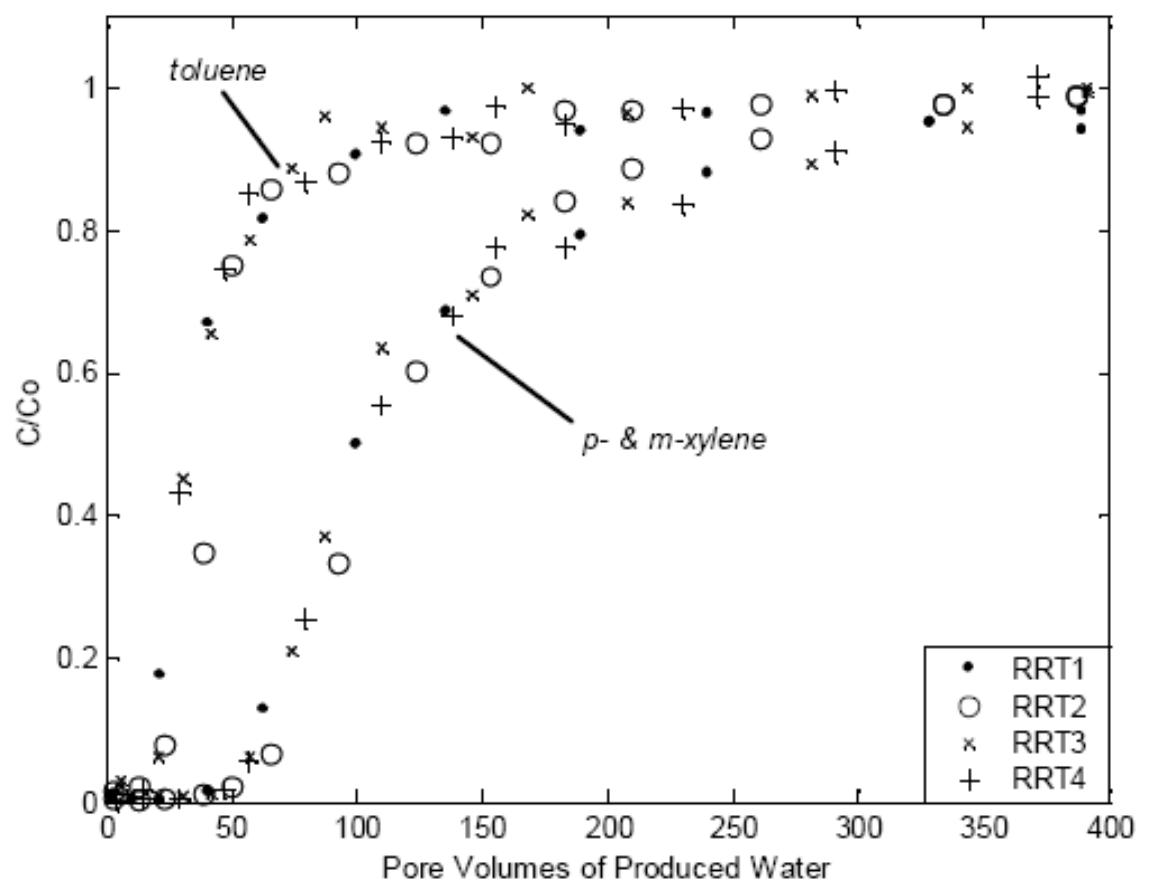

Figure 4.9 Reproducibility of BTCs for toluene and $p$ - and $m$-xylene on virgin SMZ 

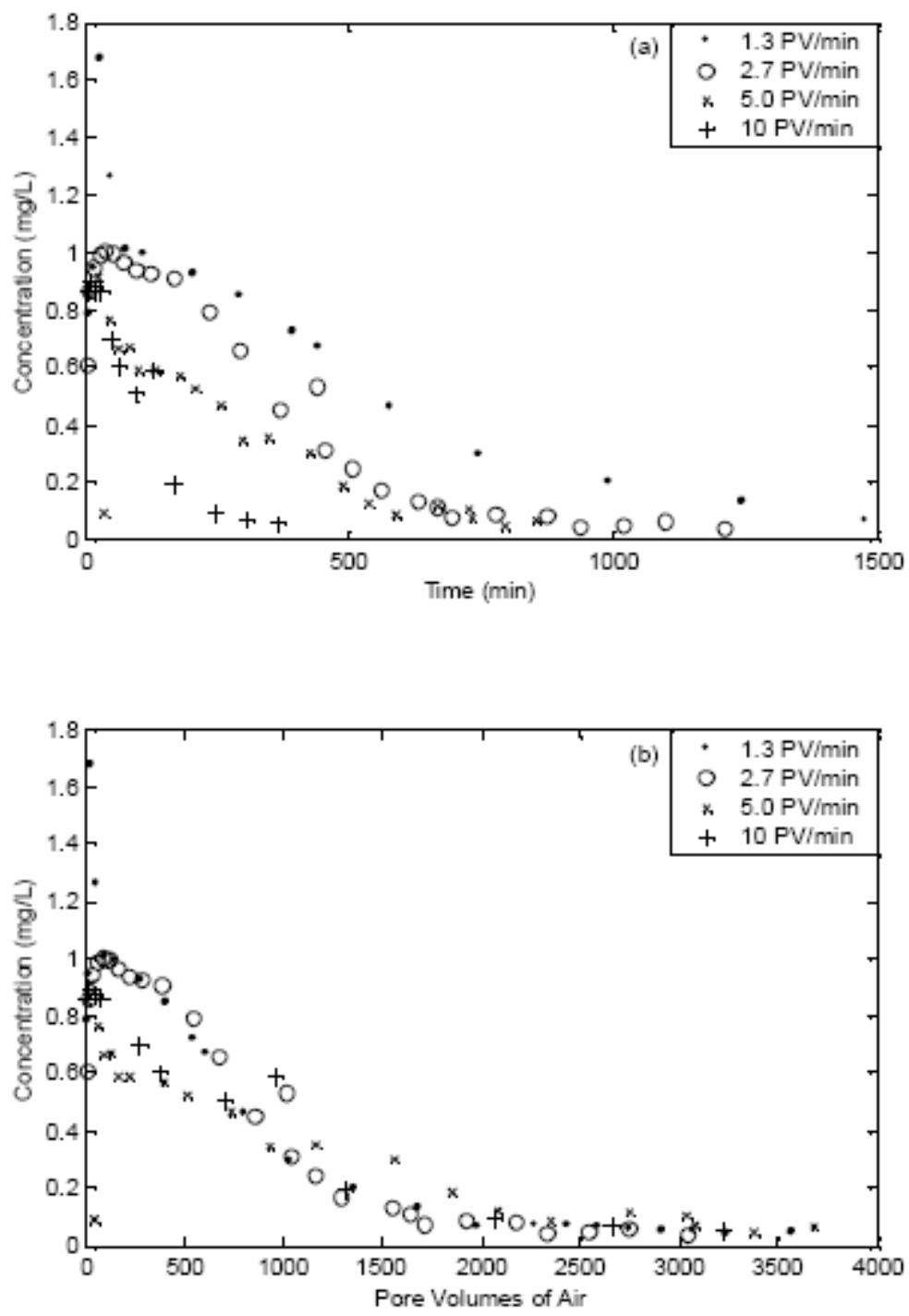

Figure $4.10 p$ - and $m$-xylene regeneration curves as a function of (a) time and (b) pore volumes of air. Columns RRT1, RRT2, RRT3, and RRT4 used airflow rates of 1.3 PV/min, 2.7 PV/min, 5 PV/min, and 10 PV/min, respectively.

2.7 PV/min). This is consistent with a kinetically-limited desorption mechanism for BTEX compounds during air sparging. However, nearly all of the $p$ - and $m$-xylene was removed after $2000 \mathrm{PV}$ of air, regardless of airflow rate. This suggests that kinetic effects did not play a large role in regeneration. The number of pore volumes of air required for regeneration can be predicted simply by knowing the volume of air that was pumped through the columns. Additionally, deviations in early-time removal may have been due 
to variations in the rate at which the column dried. No water was removed by gravity prior to regeneration, resulting in saturated conditions as each cycle began. As the column dried an increasing percentage of the BTEX-saturated SMZ surface was available for air stripping.

\subsubsection{Long Term Stability (LST) Experimental Results}

Tritium breakthrough curves (BTCs) from column LST1 for the virgin SMZ, after the 25 th regeneration cycle, and after the 50th regeneration cycle are shown in Figures 4.11a, $\mathrm{b}$, and c, respectively. These BTCs were well described by the 1-dimensional advection-dispersion equation:

$$
R \frac{\partial C^{*}}{\partial T}=\frac{1}{P} \frac{\partial^{2} C^{*}}{\partial X^{2}}-\frac{\partial C^{*}}{\partial X}
$$

where:

$$
\begin{gathered}
C^{*}=\frac{C}{C_{0}} \\
P=\frac{v L}{D} \\
R=1+\left(\frac{\rho}{\theta}\right) K_{d} \\
T=\frac{v t}{L} \\
X=\frac{x}{L}
\end{gathered}
$$

and $R$ is the retardation factor, $\mathrm{C} *$ is dimensionless solute concentration, $T$ is dimensionless time (pore volumes), $P$ is the Peclet number, $X$ is dimensionless length, $C$ is the effluent solute concentration $\left(\mathrm{ML}^{3}\right), \mathrm{c}_{0}$ is the influent solute concentration $\left(\mathrm{ML}^{-3}\right), v$ is the pore-water velocity $\left(\mathrm{LT}^{-1}\right), L$ is the column length $(\mathrm{L}), D$ is the dispersion coefficient $\left(\mathrm{L}^{2} \mathrm{~T}^{-1}\right), \rho$ is bulk density $\left(\mathrm{ML}^{-3}\right), \theta$ is volumetric water content, $K d$ is the linear equilibrium sorption constant $\left(\mathrm{L}^{3} \mathrm{M}^{-1}\right), t$ is time $(\mathrm{T})$, and $x$ is distance $(\mathrm{L})$. Equation 4.2 was fit to the tritium data using the nonlinear optimization program, CXTFIT2. 

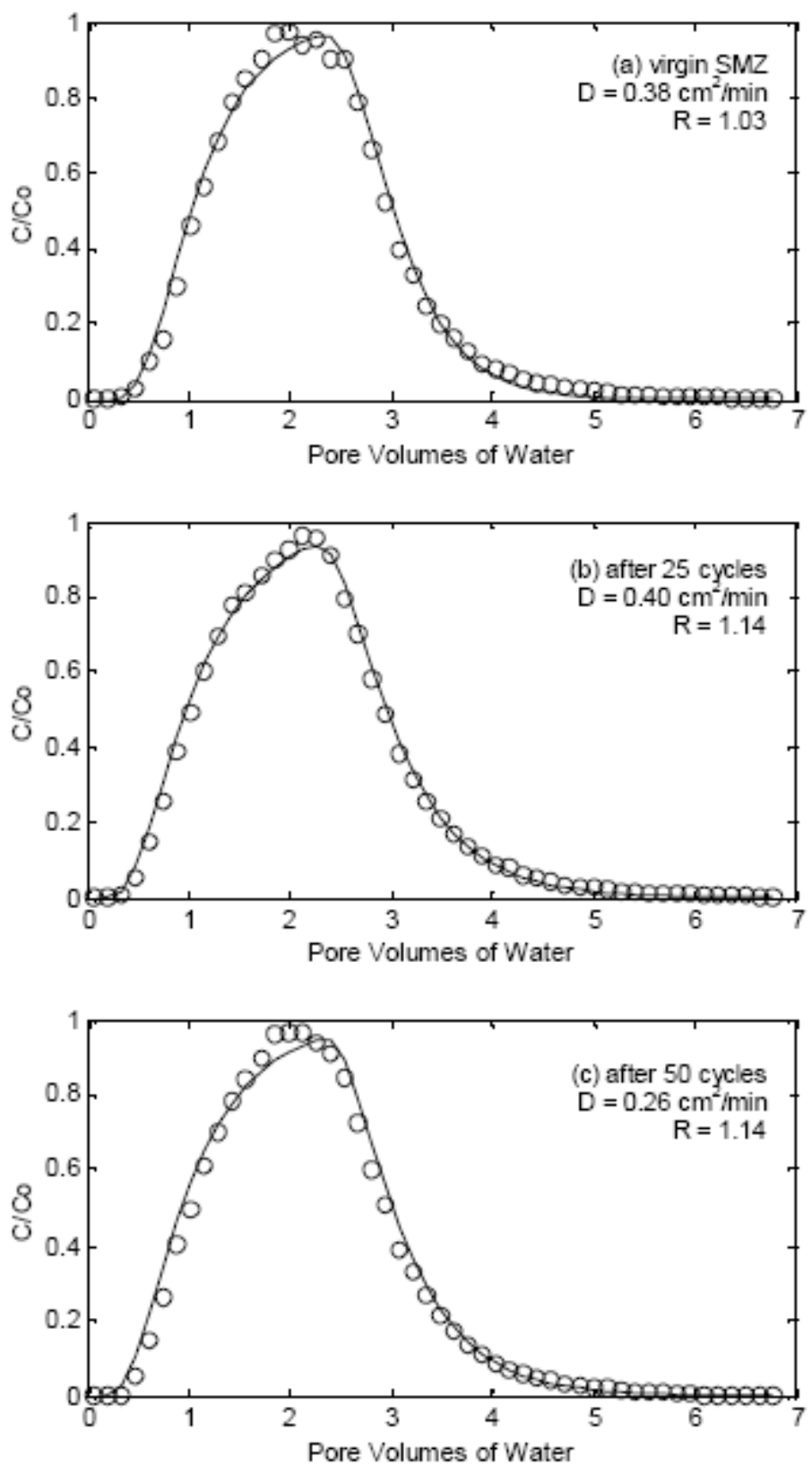

Figure 4.11 BTCs of tritiated water in column LST2 for (a) virgin SMZ and (b) after the $25^{\text {th }}$ regeneration cycle and (c) after the 50th regeneration cycle (Solid lines represent fitted values using an equilibrium advection-dispersion equation). 
A flux-type upper boundary and semi-infinite lower boundary condition were used, $v$ was treated as a known value, and $R$ and $D$ were fitted. As seen in Figure 4.11, a good fit was achieved with the equilibrium model. The fitted $D$ and $R$ values are shown in Table 4.5. No distinct trends were observed that would have indicated a change in the column hydraulic properties over time. The fact that the tritium tracer is well described by Equation 4.2 suggests that physical nonequilibrium (presence of immobile water) was not a major factor for these column tests.

Table 4.5 Fitted $D$ and $R$ values for tritium tracer tests conducted on columns LST1 and LST2 for the virgin column, after the 25th regeneration cycle, and after the 50th regeneration cycle.

$\begin{array}{llcc} & \text { Column } & \frac{\mathrm{D}}{2} & \\ & \text { Virgin SMZ } & 0.46 & \\ \text { LST1 } & \text { after 25 cycles } & 0.73 & 1.02 \\ & \text { after 50 cycles } & 0.45 & 1.09 \\ & \text { Virgin SMZ } & 0.38 & 1.03 \\ \text { LST2 } & \text { after 25 cycles } & 0.40 & 1.14 \\ & \text { after 50 cycles } & 0.26 & 1.14\end{array}$

BTCs for benzene and $p$ - and $m$-xylene for every 5 th cycle on column LST1 are shown in Figures 4.12a and 4.12b. Figure 4.13 shows observed $p$ - and $m$-xylene breakthrough from the first sorption cycle on column LST1, as well as the fitted BTC using Equation 4.2. Clearly, the simple equilibrium advection-dispersion equation did not adequately describe the sorption of $p$ - and $m$-xylene on SMZ, indicating nonequilibrium processes were present. Similar trends were found during 50 cycles of sorption and regeneration for each of the other BTEX compounds. The presence of immobile water domains was ruled out by the tritium experiments. 

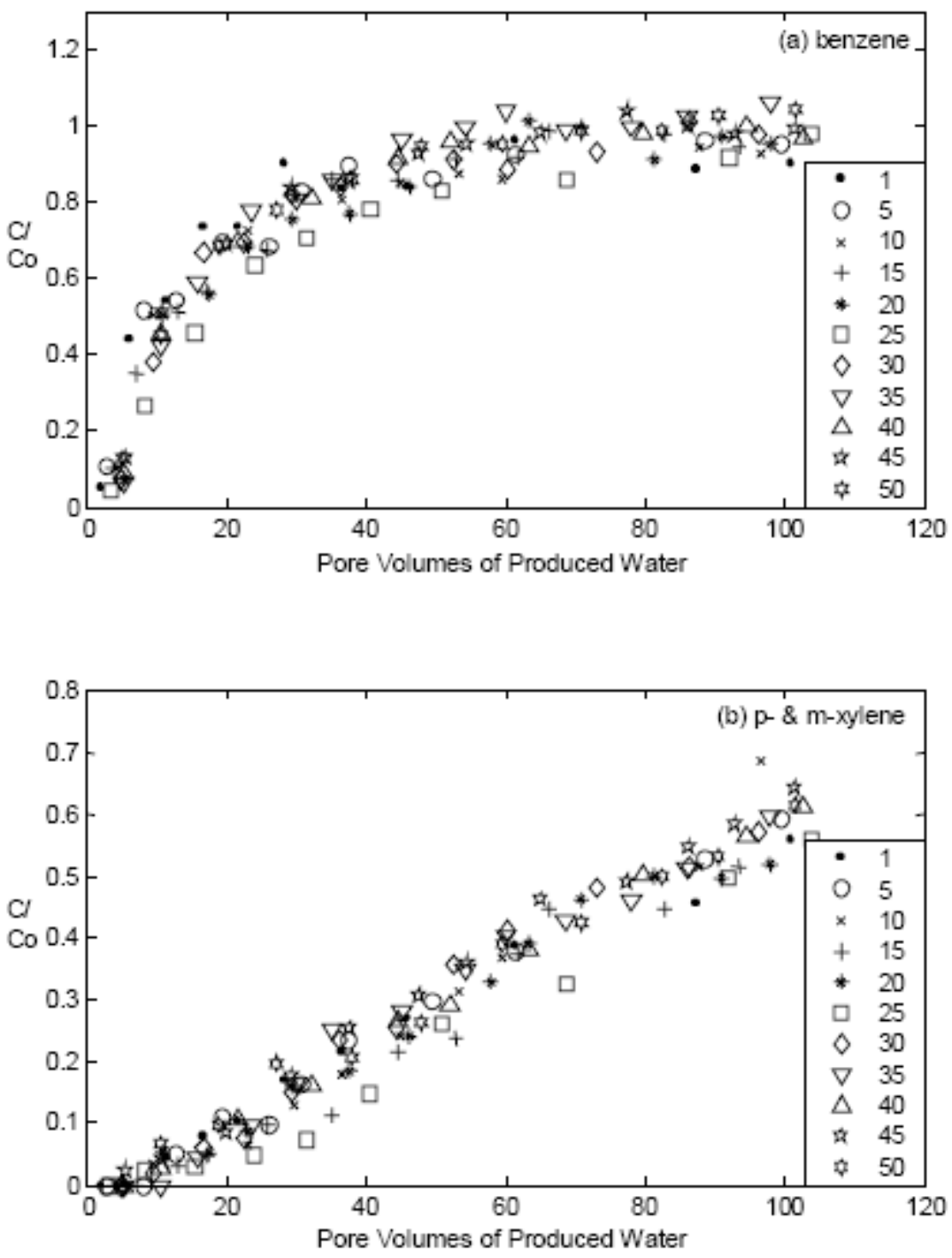

Figure 4.12. BTCs for every fifth sorption cycle on column LST1 for (a) benzene and (b) p- and m-xylene 


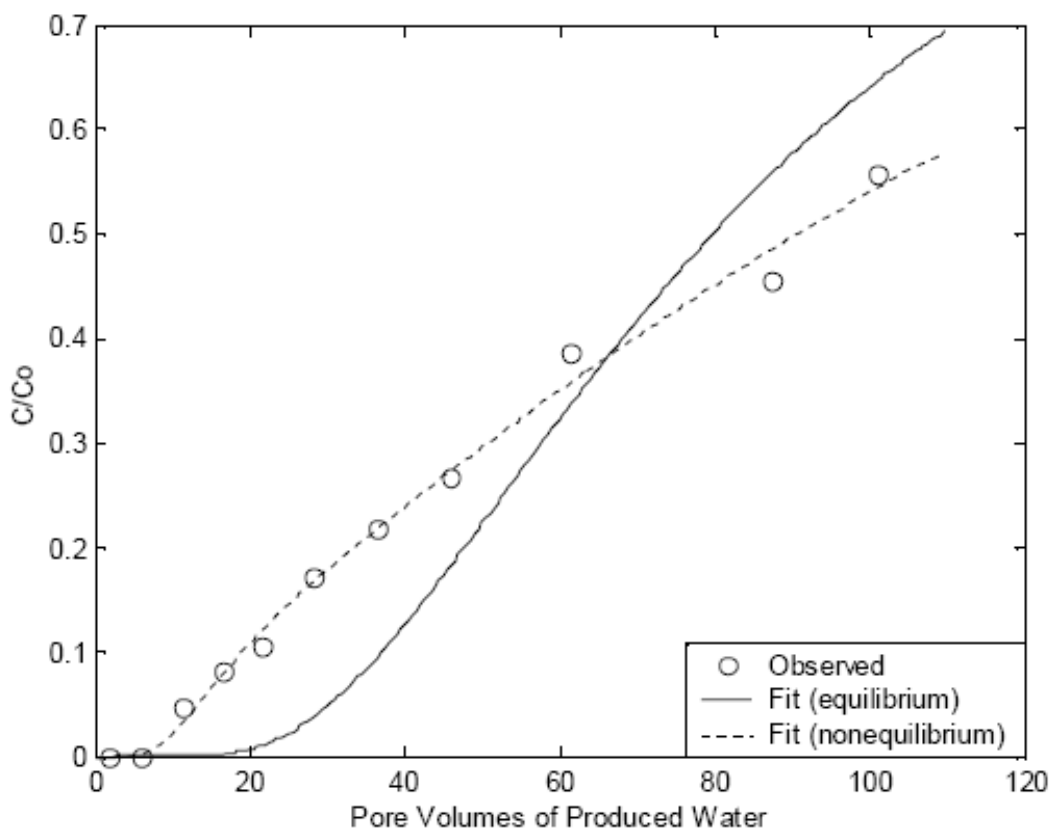

Figure 4.13 Observed and fitted BTCs of $p$ - and $m$-xylene for the first sorption cycle on column LST1. The solid line shows the fit using an equilibrium advectiondispersion equation while the dashed line shows the fit using a two-site chemical nonequilibrium advection-dispersion equation.

Chemical nonequilibrium may have occurred due to slow kinetics during the partitioning of BTEX compounds from the aqueous phase into the hydrophobic regions of the SMZ (Pignatello and Xing, 1996). Thus, a two-site chemical nonequilibrium advectiondispersion model was chosen based on Toride et al. (1995):

$$
\begin{gathered}
\beta R \frac{\partial C_{1}}{\partial T}=\frac{1}{P} \frac{\partial^{2} C_{1}}{\partial X^{2}}-\frac{\partial C_{1}}{\partial X}-\omega\left(C_{1}-C_{2}\right) \\
(1-\beta) R \frac{\partial C_{2}}{\partial p}=\omega\left(C_{1}-C_{2}\right)
\end{gathered}
$$

where:

$$
\begin{gathered}
\beta=\frac{\theta+f \rho K_{d}}{\theta+\rho K_{d}} \\
C_{1}=\frac{c}{c_{0}}
\end{gathered}
$$




$$
\begin{gathered}
C_{2}=\frac{s_{k}}{(1-f) K_{d} c_{o}} \\
\omega=\frac{\alpha(1-\beta) R L}{v}
\end{gathered}
$$

and subscripts 1,2 , and $k$ refer to equilibrium sites, nonequilibrium sites, and kinetic adsorption sites, respectively; $f$ is the fraction of sorption sites that are always at equilibrium, $s$ is the concentration of the adsorbed phase, and $\omega$ is a first-order kinetic rate coefficient $\left(\mathrm{T}^{-1}\right)$. Equations 4.8 and 4.9 were fit to the observed BTEX data using CXTFIT (Toride et al. 1995). A flux-type upper boundary and semi-infinite lower boundary condition were imposed, $v$ was treated as a fixed value, and $D, \beta$, and $\omega$ were fitted with the program. $K d$ for each BTEX compound was calculated for every analyzed sorption cycle using Equation 4.5 and the fitted value of $R$. Figure 4.14 shows the values of $K d$ plotted for benzene and $p$ - and $m$-xylene, respectively. The slopes for these best-fit lines, in addition to the best-fit lines for the other BTEX compounds, are shown in Table 4.6. A loss in sorptive capacity over time would be indicated by a decreasing trend in $K_{d}$ values as the number of sorption cycles increased. If sorption of BTEX on SMZ occurs via partitioning (Bowman et al. 1995; Neel and Bowman, 1992), it would be expected that a decrease in sorption capacity for one compound would be concurrent with a decrease in sorption capacity for all of the other compounds. As Table 4.6 shows, all of the slope values are negative. However, the p-values for the slopes calculated by the linear regression are greater than 0.05 in every case except on column LST1 for $o$-xylene, and on column LST2 for toluene and $p$ - and $m$-xylene. Thus, in every other case the slope is not significantly different than zero. Although there appears to be a trend of decreasing $K d$ with increasing number of sorption cycles, the trend is statistically weak.

Off-gas concentrations of toluene and $p$ - and $m$-xylene are shown in Figure 4.15 for each of the measured regeneration cycles on column LST1. Reproducibility of the regeneration experiments was excellent. Early-time variability in off-gas concentration was once again observed. This variability may indicate that the degree of water saturation of the column dictates early-time off-gas concentrations during regeneration. The hydraulic conductivity of the columns was measured after every fifth regeneration cycle. After the 25 th cycle, the conductivity of column LST1 had dropped to approximately $3 \%$ of the virgin-SMZ column. After 50 cycles both columns appeared to have lost $98 \%$ of their original conductivity. However, conductivity measured after the inlet and outlet frits were replaced showed that the columns had retained roughly $70 \%$ of their original conductivity, indicating the majority of the conductivity loss can be accounted for by clogging of the frits. 

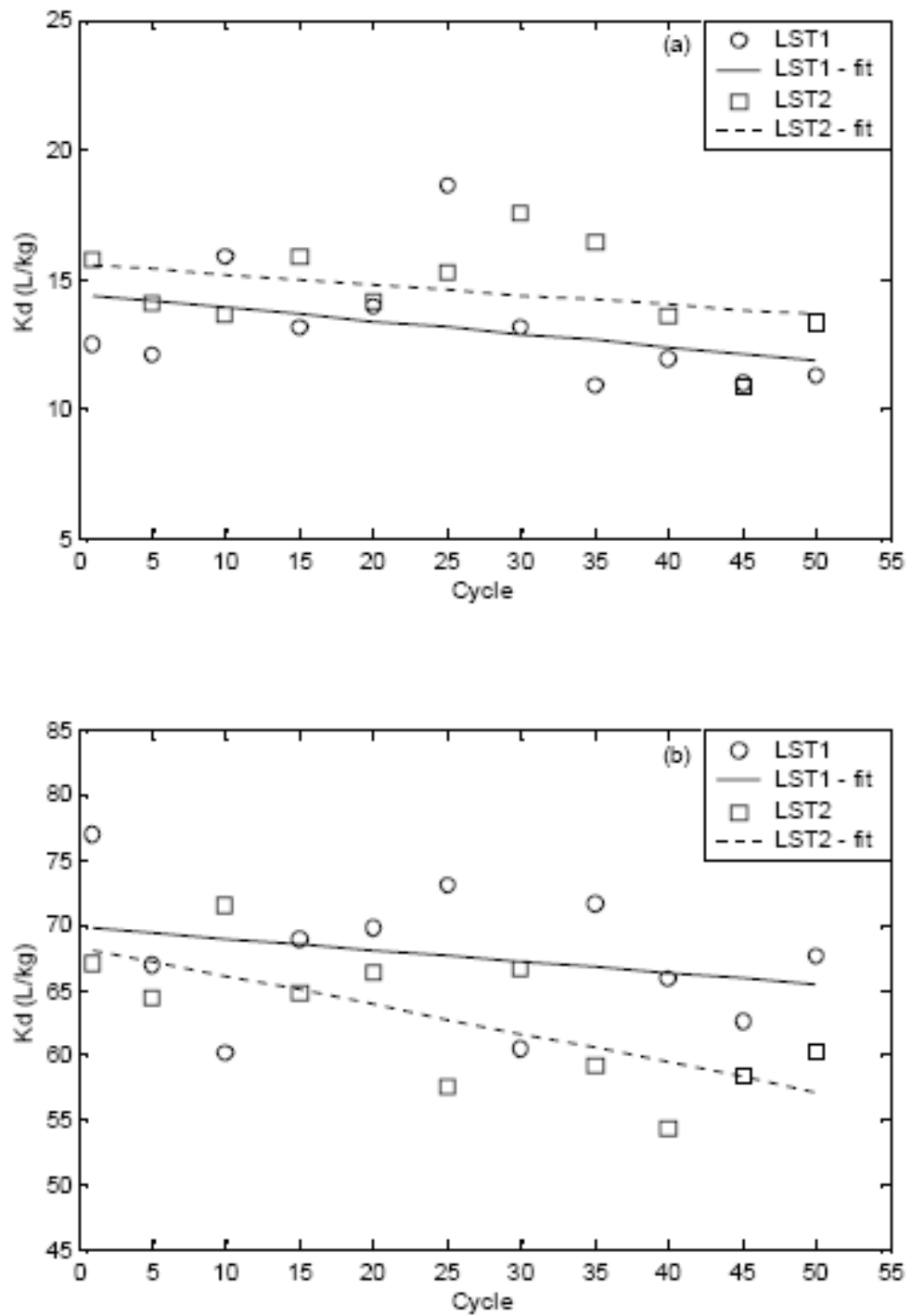

Figure 4.14 Distribution coefficients and lines fit to the Kd values for columns LST1 and LST2 for (a) benzene and (b) $p$ - and $m$-xylene. 
Final Technical Report

DE-FC26-02NT15461

Table 4.6 Impact of regeneration on BTEX distribution coefficients on SMZ

\begin{tabular}{|c|c|c|c|c|c|}
\hline & Benzene & $\underline{\text { Toluene }}$ & Ethylbenzene & $\frac{\text { p- \& m- }}{\text { xylene }}$ & o-xylene \\
\hline $\log \mathrm{K}_{\mathrm{ow}}{ }^{1}$ & 2.1 & 2.69 & 3.15 & $3 . \overline{15,3.20}$ & 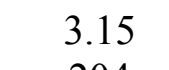 \\
\hline olubility $^{1}(\mathrm{mg} / \mathrm{L}) 25^{\circ} \mathrm{C}$ & 1850 & 470 & 140 & 200,173 & 204 \\
\hline
\end{tabular}

Column

\begin{tabular}{|c|c|c|c|c|c|c|}
\hline \multirow{4}{*}{ LST1 } & $\mathrm{K}_{\mathrm{d}}(\mathrm{L} / \mathrm{kg})$ & 13.1 & 31.8 & 67.6 & 67.7 & 64.6 \\
\hline & Std. Dev. & 2.3 & 3.9 & 7.8 & 5.2 & 9.3 \\
\hline & Slope $\left(K_{d} /\right.$ cycle $)$ & -0.05 & -0.03 & -0.27 & -0.09 & -0.36 \\
\hline & $p$-value & 0.27 & 0.72 & 0.08 & 0.41 & 0.04 \\
\hline \multirow{4}{*}{ LST2 } & $\mathrm{K}_{\mathrm{d}}(\mathrm{L} / \mathrm{kg})$ & 14.6 & 29.4 & 62.7 & 62.8 & 62.9 \\
\hline & Std. Dev. & 1.8 & 3.3 & 4.6 & 5.2 & 5.1 \\
\hline & Slope $\left(K_{d} /\right.$ cycle $)$ & -0.04 & -0.15 & -0.12 & -0.22 & -0.16 \\
\hline & $p$-value & 0.30 & 0.01 & 0.20 & 0.02 & 0.11 \\
\hline
\end{tabular}

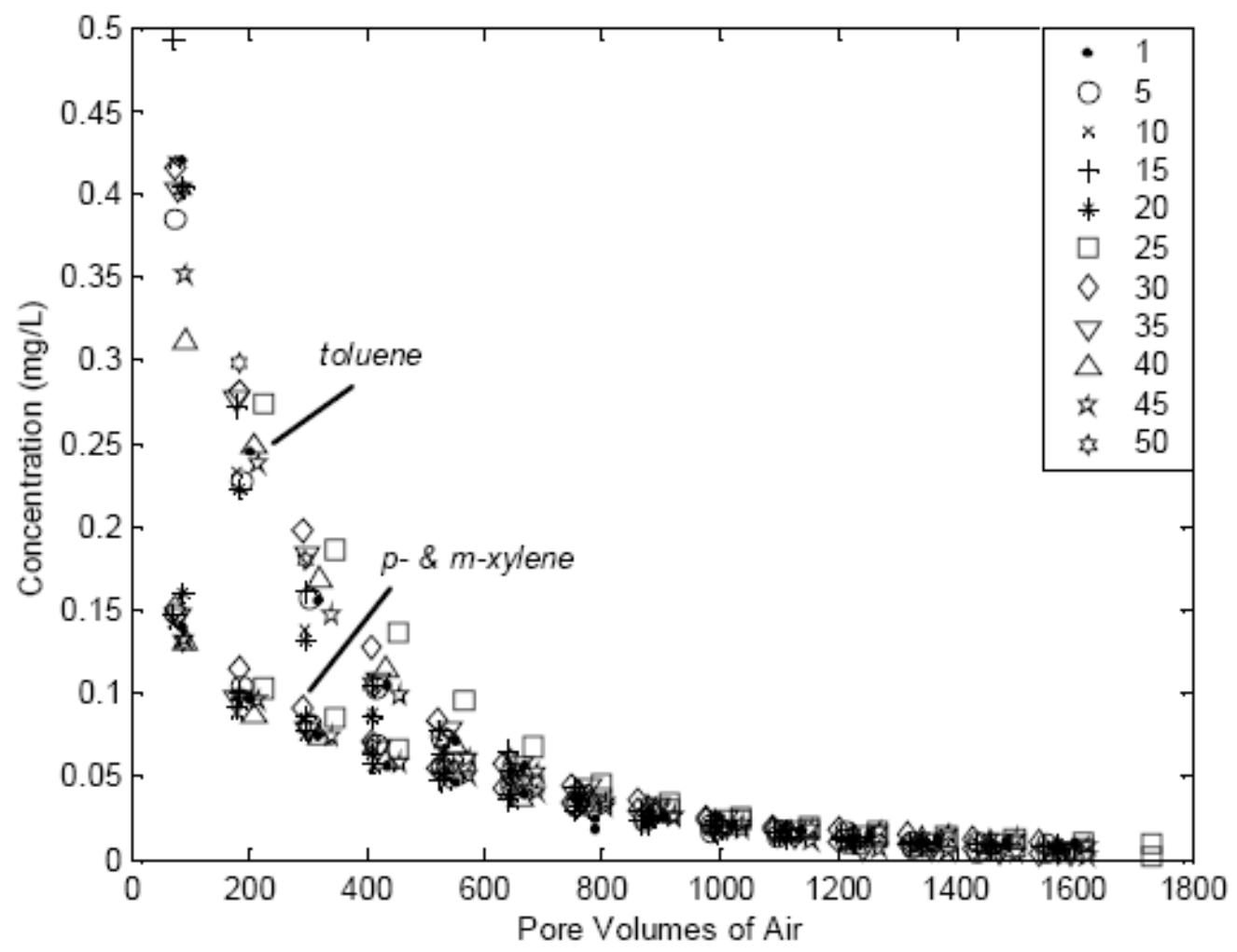

Figure 4.15 Vapor-phase concentrations of toluene and $p$ - and $m$-xylene over 50 regeneration cycles on column LST1. 
Several factors could account for the remaining 30\% loss in hydraulic conductivity, among them particle attrition, formation of coatings on the SMZ grains, and biofouling of the column. However, biological testing for the presence of DNA and/or proteins on the used SMZ was negative for both replicate columns. This rules out biofouling as a mechanism for hydraulic conductivity loss. As the LST column experiments proceeded, a distinct brown coloring of the zeolite particles was noted. Total digestion and compositional analysis of the used SMZ was conducted to determine whether the discoloration was due to precipitation of iron or manganese surface coatings on the SMZ. These analyses did not reveal any measurable increase in iron or manganese relative to virgin SMZ. SEM analysis also did not reveal the cause of the reduction in hydraulic conductivity.

Particle-size analysis conducted by the hydrometer method revealed a high amount of particle attrition. Virgin SMZ contained only $1.83 \%$ fines (smaller than $0.075 \mathrm{~mm}$ ) while the used SMZ from columns LST1 and LST2 contained $13.9 \%$ and $17.9 \%$ fines, respectively. Particle attrition appears to be the most likely cause of the observed hydraulic conductivity loss. Attempts were made to quantify the amount of surfactant lost from SMZ during the 50 cycles of the LST experiments. HDTMA concentration in the effluent water was measured using an HPLC method described by Li and Bowman (1997). The results of these attempts were confounded by a compound present in the influent produced water that had a similar elution time as HDTMA. Even though direct measurements of HDTMA loss were inconclusive, indirect evidence exists to infer the limits of surfactant wash-off. If HDTMA washed off such that the coverage on the zeolite surface was below monolayer coverage (below $90 \mathrm{mmol} / \mathrm{kg}$ ), pronounced decrease in sorption capacity would be have been observed. This was shown by Li and Bowman (1998), who observed that sorption of PCE on SMZ increased linearly as a function of surfactant loading rate up to the equivalent of monolayer loading capacity. Additional surfactant loading led to minimal increases in sorptive capacity for PCE (Li and Bowman, 1998). Since little to no loss in sorptive capacity was observed for the current study, it was presumed that surfactant loading remained, at a minimum, at the equivalent monolayer loading capacity throughout the LST experiments. It is expected, however, that some surfactant wash off occurred. Li et al. (1998) found that as much as $35 \mathrm{mmol} / \mathrm{kg}$ of HDTMA was lost from SMZ during a column test after only $90 \mathrm{PV}$ of solution had passed through the column. However, the resultant surfactant loading after the $35 \mathrm{mmol} / \mathrm{kg}$ wash off coincided with the equivalent monolayer coverage. Additional wash off was not observed. The fact that the monolayer coverage is more stable than bilayer coverage is expected considering the forces holding surfactant molecules to the zeolite surface (electrostatic interactions) are stronger than the forces holding the upper layer of surfactant to the lower layer (hydrophobic interactions) (Li et al. 1998). 


\subsection{Performance of VPB Under Steady Feed Conditions (Laboratory Scale)}

\subsubsection{Polyurethane Foam Biofilter}

Performance in the polyurethane biofilter stabilized after adjusting the nutrient supply system and mixing the packing media on Day 60. Maximum BTEX removal efficiencies of greater than $99 \%$ were achieved. Linear BTEX removal profiles were observed across the reactor immediately after the biofilter packing material was mixed on Day 60 (Figure 4.16a). However, as time passed, exponential BTEX removal profiles were observed with the greatest removals observed near the biofilter inlet where the biomass concentrations were the highest (Figures 4.16b and 4.17). Benzene and toluene, in particular, were almost completely degraded in the first section of the biofilter column. This type of removal profile is typical of an optimized biofilter system that is not nutrient limited and has not accumulated excess biomass.

After four months of continuous operation treating a $130 \mathrm{ppm}_{\mathrm{v}}$ BTEX feed, VOC removal across the biofilter declined slightly although the overall VOC removal remained above $95 \%$ (Figure 4.16c). Xylene removal was found to be the most sensitive to extended operational periods while toluene and ethylbenzene were the least sensitive, which is consistent with previously reported results of Deeb (2001). Throughout the 128 day study, leachate $\mathrm{pH}$ was maintained in the range of 6.3 to 7.2 due to the circulation of a buffered nutrient solution ( $\mathrm{pH}$ 6.35). Pressure drops less than 0.01 inches of water were observed throughout the operation, indicating that polyurethane foam materials have excellent properties for preventing bed clogging.

The experiments conducted with the lab-scale biofilter packed with polyurethane foam (synthetic media) and provided a steady supply of VOCs indicate that this system can achieve high BTEX removal efficiencies once the nutrient delivery system is optimized. The xylene isomers were found to require the greatest biofilter bed depth for removal over long term operation indicating that these VOCs could ultimately control the size of the biofilter needed in a field application. Neither bed acidification nor significant pressure drop was observed after four months of operation indicating that the polyurethane foam biofilter has the potential to be used in field application. However, frequent nutrient addition was required to maintain performance $-\mathrm{a}$ fact that would be cumbersome at some field applications where minimal operating support is provided. 
(A)

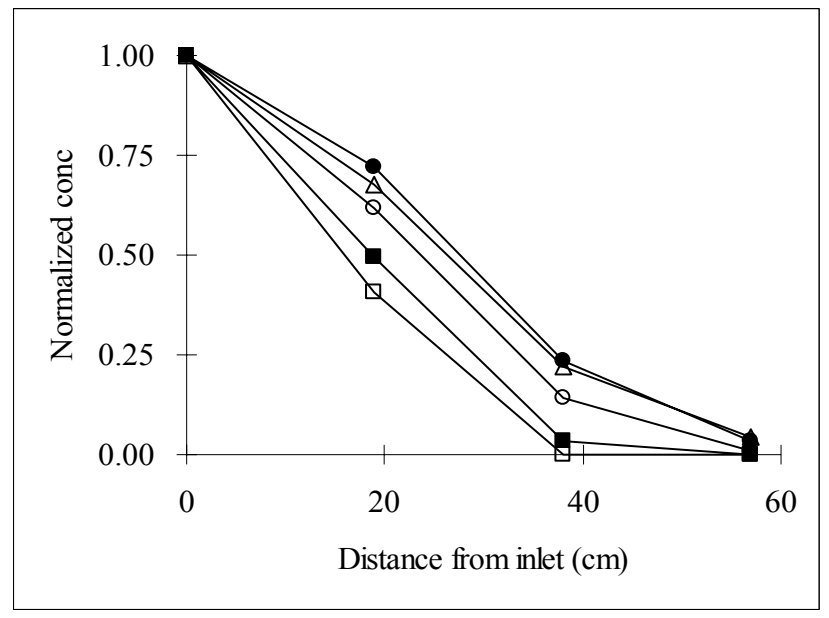

(B)

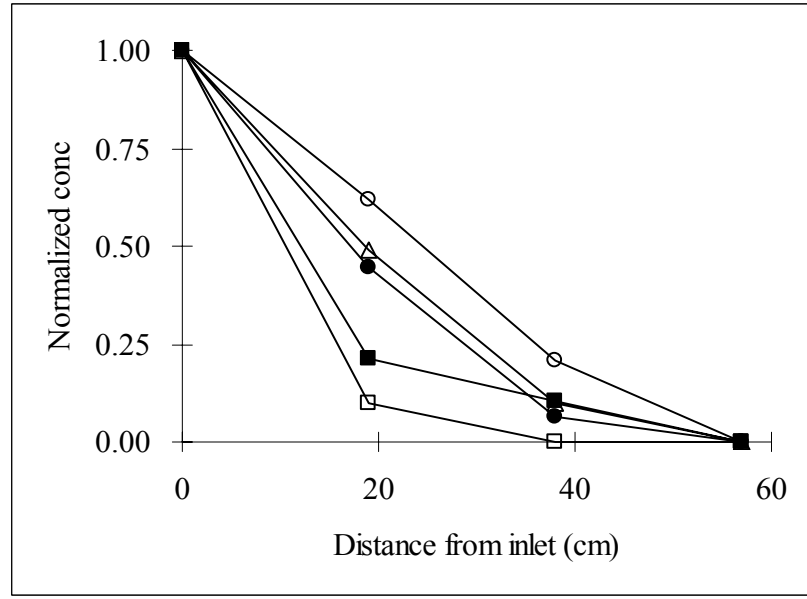

(C)

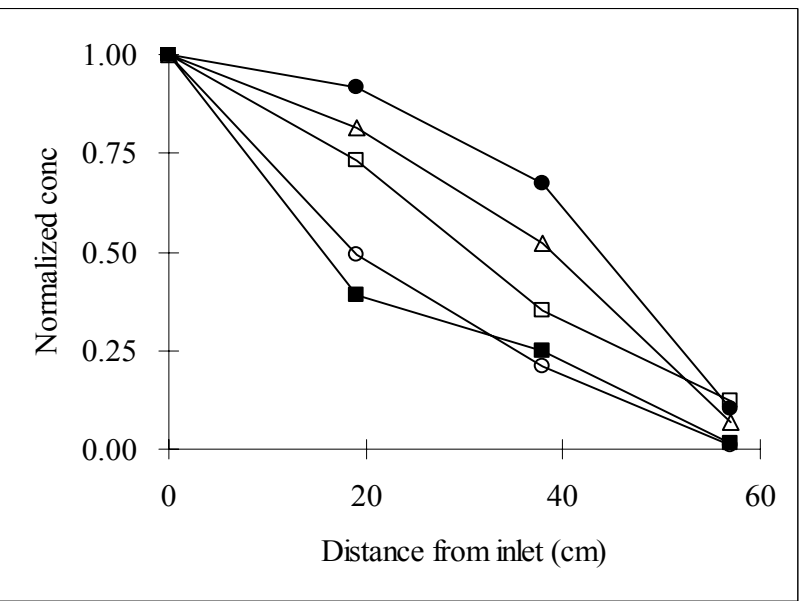

Figure 4.16. Normalized VOC removal profiles along the foam biofilter column on (A) Day 63, (B) Day 73, and (C) Day 128. ( $\square$; Benzene, $\square$; Toluene, $\circ$; Ethyl benzene, $\bullet$; p\&m xylene, $\Delta$; o-xylene) 


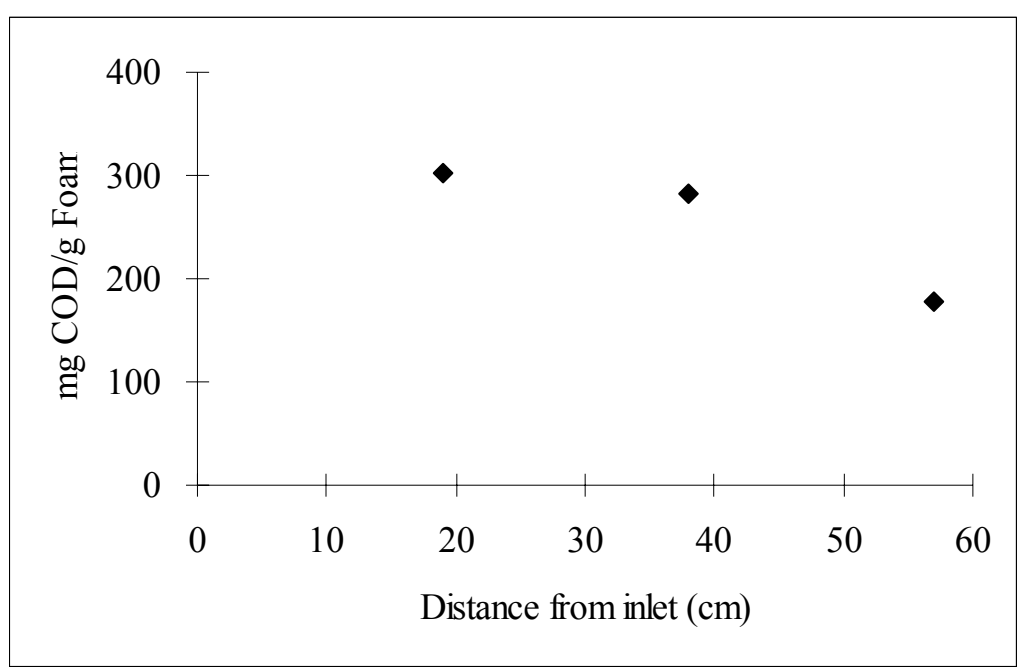

Figure 4.17 Total biomass accumulation as determined by COD measurements along the foam biofilter column on Day 88 of operation.

\subsubsection{Compost Biofilter}

The compost biofilter was operated for over 450 days, and continuously provided 130 $\mathrm{ppm}_{\mathrm{v}}$ of BTEX except for the following two test periods: (1) periodic shutdown tests on Days 26 - 47 and (2) spike feeding tests on Days 117 - 202. Within two weeks of starting the VOC feed to the biofilter, the compost biofilter achieved greater than $98 \%$ removal of the BTEX contaminants in the waste gas stream. This start up period compares favorably with that observed in the polyurethane foam biofilter which required more than a month and several adjustments to the nutrient feed system before high BTEX removals were achieved. Initially, the BTEX removal profiles along the compost biofilter column were rather linear as evident in Figure 4.18a. However, the removal profiles improved over time and eventually became exponential indicating that the biofilter removal had stabilized (Figure 4.18b). 
(A)

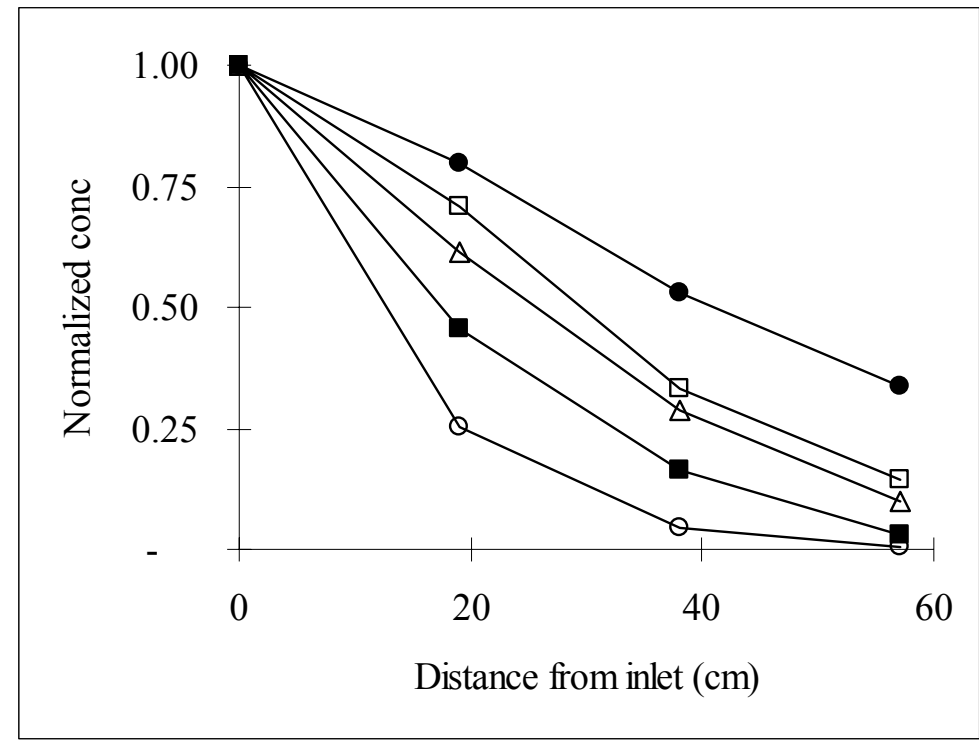

(B)

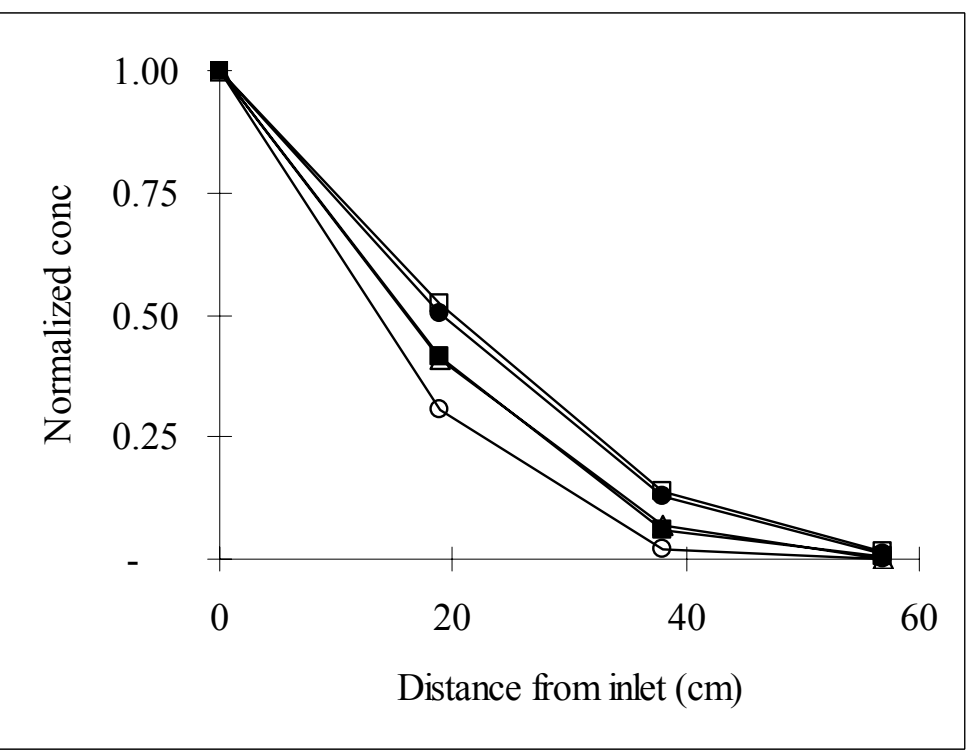

Figure 4.18 Normalized VOC removal profiles along the compost biofilter column on (A) Day 9 and (B) Day 19. ( $\square$; Benzene, $\square$; Toluene, $\circ$; Ethyl benzene, $\bullet$; p\&m xylene, $\Delta$; o-xylene)

One potential advantage of a compost biofilter over a polyurethane foam biofilter is that it may require less frequent nutrient additions to maintain biofilter performance. Indeed, the compost biofilter investigated in this study was able to operate for extended periods without a frequent nutrient supply. Just prior to starting up the compost biofilter, a concentrated HCMM was mixed with the compost packing to increase the nutrient concentration of the media. The bioreactor maintained greater than $95 \%$ removal efficiency for over 40 days without an additional supply of nutrients (Figure 4.19). However, the nitrogen supply eventually became depleted and the removal dropped 
below $60 \%$. Due to the characteristics of the compost, addition of too much nutrient solution can result in compaction, channeling, and washout of media. For this reason, a small quantity $(440 \mathrm{~mL})$ of a concentrated HCMM solution was evenly distributed on the top of the column on Day 85. After the addition of the concentrated nutrient solution, the BTEX removal efficiency recovered rapidly and exceeded $99 \%$ within two days.

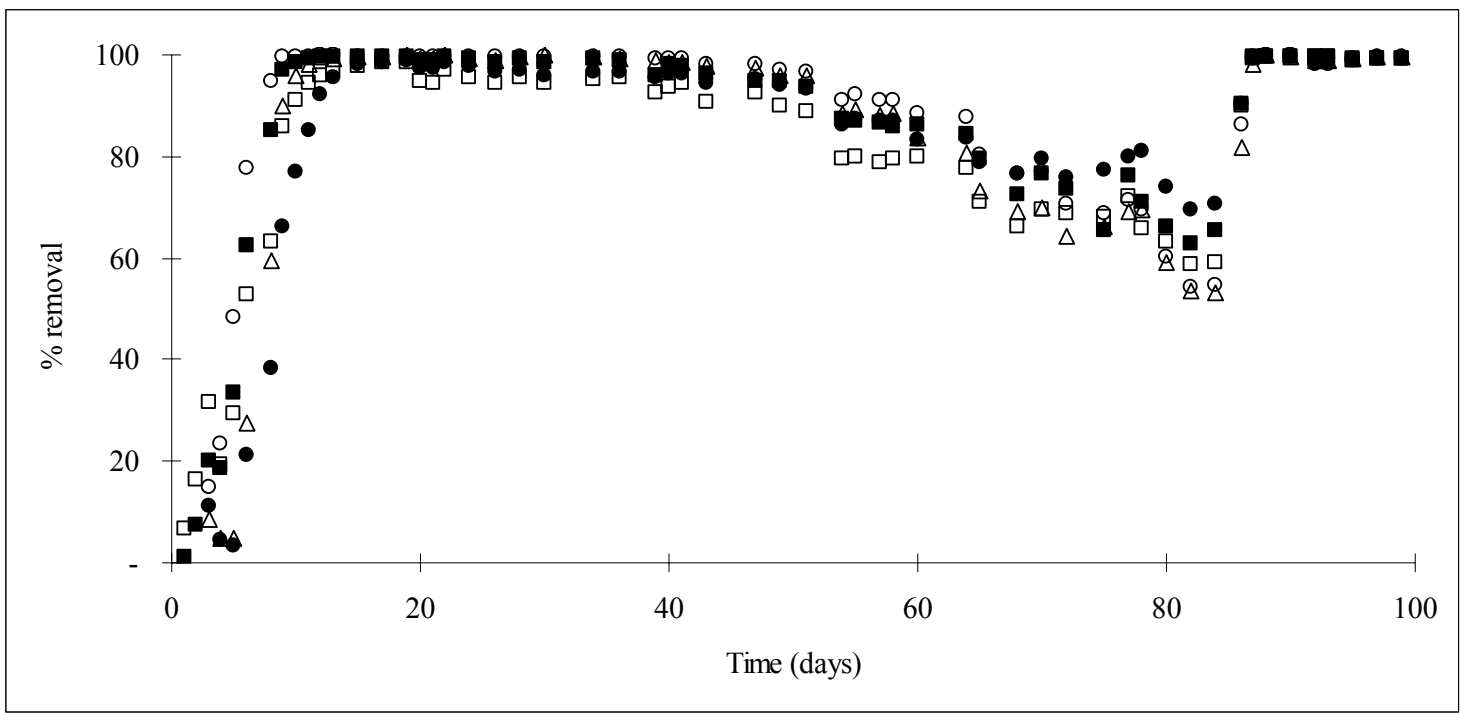

Figure 4.19 Effect of nutrient addition on BTEX removal efficiency in the compost biofilter. A concentrated nutrient solution was added on Day 85 of operation.

( $\square$; Benzene, $\square$; Toluene, $\circ$; Ethyl benzene, $\bullet$; $p \& m$ xylene, $\Delta$; o-xylene)

In addition to nutrient supply, another concern that must be addressed when designing the biofiltration system is the EBCT (Empty Bed Contact Time) that is required for the gas phase system since this will ultimately determine the size of the biofilter unit required. An experiment was therefore conducted to determine the effect of reducing the EBCT from 1 minute to 30 seconds. During the test, the inlet gas phase concentration was held constant at $130 \mathrm{ppm}_{\mathrm{v}}$ while the EBCT was decreased to 30 seconds. This change effectively increased the BTEX loading rate into the VPB from $32 \mathrm{~g} / \mathrm{m}^{3}-\mathrm{hr}$ to $64 \mathrm{~g} / \mathrm{m}^{3}-\mathrm{hr}$. As evident in Figure 4.20 below, halving the EBCT to 30 seconds reduced the BTEX removal efficiency. The BTEX removal fluctuated from 60 to $90 \%$ and more frequent nitrogen additions were required to maintain high BTEX removal. These results suggest that an EBCT greater than 30 seconds will be necessary to consistently maintain high BTEX removal efficiencies in a compost biofilter system if frequent nitrogen additions are to be avoided. 


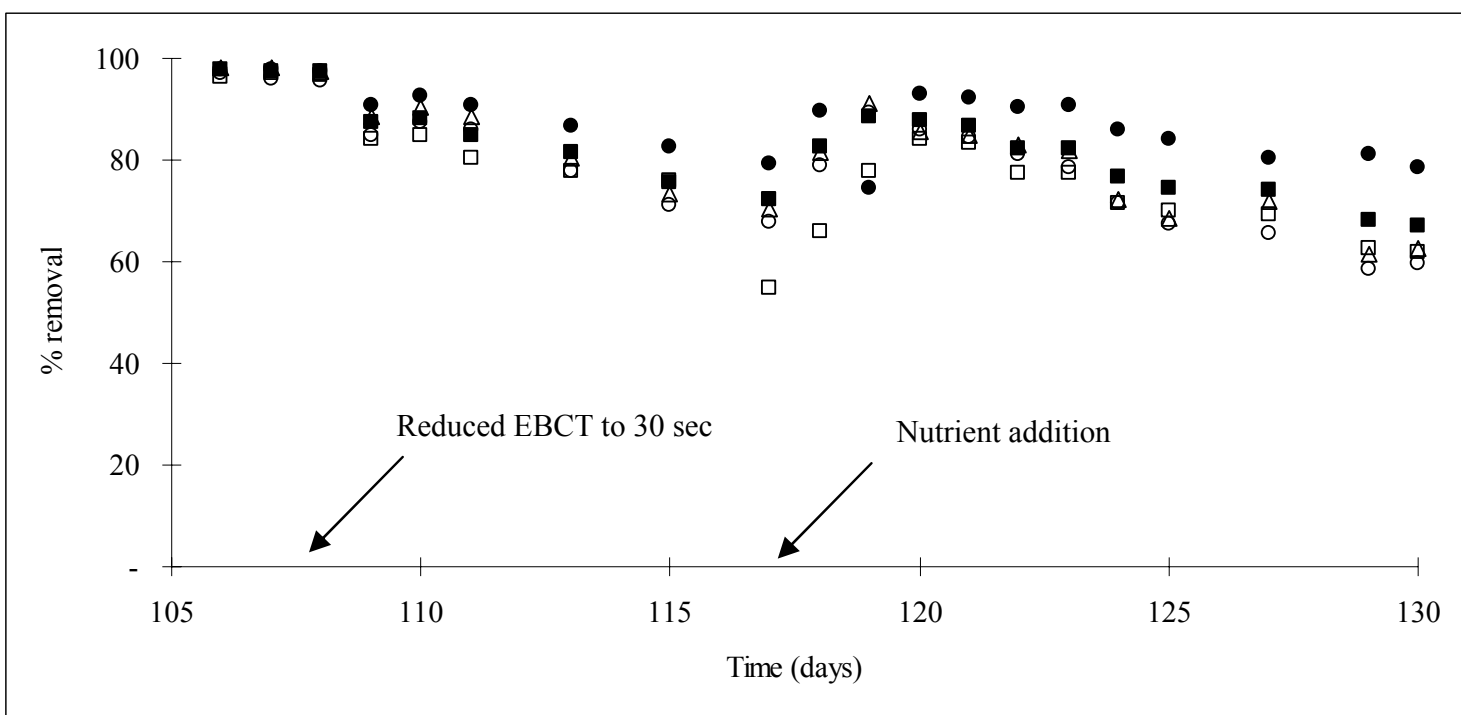

Figure 4.20 Response of the compost biofilter to reducing the gas-phase EBCT from 60 to 30 seconds. The total inlet BTEX concentration was maintained at $130 \mathbf{p p m}_{\mathrm{v}}$. ( $\square$; Benzene, $\square$; Toluene, $\circ$; Ethyl benzene, $\bullet$; p\&m xylene, $\Delta$; o-xylene)

Throughout the entire period of compost biofilter operation, leachate $\mathrm{pH}$ was maintained between 7.5 and 8.5, indicating that the oyster shell effectively worked as a pH buffer. Figure 4.21 shows the pressure drop across the compost biofilter throughout the 450 days of operation. Pressure drops less than 1.5 inches of water was observed for 250 days of operation. However, after the $6^{\text {th }}$ addition of nutrient solution (Day 262) to the top of biofilter, a gradual increase of pressure drop to 11.5 inches of water was observed. To prevent excessive head loss, it has been recommended that $60 \%$ (by weight) of the biofilter media be composed of particles greater than $4 \mathrm{~mm}$ in diameter (Corsi and Seed 1995). In this study, smaller compost particles $(>2 \mathrm{~mm})$ were mixed with the perlite bulking agent (36.5\% by volume) For long term operation of a compost biofilter, use of larger size compost materials and higher volumes of perlite is recommended to prevent compaction of the biofilter bed. When fresh compost-based material was mixed with existing packing media at an equal volume ratio (i.e., $1: 1$ ) on Day 426 to improve the porosity of bed, the pressure drop decreased to less than 0.5 inches, and high VOC removal efficiencies were once again achieved until the end of test (Day 450). 


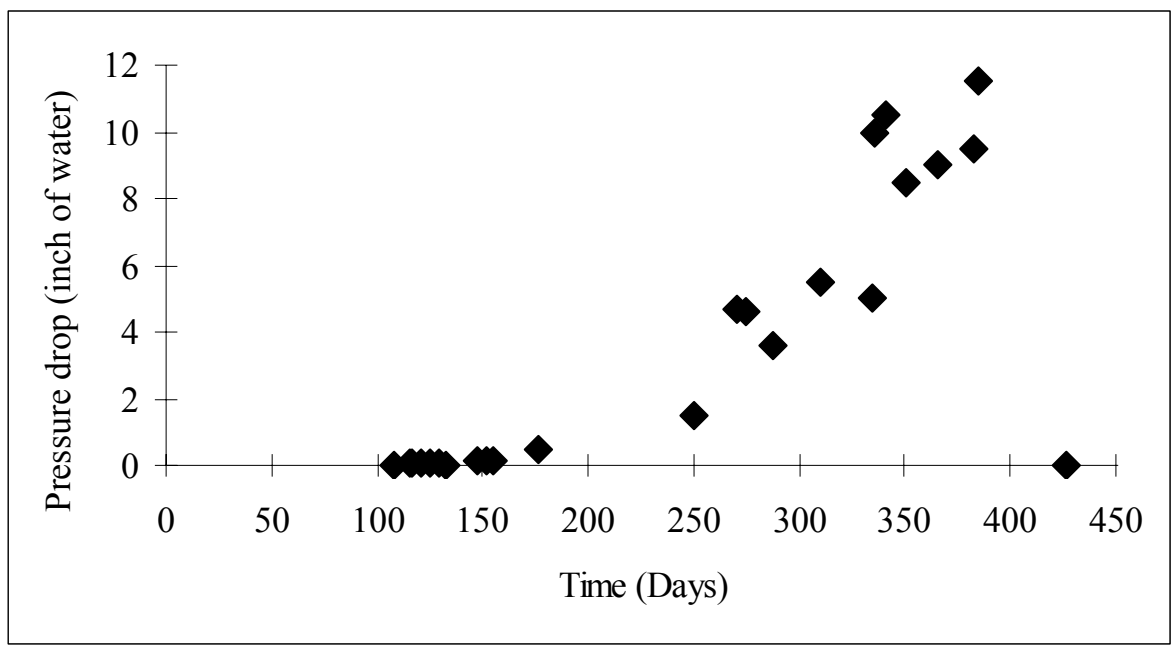

Figure 4.21 Pressure drop across the compost biofilter column

The experiments conducted with a lab-scale biofilter packed with compost based materials indicate that this system can achieve high BTEX removal efficiencies within two weeks of start up. Mixing of a concentrated nutrient solution during the start up of biofilter ensured high removals of BTEX for extended periods without external nutrient addition. No bed acidification was observed during the operating period due to the buffering provided by the oyster shell in bed.

However, the original nutrient supply present in the compost packing material was eventually depleted, and an external nutrient supply was necessary for long term operation. The frequency of nutrient addition required was much lower than that required by the polyurethane foam biofilter. The pressure drop across the compost bed is the main drawback of natural media, but this problem could be minimized by mixing inert media with the compost. Considering the fact that many of these treatment systems are located in remote areas where minimal maintenance is desired, the results indicate that a compost-based packing media may be a better choice than polyurethane foam.

\subsection{Performance of VPB under Variable Loading Conditions (Laboratory-Scale)}

\subsubsection{Periodic Shutdowns}

Biofilters packed with polyurethane foam or compost based materials can achieve high BTEX removals during continuous operation, as discussed above. However, one challenge to field application of biofilters is frequent system shutdowns. These shutdowns may result from unintentional maintenance problems or may be intentional as part of scheduled shutdowns resulting from the operating schedule of the facility. As compared to other physicochemical treatment systems, biological treatment systems are more sensitive to unsteady operation, since periods of carbon deprivation can affect biomass metabolism and result in a deterioration of biofilter performance. It was therefore necessary to investigate the response of biofilters to periodic system shutdowns 
to better delineate the operating range of biofilters and to understand the buffering levels that may be required to improve performance.

To this end, the foam biofilter used in the continuous operation tests described previously was periodically subjected to shutdown tests that ranged from 1 to 2.8 days in length. During each shutdown test, no VOCs were provided to the column but the air and humidity were supplied as usual. To ensure that the biofilter system stabilized between each shutdown test, the biofilter was supplied a $130 \mathrm{ppm}_{\mathrm{v}}$ BTEX mixture continuously for a period of three days following each shutdown test. The recovery of the biofilter following each shutdown test was monitored until the overall removal efficiency of BTEX in the biofilter exceeded 90\% (Figure 4.22).

(A)

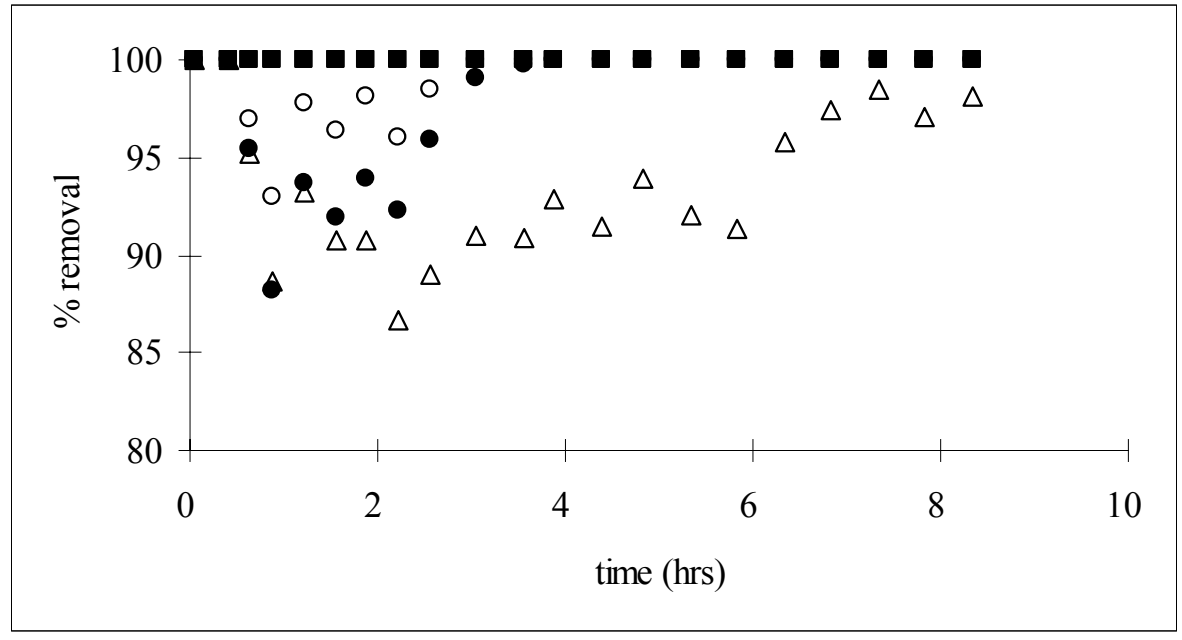

(B)

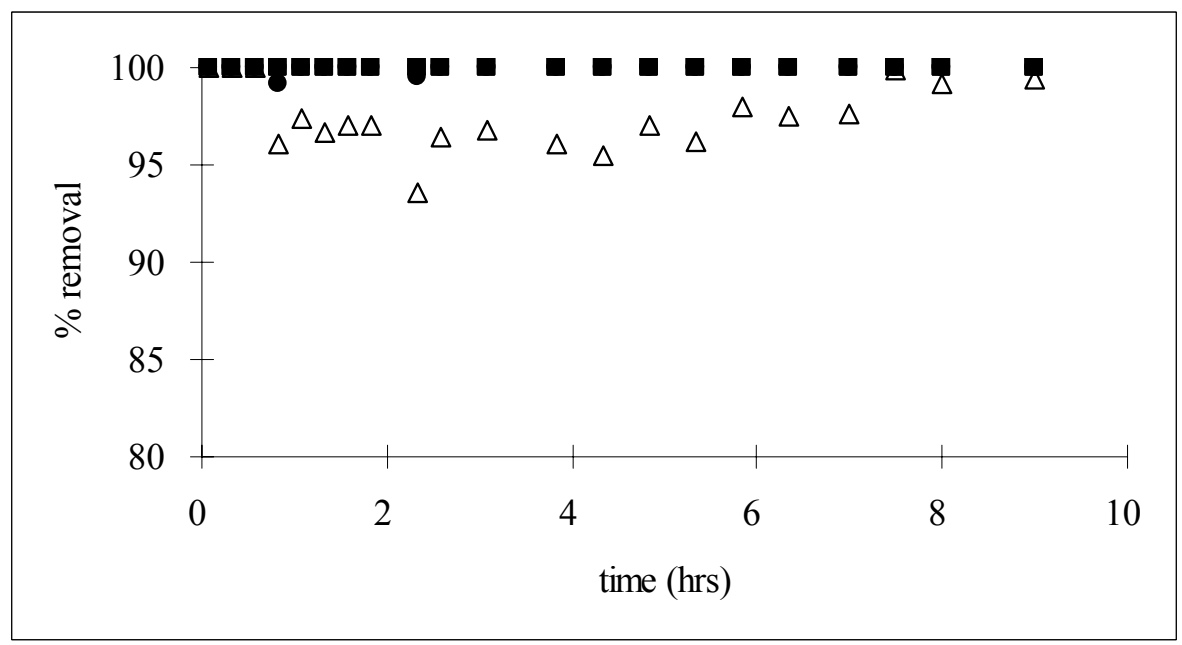

Figure 4.22 BTEX removal efficiency after a 24-hour shutdown period in the polyurethane foam biofilter. (A): $1^{\text {st }}$ shutdown, (B): $3^{\text {rd }}$ shutdown. ( $\square$; Benzene, $\square$; Toluene, $\circ$; Ethyl benzene, $\bullet$; $p \& m$ xylene, $\Delta$; o-xylene) 
Figure 4.22a shows the response of the foam biofilter after a one-day shutdown test in which the VOC feed to the column was interrupted for a 24 hour period. When the BTEX feed was resumed after the one-day shutdown period, a minimal effect on BTEX removal was observed and the BTEX removal efficiency in the biofilter recovered to preshutdown levels within 10 hours. The shutdown had the greatest effect on $o$-xylene removals which declined to $85 \%$ before recovering to $98 \%$. As evident in Figure $4.22 \mathrm{~b}$, the bioreactor response improved after several shutdown tests as the biomass in the system adapted to the short periodic feed cycle.

Figure 4.23 shows the response of the foam biofilter after a 2.8-day shutdown test which simulated an extended weekend shutdown period. A greater reduction in BTEX removal was observed following the 2.8-day shutdown test than was observed during the 1-day shutdown test, but the system again recovered full BTEX removal efficiency within 10 hours after the first shutdown. As in the previous experiments, xylene removal was detrimentally impacted by the 2.8 -day shutdown period. Benzene removal was also sensitive to the 2.8-day shutdown period in contrast to the one-day shutdown experiments which showed little effect on benzene removal. As shown in Figure 4.23b, the percent removal decreased in the subsequent shutdown tests indicating that repeated weekend long shutdowns cause deterioration in biofilter performance.

Figure 4.24 summarizes the results of the repeated one-day shutdown tests in the compost biofilter. In the 24 hour-shutdown test, benzene percent removal decreased to $84 \%$ and p\&m-xylene decreased below 95\%, but the removal of the other chemicals remained above 95\% removal (Figure 4.24a). However, the removal of benzene recovered quickly and within approximately 6 hours, the removal efficiency exceeded $95 \%$. These results indicate that a compost biofilter that has been provided a continuous VOC supply can handle short periods without a carbon source. The same one-day shutdown test was repeated several times to investigate the bioreactor response in periodic shutdowns. Figure $4.24 \mathrm{~b}$ shows the recovery of VOC removal efficiency after the $3^{\text {rd }}$ one-day shutdown test. Higher removal efficiencies for each of the BTEX constituents were observed following the third shutdown test than were observed following the first shutdown test. These results imply that the biomass in the compost biofilter can adapt well to short, repeated system shutdowns as was observed in the foam biofilter. 
(A)

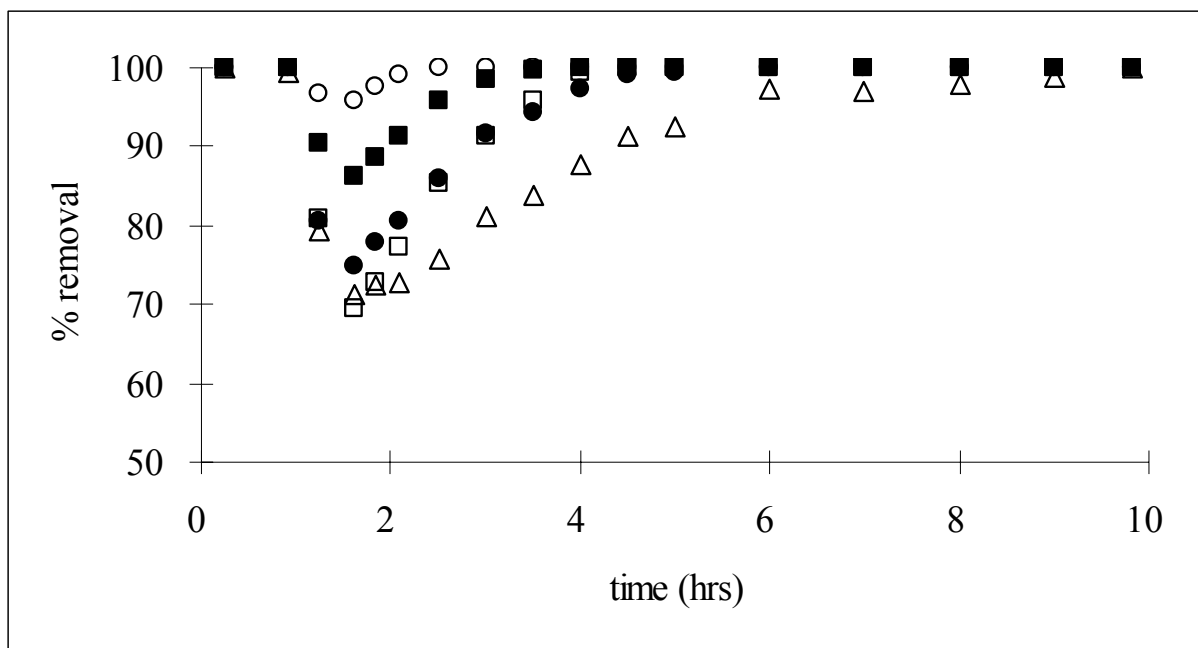

(B)

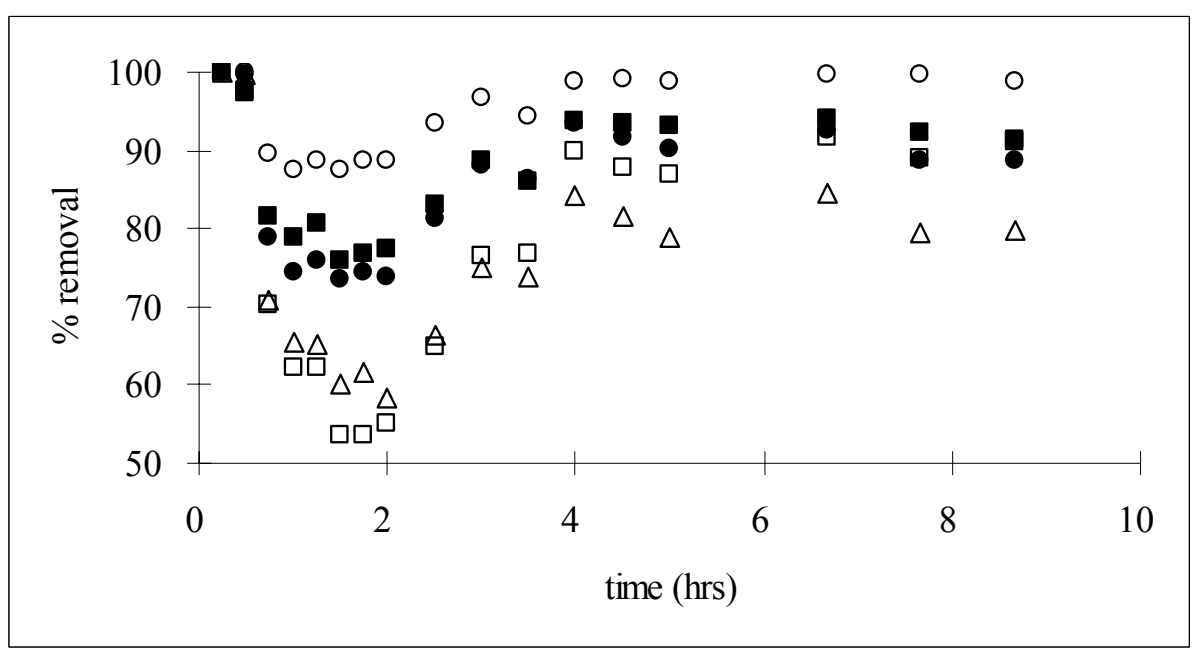

Figure 4.23 BTEX removal efficiency after a 2.8-day shutdown period in the polyurethane foam biofilter. (A): $1^{\text {st }}$ shutdown, (B): $3^{\text {rd }}$ shutdown.

( $\square$; Benzene, $\square$; Toluene, $\circ$; Ethyl benzene, $\bullet$; $p \& m$ xylene, $\Delta$; o-xylene) 
(A)

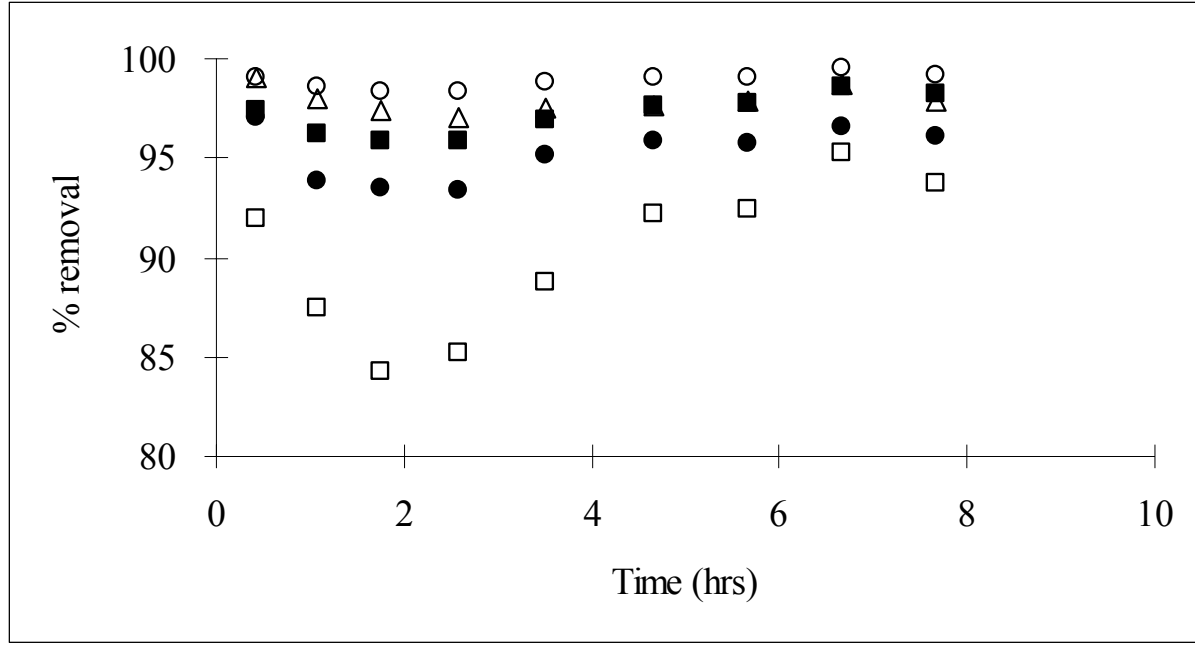

(B)

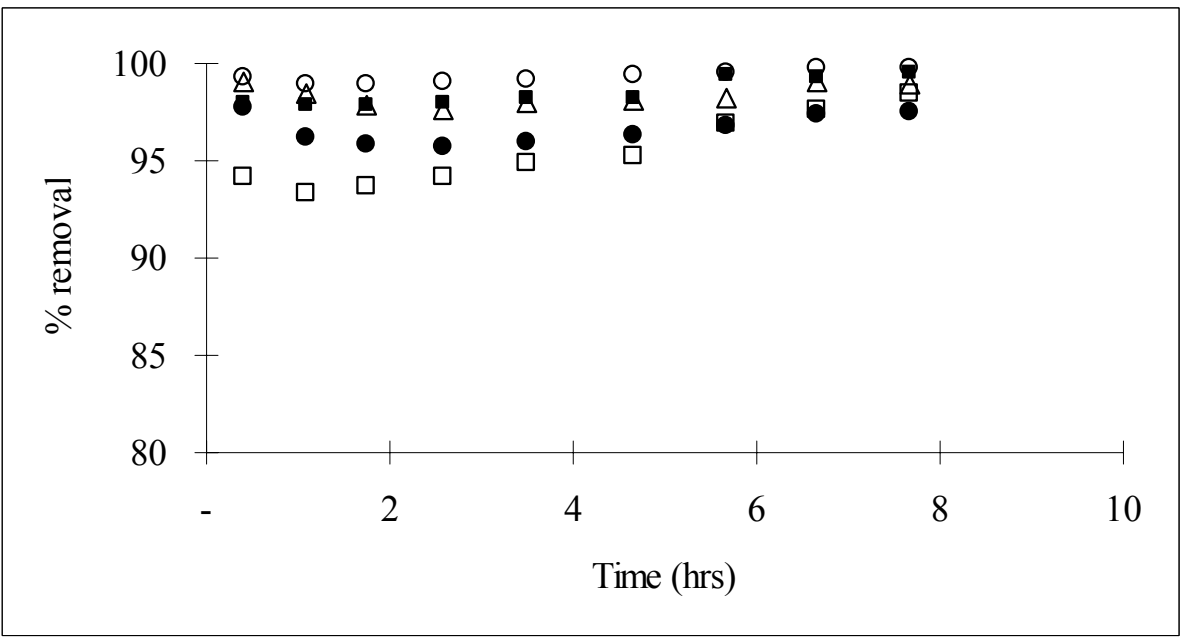

Figure 4.24 BTEX removal efficiency after a 24-hour shutdown period in the compost biofilter. (A): $1^{\text {st }}$ shutdown, (B): $3^{\text {rd }}$ shutdown. ( $\square$; Benzene, $\square$; Toluene, $\circ$; Ethyl benzene, $\bullet$; $p \& m$ xylene, $\Delta$; o-xylene)

The response of the compost biofilter to a 2.8-day shutdown period was also examined. The response of the system following resumption of the BTEX feed is presented in Figure 4.25. Compared to the one-day shutdown tests, the BTEX removal was more seriously affected by the long term shutdown test. The percent removal of benzene following the shutdown test decreased to $54 \%$ with lower declines observed for $p \& m$ xylene and toluene. However, the overall BTEX removal efficiency recovered to $90 \%$ within eight hours. Unlike the 1-day shutdown tests, no improvement in BTEX removal efficiency was observed after repeated 2.8-day shutdown tests (Figure 4.25b). Benzene removal before this shutdown test (i.e., in the continuous operating condition) was lowest 
(A)

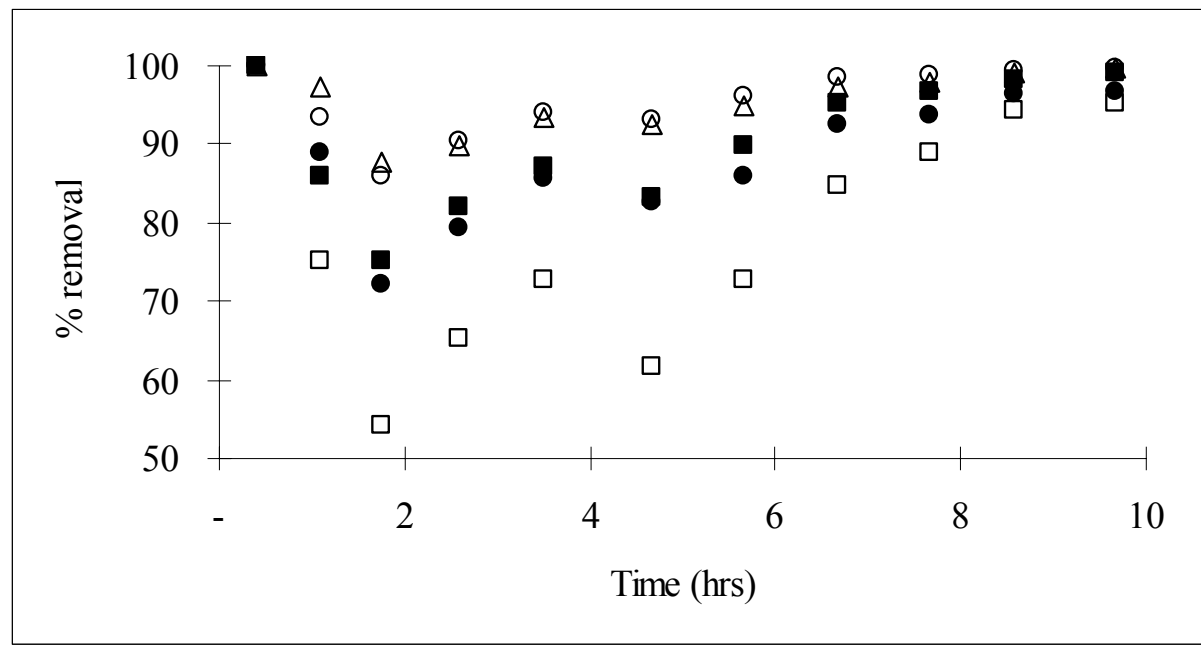

(B)

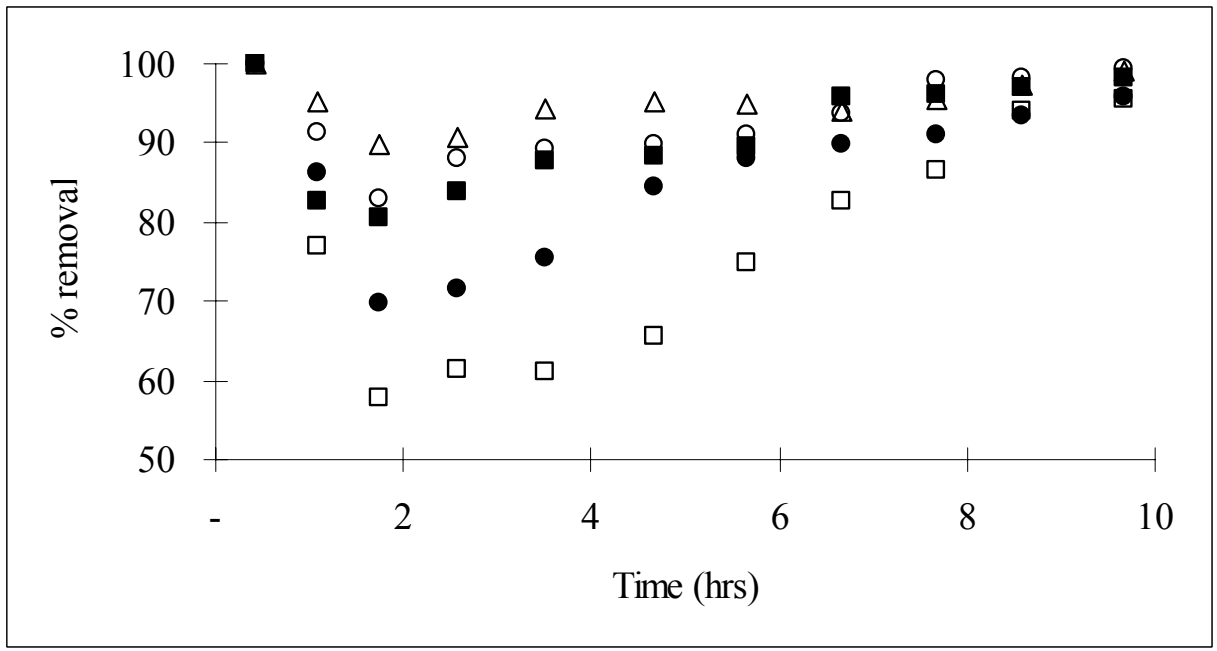

Figure 4.25 BTEX removal efficiency after a 2.8-day shutdown period in the compost biofilter: (A): $1^{\text {st }}$ shutdown, (B): $3^{\text {rd }}$ shutdown.

( $\square$; Benzene, $\square$; Toluene, $\circ$; Ethyl benzene, $\bullet$; $p \& m$ xylene, $\Delta$; o-xylene)

(approximately 95\%) among other VOCs (more than 98\%), therefore, it could be concluded that benzene is the limiting pollutant that will control the design of a compost biofilter treating BTEX mixtures.

\subsection{Field Test Results}

Field testing of the combined system was conducted at a produced water treatment and disposal facility located in New Mexico. Prior to the test, samples of the influent water were collected and analyzed by DHL Analytical. The results of this analysis are shown in Table 4.7. 
Table 4.7 Composition of produced water at the salt water disposal facility located in New Mexico.

\begin{tabular}{lc||lc}
\hline \multirow{2}{*}{ Analyte } & $\begin{array}{c}\text { Concentration } \\
\text { (mg/L) }\end{array}$ & Analyte & $\begin{array}{c}\text { Concentration } \\
\text { Gasoline range organics (C6-C10) }\end{array}$ \\
\hline Diesel range organics (C10-C28) & 23.5 & Naphthalene & 2-methylnaphthalene \\
Total dissolved solids (TDS) & 11,076 & Barium & 0.03 \\
Total organic carbon (TOC) & 318 & Calcium & 0.01 \\
Benzene & 2.2 & Magnesium & 0.7 \\
Toluene & 7.1 & Potassium & 77.8 \\
Ethylbenzene & 0.4 & Selenium & 25.4 \\
p\&m-xylene & 3.9 & Sodium & 74.7 \\
o-xylene & 1.1 & Bromide & 0.014 \\
Acetone & 3.1 & Chloride & 3,700 \\
Phenol & 1.2 & Sulfate & 12 \\
2-methylphenol & 0.6 & Acetate & 5,360 \\
4-methylphenol & 0.03 & Malonate & 408 \\
2,4-dimethylphenol & 0.01 & & 258.9 \\
\hline
\end{tabular}

\subsubsection{Adsorption on SMZ}

The breakthrough curves of selected organic compounds in produced water through the virgin SMZ columns are shown in Figures 4.26a and 4.26b. At the $27 \mathrm{gph}$ flow rate, the upstream, column was disconnected when benzene reached complete breakthrough and the downstream column remained online until toluene reached complete breakthrough. The corresponding $K_{d}$ values calculated for benzene and toluene are $11.4 \mathrm{~L} / \mathrm{kg}$ and 20.9 $\mathrm{L} / \mathrm{kg}$, respectively. The other volatile compounds including ethylbenzene, $p \& m$-xylene and $o$-xylene exhibited similar breakthrough curves to benzene and toluene. Two of six monitored SVOCs, phenol and 2-methylphenol, were also detected in the SMZ effluent. The remaining SVOCs (4-methylphenol, 2,4-dimethylphenol, naphthalene and 2methylnaphthalene) never broke through the column. The concentrations of detectable organic anions including acetate, propionate and malonate in the influent and effluent of the system were similar indicating that the SMZ has low sorption capacity for the organic anions found in produced water (Figure 4.26b). Other anions including formate, butyrate, valerate, succinate and glutarate were not detected in the source produced water during the pilot test. 

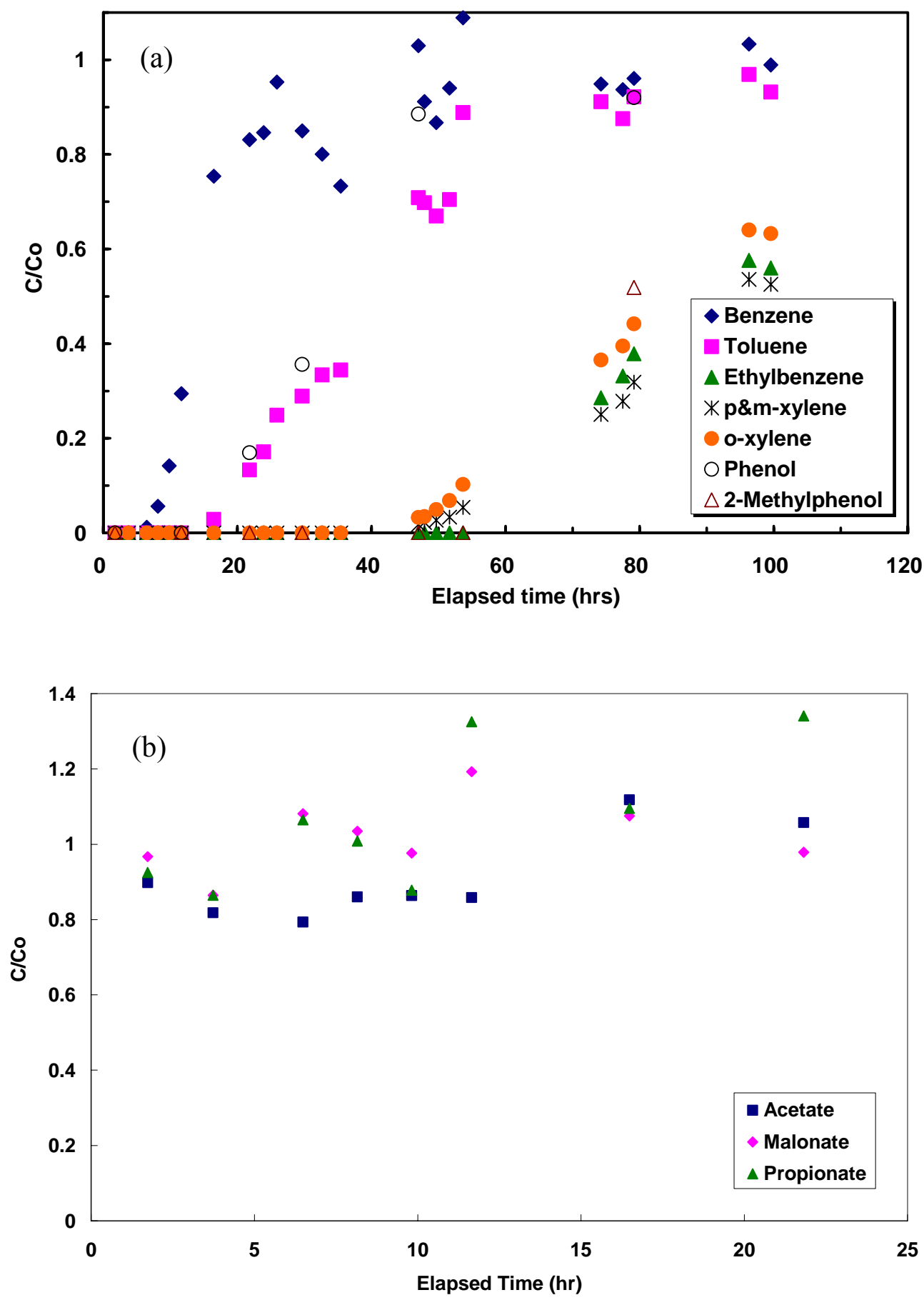

Figure 4.26 Breakthrough curves of selected organic compounds in produced water through virgin SMZ at a flow rate of $27 \mathrm{gph}$. 
The breakthrough curves of benzene and toluene in this field test in New Mexico were compared with those obtained in the previous field test in Wyoming (Figure 4.27) in order to examine how the SMZ performance was affected by BTEX concentrations in different produced water. The major differences between these two field tests included: (1) in the New Mexico field test, two virgin SMZ columns in series were operated at an average flow rate of $27 \mathrm{gph}$, while in the previous Wyoming field test a single virgin SMZ column was operated at an average flow rate of $25 \mathrm{gph}$, and (2) BTEX concentrations found in produced water in the New Mexico site were five times lower than these found in the Wyoming site. However, the TDS concentrations found at the two sites were similar. As shown in Figure 4.27, the virgin SMZ provides a fairly constant sorption capacity for benzene in terms of treating the same pore volumes of produced water. These results indicate that produced waters with similar salinities yield similar performance for benzene. Since benzene is the least hydrophobic compound, it breaks through the columns first and constrains the design of the system. The similarity in the benzene removals between the two field tests where the benzene concentrations differed by up to an order of magnitude also suggest that the adsorption isotherms are linear.

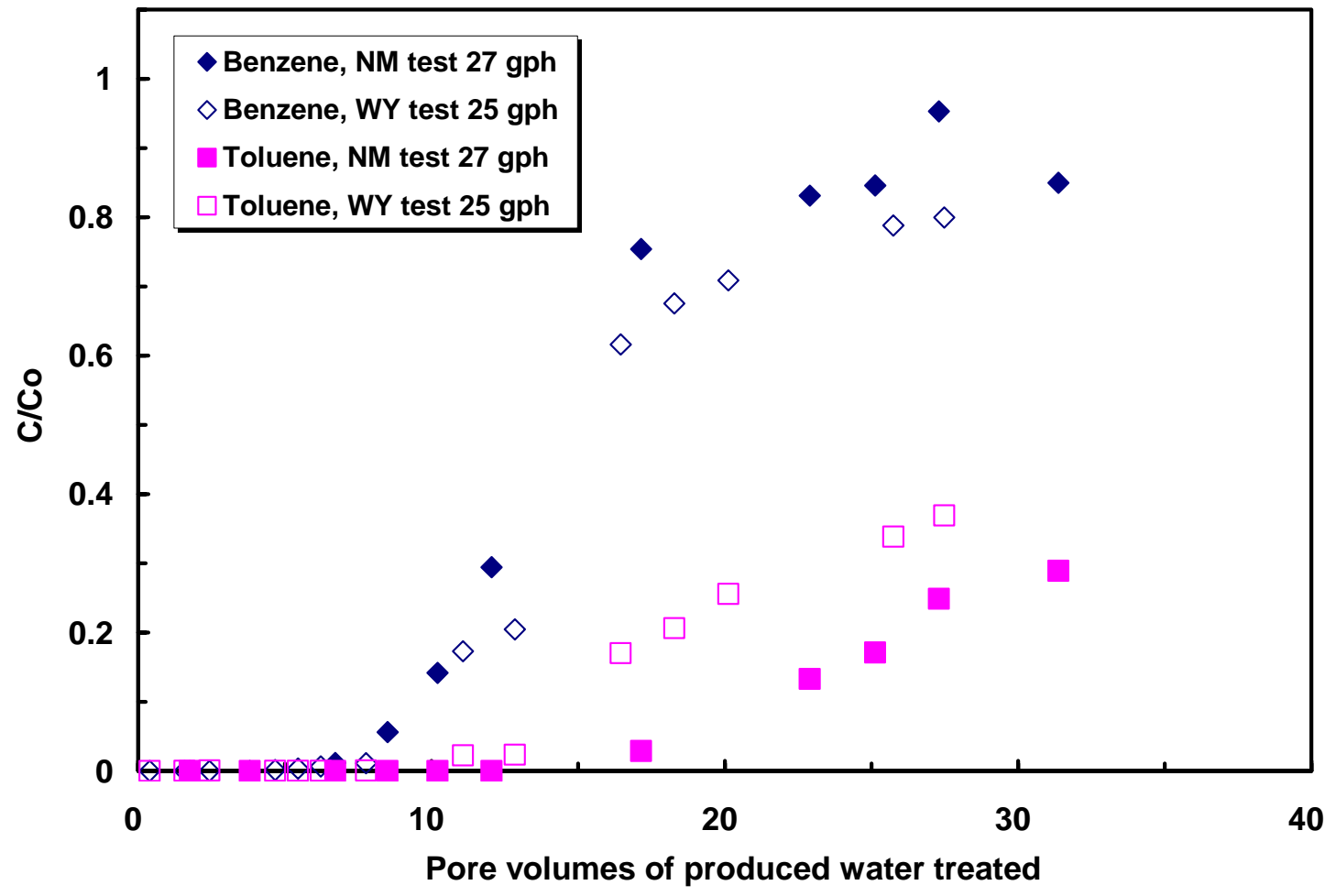

Figure 4.27 Comparison of benzene and toluene breakthrough curves on virgin SMZ in two field tests conducted separately in New Mexico, 2005 and in Wyoming, 2002. 
The performance of the virgin and regenerated SMZ columns were examined during the New Mexico field test to determine how the sorption capacity of the SMZ was affected by regeneration. Figure 4.28 compares the benzene breakthrough profiles from a virgin SMZ column to that observed from a SMZ column that had been saturated and then regenerated with air. As evident in the figure, BTEX was observed in the effluent from the regenerated SMZ column immediately after it was placed back online. It is believed that residual water remained in the SMZ column even after the previous regeneration cycle because the configuration of the SMZ columns did not allow all of the water to be drained from the columns. As a result, this BTEX laden water was carried over to the next sorption cycle when the SMZ column was reconnected to the system and produced water flowed through it again. Despite this initial spike in effluent concentration, the regenerated SMZ provided higher sorption capacity for benzene (Figure 4.28) and toluene (data not shown) than did the virgin SMZ during the first 30 pore volumes.

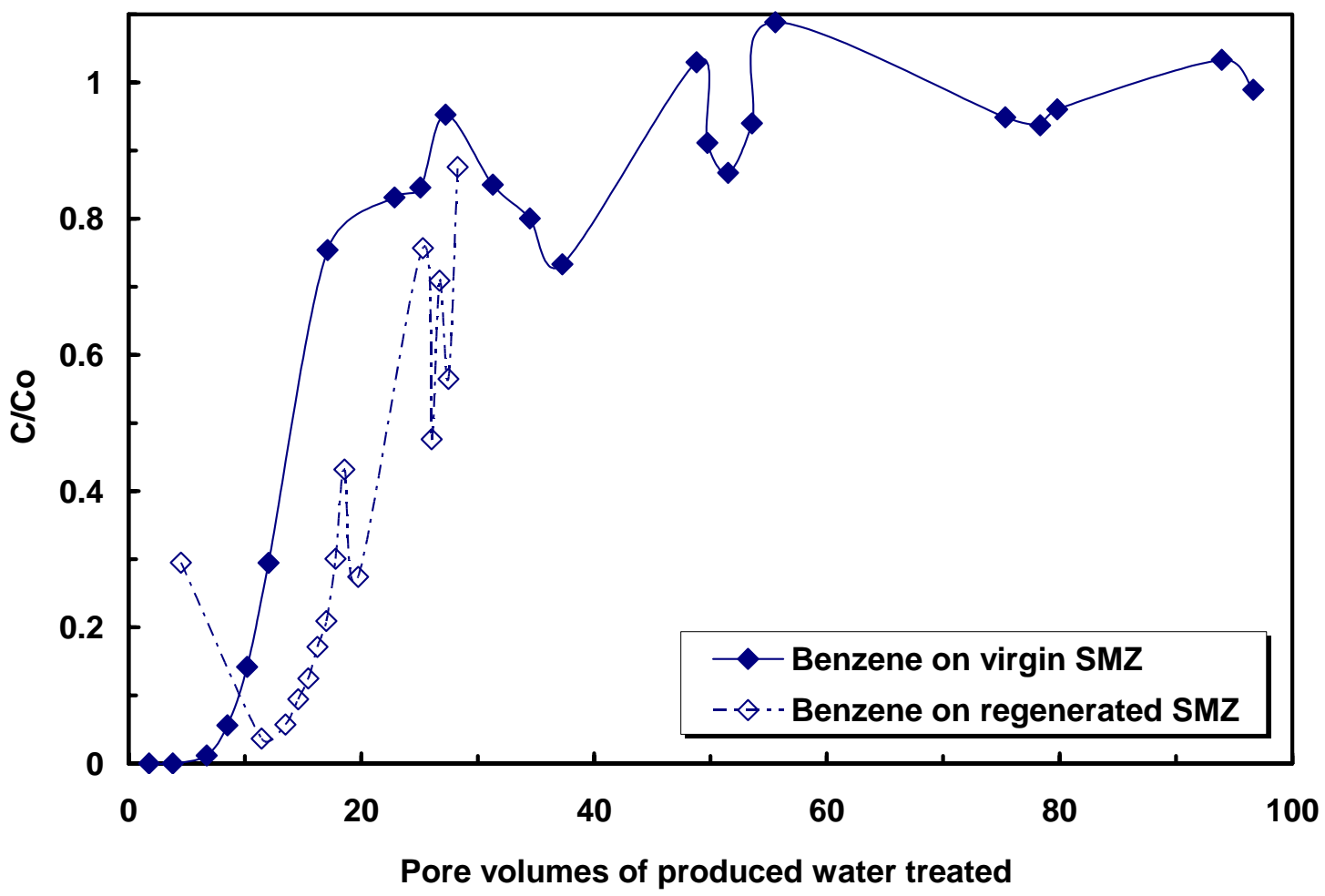

Figure 4.28 Comparison of benzene breakthrough curves on virgin and regenerated SMZ. The average produced water flow rates during the test of the virgin SMZ and the regenerated SMZ were $27 \mathrm{gph}$ and $10 \mathrm{gph}$, respectively. 
The performance of the pilot SMZ system was investigated at three produced water flow rates during the New Mexico field test: $27 \mathrm{gph}, 10 \mathrm{gph}$ and $5 \mathrm{gph}$. As evident in Figure 4.29, the flow rate had no affect on SMZ performance for the first 10 pore volumes indicating that liquid phase mass transfer was not limiting under the conditions evaluated in the field test. The greatest difference in sorption is evident at later times when the SMZ column operated at 10 gph continued to sorb benzene and the virgin SMZ column operated at $27 \mathrm{gph}$ became saturated. This difference in sorption is not likely a result of the different flow rates but rather due to the fact that the SVOCs and other organics that sorbed onto the SMZ column during the initial runs actually increases the sorption capacity of the SMZ for organics such as benzene.

In the field test, SMZ performance over two sorption/regeneration cycles was examined at a produced water flow rate of $5 \mathrm{gph}$. The goal of this test was to demonstrate that it was possible to treat produced water continuously in the SMZ/VPB system. After saturating the first $\mathrm{SMZ}$ column, the saturated column was pulled offline and regenerated with air. The second SMZ column remained online treating produced water until the benzene concentration in the effluent reached $20 \%$ of the influent benzene concentration. At this point, the regenerated SMZ column was placed back online. The breakthrough curves of BTEX through the SMZ columns over two complete cycles are shown in Figure 4.30 During the test, the effluent BTEX concentrations remained below $20 \%$ of influent concentrations, except for two transitory effluent spikes in benzene concentration that occurred due to the carryover problem described earlier.

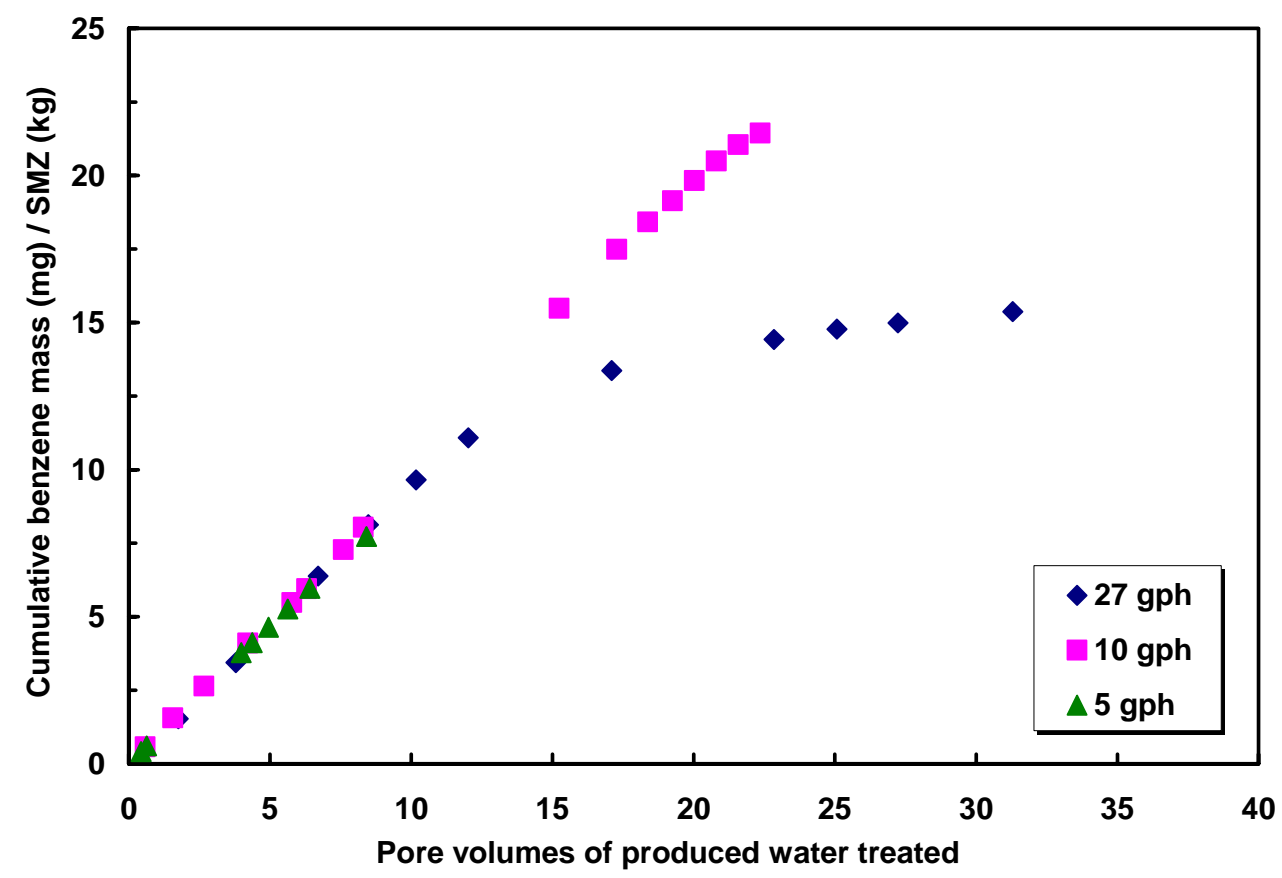

Figure 4.29 Cumulative mass of benzene on SMZ over different flow rates used in the New Mexico field test. 


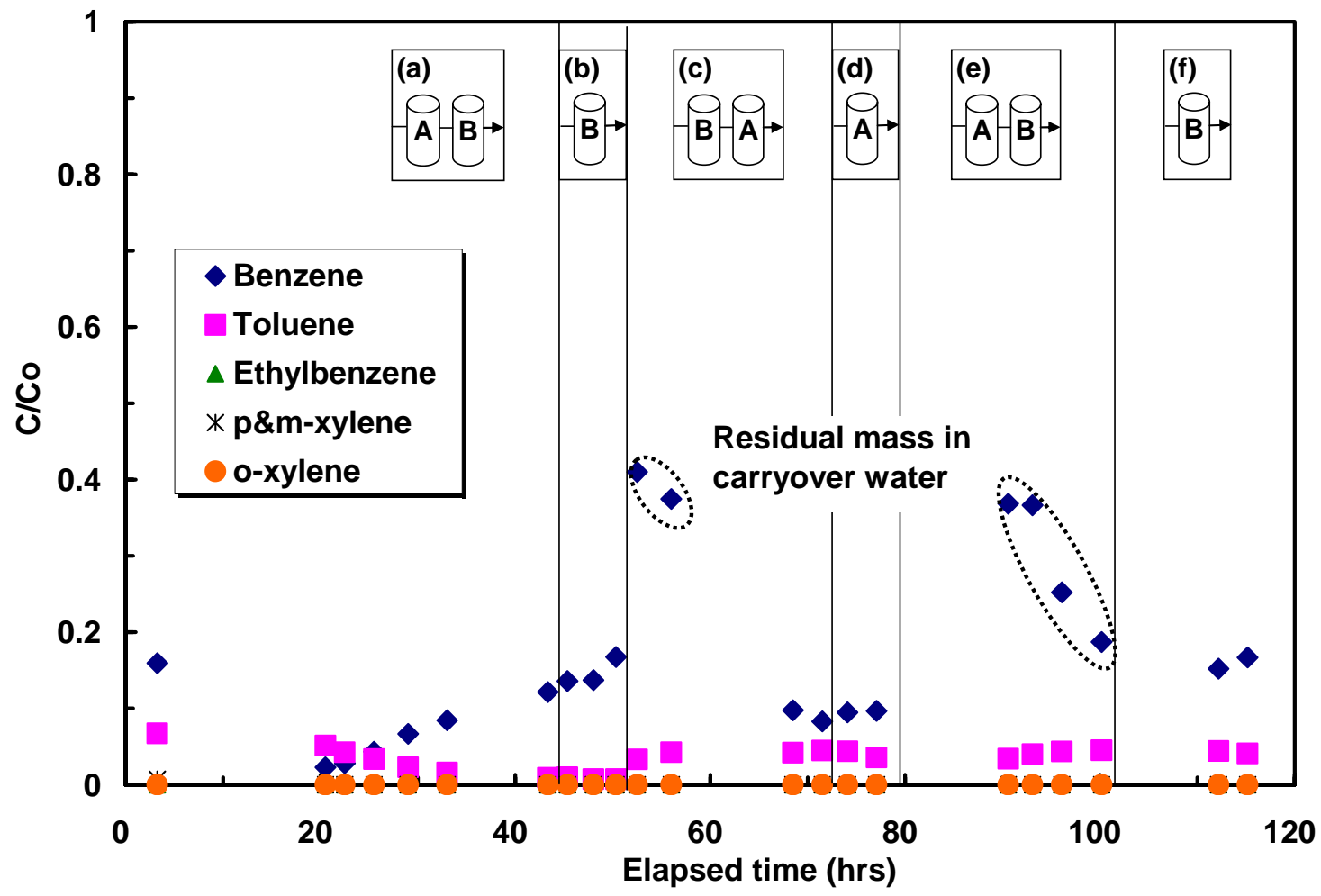

Figure 4.30 BTEX breakthrough on regenerated SMZ over two sorption/ regeneration cycles at $5 \mathrm{gph}$ flow rate during the New Mexico field test. In stages (a), (c), (e): two columns (noted as A and B) were online. In stages of (b), (d), (f): one column was online while the other column was regenerated.

\subsubsection{SMZ Regeneration \& Off-Gas Treatment in the VPB}

A typical BTEX concentration profile observed in the regenerated gas stream during the New Mexico field test is presented in Figure 4.31a. Lab-scale regeneration results obtained previously are presented in Figure $4.31 \mathrm{~b}$ for comparison. In both cases, benzene desorption occurred very rapidly compared to other chemicals. In the laboratory tests, the SMZ column was completely saturated with BTEX before regeneration was initiated. However in the field test, the SMZ sorption cycle was generally terminated when benzene reached $100 \%$ breakthrough even though the breakthrough percentages of the other components were only approximately: toluene $70 \%$, o-xylene $15 \%$, ethyl benzene and $p \& m$-xylenes $<10 \%$. As a result, the concentration of benzene in the regenerated gas stream was higher than the other compounds during the field test. Toluene levels were similar to the benzene levels indicating that the downstream VPB would have to treat high levels of benzene and toluene initially if no buffering system was in place. 

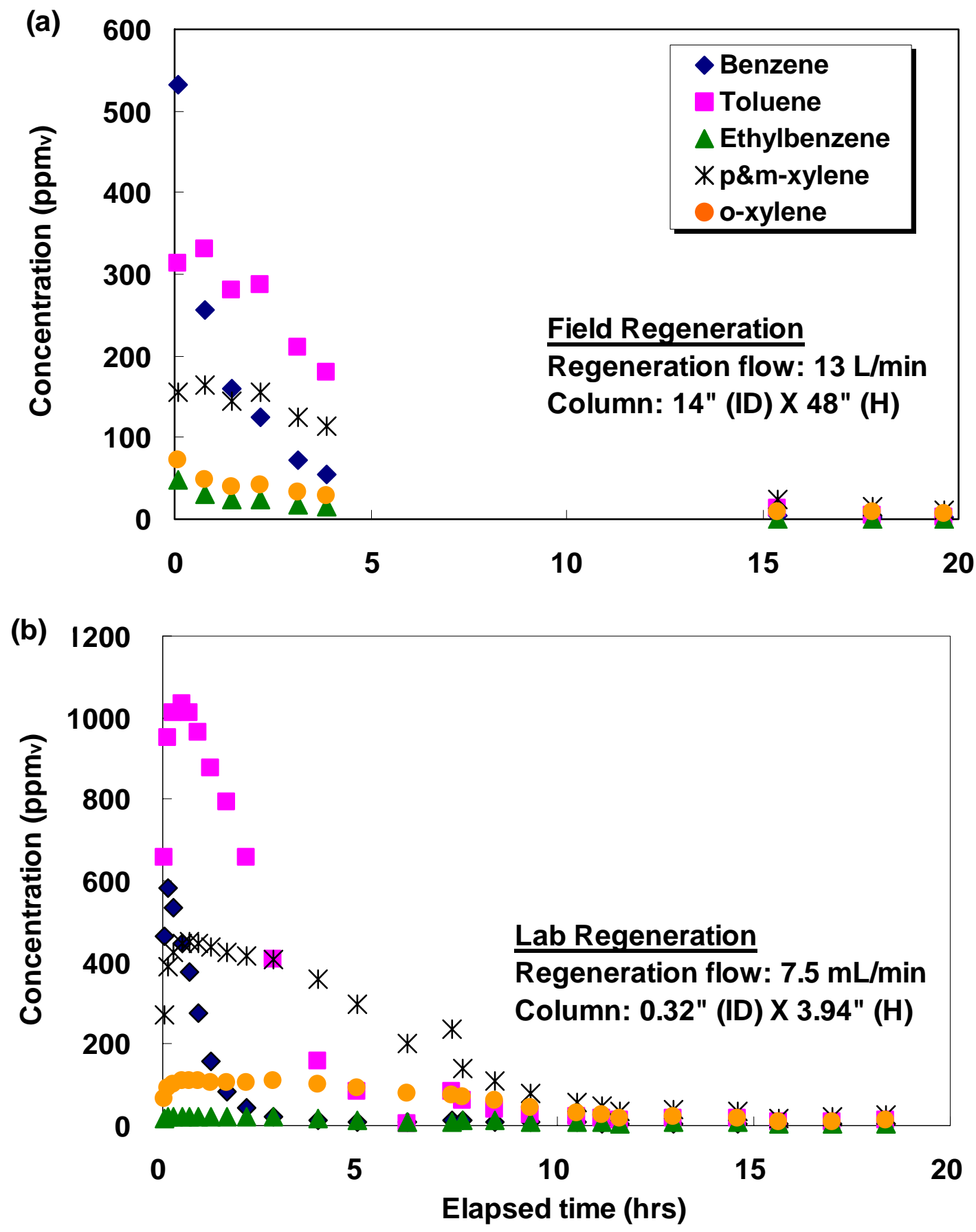

Figure 4.31 BTEX concentration profile of gas phase effluent during regeneration of SMZ column: (a) Regeneration in the field, and (b) regeneration in the lab. 
During the field test, the regenerated gas stream was buffered by a load equalizing column containing a GAC sorbent. As shown in 4.31a, benzene and toluene were the major components present in the regenerated gas stream. The concentrations of these two chemicals in the gas stream entering and exiting the GAC column during a regeneration cycle are presented in Figure 4.32. The results indicate that the GAC column effectively reduced the benzene and toluene concentrations in the gas stream. The GAC system was more effective at the 5 second EBCT where it reduced the benzene concentration to below $100 \mathrm{ppm}_{\mathrm{v}}$, an ideal level for successful biodegradation in the VPB.

After passing through the GAC buffering column, the VOC-laden gas stream from the SMZ regeneration process was fed to the VPB. Figure 4.33 shows the subsequent removal of benzene and toluene in the VPB for two different operating conditions. During the beginning of the field trial, the VPB was operated with a microbial community that had been adapted to an inlet benzene concentration of only $12 \mathrm{ppm}_{\mathrm{v}}$. As a result, the benzene removal efficiency observed in the VPB was very poor when subjected to an inlet benzene concentration of $170 \mathrm{ppm}_{\mathrm{v}}$, as shown in Figure 4.33a. The toluene removal was better even when it was subjected to an inlet concentration of 110 $\mathrm{ppm}_{\mathrm{v}}$. To improve the performance of the VPB and acclimate the microbial population to a higher benzene concentration, a surrogate BTEX feed was provided to the VPB during the shut down periods and the benzene concentration in this feed was increased to 90 $\mathrm{ppm}_{\mathrm{v}}$. As a result, the biomass in the VPB became accustomed to $90 \mathrm{ppm}_{\mathrm{v}}$ benzene levels and could remove more than $95 \%$ of the benzene introduced to the column during the regeneration process (Figure 4.33b). These results along with similar results obtained in the SMZ sorption and regeneration experiments indicate that benzene will control the design and operation of the coupled SMZ/VPB system for BTEX removal from produced water.

During the field test, each SMZ column was used for several cycles of sorption and regeneration. In order to evaluate the effectiveness of regeneration using air-sparaging for BTEX recovery from the SMZ columns, the fraction of total BTEX mass sorbed onto the SMZ that was recovered in the air was calculated based on each cycle of sorption and regeneration. The plot of recovered BTEX mass fraction during each regeneration as a function of regeneration period is shown in Figure 4.34. As shown in Figure 4.34, the SMZ was successfully regenerated using air-sparging and the recovered BTEX mass fraction was proportional to the regeneration period employed. Even though the BTEX compounds were not completely removed from the regenerated SMZ, the sorption capacity provided by the regenerated SMZ increased with operating period during this field test. 

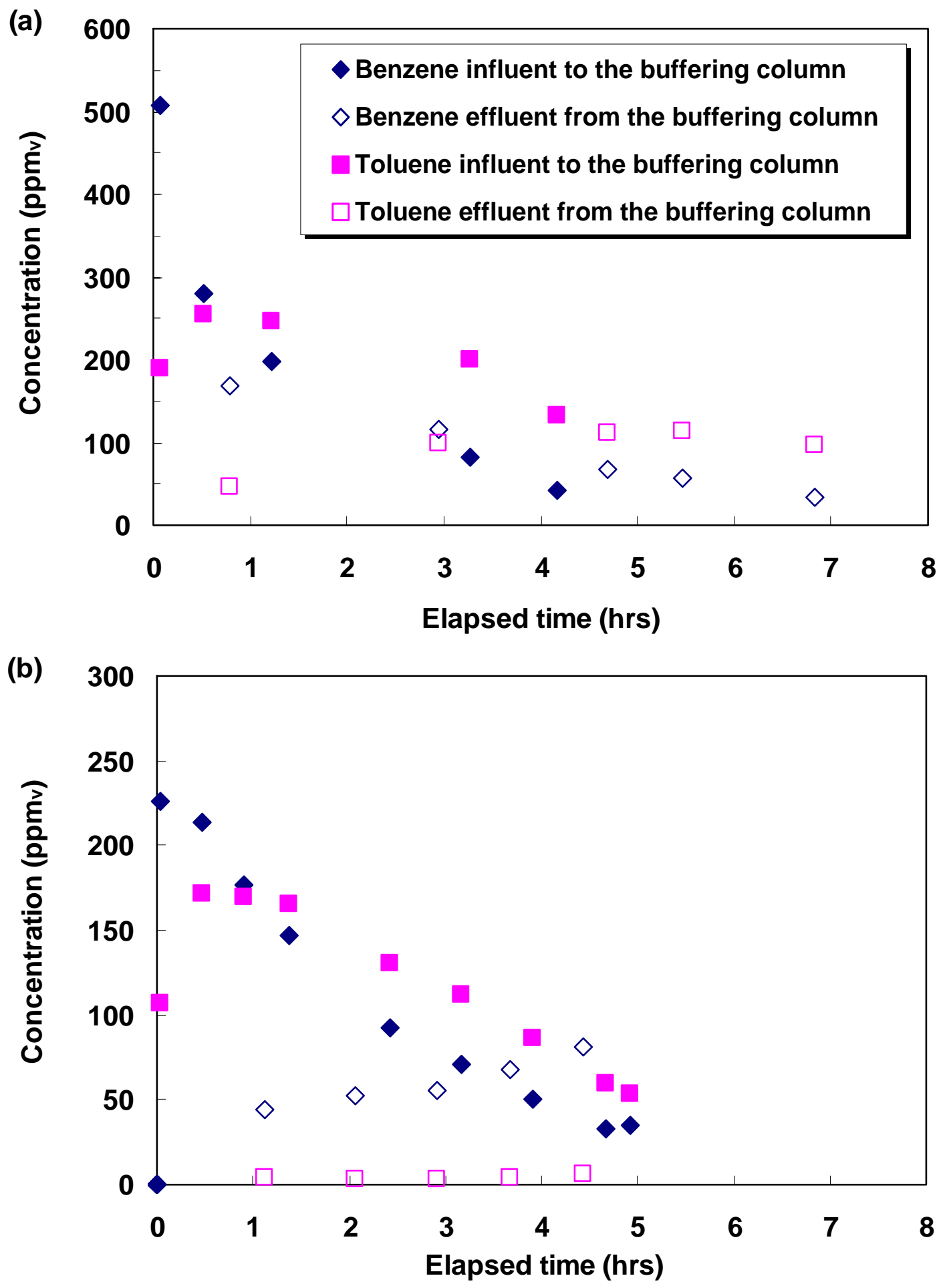

Figure 4.32 Benzene and toluene concentrations in the gas stream entering and exiting the GAC buffering column during SMZ regeneration. (a) 1 second EBCT in the buffering column, and (b) 5 second EBCT in the buffering column. 

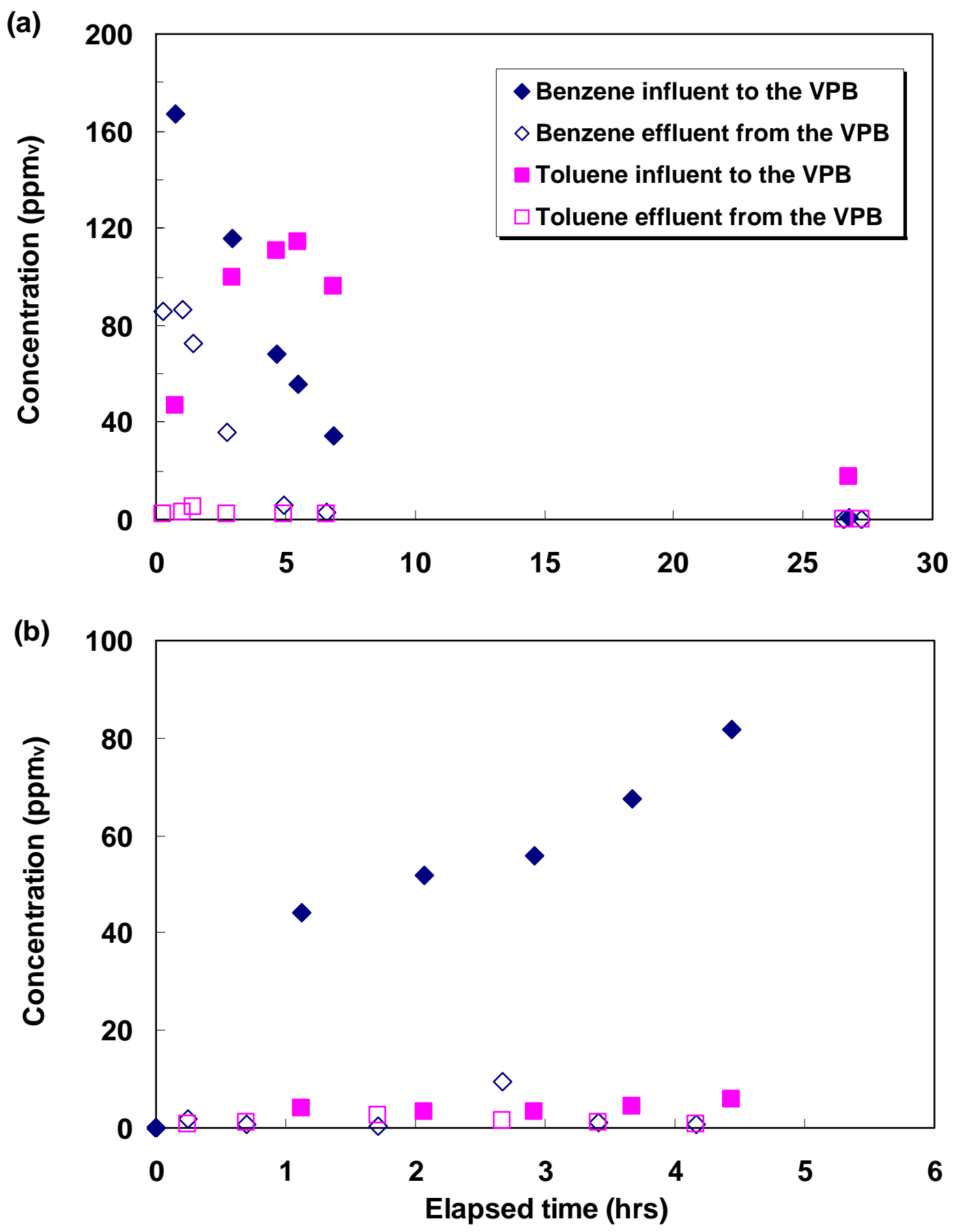

Figure 4.33 Removal of VOCs in the VPB during the field test at two different operating conditions. (a) Biomass accustomed to low concentration $\left(12 \mathbf{p p m}_{\mathrm{v}}\right)$ of benzene, and (b) biomass accustomed to high concentration $\left(90 \mathrm{ppm}_{\mathrm{v}}\right)$ of benzene. 


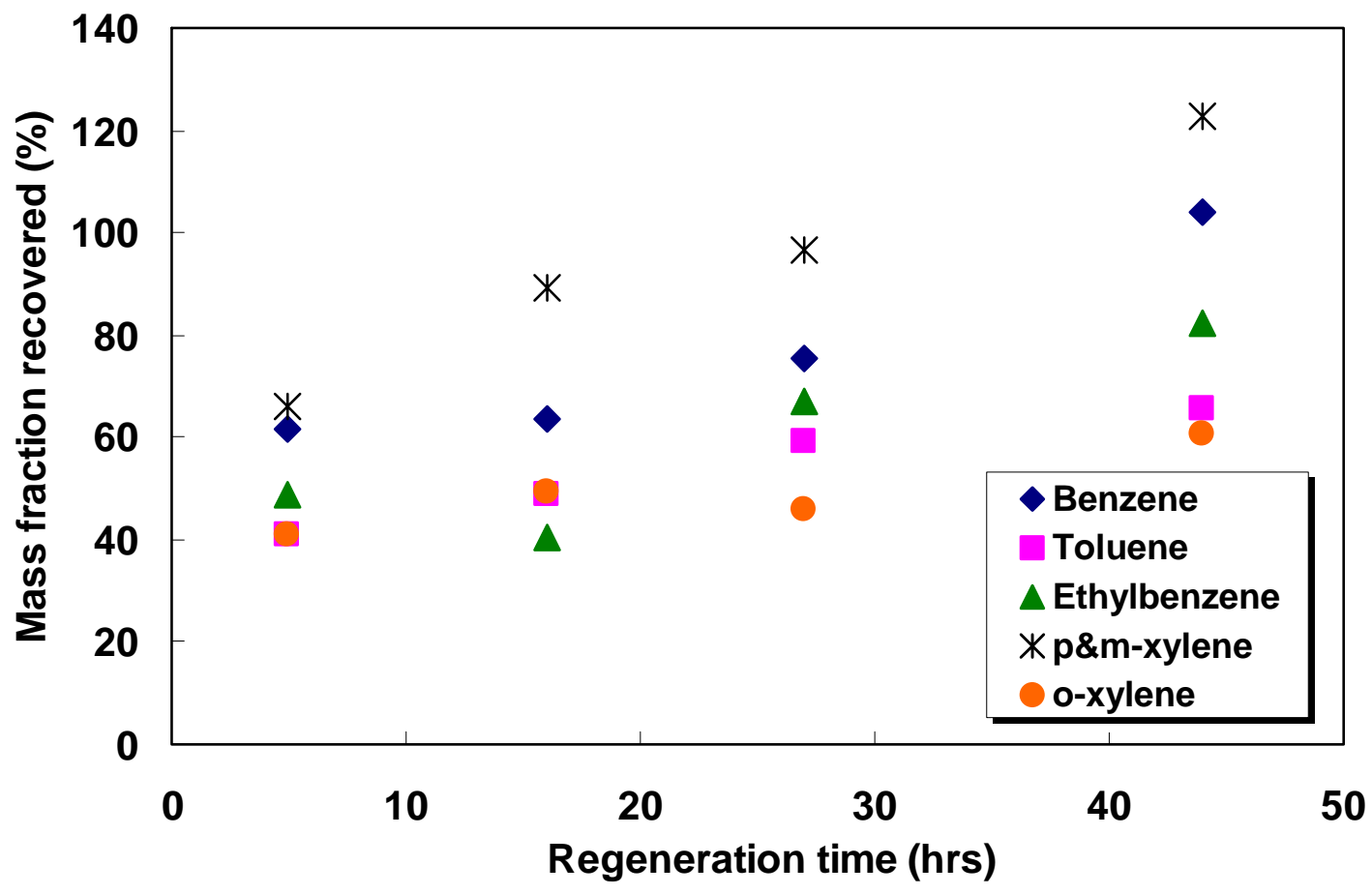

Figure 4.34 Mass fraction of adsorbed BTEX removed from the SMZ as a function of air sparging regeneration time.

Figure 4.35 summarizes the typical BTEX concentrations observed throughout the SMZ regeneration and VPB system during the New Mexico field test. As is evident in the figure, the GAC buffering system greatly reduced the peak BTEX concentrations reaching the VPB. As a result, the VPB was able to remove greater than $90 \%$ of the influent BTEX. The pilot scale testing also demonstrated that SMZ removal at the New Mexico site was consistent with our predictions that were based on our previous pilot and laboratory testing. Varying flow rates of 5-27 gph and repeated sorption/regeneration cycles had no significant impacts on SMZ performance. SMZ regeneration using air sparging was sufficient to maintain the SMZ sorption capacity and allowed for continuous operation of the system. However, an effluent spike was repeatedly observed after initial start-up of the system. It is believed that this is due to residual water remaining in the SMZ columns after regeneration. This problem can be addressed by redesigning the SMZ columns so that they can be completely drained of water prior to the air regeneration step. 


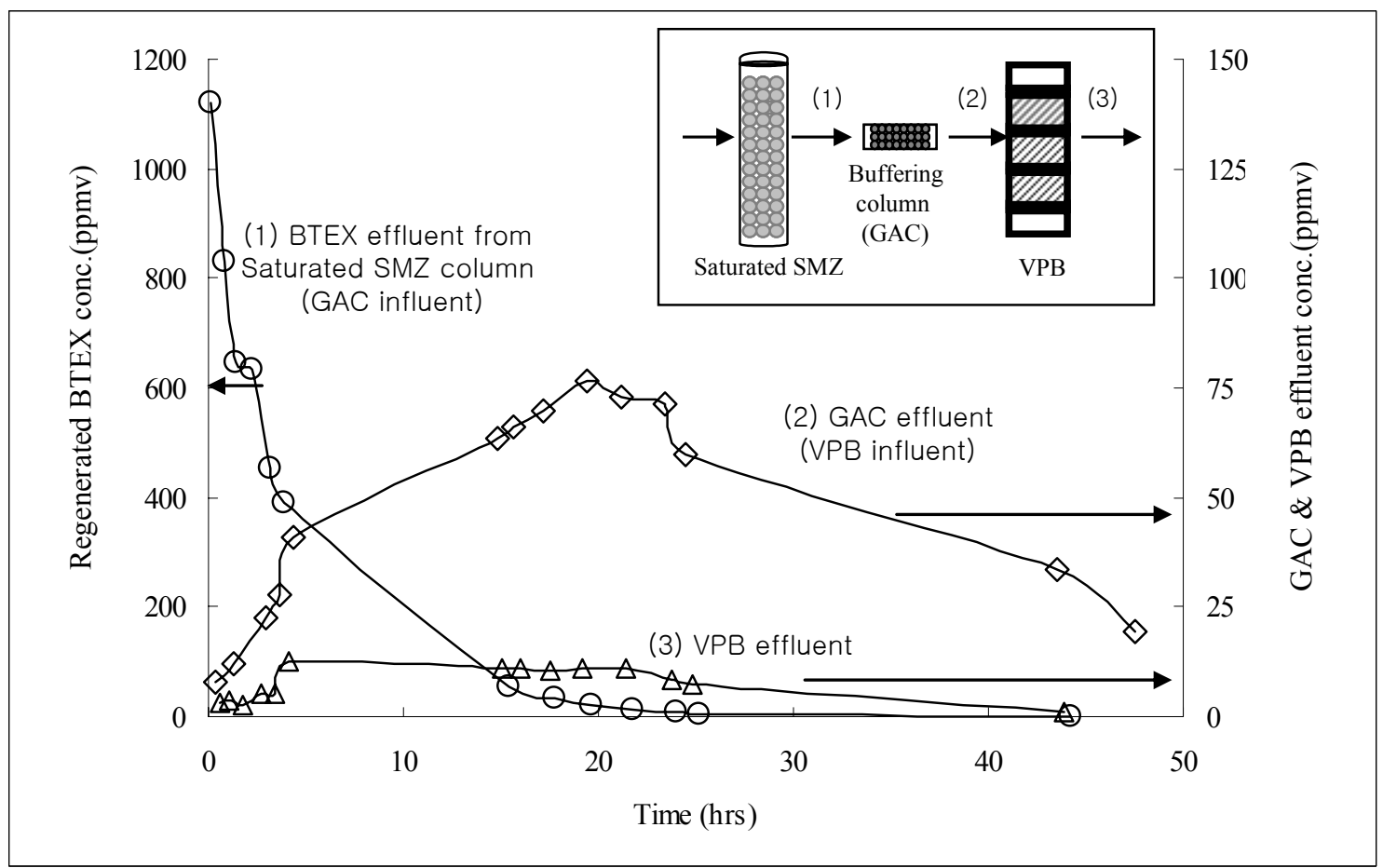

Figure 4.35 Performance of the GAC buffering column and VPB during the regeneration of the saturated SMZ field column. Schematic diagram in the inset represents the treatment process. Air flow rate during regeneration was $13 \mathrm{~L} / \mathrm{min}$ which resulted in a 1 second $\mathrm{EBCT}$ in the buffering column and a 73-second EBCT in the VPB. $\diamond, \diamond$, and $\Delta$ represent the GAC influent (1), GAC effluent (2) and VPB effluent (3), respectively. 


\subsection{Engineering and Economic Assessment}

Complete assessment of the surfactant modified zeolite and vapor phase biofilter (SMZ/VBP) system as a treatment option for produced water must include an economic evaluation of the process that includes engineering cost estimates for installation, operation and maintenance. Several design and utilization issues must be addressed in order to develop an economic assessment of any treatment system for produced water including: site location (i.e. well head vs. centralized treatment site), end use of the treated water, and federal, state and local regulations governing the disposal or re-use of produced water.

The location of a treatment system determines the size, automation and support systems required for the process. Designated end use and applicable regulations determine the target water quality parameters and disposal options for treated produced water. This research investigated disposal options, applicable regulations and treatment targets as a function of end use.

Initial design parameters for the system were developed based on laboratory and field experience from this project and our previous research (Katz et al., 2003, Ranck et al., 2005). These parameters include sorption capacity and hydraulic loading of the SMZ, physical parameters of the sorption media, such as porosity and bulk density and inlet BTEX concentrations. Vapor phase biofilter design parameters include a maximum inlet concentration of BTEX and a bed residence time. Based on pre-set values for these parameters, cost estimations for low, medium and high flow rates of produced water at 6 gpm, $20 \mathrm{gpm}$ and $40 \mathrm{gpm}$ with $25 \mathrm{mg} / \mathrm{L}$ benzene and $25000 \mathrm{mg} / \mathrm{L}$ BTEX have been determined. These costs are compared to produced water disposal via injection wells based on cost survey information from producers in the western United States and the San Juan Basin, New Mexico.

\subsubsection{Selection of Facility Location}

One of the most significant limitations associated with re-use of treated water is the high cost and variability of transportation costs. Transportation costs range from 60 to $80 \%$ of the total treatment costs for many producers; therefore, an on-site well-head treatment system would provide immediate benefit to producers. A well-head system requires pretreatment of the water utilizing oil and grease separators and filtration prior to treatment in the SMZ/VPB system. Issues that must be addressed at each site include utility access, such as electricity and fresh water, manpower monitoring requirements and availability of on-site disposal of the treated water. Most well sites in the western United States are located in remote areas and may only be visited once a week or monitored remotely. A well head system can be designed for specific applications; however, additional automation and monitoring will be required, along with environmental controls for an off-gas treatment system such as the vapor phase biofilter. Due to the highly variable 
water chemistry and quantity of produced water at individual wells, designing a generic well-head treatment package is not feasible for a general assessment of this process. The driving force for a well-head application is reduction in transportation costs; however, unless there is a local disposal method available, transportation costs will still be incurred to deliver the water to a final location, where it can be discharged to a water body or used in agriculture or other industries.

For this economic and engineering analysis, the SMZ/VPB process will be designed for a centralized salt water disposal facility. Generally, the volatile organic compounds and total dissolved solids composition of the water is fairly constant at these locations and pre-treatment and storage options are already in place.

\subsubsection{Design Criteria and Assumptions}

The SMZ/VPB process removes and destroys volatile organic compounds, specifically benzene, toluene, ethylbenzene and xylene (BTEX) in produced water. Adsorption of BTEX from produced water onto surfactant modified zeolite has been demonstrated in the laboratory and the field. One of the key benefits of this adsorbent is that it regenerates readily in the field via air sparging. Thus, the system is designed to cycle multiple SMZ sorption columns between sorption and regeneration for continuous operation. This process can be coupled with a desalination process to reduce the total dissolved solids, if necessary, depending on the re-use or end-use requirements of the water.

The initial design of the SMZ system was developed based on two pilot systems and includes three columns operating in series, allowing one to be regenerated while the other two are on line. This configuration provides continuous feed to the single vapor phase biofilter. The biofilter converts the volatile organic compounds to carbon dioxide and water.

SMZ and VPB columns were designed on the basis of various influent flow rates representing a single well produced water flow rate, and average and high flow rates for a centralized salt water disposal facility:
Low Flow
$6 \mathrm{gal} / \mathrm{min}$
Medium Flow (Average SWD)
$20 \mathrm{gal} / \mathrm{min}$
High Flow (Large Volume SWD) $40 \mathrm{gal} / \mathrm{min}$.

The design of the packed bed SMZ column is based on the distribution coefficient for benzene, $\mathrm{K}_{\mathrm{d}}(\mathrm{L} / \mathrm{g} \mathrm{SMZ})$, hydraulic loading rate $\left(\mathrm{gpm} / \mathrm{ft}^{2}\right)$, and the porosity and bulk density of the SMZ. Measured values of $K_{d}$, benzene for saline water range from 0.00934 to $0.0146 \mathrm{~L}$ solute/g SMZ at salinity levels of 30,000 and 100,000 ppm respectively. (Katz 
et al., 2003) Benzene has been shown to be the first BTEX compound to breakthrough the SMZ sorption system and research has also shown that benzene sorption is independent of the presence of other BTEX compounds.

Based on a designated in-service time for each SMZ column, influent flow rate and benzene concentration, the total amount of benzene to be removed was calculated from a linear isotherm equation:

$$
\mathrm{q}_{\mathrm{e}}=\mathrm{K}_{\mathrm{d}} * \mathrm{C}_{\mathrm{e}}
$$

where $\mathrm{q}_{\mathrm{e}}=$ adsorption capacity (mass of benzene/mass of SMZ)

$$
\begin{aligned}
& \mathrm{K}_{\mathrm{d}}=\text { distribution coefficient (volume of solution/mass of SMZ) } \\
& \mathrm{C}_{\mathrm{e}}=\text { equilibrium concentration (mass of benzene/volume of solution). }
\end{aligned}
$$

The mass of SMZ required to adsorb the influent benzene was determined from the adsorption capacity of the SMZ and time in service before regeneration. By setting $\mathrm{C}_{\mathrm{e}}$ equal to the inlet benzene concentration to find $\mathrm{q}_{\mathrm{e}}$, the mass of SMZ was determined:

Mass of SMZ = the mass of benzene to be removed/adsorption capacity.

The volume of SMZ was calculated by dividing the mass of the SMZ by the bulk density of the SMZ. The cylindrical cross-sectional area and corresponding diameter of the column was determined from the hydraulic loading specified by the designer and the inlet flow rate:

Area $=$ flow rate/hydraulic loading

The packed bed height was calculated from:

Bed height $=$ Volume of SMZ/Area

These calculations provide the column diameter and packed bed height used to estimate the cost of the columns using standard cost estimation correlations. A spreadsheet has been developed incorporating the design equations which is presented in Table 4.8. 
Final Technical Report

DE-FC26-02NT15461

Table 4.8 SMZ column design parameters for $6 \mathrm{gpm}$ design flow

\begin{tabular}{|c|c|}
\hline Design Parameters: & \\
\hline Sorbent Characteristics & \\
\hline Porosity & 0.6 \\
\hline Bulk Density & 1 \\
\hline Kd (Benzene) & 0.00943 \\
\hline Hydraulic Loading rate(gpm) & 1.0 \\
\hline Produced Water Characteristics & \\
\hline Total BTEX Conc (ug/L) & 25000 \\
\hline Benzene inlet conc (ug/L) & 2500 \\
\hline Flow Rate (L/day) & 32800 \\
\hline Service Time (day) & 0.5 \\
\hline Design Calculations & \\
\hline Benzene Adsorbed (mg) & 41000 \\
\hline Mass of SMZ (g) & 1739130.43 \\
\hline Volume of SMZ (L) & 1739.13 \\
\hline Cross Sectional Area of Column $\left(\mathrm{ft}^{2}\right)$ & 8.02 \\
\hline Adsorption Capacity (qe) & 23.575 \\
\hline Results & \\
\hline Diameter of Column (ft) & \\
\hline Column Length (ft) & \\
\hline
\end{tabular}

The design parameters for the vapor phase biofilter are presented in Table 4.9 and include: regeneration cycle times for the SMZ columns, maximum inlet BTEX concentration, empty bed residence time and superficial velocity through the bed. For a 12 hour SMZ regeneration time, two hours were allotted for ramping up the air flow to the desired value, and two hours were added to the estimated regeneration time for polishing the SMZ bed, resulting in an 8 hour regeneration time. The air flow rate was,

$$
\mathrm{Q}_{\text {air }}=\text { mass of BTEX adsorbed/regeneration time/max inlet conc. }
$$

The cross-sectional area of the vapor phase biofilter was determined from the air flow rate, $\mathrm{Q}_{\text {air }}$ divided by the superficial velocity through the bed. The bed height was set equal to the superficial velocity times the empty bed time.

The calculations presented in Table 4.10 were repeated for produced water flowrates of 6 gallons per minute, 20 gallons per minute and 40 gallons per minute to produce a set of design parameters that would encompass the range of operating conditions expected in the field. Using the dimensions for each packed tower and assuming a series of three SMZ columns and a single VPB, cost estimations for the purchase, installation, operation and maintenance of the SMZ/VPB process were completed using standard engineering cost estimation correlations. 
Final Technical Report

Table 4.9 Vapor phase biofilter design parameters

\begin{tabular}{|c|c|c|c|}
\hline \multicolumn{4}{|l|}{$\begin{array}{l}\text { SMZ Inlet and Regeneration } \\
\text { Conditions }\end{array}$} \\
\hline \multicolumn{4}{|c|}{ Regeneration Cycle Time - From SMZ Kd Based spreadsheet } \\
\hline Cycle Time $=$ & 0.5 & day & \multirow{4}{*}{$6.01 \mathrm{gpm}$} \\
\hline BTEX Inlet Conc & 25000 & $\mathrm{ug} / \mathrm{L}$ & \\
\hline Inlet Flow Rate & 32800 & L/day & \\
\hline Mass of BTEX sorbed $=$ & 410000 & $\mathrm{mg} / \mathrm{cyc}$ & \\
\hline \multicolumn{4}{|l|}{ Regeneration and VBP Sizing } \\
\hline \multicolumn{4}{|l|}{$\begin{array}{l}\text { User enters Regeneration Time } \\
\text { Regeneration Time = } \\
\text { User enters max inlet conc to VBP }\end{array}$} \\
\hline $\begin{array}{l}\text { Max inlet conc to VBP } \\
\text { Air flow rate calc: }\end{array}$ & 1000 & ppmv & $3.4765 \mathrm{mg} / \mathrm{L}$ \\
\hline $\mathrm{Q}, \operatorname{air}\left(\mathrm{ft}^{3} / \mathrm{min}\right)=$ & 8.68 & $\mathrm{ft}^{3} / \mathrm{min}$ & \\
\hline \multicolumn{4}{|l|}{ User enters superficial velocity, $\mathrm{ft} / \mathrm{min}$} \\
\hline $\mathrm{v}, \operatorname{air}(\mathrm{ft} / \mathrm{min})=$ & 2.5 & & \\
\hline Area $=Q / v$ & 3.47 & $\mathrm{ft}^{2}$ & \\
\hline Tower Diameter $(\mathrm{ft})$ & 1.05 & $\mathrm{ft}$ & \\
\hline \multicolumn{4}{|l|}{ User enters residence time in VPB } \\
\hline Residence Time $=$ & 1.5 & $\min$ & \\
\hline Bed height $=\mathrm{v}^{*}$ res time & 3.75 & $\mathrm{ft}$ & \\
\hline \multicolumn{4}{|l|}{ VBP Sizing } \\
\hline Number of 3 ' packed sections $=$ & 1 & & \\
\hline Total height of packed section $=$ & 3 & $\begin{array}{l}\text { (1 foot } b \\
\text { sections) }\end{array}$ & packed \\
\hline Number of packing support plates $=$ & 1 & & \\
\hline Diameter of Column & 1.05 & $\mathrm{ft}$ & \\
\hline Volume of biomass $=$ & 13.02 & $\mathrm{ft}^{3}$ & \\
\hline
\end{tabular}


Table 4.10 Summary of SMZ/VPB design parameters

\begin{tabular}{|c|c|c|c|c|c|}
\hline $\begin{array}{c}\text { Produced } \\
\text { Water } \\
\begin{array}{c}\text { Flowrate } \\
\text { (gpm) }\end{array}\end{array}$ & $\begin{array}{c}\text { Diameter } \\
\text { (ft) }\end{array}$ & Height (ft) & $\begin{array}{c}\text { Diameter } \\
\text { (ft) }\end{array}$ & Height (ft) & $\begin{array}{c}\text { Regeneration } \\
\text { Air Flowrate } \\
\text { (cfm) }\end{array}$ \\
\hline 6 & 2.80 & 10.20 & 2.10 & 3.80 & 9.0 \\
\hline 20 & 5.00 & 10.20 & 3.80 & 3.80 & 29.0 \\
\hline 40 & 7.20 & 10.20 & 5.40 & 3.80 & 58.0 \\
\hline
\end{tabular}

\subsubsection{SMZ/VPB Cost Estimation Correlations}

Cost estimates for the SMZ/VPB system were based on correlations for carbon steel packed towers (Peters, M., 2003) and fiberglass custom built columns (L.F.

Manufacturing, Quote 2006). Feed tank, pump and air blower costs were estimated from published cost correlations and vendor information (Peters, 2003, Mossman, 2006, AMETEK Products, 2006). Table 4.11 lists the cost estimates for the 6 gpm treatment system. Installation costs were estimated based on a percentage of the capital cost of the major equipment.

Table 4.11 SMZ capital costs - 6 gpm

\section{Capital Costs - SMZ}

(6 gpm)

\begin{tabular}{|c|c|c|c|c|}
\hline Cost of Column (\$) & Tower & Distributors & $\begin{array}{c}\text { Total } \\
/ \text { Column } \\
\end{array}$ & $\begin{array}{l}\text { Column } \\
\text { Costs (3) } \\
\end{array}$ \\
\hline Carbon steel (CS) & 8,000 & 500 & 8,500 & 25,500 \\
\hline Fiberglass (FG) & 3,040 & 500 & 3,540 & 10,620 \\
\hline Installed Costs & $\begin{array}{l}\text { Purchase } \\
\text { Cost }\end{array}$ & $\begin{array}{l}\text { Installation } \\
\text { (\% of Cost) }\end{array}$ & \multicolumn{2}{|c|}{ Installed Cost } \\
\hline Feed Tank (8000 gal) - CS & 12,000 & 30 & & 15,600 \\
\hline Feed Tank (8000 gal) - FG & 9,100 & 30 & & 11,830 \\
\hline Towers - Carbon Steel & 25,500 & 30 & & 32,500 \\
\hline Towers - Fiberglass & 10,620 & 30 & & 13,800 \\
\hline Pump & 70 & 10 & & 700 \\
\hline Air Blower & 2,000 & 10 & & 2,200 \\
\hline $\begin{array}{l}\text { Instrumentation ( } 15 \% \text { total } \\
\text { purchase of Fiberglass } \\
\text { system) }\end{array}$ & 3,600 & 15 & & 4,140 \\
\hline $\begin{array}{l}\text { Total Installed Cost - } \\
\text { Carbon Steel }\end{array}$ & & & & 55,140 \\
\hline $\begin{array}{l}\text { Total Installed Cost - } \\
\text { Fiber Glass }\end{array}$ & & & & 32,740 \\
\hline
\end{tabular}


Cost estimates were completed for the 20 gpm and 40 gpm treatment systems (Tables 4.12 and 4.13, respectively) using the same installation cost ratios and applicable cost correlations and quotes for tower, tank, pump and blower sizes.

Table 4.12 Capital costs for a 20 gpm SMZ system

\begin{tabular}{|c|c|c|c|c|}
\hline Cost of Column (\$) & Tower & Distributors & $\begin{array}{c}\text { Total } \\
\text { /Column }\end{array}$ & $\begin{array}{c}\text { Column } \\
\text { Costs (3) }\end{array}$ \\
\hline Carbon steel (CS) & 9300 & 700 & 10,000 & 30,000 \\
\hline Fiberglass (FG) & 4700 & 700 & 5400 & 16,200 \\
\hline Installed Costs & $\begin{array}{l}\text { Purchase } \\
\text { Cost }\end{array}$ & $\begin{array}{l}\text { Installation } \\
\text { (\% of Cost) }\end{array}$ & \multicolumn{2}{|c|}{ Installed Cost } \\
\hline Feed Tank (3 -8000 gal)CS & 36,000 & 30 & & 46,800 \\
\hline Feed Tank (3 -8000 gal)FG & 27,300 & 30 & & 35,490 \\
\hline Towers - Carbon Steel & 30,000 & 30 & & 39,000 \\
\hline Towers - Fiberglass & 16,200 & 30 & & 21,060 \\
\hline Pump - Reciprocating & 1,000 & 10 & & 1,100 \\
\hline Air Blower & 4,000 & 10 & & 4,400 \\
\hline $\begin{array}{l}\text { Instrumentation ( } 15 \% \text { of } \\
\text { Fiberglass system) }\end{array}$ & 7,300 & 15 & & 9,500 \\
\hline $\begin{array}{l}\text { Total Installed Cost - } \\
\text { Carbon Steel }\end{array}$ & & & & 100,800 \\
\hline $\begin{array}{l}\text { Total Installed Cost - } \\
\text { Fiber Glass }\end{array}$ & & & & 71,550 \\
\hline
\end{tabular}

Table 4.13 Capital costs for a 40 gpm SMZsystem

\begin{tabular}{|c|c|c|c|c|}
\hline Cost of Column (\$) & Tower & Distributors & $\begin{array}{c}\text { Total } \\
\text { /Column }\end{array}$ & $\begin{array}{l}\text { Column } \\
\text { Costs (3) }\end{array}$ \\
\hline Carbon steel (CS) & 10,500 & 1,000 & 11,500 & 34,500 \\
\hline Fiberglass (FG) & 6,500 & 1,000 & 7,500 & 22,500 \\
\hline Installed Costs & $\begin{array}{l}\text { Purchase } \\
\text { Cost }\end{array}$ & $\begin{array}{l}\text { Installation } \\
\text { (\% of Cost) }\end{array}$ & \multicolumn{2}{|c|}{ Installed Cost } \\
\hline Feed Tank (6 -8000 gal)CS & 72,000 & 30 & & 93,600 \\
\hline Feed Tank (6 -8000 gal)FG & 54,600 & 30 & & 71,000 \\
\hline Towers - Carbon Steel & 34,500 & 30 & & 44,900 \\
\hline Towers - Fiberglass & 22,500 & 30 & & 29,300 \\
\hline Pump - Reciprocating & 1,500 & 10 & & 1,650 \\
\hline Air Blower & 8,000 & 10 & & 8,800 \\
\hline $\begin{array}{l}\text { Instrumentation ( } 15 \% \text { of } \\
\text { Fiberglass system) }\end{array}$ & 13,000 & 15 & & 15,000 \\
\hline $\begin{array}{l}\text { Total Installed Cost - } \\
\text { Carbon Steel }\end{array}$ & & & & 163,950 \\
\hline $\begin{array}{l}\text { Total Installed Cost - } \\
\text { Fiber Glass }\end{array}$ & & & & 125,750 \\
\hline
\end{tabular}


Annualized costs based on $6 \%$ interest and a 20 year life were calculated using

$$
\text { Annualized Cost }(\$)=\text { Capital Cost } *\left[i^{*}(1+\mathrm{i})^{\mathrm{T}} /\left((1+\mathrm{i})^{\mathrm{T}}-1\right)\right]
$$

where $\mathrm{T}$ is the years of service and i represents the interest rate. The annualized costs were then normalized on a 1000 gal of treated water basis. The results of this analysis are presented in Table 4.14 .

Table 4.14 SMZ installed and annualized costs

\begin{tabular}{|l|c|c|c|c|}
\hline $\begin{array}{l}\text { SMZ } \\
\text { Flow Rate }\end{array}$ & $\begin{array}{c}\text { Tower } \\
\text { Diameter } \\
(\mathbf{f t})\end{array}$ & $\begin{array}{c}\text { Packed Bed } \\
\text { Height } \\
(\mathbf{f t})\end{array}$ & $\begin{array}{c}\text { Installed Cost } \\
\mathbf{( 3 ~ C o l u m n s )}\end{array}$ & $\begin{array}{c}\text { Annualized Cost } \\
\mathbf{( \$ )}\end{array}$ \\
\hline \multicolumn{5}{|c|}{ Carbon Steel } \\
\hline $6 \mathrm{gpm}$ & 2.8 & 10.2 & 55,140 & $\$ 1.59 / 1000 \mathrm{gal}$ \\
\hline $20 \mathrm{gpm}$ & 5.0 & 10.2 & 100,800 & $\$ 0.87 / 1000 \mathrm{gal}$ \\
\hline $40 \mathrm{gpm}$ & 7.2 & 10.2 & 163,950 & $\$ 0.71 / 1000 \mathrm{gal}$ \\
\hline \multicolumn{5}{|c|}{ Fiber glass } \\
\hline $6 \mathrm{gpm}$ & 2.8 & 10.2 & 32,740 & $\$ 0.94 / 1000 \mathrm{gal}$ \\
\hline $20 \mathrm{gpm}$ & 5.0 & 10.2 & 71,550 & $\$ 0.62 / 1000 \mathrm{gal}$ \\
\hline $40 \mathrm{gpm}$ & 7.2 & 10.2 & 125,750 & $\$ 0.54 / 1000 \mathrm{gal}$ \\
\hline
\end{tabular}

The same cost estimate correlations were used for the vapor phase biofilter for carbon steel packed towers (Table 4-15). Installation costs were estimated as $30 \%$ of the purchase cost and instrumentation was estimated at $25 \%$ of the purchase cost.

Annualized costs were based on a life of 20 years and $6 \%$ interest rate.

Table 4.15 Installed and annualized costs for vapor phase biofilter systems

\begin{tabular}{|c|c|c|c|c|c|c|}
\hline $\begin{array}{c}\text { SMZ } \\
\text { Rate }\end{array}$ & $\begin{array}{c}\text { VPB } \\
\text { Diameter } \\
(\mathrm{ft})\end{array}$ & $\begin{array}{c}\text { VPB } \\
\text { Packed } \\
\text { Bed } \\
\text { Height } \\
(\mathrm{ft})\end{array}$ & $\begin{array}{c}\text { Installed } \\
\text { Cost }\end{array}$ & $\begin{array}{c}\text { Instrumentation } \\
\text { Cost }\end{array}$ & $\begin{array}{c}\text { Total } \\
\text { Cost }\end{array}$ & $\begin{array}{c}\text { Annualized } \\
6 \% \text { interest, } 20 \\
\text { yr life }\end{array}$ \\
\hline $6 \mathrm{gpm}$ & 2.1 & 3.8 & 5,200 & 1,000 & 6,200 & $\$ 0.18 / 1000$ gal \\
\hline $20 \mathrm{gpm}$ & 3.8 & 3.8 & 6,240 & 1,200 & 7,440 & $\$ 0.06 / 1000$ gal \\
\hline $40 \mathrm{gpm}$ & 5.4 & 3.8 & 7,280 & 1,400 & 8,680 & $\$ 0.04 / 1000$ gal \\
\hline
\end{tabular}

Operating costs for the system have been calculated as shown in Table 4-16 for the $6 \mathrm{gpm}$ design feed rate. The calculations were based on the estimated SMZ replacement schedule and power costs associated with the air blower for regeneration and feed pumps for the system. Ideally, the SMZ will be replaced annually or semi-annually at a cost of $\$ 0.46 / \mathrm{kg} \mathrm{SMZ}$ for annual replacement. Power costs were estimated based on the 
Table 4.16 Operating costs for a $6 \mathrm{gpm}$ design flowrate

\begin{tabular}{|c|c|c|c|c|}
\hline $\begin{array}{c}\text { Operating Costs } \\
-6 \mathrm{gpm}\end{array}$ & & & & \\
\hline $\begin{array}{l}\text { SMZ } \\
\text { Replacement } \\
\text { Schedule } \\
\text { (months) }\end{array}$ & $\begin{array}{c}\text { Cost of SMZ } \\
\$ / y r \\
\end{array}$ & $\begin{array}{c}\text { SMZ } \\
\text { Cost/1000 gal } \\
\end{array}$ & $\begin{array}{l}\text { Power Costs } \\
\text { Cost/1000 } \\
\text { gal }\end{array}$ & $\begin{array}{l}\text { Total } \\
\text { Operating } \\
\text { Costs } \\
\text { Cost } / 1000 \text { gal }\end{array}$ \\
\hline 1.00 & 9658.54 & $\$ 3.17$ & $\$ 0.22$ & $\$ 3.39$ \\
\hline 3.00 & 3219.51 & 1.06 & 0.22 & 1.28 \\
\hline 6.00 & 1609.76 & 0.53 & 0.22 & 0.75 \\
\hline 9.00 & 1073.17 & 0.35 & 0.22 & 0.57 \\
\hline 12.00 & 804.88 & 0.26 & 0.22 & 0.48 \\
\hline
\end{tabular}

horsepower requirements of the air blower and produced water feed pump. For the 6 gpm feed rate, a $0.5 \mathrm{HP}$ reciprocating pump should provide adequate pressure for the SMZ operation; likewise, 1.0 HP for $20 \mathrm{gpm}$ and 1.5 HP for $40 \mathrm{gpm}$ feed flow rates (Mossman, 2006). The air blower will require a 0.25 to 0.5 HP motor (AMETEK, 2006). Based on motor efficiencies of 0.4 (Peters, 2003), and an average cost of electricity in the United States of \$0.0527/kilowatt-hr (Energy Information Administration, 2005), the annual operating costs for the air blower and pump for each system was estimated from: Annual cost $(\$)=\underline{\mathrm{HP} * 0.746 * \text { Power Cost }(\$ / \text { kilowatt-hr }) * \text { Hours of operation }}$ Motor efficiency

Assuming 350 days/year of operation, the annual power cost for operating the air blower and feed water pump at $6 \mathrm{gpm}$ was $\$ 620$ (\$0.22/1000 gal). Annual power costs for 20 gpm and 40 gpm design flowrates were $\$ 1240$ (\$0.12/1000 gal) and \$1650 (\$0.082/1000 gal), respectively.

Total annualized cost, including capital and operating costs, of the SMZ/VPB system treating 6 gallons per minute of produced water containing $25 \mathrm{mg} / \mathrm{L} \mathrm{BTEX}$ and assuming annual replacement of the SMZ was approximately $\$ 1.60 / 1000$ gallons $(\$ 0.06 / \mathrm{bbl})$ treated to $\$ 2.25 / 1000$ gallons $(\$ 0.09 / \mathrm{bbl})$ treated for a fiberglass and carbon steel system, respectively. Treating 20 gallons per minute of produced water results in estimated total annualized costs of $\$ 0.80 / 1000$ gal $(\$ 0.032 / \mathrm{bbl})$ to $\$ 1.05 / 1000$ gallons $(\$ 0.042 / \mathrm{bbl})$ for fiberglass and carbon steel systems, respectively. For 40 gallons per minute, the annualized costs were $\$ 0.66 / 1000$ gallons $(\$ 0.026 / \mathrm{bbl})$ to $\$ 0.83 / 1000$ gallons $(\$ 0.033 / \mathrm{bbl})$ for fiberglass and carbon steel systems.

\subsubsection{Reverse Osmosis Option}

Final treatment of produced water with total dissolved solids greater than 2,000 mg/L will generally require desalination. Successful use of reverse osmosis in the treatment of produced water is rare because of operational issues, such as fouling of the membranes 
due to the composition of produced water (Hayes, 2004 and Burnett 2004). The SMZ/VBP will remove and destroy the BTEX compounds that contribute to microbial growth on the membranes. While the SMZ/VBP does not remove organic acids present in the produced water, the removal of BTEX and filtration effects of the SMZ will provide additional water pre-conditioning prior to desalination.

The cost of reverse osmosis depends on several factors including: salinity of incoming water, plant capacity, site conditions, availability of qualified labor, energy costs and plant life and amortization (Ettouney, 2002). In general, cost estimates are classified into two levels based on the TDS level of the source water: brackish water (TDS $<10,000$ $\mathrm{mg} / \mathrm{L}$ ) and seawater (TDS $\geq 30,000 \mathrm{mg} / \mathrm{L}$ ). Costs include capital recovery, operation and maintenance and concentrate brine disposal. Operation and maintenance costs are dependent on pre- and post treatment requirements, membrane replacements and power costs. For example, sea water desalination requires high pressures typically greater than 800 psi, while brackish water pressures range from 250 to 400 psi (Welgemoed, 2005).

A number of studies have reported cost estimates for brackish water. Average operation and maintenance costs reported from a survey of 22 brackish water reverse osmosis treatment plants in the United States during 1999 were $\$ 1.28 / 1000$ gal of permeate produced (Welgemoed, 2005). A study prepared by HDR Engineering in 2000 for the Texas Water Development board estimated production costs of brackish groundwater range from $\$ 0.71$ to $\$ 2.37$ per 1000/gal. The higher costs are associated with higher TDS content and lower flow rates.

Capital costs for reverse osmosis systems are varied and depend greatly on capacity and treatment level required. The Texas Water Development board estimates that an average cost including capital costs, debt service and operating costs for brackish water is $\$ 1.50 / 1000$ gal and $\$ 2.50$ to $\$ 3.50 / 1000$ gal for sea water. (TWDB Desal, 2006).

Based on the ranges presented above, a general estimate of $\$ 2.50 / 1000$ gal for reverse osmosis treatment was used for cost comparisons in this study. This number is based on relatively low flowrates of 6, 20 and 40 gpm and a TDS value near 10,000 mg/L which places the influent at the upper end of the brackish water ranges. Fortunately, the effluent target for the reverse osmosis treatment is relatively high $(2000 \mathrm{mg} / \mathrm{L})$ if the produced water is re-used within the oil and gas industry or diluted with other waters for use in the power industry.

\subsubsection{Total Cost Estimates for SMZ/VPB with Reverse Osmosis}

The cost of a reverse osmosis system combined with the SMZ/VPB system represents the total treatment cost for a typical produced water system. A summary of the annualized capital and operational and maintenance costs of the SMZ/VPB with reverse osmosis is summarized in Table 4.17. 
Table 4.17 Cost estimate for SMZ/VPB with reverse osmosis

\begin{tabular}{|l|l|l|l|l|}
\hline & \multicolumn{2}{|c|}{ SMZ/VPB } & Reverse Osmosis & Total $/ 1000$ gal \\
& Fiberglass & \multicolumn{1}{|c|}{ Carbon Steel } & & \\
\hline 6 gpm & $\$ 1.60 / 1000$ gal & $\$ 2.25 / 1000$ gal & $\$ 2.50 / 1000$ gal & $\$ 4.10-\$ 4.75$ \\
\hline 20 gpm & $\$ 0.80 / 1000$ gal & $\$ 1.05 / 1000$ gal & $\$ 2.50 / 1000$ gal & $\$ 3.30-\$ 3.55$ \\
\hline 40 gpm & $\$ 0.66 / 1000$ gal & $\$ 0.83 / 1000$ gal & $\$ 2.50 / 1000$ gal & $\$ 3.16-\$ 3.33$ \\
\hline
\end{tabular}

The treatment cost estimates provided in Table 4.17 can be used to determine the feasibility of this system when compared to the current value of water in a given scenario based on site location, pre-treatment and storage availability, influent water quality and quantity and desired effluent quality.

\subsubsection{Cost Survey of Disposal Costs for Produced Water}

Treatment and disposal of co-produced water have a direct impact on the profitability of oil and gas production. In the past, open pit evaporation at the well site was the most economical option for smaller volumes of produced water. However, environmental concerns have motivated the industry to re-use produced water in exploration and production or dispose the water via salt water injection wells. This cost survey focuses on treatment and disposal costs associated with salt water injection wells which is the most common method for disposal in the U.S. (Boysen, personal communication, 2004).

The capital cost of drilling a salt water injection well is on the order of $\$ 2,000,000$ with another $\$ 1,000,000$ for constructing surface support structures. The industry designs these facilities for a 20 year life of a salt water disposal well, yielding an annualized cost at $6 \%$ interest rate of $\$ 261,554$. Assuming an annual disposal rate of 16 million gallons per well, the capital cost is $\$ 16.35 / 1000$ gal or $\$ 0.65 / \mathrm{bbl}$.

For companies without the resources to own salt water disposal wells, commercial disposal is available. It is estimated that in the San Juan Basin in northwestern New Mexico approximately one third of the salt water disposal is through company owned wells, one third through wells jointly owned with another producer and one third through commercially operated wells. (Christianson, 2004) Not including transportation costs, the average cost per barrel for disposal through salt water injection wells ranged from $\$ 0.04$ to $\$ 1.88$ for owned or co-owned versus commercially operated wells in 1998 and $\$ 0.30$ to $\$ 2.80$ in 2001 for operations in the San Juan Basin (Christianson, 2004). BC Technologies surveyed producers in the San Juan Basin during 2002 and 2004 and reported company owned re-injection costs ranging between $\$ 0.50$ to $\$ 0.60 / \mathrm{bbl}$ and $\$ 1.50$ to $\$ 2.50 / \mathrm{bbl}$ for commercial or contracted injection. These costs do not include transportation costs to the salt water disposal site. Transportation costs include water hauling equipment, manpower and fuel. Fuel costs, which have dramatically increased during the past five years, are the major contributor to transportation costs. 
Rocky Mountain No 2 Diesel Retail Sales by All Sellers (Cents per Gallon) Ref. Energy Information Administration, Department of Energy

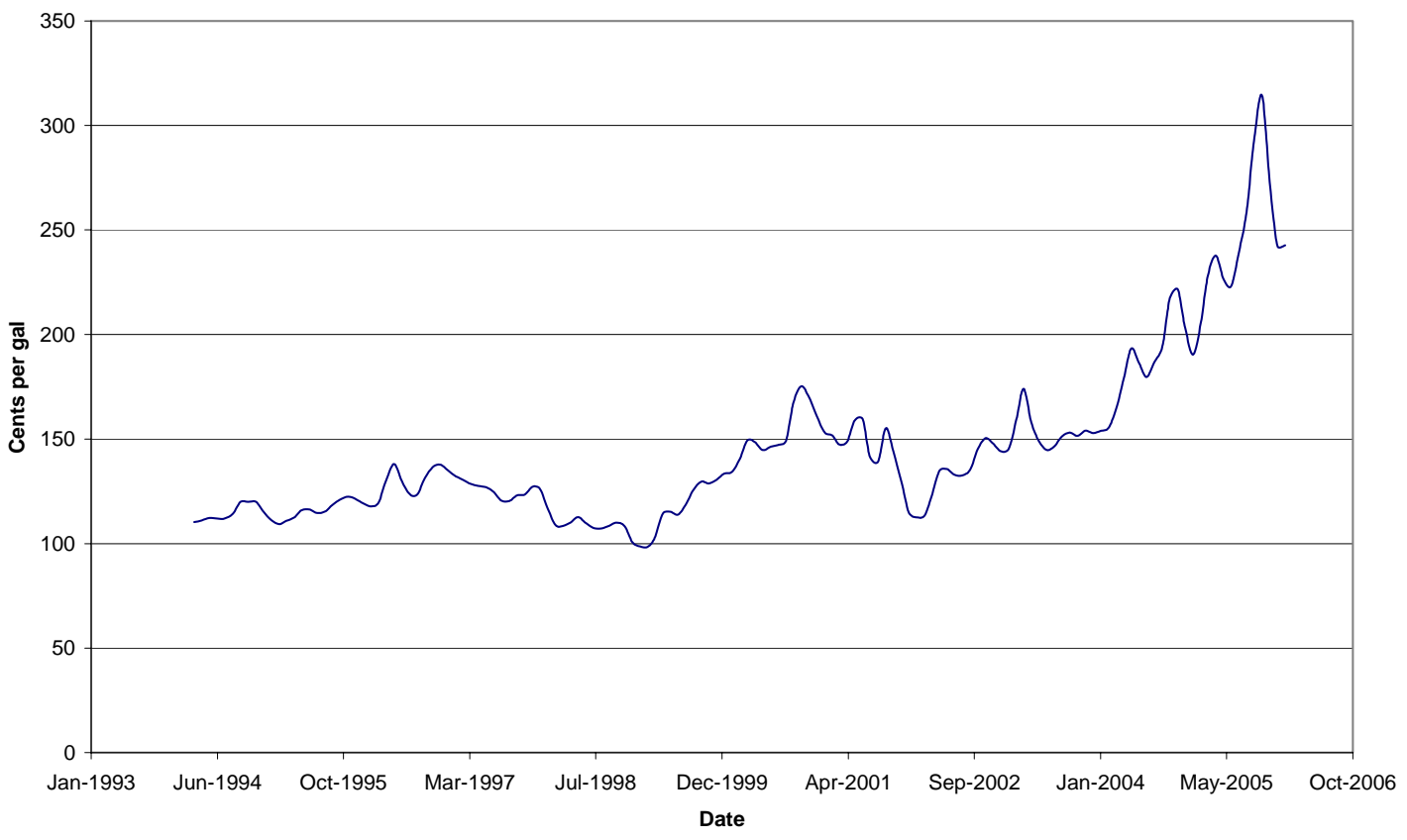

Figure 4.36 Diesel prices for 1993 - 2006

Transportation costs are a function of the remoteness of wells and the volume of water being moved. Remote wells with difficult access and located significant distances from the salt water disposal facility can increase disposal costs by $\$ 2.00$ to $\$ 2.50 / \mathrm{bbl}$. (Christianson, 2004) In addition to transportation costs, the cost of treatment prior to disposal must be included in the cost analysis. Salt water injection operation and maintenance costs include filtering and chemical treatment of the produced water, fuel and electricity costs and overhead for well repair. A summary of these costs is provided in Table 4.18.

Table 4.18 Injection operation and maintenance costs

\begin{tabular}{|l|l|}
\hline Chemical Treatment & $\$ 0.03$ to $\$ 0.05 / \mathrm{bbl}$ \\
\hline Filtering & $\$ 0.30 / \mathrm{bbl}$ \\
\hline Fuel/Electricity (on-site) & $\$ 0.20 / \mathrm{bbl}$ \\
\hline Misc & $\$ 0.05 / \mathrm{bbl}$ \\
\hline Well Repair & $\$ 0.02$ to $\$ 0.20 / \mathrm{bbl}$ \\
\hline Total Costs & $\$ .60$ to $\$ .80 / \mathrm{bbl}$ \\
\hline
\end{tabular}


Average operating costs reported by a producer in northwestern New Mexico for salt water re-injection of over four million barrels of produced water in 2004 was $\$ 0.60 / \mathrm{bbl}$. Total disposal costs, including transportation and operations costs, reported by BC Technologies and confirmed by an individual producer ranged from $\$ 1.50$ to $\$ 4.00 / \mathrm{bbl}$. These ranges were based on fuel costs prior to January, 2004. Incorporating the increase in fuel costs from January, 2004 to January, 2006 from $\$ 1.54 /$ gal to $\$ 2.42$ and assuming fuel costs are $50 \%$ of the total transportation costs, the estimated current total disposal costs range from $\$ 1.75 / \mathrm{bbl}$ to $\$ 4.90 / \mathrm{bbl}$ (see Table 4.19)

Table 4.19 Estimates of total costs for salt water disposal in 2006

\begin{tabular}{|c|l|l|}
\hline & Min & Max \\
\hline Total Cost $(\$ / \mathrm{bbl})$ & $1.50 \$ / \mathrm{bbl}$ & $4.00 \$ / \mathrm{bbl}$ \\
\hline Operating Costs (\$/bbl) & $0.60 \$ / \mathrm{bbl}$ & $0.80 \$ / \mathrm{bbl}$ \\
\hline $\begin{array}{c}\text { Transportation Costs } \\
(\$ / \mathrm{bbl})\end{array}$ & $0.90 \$ / \mathrm{bbl}$ & $3.20 \$ / \mathrm{bbl}$ \\
\hline $\begin{array}{c}\text { Fuel Cost } \\
(50 \% \text { Transportation) }\end{array}$ & $0.45 \$ / \mathrm{bbl}$ & $1.60 \$ / \mathrm{bbl}$ \\
\hline $\begin{array}{c}\text { Increase in Fuel Costs } \\
(2004 \text { to 2006) }\end{array}$ & $157 \%$ & $157 \%$ \\
\hline Increased Fuel Costs & $0.71 \$ / \mathrm{bbl}$ & $2.51 \$ / \mathrm{bbl}$ \\
\hline Total Costs (2006) & $1.76 \$ / \mathrm{bbl}$ & $4.91 \$ / \mathrm{bbl}$ \\
\hline
\end{tabular}

This cost survey provides a solid foundation for comparison and motivation to evaluate treatment options with the potential to reduce capital, operating and transportation costs.

\subsubsection{Cost of Treatment Compared to Cost of Current Water Supply Options}

The proposed SMZ/VPB system may be a viable alternative to the current salt water reinjection practice. Economic comparison of these two options was made using a price per 1000 gal or price per barrel of produced water treated (or disposed of). Since transportation costs will be the same for both systems, treatment costs were compared based only on operating and maintenance costs. Assuming that the same level of filtration, chemical pre-treatment and electricity requirements are maintained for both systems, the net cost for operating and maintenance for salt water injection is $\$ 0.07$ to $\$ 0.25 / \mathrm{bbl}$ or $\$ 1.75 / 1000$ gal to $\$ 6.25 / 1000$ gal. As shown in Table 4.17 , total costs for treatment of produced water using SMZ/VPB with reverse osmosis range from $\$ 3.16 / 1000$ gal to $\$ 4.75 / 1000$ gal. These values are based on an existing salt water disposal facility infrastructure providing bulk storage, separation and filtration. Reverse osmosis represents $53 \%$ to $79 \%$ of the cost of the proposed SMZ/VBP with reverse osmosis process. These costs may actually be lower due to on-site availability of 
concentrate brine disposal and less stringent effluent requirements, as most RO units are designed to treat to drinking water quality. While the treatment costs of $\$ 3.16 / 1000$ gal to $\$ 4.75 / 1000$ gal fall within the range of the current costs for deep injection of produced water, additional economic incentives are necessary for implementation. These incentives may come in the form of a tax credit for delivery of water to the Pecos River for operators in New Mexico (NMSA 7-2A-20) or reduction in costs in oil and gas exploration and recovery.

Currently, the cost of water from the San Juan River for use in San Juan Generating Facility owned and operated by the Public Service Corporation of New Mexico is $\$ 228 /$ acre-foot or $\$ 0.70 / 1000$ gal. Without considering transportation costs, the price of water will have to rise to $\$ 1030$ /acre-foot for the SMZ/VBP with reverse osmosis process to be competitive as a water resource. While seemingly unlikely, the recent increase to $\$ 228 /$ acre-foot was a 25 fold increase from the previous contract at \$9/acre-foot. Additionally, the nearby City of Farmington charges \$1.62/1000 gallons or \$527/acrefoot (Western Resource Advocates, 2006) for water. These rates indicate that the SMZ/VBP with reverse osmosis may become a viable treatment option for produced water.

\subsection{Regulatory Issues}

Treatment requirements for produced water will be defined by the end use and water quality criteria for each use. While some re-use of produced water has occurred in the oil and gas industry for operations such as pressurizing formations, no surface disposal or utilization of water in other industries has occurred in the state of New Mexico (Oil Conservation Division, August 2001). However, produced water from coal bed methane (CBM) wells has been used for agriculture in Wyoming and Montana. CBM produced water is typically low in BTEX concentrations and total dissolved solids. Disposal of treated produced water to surface waters and to industrial users will ease withdrawal limitations during droughts and supply additional water for downstream users. Industries potentially benefiting from the re-use of treated produced water include the power, oil and gas and agriculture industries. Each of these end uses will require industry specific water quality criteria and will be regulated by different local, state and federal rules and regulations.

\subsubsection{Beneficial Re-use versus Disposal}

Water rights are very important in the arid western United States. Each state has implemented a system that grants permitted rights for the withdrawal and use of ground and surface waters. The majority of the western states' water right systems are based on prior appropriation - first in time, first in right. This system becomes very complicated when dealing with multiple users and multiple priorities. Water that is co-produced during oil and gas production is treated as a waste product of the industry, unless the water is re-used outside the industry in a beneficial manner. 
Produced water is regulated very differently from groundwater brought to the surface for beneficial use. In the State of New Mexico, the Office of the State Engineer is charged with administering the state's water resources including surface and groundwater resources. However, produced water disposition is regulated by the Oil Conservation Division of the New Mexico Energy, Minerals and Natural Resources Department. The modification to the Oil and Gas Act through Senate Bill 313 in 2004 expanded the disposition of produced waters by stating the Oil Conservation Division is authorized to make rules, regulations and orders,

"to regulate the disposition of water produced or used in connection with the drilling for or producing of oil or gas or both and to direct surface or subsurface disposal of the water, including disposition by use in drilling for or production of oil or gas, in road construction or maintenance or other construction, in the generation of electricity or in other industrial processes, in a manner that will afford reasonable protection against contamination of fresh water supplies designated by the state engineer;"' (70-2-12 (15) NMAC 1978).

The inclusion of disposition of produced water in industrial processes and in the production of oil or gas allows for the treatment and re-use of produced water without identifying the original water rights owners. This is critical for the re-use of water from a centralized salt water disposal facility that processes large volumes of water from hundreds of individual wells.

\subsubsection{Discharge to Surface Waters}

The 1972 Clean Water Act (CWA) provides the statutory framework for the National Pollutant Discharge Elimination System (NPDES) permit program. Designed to regulate the discharge of pollutants from point sources to waters in the United States, the CWA gives the Environmental Protection Agency (EPA) the authority to set effluent limits to ensure the protection of the receiving water. The EPA works with individual states to develop a permit system and set technology-based and water quality-based limits. Anyone wishing to discharge water containing identified pollutants must first obtain an NPDES permit. The CWA allows the EPA to authorize state governments to implement NPDES permitting programs. Most of the western states currently have state level programs for issuing NPDES permits; however, the State of New Mexico is one of six states without a state level program. New Mexico is currently petitioning the EPA for state authorization for NPDES permits in New Mexico (NPDES -Specific State Program Status, June 2005, NMAC 20.6.5 Draft NMPDES Regulations, June 2005).

Discharge to surface waters must not degrade the receiving waters' quality. State level water quality commissions set discharge criteria. For example, in New Mexico any discharge to surface waters is regulated by the New Mexico Water Quality Control Commission (NMWQCC). The NMWQCC Regulation, Section 20.6, lists numeric criteria for any constituent listed on the EPA's toxic pollutant list for discharge to surface 
waters (NMWQCC 20.6.4.900 (J)). Similar regulations exist in other states that provide the target effluent limits for any treatment process discharging produced water to surface waters.

In 2002, the New Mexico legislature passed a bill allowing for a tax credit for produced water delivered to the Pecos River to encourage oil and gas producers to treat the produced water to a level that can be used to supplement flow in the Pecos River. Because produced water contains pollutants identified on the EPA's toxic pollutant list, operators wishing to deliver water to the Pecos River will be required to obtain an NPDES permit. NPDES permits are based on water quality standards for specific water bodies. States have the ability to set numeric standards or simply state that the incoming water does not degrade the designated uses of the surface water.

\subsubsection{Power Industry}

Water is a critical element in the production of electricity. Power plants utilize water in cooling systems, steam generation and air pollution control. The San Juan Generating Station (SJGS), owned by the Public Service Company of New Mexico (PMN) is an 1800 MW coal fired power plant located near Farmington, NM. Over the years, the facility has worked to eliminate all water discharges by recycling and reusing water within the plant. Final aqueous waste is sent to the evaporating ponds on site. Annually, SJGS utilizes approximately 24,000 acre-ft of water, pumping nearly 18,000 gallons per minute from the San Juan River. It is estimated the McGrath Salt Water Disposal Site, owned and operated by Burlington Resources, Inc. could provide approximately 700 acre-ft of water per year (Personal communication Matt Lavery, PMN, 5/13/2005). The two primary driving forces for investigating additional sources of water for SJGS is the lack of water in the San Juan River during low flow years and the increase in cost of river water beginning in January of 2006 from a historically low value of \$9/acre-ft to current market value of $\$ 228$ /acre-ft.

The primary use of water by SJGS is in the cooling towers; however, water is also used in absorbers (air pollution control) and brine concentrators producing condensate as boiler feed water. The majority of the water loss experienced by the plant is through cooling tower evaporation and loss. Additional water loss occurs during boiler blow-downs, when boiler waste is sent to the evaporating ponds and as flue gas moisture exiting the stack. The primary constituents of concern in the influent water are total dissolved solids (TDS), chlorides and BTEX. The TDS and chlorides cause scaling and corrosion issues in the power plant. The San Juan River typically contains between 300 and $500 \mathrm{mg} / \mathrm{L}$ TDS and 10 to $20 \mathrm{ppm}$ chlorides (Fayad, 2005). Measured concentrations from a salt water disposal site in New Mexico are shown in Table 4.20. 
Table 4.20 Water quality of produced water and targets for SJGS

\begin{tabular}{|l|c|c|c|}
\hline & TDS (mg/L) & $\begin{array}{l}\text { Chlorides } \\
\text { (mg/L) }\end{array}$ & BTEX (mg/L) \\
\hline $\begin{array}{l}\text { Current Plant } \\
\text { Influent }\end{array}$ & 500 & 20 & 0 \\
\hline $\begin{array}{l}\text { Produced Water } \\
\text { at McGrath } \\
\text { SWD Facility }\end{array}$ & 10,000 & 5360 & 23 \\
\hline $\begin{array}{l}\text { Produced Water } \\
\text { Targets for } \\
\text { SJGS }\end{array}$ & $\begin{array}{c}2000^{*} \\
\text { Dependent on } \\
\text { point of use }\end{array}$ & 1000 & \\
\hline
\end{tabular}

Several scenarios have been considered by SJGS for incorporating produced water into their facility. These include direct use of produced water into the scrubbers, which can handle higher chlorides, dilution of produced water with river water and treatment of the produced water.

K. Zammit and M. DiFilippo, EPRI, studied the use of produced water in the San Juan Generating Station re-circulating cooling systems under a DOE Award, No. 41906. In their Semi-Annual Technical Progress Report (Zammit, Oct. 2004), they provided a list for water quality criteria by process area for the SJGS. This list is presented here in Table 4.21.

Table 4.21 Water quality goals for SJGS (Zammit, Oct. 2004)

\begin{tabular}{|l|l|l|}
\hline $\begin{array}{l}\text { Cooling } \\
\text { Tower }\end{array}$ & Ca & $\begin{array}{l}1600 \mathrm{mg} / \mathrm{L} \text { as } \\
\mathrm{CaCO}_{3}\end{array}$ \\
\hline & $\mathbf{S i O 2}$ & $150 \mathrm{mg} / \mathrm{L}$ \\
\cline { 2 - 3 } & $\mathrm{Cl}$ & $1000 \mathrm{mg} / \mathrm{L}$ \\
\hline \multirow{2}{*}{ Absorbers } & Cl & $5000 \mathrm{mg} / \mathrm{L}$ \\
\hline & & $2000 \mathrm{mg} / \mathrm{L}$ \\
\hline Ash System & TDS & $9000 \mathrm{mg} / \mathrm{L}$ \\
\hline $\begin{array}{l}\text { Brine } \\
\text { Concentrators }\end{array}$ & Cl & \\
\hline
\end{tabular}


The EPRI report evaluates ten off-the-shelf treatment technologies for treating produced water for supplemental water for SJGS. These technologies include reverse osmosis and brine concentration to reduce the chlorides and TDS. Pretreatment to reduce fouling due to mineral scale, particulate matter, biological films, non-soluble oils and colloidal matter must be included as well. (Zammit, 2004). Their recommendation for treating produced water containing 14,000 mg/L TDS includes a combination of HERO ${ }^{\circledR}$ (modified reverse osmosis) and brine concentration due to the potential of this option for producing the lowest capital and operating costs. (Zammit, 2004). The presence of volatile organic compounds (VOCs) such as benzene, toluene, ethylbenzene and xylene presents additional challenges in terms of re-use of produced water by SJGS. Coal bed methane (CBM) produced water typically contains less than $0.5 \mathrm{mg} / \mathrm{L}$ of these compounds, while produced water from conventional wells may run between 10 and $20 \mathrm{mg} / \mathrm{L}$ (Zammit, 2004). Sites typically receive both conventional and CBM produced water. The water at the New Mexico site studied in this research after filtration, just prior to re-injection contains up to $23 \mathrm{mg} / \mathrm{L}$ of BTEX (Zammit, 2004). Due to dilution and loss during aeration, Zammit and DiFilippo believe BTEX levels will be non-detectable in the absorber liquor or cooling tower circulating water (Zammit, 2004). No data to justify this statement was provided, and it is not clear that transmission to the atmosphere would be an acceptable treatment option for BTEX.

Treatment of produced water via SMZ/VPB system would remove and destroy the BTEX prior to desalination process, such as reverse osmosis, brine concentration or electrodialysis. Removal of these compounds will reduce fouling of membranes used in desalination treatment. In addition, SMZ/VPB treatment can be performed on site at or at a central collection system in the San Juan Basin.

The current issue with use of produced water in the San Juan Basin is delivering produced water to SJGS. A bill in the 2004 New Mexico State Legislature proposed a tax credit for construction of a pipeline and collection system in the region. However, the tax credit was not approved and trucking costs would be prohibitive. M. Lavery, PMN Director of Water Resources, has investigated use of abandoned pipelines and "close-in" collection of produced water for use at SJGS; as well as satellite treatment stations resulting in smaller pipelines. While delivery options are still being pursued, treatment of the produced water for use in the power industry must focus on reducing the total dissolved solids, chlorides and BTEX.

\subsubsection{Oil and Gas Industry}

Re-use and disposal of produced water within the oil and gas industry is regulated by state level oil and gas agencies. These agencies monitor and permit surface and subsurface disposal methods (such as salt water injection and evaporation and re-use in road construction and maintenance) subsequent to oil and gas exploration and production. The primary constituents of concern are chlorides, iron, hardness and hydrogen sulfide. 
In 2002, Marathon Oil reported using over 4,000,000 gallons of produced water in their drilling operations. The produced water was deemed usable if total dissolved solids were less than $15,000 \mathrm{mg} / \mathrm{L}$. The water was treated to minimize hydrogen sulfide concentrations to prevent personnel exposure and equipment corrosion.

Production specialists in New Mexico are investigating re-use of produced water in cementing operations and fracturing of formations. The recommended water quality limits presented in Table 4.22 are being considered by operators in northwestern New Mexico (Jim Jones, personal communication, July 2005).

Table 4.22 Water quality limits for the oil and gas industry

\begin{tabular}{|l|l|l|}
\hline & Frac Fluids & Cement Water \\
\hline Sodium Chloride & $<8 \%$ & $<10 \%$ \\
\hline Hardness & $<1000 \mathrm{ppm}$ & ---- \\
\hline Iron & $<10 \mathrm{ppm}$ & ---- \\
\hline BTEX & Not regulated & Not regulated \\
\hline
\end{tabular}

Expanded re-use of produced water in the oil and gas industry will reduce disposal costs associated with re-injection or evaporation. Each producer will have to evaluate how best to incorporate produced water in their processes based on availability and transportation and handling costs.

\subsubsection{Agriculture Industry}

Treated produced water utilized in stock tanks not directly discharged into surface waters, does not require a NPDES permit. Under the 40 CFR 435, EPA Regulations, Subpart E, produced water located onshore, in the continental United States and west of the $98^{\text {th }}$ meridian that is good enough quality for wildlife or livestock watering or other agricultural uses can be discharged to the surface without a permit; as long as the oil and grease content is less than $35 \mathrm{mg} / \mathrm{L}$. The State of New Mexico has established certain criteria for water used for irrigation and livestock watering.

The 2005 revision of New Mexico Water Quality Rule 20.6.4 NMAC (20.6.4.900 (D)), set numeric criteria that apply for Irrigation and Irrigation Storage. These criteria include a limit of dissolved selenium of $0.13 \mathrm{mg} /$ liter and $0.25 \mathrm{mg} / \mathrm{liter}$, if the dissolved selenium is in the presence of more than $500 \mathrm{mg} /$ liter of sulfates. A summary of the metal criteria is presented in Table 4.23. 


\section{Table 4.23 Irrigation Numeric Criteria - NMWQ 20.6.4}

\begin{tabular}{||l||l||}
\hline Aluminum & $5000 \mathrm{ug} / \mathrm{L}$ \\
\hline \hline Arsenic & $100 \mathrm{ug} / \mathrm{L}$ \\
\hline \hline Boron & $750 \mathrm{ug} / \mathrm{L}$ \\
\hline \hline Cadmium & $10 \mathrm{ug} / \mathrm{L}$ \\
\hline \hline Chromium & $100 \mathrm{ug} / \mathrm{L}$ \\
\hline \hline Cobalt & $50 \mathrm{ug} / \mathrm{L}$ \\
\hline \hline Copper & $200 \mathrm{ug} / \mathrm{L}$ \\
\hline \hline Lead & $5000 \mathrm{ug} / \mathrm{L}$ \\
\hline \hline Molybdenum & $1000 \mathrm{ug} / \mathrm{L}$ \\
\hline \hline Vanadium & $100 \mathrm{ug} / \mathrm{L}$ \\
\hline \hline Zinc & $2000 \mathrm{ug} / \mathrm{L}$ \\
\hline \hline
\end{tabular}

Organic chemicals, such as benzene, toluene or ethylbenzene are not listed as compounds regulated under New Mexico Water Quality Rule 20.6.4.

The same rule lists numeric criteria for livestock watering which are provided in Table 4.24:

These criteria have been established for groundwater containing less than $10,000 \mathrm{mg} / \mathrm{L}$ total dissolved solids that is to be used for irrigation or livestock watering. Treated produced water that could be used for irrigation or livestock watering would need to meet these criteria.

Use of produced water from coal bed methane wells in agriculture is generally acceptable due to low concentrations of volatile organics and total dissolved solids. Areas in Wyoming and Montana are utilizing produced water from coal bed methane wells for livestock watering and irrigation. However, recent concerns regarding soil contamination and aquifer dewatering have lead to lawsuits and injunctions halting new drilling permits for coal bed methane extraction in southeastern Montana (Northern Plains Resource Council, 2005).

New Mexico coal bed methane wells are generally from mature fields and produce fewer barrels of water per million cubic feet of gas than newer wells in Montana and Wyoming. (Kuipers 2004). Water analysis of the New Mexico wells indicates much higher concentrations of total dissolved solids, bicarbonates and chlorides (Kuipers 2004). Research has indicated that varying levels of sodium, calcium and magnesium can 
Table 4.24 Livestock water limits, NMWQ 20.6.4

\begin{tabular}{||l|l||}
\hline ALUMINUM (UG/L) & 500 \\
\hline Arsenic (ug/L) & 20 \\
\hline Barium (mg/L) & 10 \\
\hline Boron (ug/L) & 5000 \\
\hline Cadmium (ug/L) & 5 \\
\hline Chromium (ug/L) & 1000 \\
\hline Cobalt (ug/L) & 1000 \\
\hline Copper (ug/L) & 500 \\
\hline Fluoride (mg/L) & 2 \\
\hline Lead (ug/L) & 100 \\
\hline Mercury (ug/L) & 10 \\
\hline Nickel (ug/L) & 250 \\
\hline Nitrate+Nitrite (mg/L as N) & 132 \\
\hline Vanadium (ug/L) & 100 \\
\hline Selenium (ug/L) & 50 \\
\hline Zinc (mg/L) & 5 \\
\hline Adjusted gross alpha (pCi/L) & 15 \\
\hline $\begin{array}{l}\text { Radium 226+Radium } 228 \\
\text { (pCi/L) }\end{array}$ & 30.0 \\
\hline Tritium (pCi/L) & $\mathbf{2 0 , 0 0 0}$ \\
\hline \hline
\end{tabular}

drastically affect soil infiltration rates and permeability. Ayers and Westcot (1985) have shown that increasing sodium adsorption rate, SAR and salinity of applied water result in moderate to severe reductions in infiltration rates. The sodium adsorption rate is a ratio of the sodium ion concentration to the square root of the sum of the calcium ion and magnesium ion concentrations in meq/L:

$$
\mathrm{SAR}=\frac{\mathrm{Na}^{+}}{\left(\left[\mathrm{Ca}^{2+}\right]+\left[\mathrm{Mg}^{2+}\right]\right)^{1 / 2}}
$$

Target SAR values for use of treated produced water in agriculture have been proposed by Tom Hayes and Dan Arthur in their report, "Overview of Emerging Produced Water Treatment Technologies" (Hays, October 2004). In this report, they state that soils with SAR values greater than 12 suffer from decreased water penetration. Hayes and Arthur recommend TDS and SAR limits presented in Table 4.25. These values vary depending on the end use: 
Table 4.25 Recommended TDS and SAR limits

\begin{tabular}{|c|c|c|}
\hline & Irrigation & Livestock \\
\hline TDS (mg/L) & 2,000 & 5,000 \\
\hline SAR & 6 & $5-8$ \\
\hline
\end{tabular}

SAR values for produced water from the San Juan Basin in Colorado, New Mexico, Arizona and Utah range from 120.9 to 301.6 (Hayes, 2004). These values indicate treatment options for produced water from the San Juan Basin will require desalination, and possibly water softening, to reduce the SAR values to acceptable limits for use in irrigation and/or livestock watering.

If the use of the treated produced water in the agricultural industry is deemed "beneficial" to the end-user, instead of a method of disposing of the produced water, the water rights to the water must be identified. In many of the western states this has already been done. For example in Montana and Wyoming, operators must have surface owner agreements and groundwater appropriation rights. (ALL Consulting, 2004)

As long as the produced water is not utilized for individual beneficial use and is disposed of in accordance with Rule 19.15.9.715 Disposition of Produced Water by Use, water rights should not be an issue. However, if a well head treatment is developed and treated water is disposed of on the land surface or sub-surface, water rights issues and surface owner agreements will need to be addressed. 


\section{REFERENCES}

Abumaizar, R. J., Kocher, W., and Smith, E. H. (1998). "Biofiltration of BTEX contaminated air streams using compost-activated carbon filter media." Journal of Hazardous Materials, 60(2), 111-126.

Allen, D. T., and Rosselot, K. S. (1994). "Pollution Prevention at the Macro Scale Flows of Wastes, Industrial Ecology and Life-Cycle Analyses." Waste Management, 14(3-4), 317-328.

Alonso, C., Suidan, M. T., Sorial, G. A., Smith, F. L., Biswas, P., Smith, P. J., and Brenner, R. C. (1997). "Gas treatment in trickle-bed biofilters: Biomass, how much is enough?" Biotechnology and Bioengineering, 54(6), 583-594.

Al-Rayes, A. W., Kinney, K. A., Seibert, A. F., and Corsi, R. L. (2001). "Load dampening system for vapor phase bioreactors." Journal of Environmental Engineering-Asce, 127(3), 224-232.

Altare, C., Bowman, R.S., Sullivan, E.J., Katz, L.E., and Kinney, K.A., "Removal of Organic Contaminants from Produced Water Using a Surfactant-Modified Zeolite System", presentation at the Geological Society of America Annual Meeting \& Exposition, Salt Lake City, UT, October 16-19, 2005.

American Petroleum Institute (API), 2000. Overview of exploration and production waste volumes and waste management practices in the United States. API, Washington, D.C.

AMETEK Products, www.ametektmd.com, EN101 Regenerative Blower Specs, 2006.

ASTM, in Annual Book of ASTM Standards, Soil and Rock (I): 04.08, American Society for Testing Materials, West Conshohocken, PA, 1995.

Barrer, R.M.; Papadopoulos, R.; Rees, L.V.C. (1967) "Exchange of Sodium in Clinoptilolite by Organic Cations." Journal of Inorganic and Nuclear Chemistry. 29, 2047-2063.

Bilstad, T.; Espedal, E. "Membrane Separation of Produced Water. (1996)" Water Science and Technology. 34 (9) 239-246.

Bowman, R.S.,Haggerty, G. M., Huddleston, R.G., Neel, D., Flynn, M. M, in Sabatini, D.A., Knox, R. C., Harwell, J. H., (Editors), Surfactant-enhanced subsurface remediation, American Chemical Society, Washington, DC, 1995, p. 54.

Bowman, R.S.; Sullivan, E.J.; Li, Z. "Mechanisms of Contaminant Sorption by Surfactant-Modified Zeolite" In Proceedings of the WERC/HSRC 1997 Joint Conference on the Environment. April 22-24, 1997. Albuquerque, New Mexico. 104-108.

Boysen, D.B., B.C. Technologies, personal communication, December, 2004.

Briggs, P.H, in Arbogast, B.F., (Editor), Analytical methods manual for the Mineral Resources Program Arbogast, B.F. ed., U.S. Geological Survey: U.S. Geological Survey Open-Fil, U.S. Geological Survey, Washington, D.C., 1996, p.77.

Burnett, D. B., Global Petroleum Institute, Texas Water Resources Institute, Texas A \& M University, "Potential for Beneficial Use of Oil and Gas Produced Water", www.twdb.state.tx.us , 2004.

Cal, M. P., Rood, M. J., and Larson, S. M. (1996). "Removal of VOCs from humidified gas streams using activated carbon cloth." Gas Separation \& Purification, 10(2), 117-121. 
California MTBE Research Partnership. "Evaluation of the Applicability of Synthetic Resin Sorbents for MTBE Removal from Water." Ed. G. Melin of National Water Research Institute. December 1999.

Chang, K. S., Lu, C. Y., and Lin, M. R. (2001). "Treatment of volatile organic compounds from polyurethane and epoxy manufacture by a trickle-bed air biofilter." Journal of Bioscience and Bioengineering, 92(2), 126-130.

Chen, C. Y., and Wu, S. C. (1998). "The influence of relative humidity on the adsorption of toluene by soils - Interpretation with the adsorption energy distribution functions." Chemosphere, 37(8), 1437-1444.

Chen, Y.L.; Chen, S.; Frank, C.; Israelachvili, J. (1992) "Molecular Mechanisms and Kinetics During the Self-Assembly of Surfactant Layers." Journal of Colloid and Interface Science. 153, 244-265.

Chiou, C. T.; Porter, P. E.; Schmedding, D. W. (1983) "Partition equilibria of nonionic organic compounds between soil organic matter and water". Environ. Sci. Technol. $17,227-231$.

Christianson, B., Burlington Industries, personal communication, December 2004.

Cox, H. H. J., and Deshusses, M. A. (1999). "Chemical removal of biomass from waste air biotrickling filters: Screening of chemicals of potential interest." Water Research, 33(10), 2383-2391.

Cox, H. H. J., and Deshusses, M. A. (2002). "Effect of starvation on the performance and re-acclimation of biotrickling filters for air pollution control." Environmental Science \& Technology, 36(14), 3069-3073.

Crittenden, J. C., Cortright, R. D., Rick, B., Tang, S. R., and Perram, D. (1988). "Using Gac to Remove Vocs from Air Stripper Off-Gas." Journal American Water Works Association, 80(5), 73-84.

Deeb, R. A. and Alvarez-Cohen, L (1999) "Temperature Effects and Substrate Interactions During the Aerobic Biotransformation of BTEX Mixtures by TolueneEnriched Consortia and Rhodococcus rhodochrous." Biotechnol. Bioeng., vol. 62, no. 5, 526-536.

Deeb, R. A., Hu, H. Y., Hanson, J. R., Scow, K. M., and Alvarez-Cohen, L. (2001). "Substrate interactions in BTEX and MTBE mixtures by an MTBE-degrading isolate." Environmental Science \& Technology, 35(2), 312-317.

Delhomenie, M. C., and Heitz, M. (2005). "Biofiltration of air: A review." Critical Reviews in Biotechnology, 25(1-2), 53-72.

Deshusses, M. A., Hamer, G. and Dunn, I. J. (1995) "Behavior of Biofilters for Waste Air Biotreatment." Environ. Sci. Technol., vol. 29, 1048-1058.

Deshusses, M. A. (1997). "Transient behavior of biofilters: Start-up, carbon balances, and interactions between pollutants." Journal of Environmental Engineering-Asce, 123(6), 563-568.

Deshusses, M. A., Webster, T. S., (2000). "Construction and economics of a pilot/fullscale biological trickling filter reactor for the removal of volatile organic compounds from polluted air”. J. Air Waste Manage. Assoc. 50, 1947-1956.

Dewulf, J.; Van Langenhove H.; Grare S. (1999) "Sediment / Water and Octanol / Water Equilibrium Partitioning of Volatile Organic Compounds: Temperature Dependence in the $2-25^{\circ} \mathrm{C}$ Range" Water Research 33 (10) 2424-2436. 
Dirk-Faitakis, C., and Allen, D. G. (2003). "Biofiltration of cyclic air emissions of alphapinene at low and high frequencies." Journal of the Air \& Waste Management Association, 53(11), 1373-1383.

Doula, M.; Ioannou, A.; Dimirkou, A. "Copper Adsorption and Si, Al, Ca, Mg, and Na Release from Clinoptilolite.” Journal of Colloid and Interface Science. 245 (2) 237 250.

du Plessis, C. A., Strauss, J. M., and Riedel, K. H. J. (2001). "BTEX catabolism interactions in a toluene-acclimatized biofilter." Applied Microbiology and Biotechnology, 55(1), 122-128.

Energy Information Administration, Department of Energy, www.eia.doe.gov ,International Energy Data and Analysis, 2006

EPA NPDES, Federal Register V. 66, No. 14, pp.6607-6610

Ettouney, H. M., H. T. El-Dessouky, R. S. Faibish and P. J Gowin, "Evaluating the Economics of Desalination", www.cepmagazine.org, December 2002, pgs 32 -39.

Fillo, J.P.; Koraido, S.M.; Evans, J.M. "Sources, Characteristics, and Management of Produced Waters from Natural Gas Production and Storage Operations." Produced Water. Eds. J.P. Ray and F.R. Engelhart. Plenum Press. New York, New York. 1992, 151-161.

Freire, D. D. C., Cammarota, M. C., and Sant'anna, G. L. (2001). "Biological treatment of oil field wastewater in a sequencing batch reactor." Environmental Technology, 22(10), 1125-1135.

Gallup, D.L.; Isacoff, E.G.; Smith, D.N.III. (1996) “Use of Ambersorb® Carbonaceous Adsorbent for Removal of BTEX Compounds from Oil-Field Produced Water." Environmental Progress. 15 (3) 197-203.

Gilbert, Y., Le Bihan, Y., Buelna, G., and Lessard, P. (2005). "Application of respirometry to monitoring the biomass activity of a biofilter on an organic bed used to treat pig manure." Water Quality Research Journal of Canada, 40(2), 155 163.

Gupta, R., (2001). "Effects of competitive sorption and salinity on the sorption of BTEX compounds in produced water onto surfactant-modified zeolite". MS Thesis. University of Texas at Austin, TX, USA.

Haggerty, G.M.; Bowman, R.S. (1994) "Sorption of Chromate and Other Inorganic Anions by Organo-zeolite." Environmental Science and Technology. 28 (3) 452458.

Hays, T. and Arthur, D., "Overview of Emerging Produced Water Treatment Technologies." Presented at the 11th Annual International Petroleum Environmental Conference. Albuquerque, NM, October 12 - 15, 2004.

Hegeman, W. J. M.; van der Weijden, C. H.; Loch, J. P. G. (1995) "Sorption of benzo[a]pyrene and phenanthrene on suspended harbor sediment as a function of suspended sediment concentration and salinity: a laboratory study using the cosolvent partition coefficient”. Environ. Sci. Technol. 29, 363-371.

Jacobs, R.P.W.M.; Grant, R.O.H.; Kwant, J.; Marquenie, J.M.; Mentzer, E. "The Composition of Produced Water From Shell Operated Oil and Gas Production in the North Sea." Produced Water. Eds. J.P. Ray and F.R. Engelhart. Plenum Press. New York, New York. 1992. 13-21. 
Janks, J.S.; Cadena, F. "Investigations into the Use of Modified Zeolites for Removing Benzene, Toluene, and Xylene From Saline Produced Water." Produced Water. Eds. J.P. Ray and F.R. Engelhart. Plenum Press. New York, New York. 1992. 473-487.

Jaynes, W.F., and Vance, G. F., "BTEX Sorption by Organo-Clays: Cosorptive Enhancement and Equivalence of Interlayer Complexes," Soil Sci. Soc. Am. J., 60, 1742-1749 (1996).

Jorio, H., Bibeau, L., and Heitz, M. (2000). "Biofiltration of air contaminated by styrene: Effect of nitrogen supply, gas flow rate, and inlet concentration." Environmental Science \& Technology, 34(9), 1764-1771.

Jutras, E. M., Smart, C. M., Rupert, R., Pepper, I. L. \& Miller, R. M. (1997) "Field-Scale Biofiltration of Gasoline Vapors Extracted from Beneath a Leaking Underground Storage Tank." Biodegradation, vol. 8, 31-42.

Katz, L. E., R. S. Bowman, E.J. Sullivan, "Treatment of Produced Oil and Gas Waters with Surfactant-Modified Zeolite”, Final Technical Report, Nov. 2003, DOE Award Number: DE-AC26-99BC15221

Kinney, K. A., Loehr, R. C., and Corsi, R. L. (1999). "Vapor-phase bioreactors: Avoiding problems through better design and operation." Environmental Progress, 18(3), 222-230.

Kwon, J.-H.; Liljestrand, H. M.; Katz, L. E. Thermodynamics of partitioning of selected endocrine disrupting chemicals between water and synthetic membrane vesicles. (2006).

Laemmli, U.K, Nature 227 (1970) 680.

Lawrence, A.W.; Miller, J.A.; Miller, D.L.; Hayes, T.D. "Regional Assessment of Produced Water Treatment and Disposal Practices and Research Needs." Presented at SPE/EPA Exploration and Production Environmental Conference. Houston, Texas. March 27-29. 1995. SPE 029729.

Leson, G., and Smith, B. J. (1997). "Petroleum environmental research forum field study on biofilters for control of volatile hydrocarbons." Journal of Environmental Engineering-Asce, 123(6), 556-562.

Leson, G., and Winer, A. M. (1991). "Biofiltration - an Innovative Air-Pollution Control Technology for Voc Emissions." Journal of the Air \& Waste Management Association, 41(8), 1045-1054.

Li, C. N., and Moe, W. M. (2005). "Activated carbon load equalization of discontinuously generated acetone and toluene mixtures treated by biofiltration." Environmental Science \& Technology, 39(7), 2349-2356.

Li, Z.; Bowman, R.S. "Counterion Effects on the Sorption of Cationic Surfactant and Chromate on Natural Clinoptilolite.” Environmental Science and Technology. 31 (8) (1997) 2407-2412.

Li, Z.; Bowman, R.S. "Regeneration of Surfactant-Modified Zeolite After Saturation with Chromate and Perchloroethylene." Water Research. 35 (1) (1997) 322-326.

Li, Z. H., and Bowman, R. S. (1998). "Sorption of perchloroethylene by surfactantmodified zeolite as controlled by surfactant loading." Environmental Science \& Technology, 32(15), 2278-2282.

Li, Z.; Roy, S.J.; Zou, Y.; Bowman, R.S. "Long-Term Chemical and Biological Stability of Surfactant-Modified Zeolite.” Environmental Science and Technology. 32 (17) (1998) 2628-2632. 
Li, Z. "Sorption kinetics of hexadecyltrimethylammonium on natural clinoptilolite", Langmuir, v15, n19, sep 1999, p6428-6445.

Li, Z. H., Burt, T., and Bowman, R. S. (2000). "Sorption of ionizable organic solutes by surfactant modified zeolite." Environmental Science \& Technology, 34(17), 37563760.

Li, Z.; Bowman, R.S. "Regeneration of Surfactant-Modified Zeolite After Saturation with Chromate and Perchloroethylene." Water Research. 35 (1) (2001) 322-326.

Li, Z.; Alessi, D.; Allen, L. "Influence Selected Metal Cations onto Clinoptilolite Quality. 31 (4) (2002) 1106-1114.

Li, Z. "Influence of Solution $\mathrm{pH}$ an Ionic Strength on Chromate Uptake by Surfactant Modified Zeolite." Journal of Environmental Engineering. 130 (2) (2004) 205-208.

Lide, D.R. CRC Handbook of Chemistry \& Physics. 75th Edition. CRC Press, Boca Raton, FL. (1994)

Lu, C. Y., Chu, W. C., and Lin, M. R. (2000). "Removal of BTEX vapor from waste gases by a trickle bed biofilter." Journal of the Air \& Waste Management Association, 50(3), 411-417.

Lüers F.; ten Hulscher Th. E. M. "Temperature Effect on the Partitioning of Polycyclic Aromatic Hydrocarbons Between Natural Organic Carbon and Water"Chemosphere 33 (4) (1996) 643-657.

Mackay, D.; Shiu, W. Y.; Ma, K. C. Illustrated Handbook of Physical-Chemical Properties and Environmental Fate for Organic Chemicals. vol 1. Monoaromatic Hydrocarbons, Chlorobenzenes, and PCBs, Lewis Publisher, Boca Raton, 1992.

McDevit, W. F.; Long, F. A. The activity coefficient of benzene in aqueous salt solutions. J. Am. Chem. Soc. 1952, 74, 1773-1777.

Mallakin, A., and Ward, O. P. (1996). "Degradation of BTEX compounds in liquid media and in peat biofilters." Journal of Industrial Microbiology, 16(5), 309-318.

Martin, F. J., and Loehr, R. C. (1996). "Effect of periods of non-use on biofilter performance." Journal of the Air \& Waste Management Association, 46(6), 539-546.

Medina, V. E., Webster, T., Ramaratnam, M., and Devinny, J. S. (1995). "Treatment of Gasoline Residuals by Granular Activated Carbon-Based Biological Filtration."

Journal of Environmental Science and Health Part a-Environmental Science and Engineering \& Toxic and Hazardous Substance Control, 30(2), 407-422.

Moe, W. M., and Irvine, R. L. (2000). "Polyurethane foam medium for biofiltration. I: Characterization." Journal of Environmental Engineering-Asce, 126(9), 815-825.

Moe, W.M, and Irvine, R.L. (2001). "Polyurethane foam based biofilter media for toluene removal." Water science and technology, 43(11), 35-42.

Moe, W. M., and Li, C. N. (2005). "A design methodology for activated carbon load equalization systems applied to biofilters treating intermittent toluene loading." Chemical Engineering Journal, 113(2-3), 175-185.

Moe, W. M., and Qi, B. (2004). "Performance of a fungal biofilter treating gas-phase solvent mixtures during intermittent loading." Water Research, 38(9), 2259-2268.

Morgan, P., Lewis, S. T., and Watkinson, R. J. (1993). "Biodegradation of Benzene, Toluene, Ethylbenzene and Xylenes in Gas-Condensate-Contaminated Groundwater." Environmental Pollution, 82(2), 181-190.

Mossman, M.J., RSMeans Mechanical Cost Data, $29^{\text {th }}$ Edition, Reed Construction Data,Kingston, MA, 2006. 
Neel, .D., Bowman, R.S., in 36th Annual New Mexico Water Conf., New Mexico Water Resources Research Institute, Las Cruces, NM, 1992, p. 57.

Neff, J. M., and Sauer, T.C. Jr. (1996). "Aromatic hydrocarbons in produced water." Produced water 2: Environmental issues and mitigation technologies, M. R. a. S.Johnson, ed., New York, 163-175.

Nicolaisen, B. "Developments in Membrane Technology for Water Treatment," Desalination. 153, (2002) 355-360.

NMSA 7-2A-20. Credit for produced water. www.conwaygreene.com/nmsu

Olsen, R.L., and A. Davis. "Predicting the Fate and Transport of Organic Compounds in Groundwater": Part 1. Hazardous Materials Control 3. (3) (1990) 38-64.

Pakula, R., and Freeman, A. (1996). "A new continuous biofilm bioreactor for immobilized oil-degrading filamentous fungi." Biotechnology and Bioengineering, 49(1), 20-25.

Park, J. (2004). "Biodegradation of paint VOC mixtures in biofilters," Ph.D. Dissertation submitted to The University of Texas at Austin, Austin, TX.

Park, J., and Kinney, K. A. (2001). "Evaluation of slip feed system for vapor-phase bioreactors." Journal of Environmental Engineering-Asce, 127(11), 979-985.

Peng, J.; Wan, A. "Effect of Ionic Strength on Henry's Constant of Volatile Organic Compounds." Chemosphere. 36 (13) (1998) 2731-2740.

Peters, M. S., K. D Timmerhaus, R. E. Wett, Plant Design and Economics for Chemical Engineers, $5^{\text {th }}$ Edition, McGraw-Hill, New York, NY, 2003.

Pignatello, J.J., Xing, B., Environ. Sci. Technol. 30 (1996) 1.

Pinal, R.; Rao, P.S.C.; Lee, L.S.; Cline, P. "Cosolvency of Partially Miscible Organic Solvents on the Solubility of Hydrophobic Organic Chemicals.” Environmental Science and Technology 24 (5) (1990) 639-647.

Quinlan, C., Strevett, K., Ketcham, M., and Grego, J. (1999). "VOC elimination in a compost biofilter using a previously acclimated bacterial inoculum." Journal of the Air \& Waste Management Association, 49(5), 544-553.

Ranck, J. M., Bowman, R. S., Weeber, J. L., Katz, L. E., and Sullivan, E. J. (2005). "BTEX removal from produced water using surfactant-modified zeolite." Journal of Environmental Engineering-Asce, 131(3), 434-442.

Raterman, K., Sublette, K. L., and Selvaraj, P. T. (1993). "Microbial Treatment of a Synthetic Sour Brine." Journal of Industrial Microbiology, 12(1), 21-28.

Rubio, J. A.; González-Mazo, E.; Gómez-Parra, A. Sorption of linear alkylbenzenesulfonates (LAS) on marine sediment. Mar. Chem. 1996, 54, 171-177.

Ruiz, J., Bilbao, R., and Murillo, M. B. (1998). "Adsorption of different VOC onto soil minerals from gas phase: Influence of mineral, type of VOC, and air humidity." Environmental Science \& Technology, 32(8), 1079-1084.

Sambrook, J., Fritsch, E.F., Maniatis, T., Molecular Cloning: a Laboratory Manual, Cold Spring Harbor Laboratory Press, Cold Spring Harbor, NY., 1989.

Sangster, J. Octanol-water partition coefficients of simple organic compounds. J. Phys. Chem. Ref. Data 1989, 18, 1111-1229.

Santos, S.M.; Wiesner, M.R. "Ultrafiltration of Water Generated in Oil and Gas Production." Water Environment Research. 69 (6) (1997) 1120-1127.

Schwarzenbach, R.P.; Gschwend, P.M.; Imboden, D.M. Environmental Organic Chemistry. John Wiley \& Sons, Inc. New York, New York. 1993. 
Schwarzenbach, R. P.; Gschwend, P. M.; Imboden, D. M. Environmental Organic Chemistry, $2^{\text {nd }}$ ed., John Wiley \& Sons, Inc., Hoboken, NJ, USA, 2003.

Sheng, G.; Xu, S.; Boyd, S. A. Cosorption of organic contaminants from water by hexadecyltrimethylammonium-exchanged clays. Wat. Res. 1996, 30, 1483-1489.

Sheng, G.; Xu, S.; Boyd, S. A. Mechanism(s) controlling sorption of neutral organic contaminants by surfactant-derived and natural organic matter. Environ. Sci. Technol. 1996, 30, 1553-1557.

Smet, E., Chasaya, G., VanLangenhove, H., and Verstraete, W. (1996a). "The effect of inoculation and the type of carrier material used on the biofiltration of methyl sulphides." Applied Microbiology and Biotechnology, 45(1-2), 293-298.

Smith, J.P.; Tyler, A.O.; Rymell, M.C.; Sidharta, H. "Environmental Impact of Produced Waters in the Java Sea, Indonesia." Presented at 1996 SPE Asia Pacific Oil and Gas Conference. Adelaide, Australia. October 28-30, 1996. SPE 37002.

Song, J., and Kinney, K. A. (2001). "Effect of directional switching frequency on toluene degradation in a vapor-phase bioreactor." Applied Microbiology and Biotechnology, 56(1-2), 108-113.

Song, J., Ramirez, J. and Kinney, K.A. "Nitrogen Utilization in a Vapor Phase Biofilter," Water Research, 37(18): 4497-4505 (2003).

Sontheimer, H.; Crittenden, J.C.; Summers, R.S. Activated Carbon for Water Treatment. DVGW-Forschungsstelle. Karlsruhe, Germany. 1988.

Standard Methods for the Examination of Water and Wastewater, Seventeenth Edition, American Public Health Association, Washington, DC, 1989.

Stephenson, M.T. "Components of Produced Water: A Compilation of Industry Studies." Journal of Petroleum Technology. May 1992. 548-603. SPE 23313.

Storey, J. M. E., Luo, W., Isabelle, L. M., and Pankow, J. F. (1995). "Gas-Solid Partitioning of Semivolatile Organic-Compounds to Model Atmospheric SolidSurfaces as a Function of Relative-Humidity .1. Clean Quartz." Environmental Science \& Technology, 29(9), 2420-2428.

Sullivan, E.J.; Hunter, D.B.; Bowman, R.S. "Topological and Thermal Properties of Surfactant-Modified Clinoptilolite Studied by Tapping Mode ${ }^{\mathrm{TM}}$ Atomic Force Microscopy and High-Resolution Thermogravimetric Analyses." Clays and Clay Minerals. 45 (1997) 42-53.

Swanson, W. J., and Loehr, R. C. (1997). "Biofiltration: Fundamentals, design and operations principles, and applications." Journal of Environmental EngineeringAsce, 123(6), 538-546.

Tan, G. "Sorption of Benzene, Toluene, Ethylbenzene, and Xylenes onto SurfactantModified Zeolite: Effects of Temperature and Produced Water." Thesis, University of Texas at Austin, 2002.

Tang, H. M., Hwang, S. J., and Hwang, S. C. (1996). "Waste gas treatment in biofilters." Journal of the Air \& Waste Management Association, 46(4), 349-354.

Ten Hulscher Th. E. M.; Cornelissen G. "Effect of Temperature on Sorption Equilibrium and Sorption Kinetics of Organic Micropollutants - A Review" Chemosphere, Vol. 32 (4) (1996) 609-626

Texas Water Development Board, "Desalination Frequently Asked Questions", www.twdp.org, 2006. 
Thibaud, C., Erkey, C., and Akgerman, A. (1993). "Investigation of the Effect of Moisture on the Sorption and Desorption of Chlorobenzene and Toluene from Soil." Environmental Science \& Technology, 27(12), 2373-2380.

Thoma, G.J.; Bowen, M.L.; Hollensworth, D. (1999) "Dissolved Air Precipitation/Solvent Sublation for Oil-Field Produced Water Treatment." Separation and Purification Technology. 16 101-107.

Thomas, J. M., Gordy, V. R., Fiorenza, S., and Ward, C. H. (1990). "Biodegradation of Btex in Subsurface Materials Contaminated with Gasoline - Granger, Indiana." Water Science and Technology, 22(6), 53-62.

Tibbetts, P.J.C.; Buchanan, I.T.; Gawel, L.J.; Large, R. "A Comprehensive Determination of Produced Water Composition.” Produced Water. Eds. J.P. Ray and F.R. Engelhart. Plenum Press. New York, NY. 1992. 97-112.

Toride, N., Leij F. J., and Van Genuchten M. Th. "The CXTFIT Code for Estimating Transport Parameters from Laboratory or Field Tracer Experiments, Version 2.0", Research Report No. 137. US Salinity Laboratory, USDA, ARS: Riverside, CA, 1995

Um, W.; Papelis, C. "Sorption Mechanism of $\mathrm{Sr}$ and $\mathrm{Pb}$ on Zeolitized Tuffs from the Nevada Test Site as a Function of $\mathrm{pH}$ and Ionic Strength." American Mineralologist. 88 (2003) 2028-2039.

van Groenestijn, J. W., Hesselink, P. G. M., 1993. Biotechniques for air pollution control. Biodegradation 4, 283-301.

Van Wezel, A. P.; Cornelissen, G.; van Miltenburg, J. K.; Opperhuizen, A. Membrane burdens of chlorinated benzenes lower the main phase transition temperature in dipalmitoyl-phosphatidylcholine vesicles: implications for toxicity by narcotic chemicals. Environ. Toxicol. Chem. 1996, 15, 203-212.

Veil, J. A., Puder, M.G., Elcock, D., and Redweik, R. J. John A. Veil., 2004, 㽞 White Paper Describing Produced Water from Production of Crude Oil, Natural Gas and Coal Bed Methane,?Prepared for U.S. Department of Energy, National Energy Technology Laboratory Under Contract W-31-109-Eng-38, Prepared by Argonne National Laboratory, January 2004.

Wani, A. H., Branion, R. M. R., and Lau, A. K. (1998). "Effects of periods of starvation and fluctuating hydrogen sulfide concentration on biofilter dynamics and performance." Journal of Hazardous Materials, 60(3), 287-303.

Weber, F. J., and Hartmans, S. (1995). "Use of Activated Carbon as a Buffer in Biofiltration of Waste Gases with Fluctuating Concentrations of Toluene." Applied Microbiology and Biotechnology, 43(2), 365-369.

Weber, W.J. and van Vliet, B.M. "Synthetic adsorbents and activated carbons for water treatment: overview and experimental comparisons." Journal of the American Waterworks Association (AWWA). 73 (8) (1981) 420-426.

Welgemoed, T.J., "Capacitive Deionization Technology ${ }^{\mathrm{TM}}$ : Development and Evaluation of an Industrial Prototype System", Thesis, University of Pretoria, Pretoria. 2005.

Western Resource Advocates, D. Fort, "Water Rate Structures in New Mexico", www.westernresourceadvocates.org, February 2006.

Woertz, J. R., Kinney, K. A., McIntosh, N. D. P., and Szaniszlo, P. J. (2001). "Removal of toluene in a vapor-phase bioreactor containing a strain of the dimorphic black yeast Exophiala lecanii-corni." Biotechnology and Bioengineering, 75(5), 550-558. 
Woodrow, B. N.; Dorsey, J. G. Thermodynamics of micelle-water partitioning in micellar electrokinetic chromatography: comparisons with 1-octanol-water partitioning and biopartitioning. Environ. Sci. Technol. 1997, 31, 2812-2820.

Woolard, C. R., and Irvine, R. L. (1995). "Treatment of Hypersaline Waste-Water in the Sequencing Batch Reactor." Water Research, 29(4), 1159-1168.

Wright, W. F. (2005). "Transient response of vapor-phase biofilters." Chemical Engineering Journal, 113(2-3), 161-173. 
Appendix: Economic Analysis Spreadsheets 
Table A-1 - SMZ Sizing Calculations for $6 \mathrm{gpm}$ SMZ Sizing Calculations - Based on Kd \& Hydraulic Loading - 6 gpm

Sorbent Characteristics

\begin{tabular}{|l|r|l|}
\hline Porosity & 0.6 & \\
\hline Bulk Density & 1 & $\mathrm{~g} / \mathrm{cm}^{\wedge} 3$ \\
\hline Kd (Benzene) & 0.00943 & $\mathrm{~L} / \mathrm{g} \mathrm{SMZ}$ \\
\hline Hydraulic Loading rate & 1 & $\mathrm{gpm} / \mathrm{ft}^{\wedge} 2$ \\
\hline
\end{tabular}

\section{Produced Water}

Characteristics

\begin{tabular}{|l|r|l|}
\hline Total BTEX Conc & 25000 & $\mathrm{ug} / \mathrm{L}$ \\
\hline Benzene inlet conc & 2500 & $\mathrm{ug} / \mathrm{L}$ \\
\hline Flow Rate & 32800 & $\mathrm{~L} /$ day \\
\hline Service Time & 0.5 & day \\
\hline
\end{tabular}

\section{$6.01 \mathrm{gpm}$}

\section{Calculations}

\begin{tabular}{|l|r|l|r|l|}
\hline Benzene Adsorbed (mg) & 41000 & $\begin{array}{l}\text { (Inlet conc*Flow } \\
\text { Rate*Service Time) }\end{array}$ & & \\
\hline Mass of SMZ & 1739130.43 & $\begin{array}{l}\text { grams SMZ (Benz } \\
\text { adsorbed/adsorption } \\
\text { capacity) }\end{array}$ & & \\
\hline Volume of SMZ & 1739.13 & $\begin{array}{l}\text { Liters (mass/density } \\
\text { converted to Liters) }\end{array}$ & & \\
\hline $\begin{array}{l}\text { Cross Sectional Area of } \\
\text { Column }\end{array}$ & 6.01 & $\begin{array}{l}\mathrm{ft}^{\wedge} 2 \text { (flow } \\
\text { rate/hydraulic loading) }\end{array}$ & 0.559 & $\mathrm{~m}^{\wedge} 2$ \\
\hline Diameter of Column & 84.34 & cm (4*area/Pi) 0.5 & 2.767 & $\mathrm{ft}^{\wedge}$ \\
\hline Column Length & 311.32 & cm (Volume/Area) & 10.214 & $\mathrm{ft}$ \\
\hline Adsorption Capacity (qe) & 23.575 & ug benzene/g SMZ & & \\
\hline
\end{tabular}




\section{Table A-2 - Vapor Phase Biofilter Design Calculations - 6 gpm}

\begin{tabular}{|c|c|c|c|c|}
\hline $\begin{array}{l}\text { SMZ Inlet and Regeneration } \\
\text { Conditions }\end{array}$ & \multicolumn{3}{|l|}{$6 \mathrm{gpm}$} & \\
\hline \multicolumn{5}{|c|}{$\begin{array}{l}\text { Regeneration Cycle Time - From SMZ Kd Based } \\
\text { spreadsheet }\end{array}$} \\
\hline Cycle Time $=$ & 0.5 & day & & \\
\hline BTEX Inlet Conc & 25000 & $\mathrm{ug} / \mathrm{L}$ & & \\
\hline Inlet Flow Rate & 32800 & L/day & 6.01 & gpm \\
\hline Mass of BTEX sorbed = & 410000 & $\mathrm{mg} / \mathrm{cycle}$ & & \\
\hline \multicolumn{5}{|c|}{ Regeneration and VBP Sizing - 6 gpm } \\
\hline \multicolumn{5}{|c|}{$\begin{array}{l}12 \text { hours to regen, } 2 \text { hrs to ramp up air flow, } 2 \text { hrs to } \\
\text { polish }\end{array}$} \\
\hline \multirow{3}{*}{$\begin{array}{l}\text { Regeneration Time }= \\
\text { User enters max inlet conc to } \\
V B P\end{array}$} & 8 & hrs & & \\
\hline & & & & \\
\hline & $\begin{array}{l}\text { Conversio } \\
\mathrm{MWt}\end{array}$ & ppmv, 1 & $250 \mathrm{C}, 85$ & $\mathrm{~g} / \mathrm{mol}$ \\
\hline Max inlet conc to VBP & 1000 & ppmv & 3.4765 & $\mathrm{mg} / \mathrm{L}$ \\
\hline Air flow rate calc: & \multicolumn{4}{|c|}{$\begin{array}{l}\text { (BTEX mg/regen time/max inlet } \\
\text { conc) }\end{array}$} \\
\hline $\mathrm{Q}, \operatorname{air}\left(\mathrm{ft}^{\wedge} 3 / \mathrm{min}\right)=$ & 8.68 & $\mathrm{ft}^{\wedge} 3 / \mathrm{min}$ & & \\
\hline
\end{tabular}

User enters superfical velocity, $\mathrm{ft} / \mathrm{min}$

$\mathrm{v}$, air $(\mathrm{ft} / \mathrm{min})=$

Area $=\mathrm{Q} / \mathrm{V}$

Tower Diameter (ft)

\section{5}

$3.47 \mathrm{ft}^{\wedge} 2$

$2.10 \mathrm{ft}$

25.23 inches

User enters residence time in

$V P B$

Residence Time $=$

$1.5 \min$

Bed height $=\mathrm{v}^{*}$ res time

$3.75 \mathrm{ft}$

VBP Sizing - 6 gpm
Number of 3' packed sections

$=$

Total height of packed

section=

Number of packing support

plates $=$

Diameter of Column

1

Volume of biomass $=$

(1 foot between packed

4 sections)

1

$2.10 \mathrm{ft}$

$13.02 \mathrm{ft}^{\wedge} 3$ 
Table A-3 - SMZ Sizing Calculations for 20 gpm

SMZ Sizing Calculations - Based on Kd \& Hydraulic Loading

-20 gpm

Sorbent Characteristics

\begin{tabular}{|l|r|l|}
\hline Porosity & 0.6 & \\
\hline Bulk Density & 1 & $\mathrm{~g} / \mathrm{cm}^{\wedge} 3$ \\
\hline Kd (Benzene) & 0.00943 & $\mathrm{~L} / \mathrm{g} \mathrm{SMZ}$ \\
\hline Hydraulic Loading rate & 1 & $\mathrm{gpm} / \mathrm{ft}^{\wedge} 2$ \\
\hline
\end{tabular}

\section{Produced Water}

Characteristics

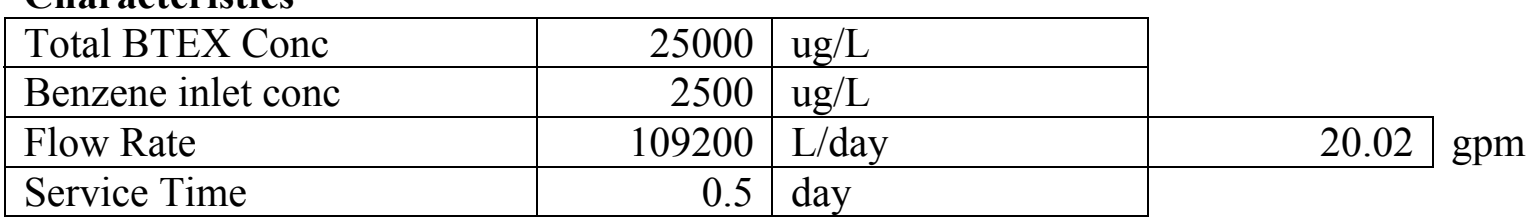

\section{Calculations}

\begin{tabular}{|c|c|c|c|c|}
\hline Benzene Adsorbed (mg) & 136500 & $\begin{array}{l}\text { (Inlet conc*Flow } \\
\text { Rate*Service Time) }\end{array}$ & & \\
\hline Mass of SMZ & 5790031.81 & $\begin{array}{l}\text { grams SMZ (Benz } \\
\text { adsorbed/adsorption } \\
\text { capacity) }\end{array}$ & & \\
\hline Volume of SMZ & 5790.03 & $\begin{array}{l}\text { Liters (mass/density } \\
\text { converted to Liters) }\end{array}$ & & \\
\hline $\begin{array}{l}\text { Cross Sectional Area of } \\
\text { Column }\end{array}$ & 20.02 & $\begin{array}{l}\mathrm{ft}^{\wedge} 2 \text { (flow } \\
\text { rate/hydraulic } \\
\text { loading) }\end{array}$ & 1.860 & $m^{\wedge} 2$ \\
\hline Diameter of Column & 153.88 & $\mathrm{~cm}\left(4^{*} \text { area } / \mathrm{Pi}\right)^{\wedge} 0.5$ & 5.049 & $\mathrm{ft}$ \\
\hline Column Length & 311.32 & cm (Volume/Area) & 10.214 & $\mathrm{ft}$ \\
\hline Adsorption Capacity (qe) & 23.575 & ug benzene/g SMZ & & \\
\hline
\end{tabular}


Table A-4 - Vapor Phase Biofilter Design Calculations - 20 gpm

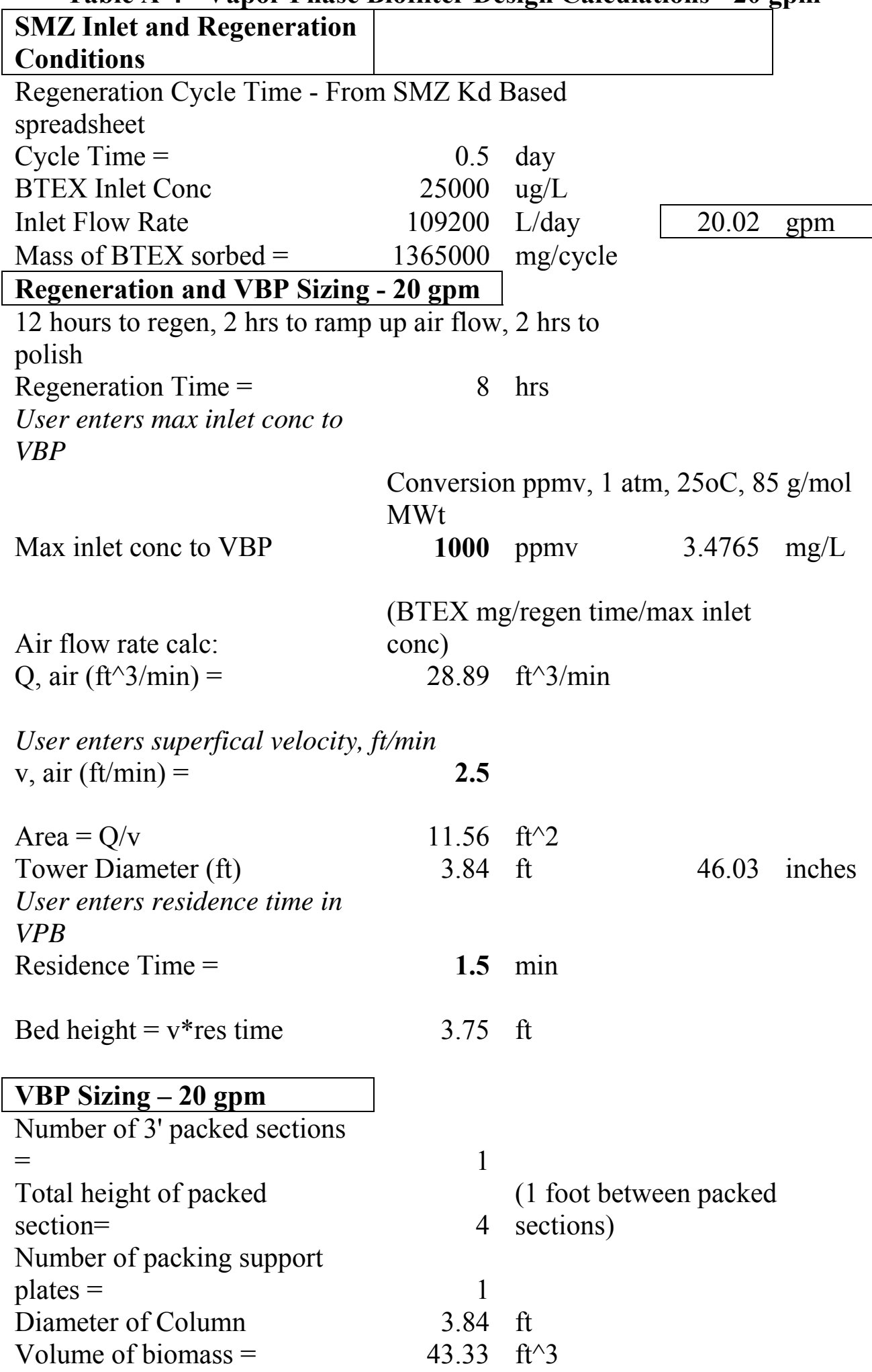


Table A-5 - SMZ Sizing Calculations for 40 gpm

SMZ Sizing Calculations - Based on Kd \& Hydraulic Loading

-40 gpm

Sorbent Characteristics

\begin{tabular}{|l|r|l|}
\hline Porosity & 0.6 & \\
\hline Bulk Density & 1 & $\mathrm{~g} / \mathrm{cm}^{\wedge} 3$ \\
\hline Kd (Benzene) & 0.00943 & $\mathrm{~L} / \mathrm{g} \mathrm{SMZ}$ \\
\hline Hydraulic Loading rate & 1 & $\mathrm{gpm} / \mathrm{ft} \wedge 2$ \\
\hline
\end{tabular}

Produced Water

Characteristics

\begin{tabular}{|c|c|c|c|}
\hline Total BTEX Conc & 25000 & $\mathrm{ug} / \mathrm{L}$ & \\
\hline Benzene inlet conc & 2500 & $\mathrm{ug} / \mathrm{L}$ & \\
\hline Flow Rate & 218400 & L/day & 40.04 \\
\hline Service Time & 0.5 & day & \\
\hline
\end{tabular}

Calculations

\begin{tabular}{|c|c|c|c|c|}
\hline Benzene Adsorbed (mg) & 273000 & $\begin{array}{l}\text { (Inlet conc*Flow } \\
\text { Rate*Service Time) }\end{array}$ & & \\
\hline Mass of SMZ & 11580063.63 & $\begin{array}{l}\text { grams SMZ (Benz } \\
\text { adsorbed/adsorption } \\
\text { capacity) }\end{array}$ & & \\
\hline Volume of SMZ & 11580.06 & $\begin{array}{l}\text { Liters (mass/density } \\
\text { converted to Liters) }\end{array}$ & & \\
\hline $\begin{array}{l}\text { Cross Sectional Area of } \\
\text { Column }\end{array}$ & 40.04 & $\begin{array}{l}\mathrm{ft}^{\wedge} 2 \text { (flow } \\
\text { rate/hydraulic } \\
\text { loading) }\end{array}$ & 3.720 & $\mathrm{~m}^{\wedge} 2$ \\
\hline Diameter of Column & 217.62 & $\mathrm{~cm}(4 * \text { area } / \mathrm{Pi})^{\wedge} 0.5$ & 7.140 & $\mathrm{ft}$ \\
\hline Column Length & 311.32 & cm (Volume/Area) & 10.214 & $\mathrm{ft}$ \\
\hline Adsorption Capacity (qe) & 23.575 & ug benzene/g SMZ & & \\
\hline
\end{tabular}


Table A-6- Vapor Phase Biofilter Design Calculations - 40 gpm

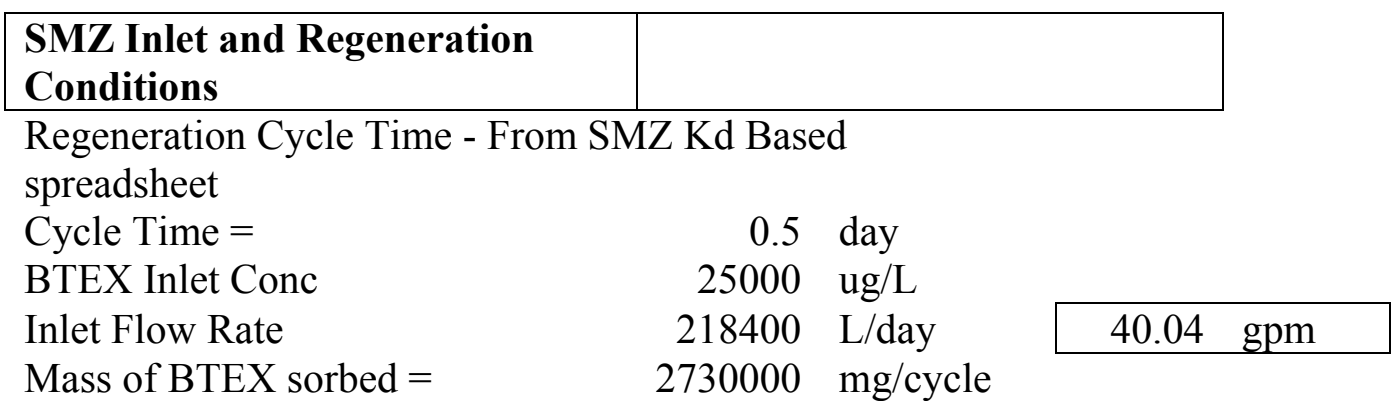

Regeneration and VBP Sizing - 40 gpm

12 hours to regen, 2 hrs to ramp up air flow, 2 hrs to polish

Regeneration Time $=$

User enters max inlet conc to VBP

Max inlet conc to VBP

34Air flow rate calc:

$\mathrm{Q}$, air $\left(\mathrm{ft}^{\wedge} 3 / \mathrm{min}\right)=$

User enters superfical velocity, $\mathrm{ft} / \mathrm{min}$

$\mathrm{v}, \operatorname{air}(\mathrm{ft} / \mathrm{min})=$

Area $=\mathrm{Q} / \mathrm{v}$

Tower Diameter $(\mathrm{ft})$

User enters residence time in VPB

Residence Time $=$

Bed height $=\mathrm{v}^{*}$ res time

\section{VBP Sizing - 40 gpm}

Number of 3' packed sections =

Total height of packed section=

Number of packing support plates

$=$

Diameter of Column

Volume of biomass $=$
Conversion ppmv, 1 atm, 25oC, $85 \mathrm{~g} / \mathrm{mol}$

$\mathrm{MWt}$

$8 \mathrm{hrs}$

1000 ppmv

$3.4765 \mathrm{mg} / \mathrm{L}$

(BTEX mg/regen time/max inlet conc)

$57.78 \mathrm{ft}^{\wedge} 3 / \mathrm{min}$

\section{5}

$23.11 \mathrm{ft}^{\wedge} 2$

$5.42 \mathrm{ft}$

65.09 inches

$1.5 \min$

$3.75 \mathrm{ft}$

1

(1 foot between packed

4 sections)

1

$5.42 \mathrm{ft}$

$86.66 \mathrm{ft}^{\wedge} 3$ 